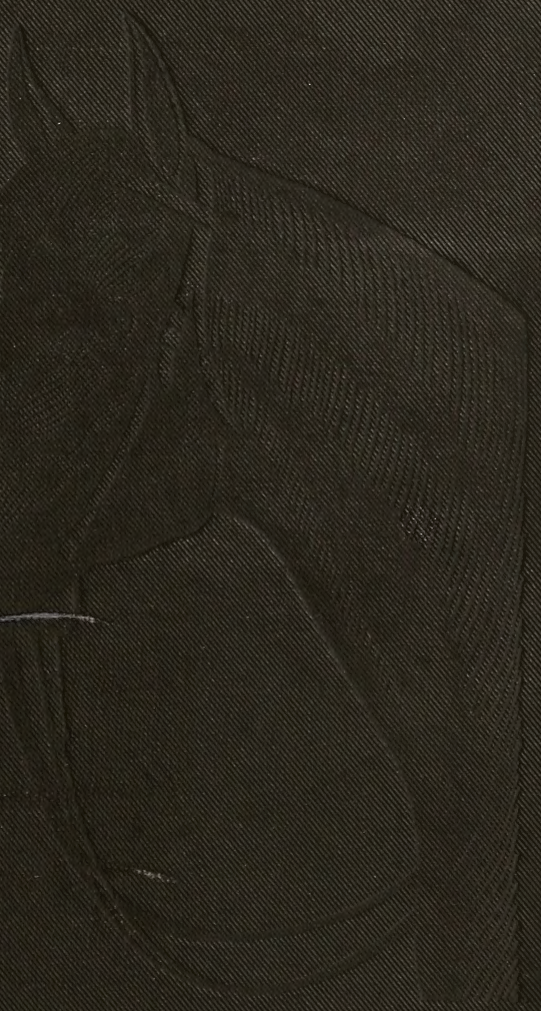




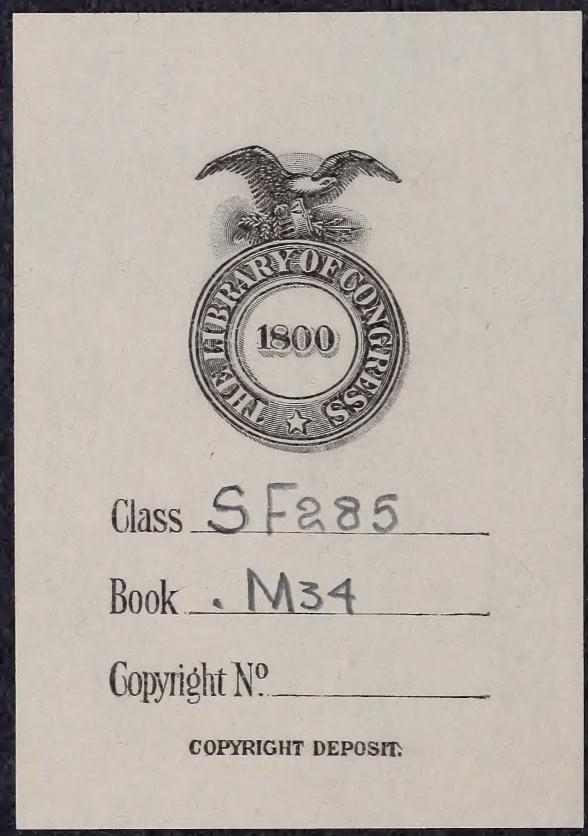







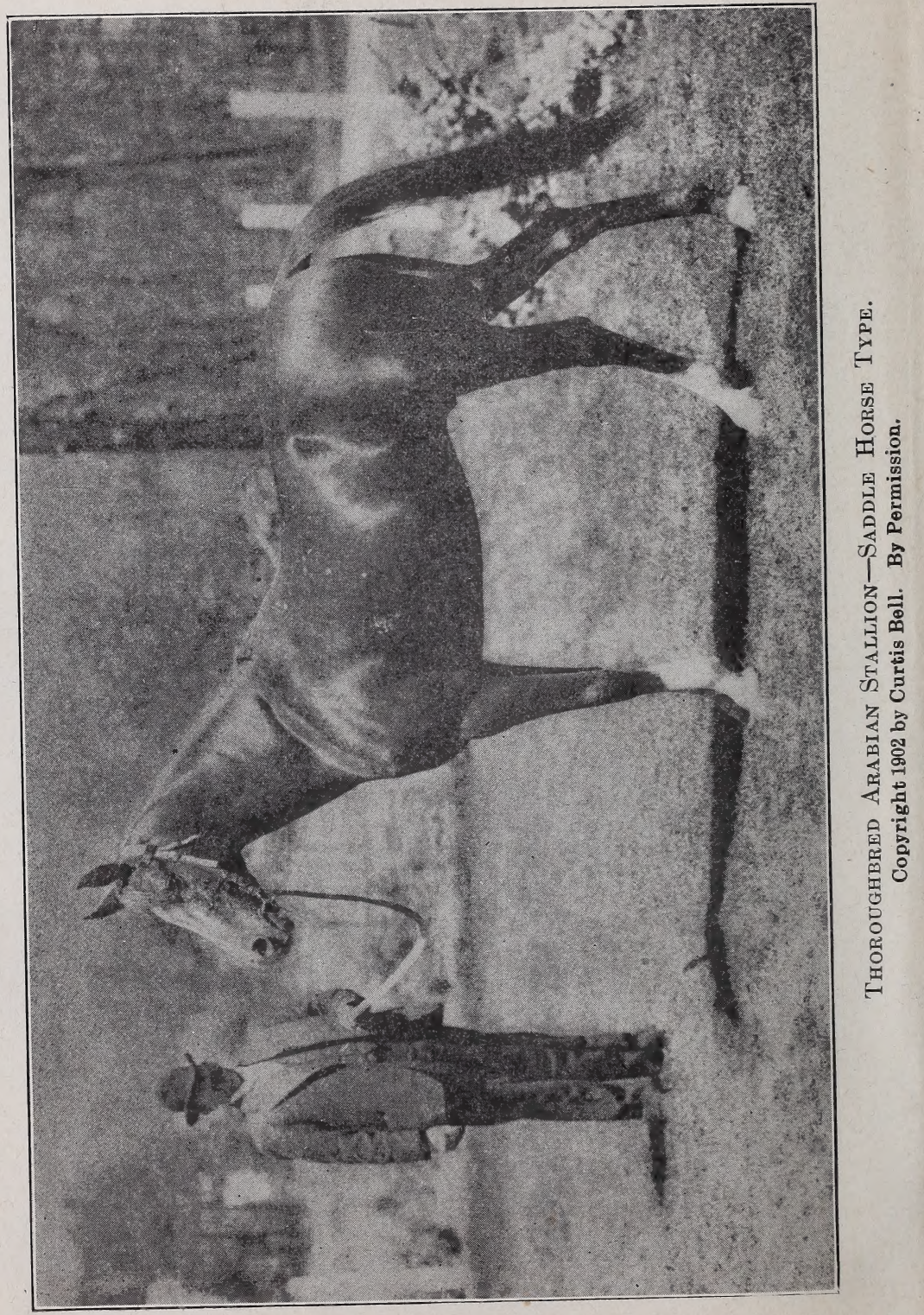




\section{Elements of Hippology}

CAPTAIN F. C. MARSHALL, Fifteenth Cavalry.

Prepared for the Department of Tactics, United States Military Academy.

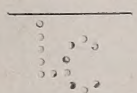

Second and Revised Edition.

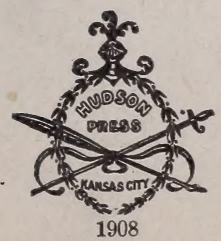



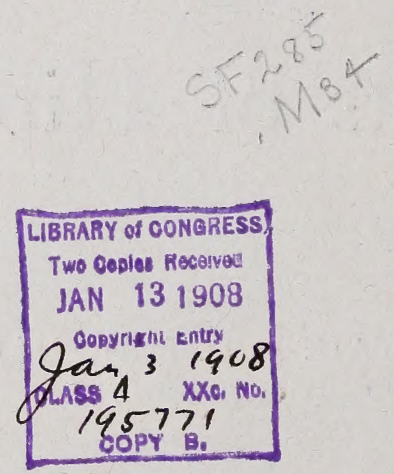

Copyright, 1908, by

Franklin Hudson Publishing Co..

Kansas City, Mo.

$\because \vdots:$ 


\section{PREFACE.}

It is due to the late General Sir Frederick Fitzwygram to give credit to his book, "Horses and Stables," for very much that is contained in this work, and the author wishes to thank his widow and her son, the present Sir Frederick Fitzwygram, for their kind permission to quote from it.

"Horses and Stables" has been the hand-book and guide of the American cavalry officer since the issuance of its first edition, and it is deeply regreted by us all that the fifth edition is to be the last to be revised by its talented author.

In the preparation of these notes the works of Dr. James Law, General Carter, Captain Hayes, James Fillis, Gouboux and Barrier, and Captain Seton, and the admirable work of the Department of Agriculture on the "Diseases of the Horse," which have been the author's guide during his service as a cavalry officer, have also been freely consulted. Whatever ideas he has developed in his experience flow from suggestions received from these and similar works. Nothing new is claimed or attempted. The effort has been made to write a comprehensive book that will cover, in outline only, all general subjects that a horseman should know.

All of the anatomical illustrations are taken from "Diseases of the Horse," a public document issued by the Bureau of Animal Industry, Department of Agriculture. The photographs for the rest of the illustrations, except as noted, were taken by Mr. W. H. Stockbridge, under the author's supervision, from horses and polo ponies at the Military Academy, and represent ordinary conditions only. No effort is made to discuss the so-called "horse of luxury," which is, after all, only an exceptionally good specimen of the type that ought to be adhered to in purchasing a horse for any special purpose.

Special thanks is due the editor of "The Rider and Driver," Mr. Samuel Walter Taylor, for his kindness in loaning photographs, and for the cover design.

United States Military Academy,

West Point, New York, January 1, 1908. 



\section{TABLE OF CONTENTS.}

IHAPTER.

I- General Discussion,

II.-Age, as Determined by the Teeth, . . 21

III.-Inflammation, . . . . . . . . . 41

IV.-The Head and Neck, . . . . . . 48

V.-Bits: Their Action, Influence, and Proper Use, 60

VI. -The Front Leg, . . . . . . 81

VII.-The Position of the Saddle, . . . 97

VIII.-The Trunk, . . . . . . . 106

IX.-The Hind Leg, . . . . . . 111

X.-The Horse's Foot, . . . . . . 122

XI.-Diseases of the Foot, . . . . . . 129

XII.-The Principles of Horseshoeing for Horses with Ordinary Feet, . . . . . 141

XIII.-The Heart, Lungs, and Air Passages, . . 155

XIV.-The Digestive Apparatus, . . . . 164

XV.-Stable Management, . . . . . 171

XVI.-Endurance of Horses.-Vices.-Punishment, . 181

XVII.-The Care of Sick Horses, . . . . 196

XVIII.-Preventable Diseases, . . . . . 201

XIX.-Irregularities of Action, . . . . 206

XX.-Judging Horses and the Examination for Sound-

ness, . . . . . . 212 


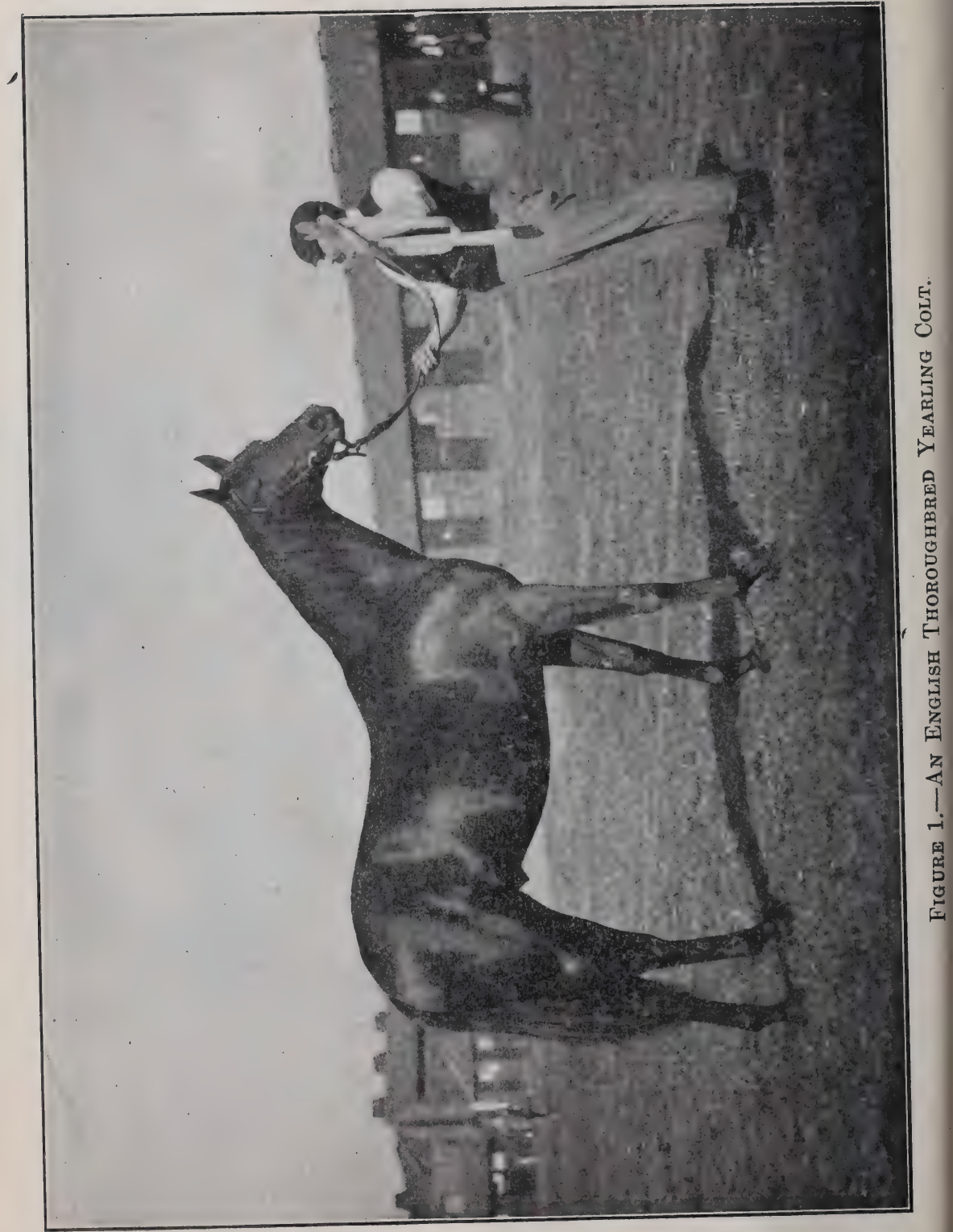




\section{CHAPTER I.}

\section{A GENERAL DISCUSSION.}

It is useless to attempt the description in a few words of the origin and development of the modern horse;* we know that as far back as authentic history reaches, horses have been used by men for the manifold purposes of peace and war, toil and recreation. For many centuries past two general types of horses have been preserved. One, which may be called the thoroughbred type, is a light, active, speedy animal, possessing great endurance. It finds its best uses for saddle and racing purposes. The other type is more powerful, but not so active, nor as fast. This type may be called, in general terms, the Flanders type. It is used for draft purposes. By crossing these two types the many special breeds and families of horses now in use arise.

A thoroughbred animal is, in the broadest meaning of the term, one of pure blood, descended for many generations from animals of the same sort. Thus, one may speak with perfect propriety of a thoroughbred fox-terrier dog, or of a thoroughbred Jersey cow, or of a thoroughbred Cotswold sheep. A thoroughbred horse, however, is a race-horse-not necessarily used for racing purposes-descended through a line of racers, from Arab stock. Any other sort of a horse that is of pure strain, descended from known ancestors of the same strain, should not be called thoroughbred, but pure-bred.

*Those who are interested in this subject will find "The Origin and Influence of the Thoroughbred Horse," by William Ridgeway (Cambridge, University Press), interesting and exhaustive. 
A stud-book is a book that is kept for the purpose of recording the pedigree and performances of thoroughbred animals. The stud-book for the American thoroughbred horse is kept by the editor of the American Stud-Book, in New York City. To entitle a horse to be registered as a thoroughbred in this studbook; his ancestors, for at least six generations of sires and five of dams, must have been so registered.

If, in examining the pedigree of a thoroughbred horse, an ancestor not of pure Arabian blood is found, the horse is said to have cold blood.

A well-bred horse is one descended from a line of selected sires and dams, chosen for the qualities they are known to im-. part to their offspring, and whose rearing has been carefully attended to.

The horse shown in Figure $1 *$ is an example of what centuries of intelligent breeding and the most scientific care can accomplish.

An ill-bred or under-bred horse is one carelessly bred, whose sires and dams have not been well chosen, and who, for generations, have been neglected in their rearing.

Figure 2 shows an under-bred polo pony of poor quality. This is a coarse animal, with abundant mane and tail. While it is a perfectly sound, serviceable animal for slow, light work, its sluggish nature, the result of careless breeding and rearing, unfits it for anything that demands courage or stamina or spirit.

The varied uses to which horses are put has led breeders to develop special strains of horses that will best accomplish the special work demanded of them.

*This colt was bred by Mr. I. Simons Harrison at his stud-farm in East Yorkshire, England, and it is due to his courtesy that the photograph is introduced here.

Mr. Harrison says of him: "This colt is very handsome and racing-like and on good lines. I hope he may, with luck, make a name for himself on the turf." 


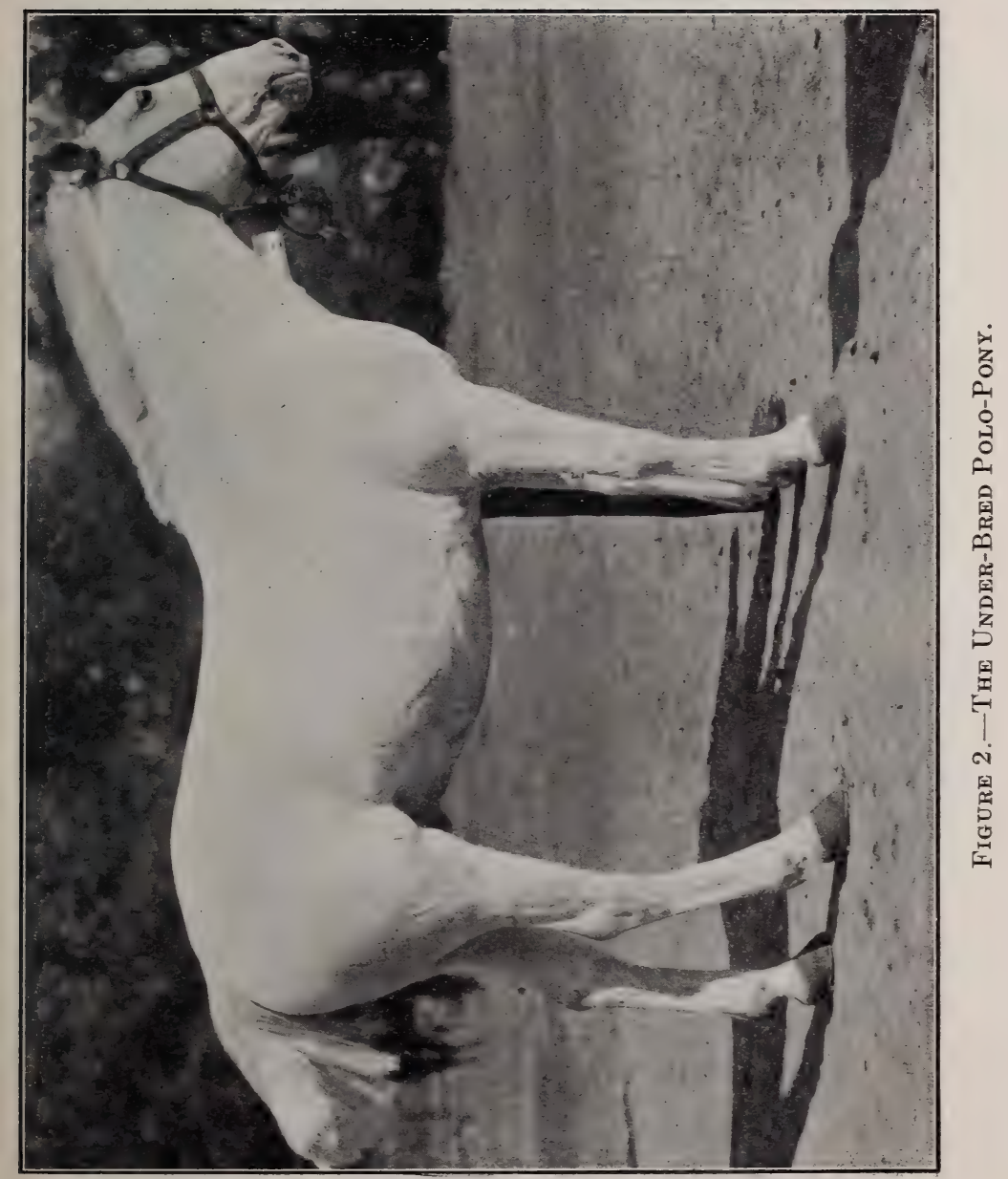




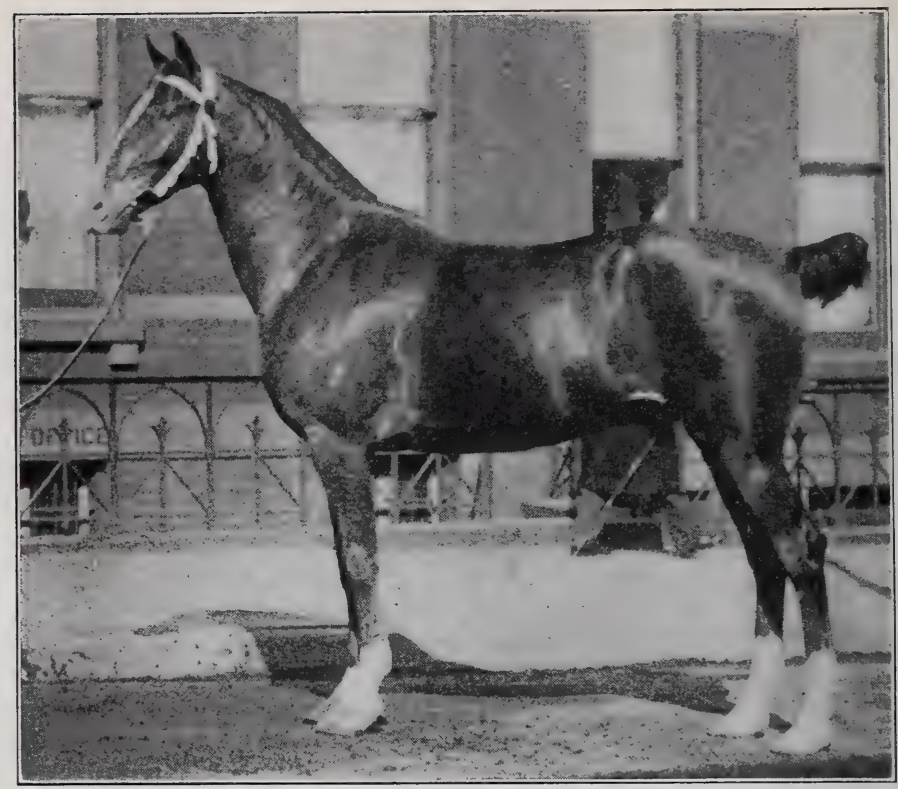

Figure 3.-The CoAch-Horse Type.

Courtesy of J. Campbell Thompson, Esq.

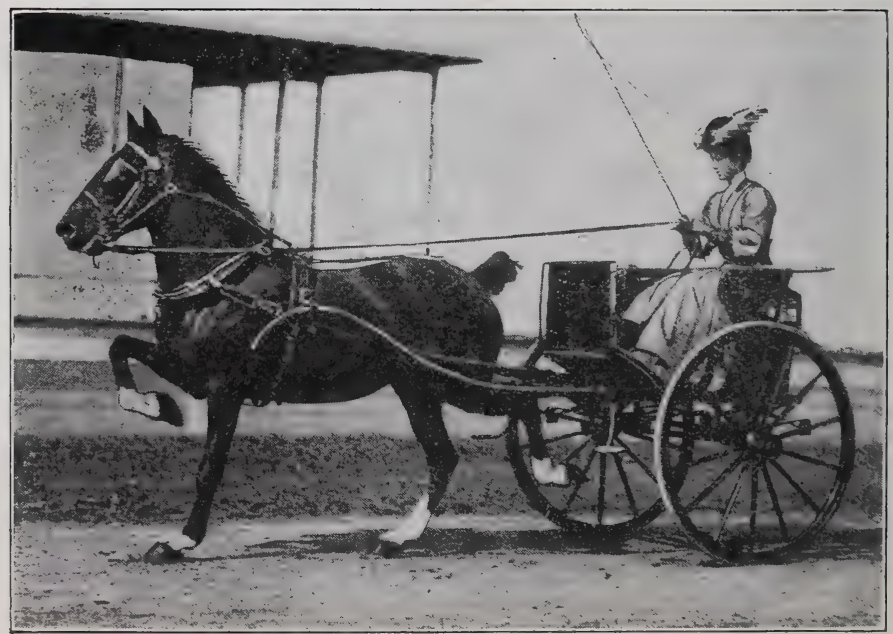

Figure 4.-The HaCKNey.

Courtesy of "The Rider and Driver." 
For heavy draft purposes, the French Percheron and English Clydesdale are the most distinctive types. The former are usually of gray color and the latter bay or brown. These are the familiar heavy dray-horses; they weigh from 1,200 to 2,000 pounds, and are the most popular heavy work-horses in the United States.

The English Shire horse is very similar to the Clydesdale, and the French draft and Norman horses to the Percheron. The Belgian and Flemish draft-horses are more ponderous than either of the above breeds, and for that reason, probably, have not caught the American horse-users' fancy.

The coach-horses are bred for moderate speed, while drawing fairly heavy loads. They are over sixteen hands high, and weigh from 1,100 to 1,300 pounds. The best-known breeds are the English coach, the French coach, and the Cleveland bay. The last named is a breed developed in the United States. These horses are not pure-bred, but are carefully bred from selected individuals.

The hackney is a breed of driving-horses of English origin very popular in the United States. They are stocky, strong, active horses, full of courage and good temper, smaller than the coach-horses, and much less rangy in build. Fashion demands of them an exaggerated knee action when in motion and a peculiar stretched-out pose when at rest.

The hunter is a saddle-horse of good size, with a strong thoroughbred cross, good at jumping, and with excellent wind. There is no particular breed of hunters. They are simply selected individuals that have proven to be useful in cross-country galloping. It is performance that makes a hunter.

The polo pony is another type of saddle-horse that depends absolutely on his individual performances to make him of any value in his class. Excellent polo ponies are bred from small mares of the mustang type by Arabian or Spanish barb sires. 


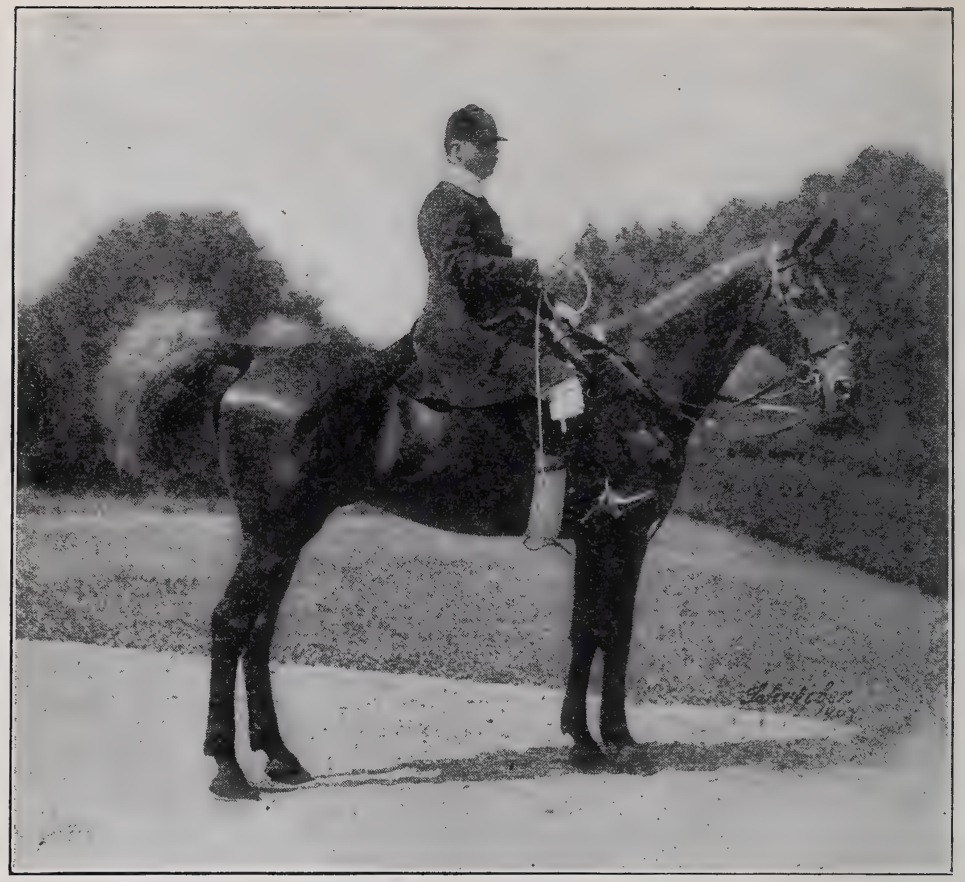

Figure 5.- A Hunter.

Courtesy of "The Rider and Driver."

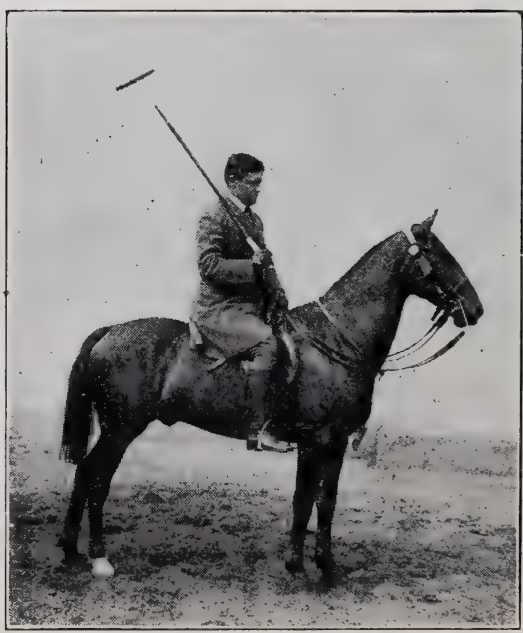

Figure 6.-A Polo-Pony.

Courtesy of M. W. Smith, Esq. 
In the United States there have been developed three strains of horses that are worthy of special notice on account of the influence each has had on the quality of the horses of the nation. These strains are the American standard trotter, the American or Kentucky saddle-horse, and the Morgan horse.

The trotter is the result of an effort to produce the best animal for racing under harness. The first horse to trot a mile in harness in less than three minutes was Yankee, who performed that feat at Harlem, N. Y., in 1806. It took a hundred years of the most careful breeding to pass the two-minute mark, and breeders are still trying to reduce the present record of $1: 58 \frac{1}{2}$, made by Lou Dillon in 1903.

The influence of remarkable individuals is singularly shown in the breeding of American trotters of record. In 1884 there were in the neighborhood of 6,000 horses in the United States that had trotted in races that were of enough moment to be recorded. "Of these, a little over 1,700 are Hambletonians; there are 657 other Messengers, making a total of 2,369 that trace in male line to Messenger. There are 762 Black Hawks, and 453 other Morgans, or a total of 1,215 that trace in male line to Justin Morgan. There are about 700 that trace in male line to Canadian sires, and the same number of Bashaws, with something over 300 which trace to thoroughbred sires other than those mentioned, and about 1,000 whose tracing is not certain."*

In other words, in 1884, seven of every twelve trotting horses of record traced back directly to Messenger or Justin Morgan, and the same proportion is probably still true. The greatest of Messenger's descendants was Rysdyk's Hambletonian. He was not a thoroughbred.

The standard American trotter is a horse that has been bred for racing under harness. It is of comparatively recent date that any care has been taken in registering these horses.

*From an article in "Spirit of the Times," February 14, 1885. 


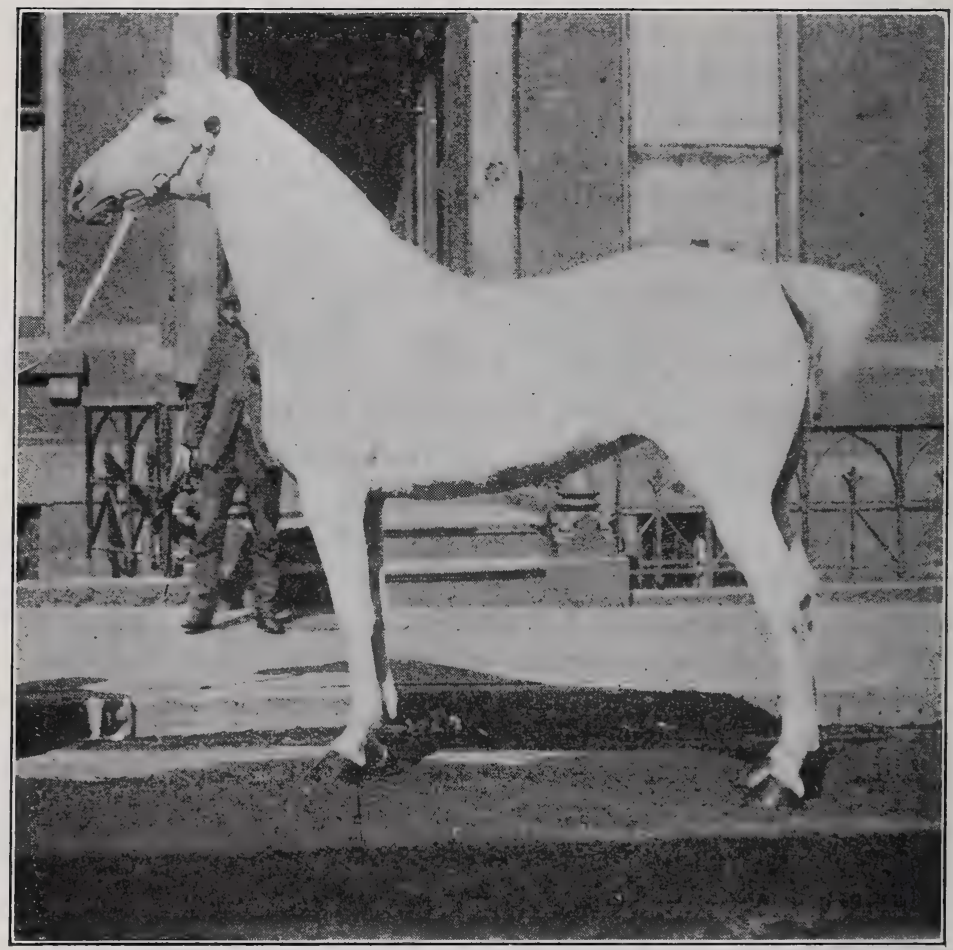

Figure 7.-Lord Clinton, Standard Morgan Trotter. Courtesy of J. Campbell Thompson, Esq.

Any horse that was speedy, or whose sire or dam was a fast trotter, or pacer even, was admitted to registry in the stud-book of the National Trotting Horse Breeders' Association. This has resulted in the greatest confusion in tracing pedigrees, and for several years has not been permitted.

The term "standard-bred" is now applied to trotting horses only that are bred to a certain standard of speed. The term does not refer to the blood of the horse, but to the excellence of the trotting performances of his sire and dam. The rules of the 
American Trotting Register Association, in whose records the pedigrees of standard-bred horses are kept, set the following as the trotting standard:

"When an animal meets these requirements and is duly registered, it shall be accepted as a standard-bred trotter:

"1. The progeny of a registered standard trotting horse and a registered standard trotting mare.

"2. A stallion sired by a registered standard trotting horse, provided his dam and grandam were sired by registered standard trotting horses, and he himself has a trotting record of $2: 30$ and is the sire of three trotters with records of $2: 30$, from different mares.

" 3 . A mare whose sire is a registered standard trotting horse, and whose dam and grandam were sired by registered standard trotting horses, provided she herself has a trotting record of $2: 30$, or is the dam of one trotter with a record of $2: 30$.

"4. A mare sired by a registered standard trotting horse, provided she is the dam of two trotters with records of $2: 30$.

" 5 . A mare sired by a registered standard trotting horse, provided her first, second, and third dams are each sired by a registered standard trotting horse."

The effect of this search for speed for racing purposes under harness has been to give to the United States a fine breed of light harness-horses. The standard trotter is not a saddle-horse; he is too rangy to be a strong weight-carrier, and too long in his stride to be a comfortable mount.

\section{AMERICAN SADDLE-HORSE REGISTER.*}

\section{RULES FOR ENTRY.}

In Effect August, 1904.

RULE 1. A stallion whose sire and dam are both registered in Saddle Horse Register is eligible.

RULE 2. A mare whose sire or dam is registered and who traces on other side to registered or foundation saddle stock is eligible.

RULE 3. A gelding tracing on either side to registered or foundation saddle stock is eligible.

Certificate of Owner or Manager of sire that mare was bred must accompany all applications for foals of 1907 and after.

* This is the form used to register American saddle-horses and contains the rules governing their entry. For a thoroughbred registry, the sixth dam must be registered to entitle the colt to be called a "thoroughbred." 


\section{FEES FOR ENTRIES, ETC. \\ In Effect from August 12, 1904.}

The fee for entry for each animal shall be $\$ 1.00$ to members of this Association and $\$ 2.00$ to non-members; but if not registered by or before December 31st next after being foaled, the fee is $\$ 5.00$ to members and $\$ 10.00$ to non-members, for stallions and mares.

For geldings, any age, the fee is $\$ 1.00$ to members and $\$ 2.00$ to non-members. Fee must accompany application.

Fee for transfers and duplicate certificates, $50 \mathrm{c}$ each.

Six volumes of Register have been issued and they are sold at $\$ 2.00$ per volume.

\section{FALSE OR FRAUDULENT ENTRIES.}

If any member of this Association knowingly makes a false or fraudulent statement in order to enter an animal in the Register, he will be expelled from the Association and his entry expunged.

If anyone not a member knowingly makes a false or fraudulent statement in order to enter an animal, his entry will be expunged and he will be debarred from making entries in the future.

\section{FOU NDATION STOCK.}

The following stallions are registered as foundation stock, and will be recognized as saddle strains under the rules above:

Denmark (thoroughbred), by Imp. Hedgeford.

John Dillard, by Indian Chief (Canadian).

Tom Hal, Imp. from Canada.

Coleman's Eureka (thoroughbred-Morgan).

Vanmeter's Waxy (thoroughbred).

Cabell's Lexington, by Gist's Black Hawk (Morgan).

Stump the Dealer (thoroughbred).

Peter's Halcorn.

Davy Crockett.

Pat Cleburne, by Benton's Gray Diomed.

Say whether stallion, mare, or gelding:

Give the name and address of the breeder of entry, and of the sire and dam if known. for name.

If you think name you select may be taken, give second choice

Write Saddle-Horse Register numbers straight. Put trotting numbers in parentheses.

If there are no " distinguishing marks," write "None" in space.

Address,

I. B. N ALL, Secretary, Louisville, Ky. 


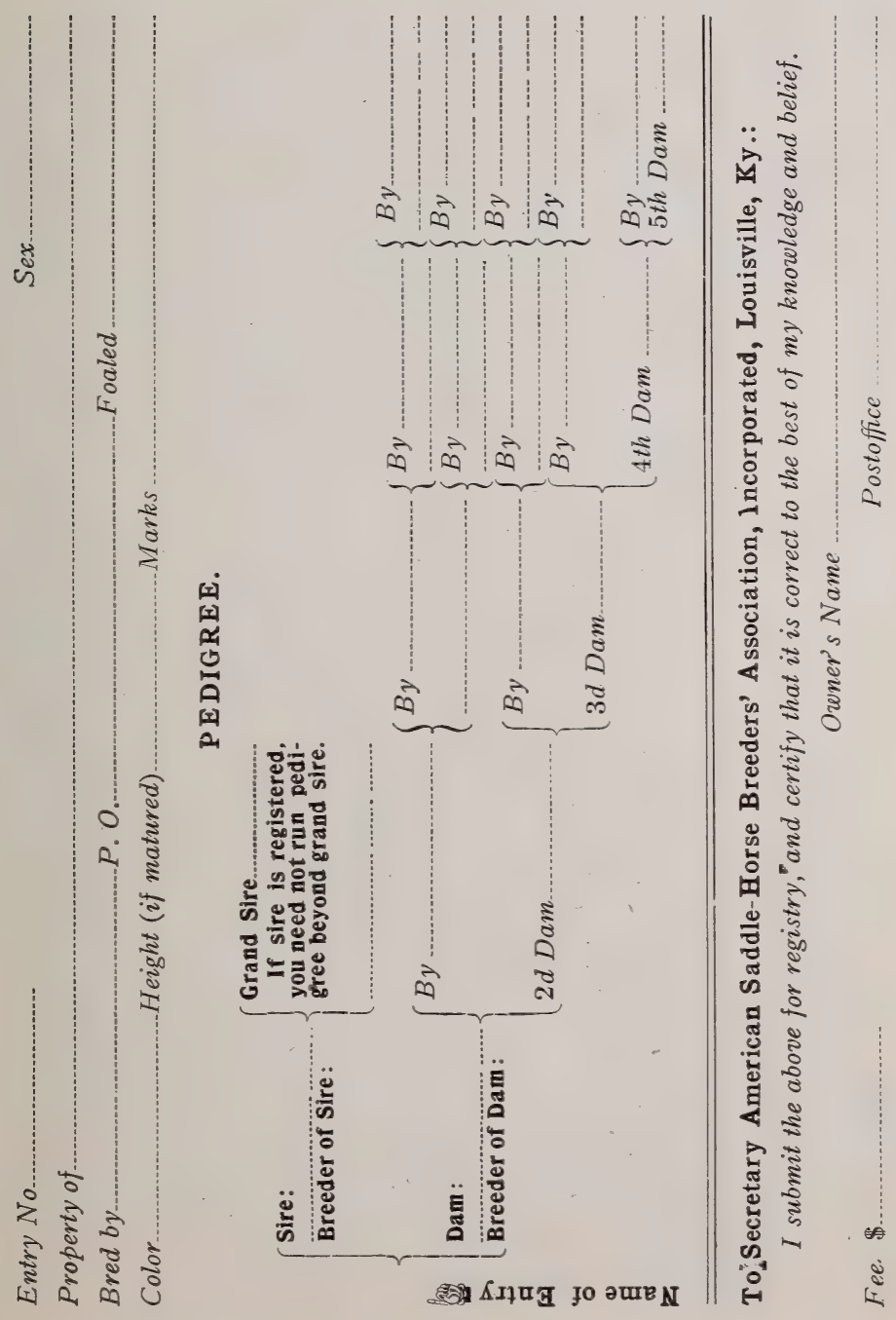




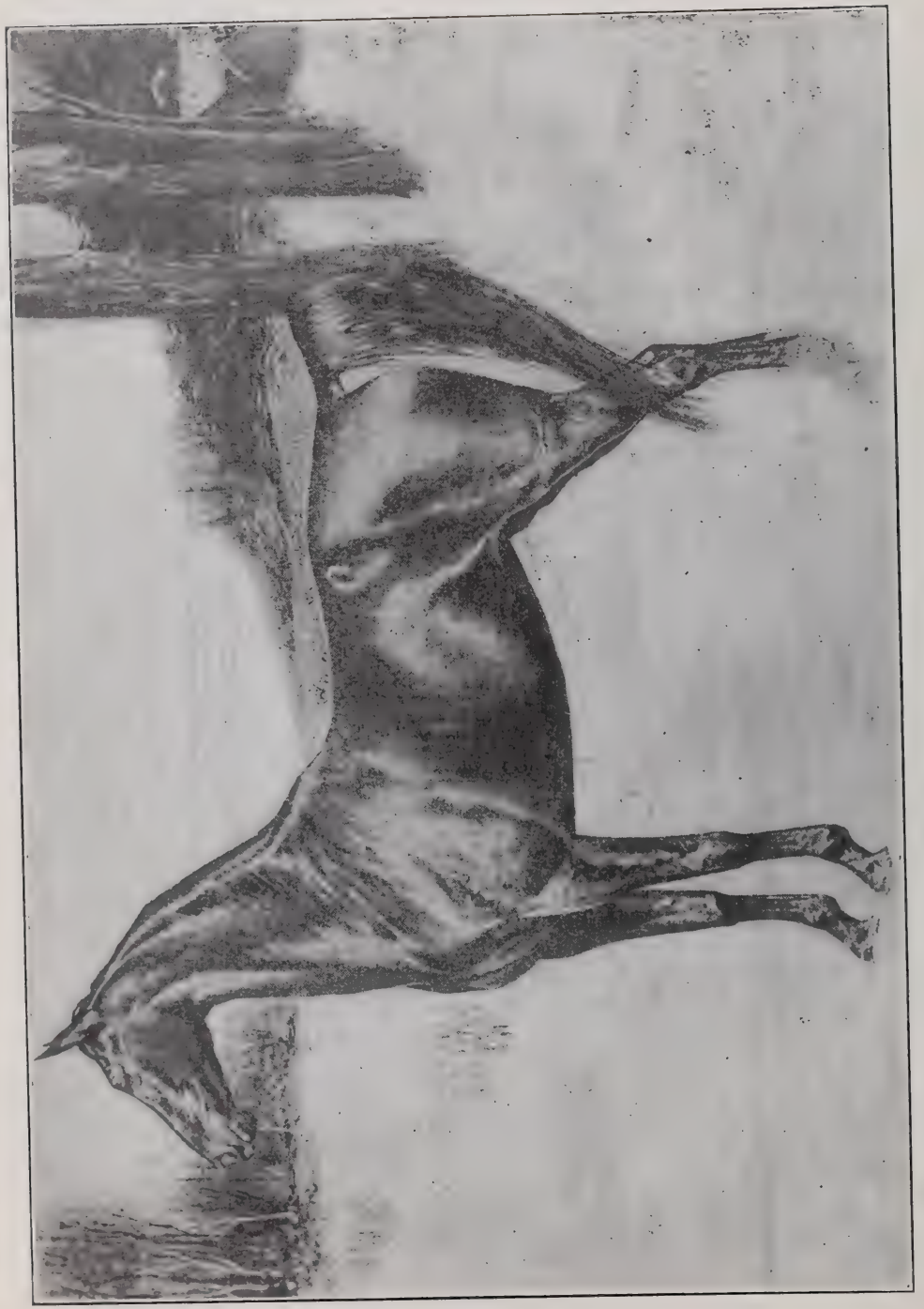

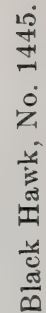

禀

हू

\%

ल 의 뭉

000

¿ 0 .

ไั่

0 -

ㄴ

U

$\infty$ ठ응

II $>$ क

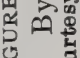

0

盾

व્. 
For a number of centuries in England, whence the larger proportion of our imported saddle-horses have come, saddlehorses have been trained to three gaits only-the walk, trot, and gallop. In the early years of the history of Kentucky, although the country was prosperous and its people rich, the roads were poor. The business of the State was done on horseback, and the demand arose for a comfortable saddle-horse. To meet this demand a breed of horses, now known as the American saddlehorse, was developed. The Canadian pacer, a horse descended from French and English stock, was crossed with the thoroughbred, and, by careful breeding, the present splendid breed of saddle-horses has resulted.

They are medium-sized, well-built animals, of good color; kind, docile, and willing. They jump well and gallop easily and make ideal mounts for cavalry, but their chief distinction is the possession of a number of artificial gaits that add greatly to the comfort of their riders.

These horses can be used as light driving-horses without injury to their gaits.*

The term "breed," as used by the farmer, signifies a group or class of animals having a number of distinctive qualities and characteristics in common, and the power to transmit those distinctive traits with a good degree of certainty.

"A breed is usually started by selecting two or more unusually good animals from a group that has been produced in a locality by reason of better food, environment, and intelligent selection, and which is usually superior to the animals of the same species in other localities. These few having been selected, inbreeding is practiced to a greater or less extent for the purpose of perpetuating and intensifying one or more desired characteristics. At first the work is usually carried on by one, or at most a few, of the most intelligent breeders, who, by improving conditions, have first improved the quality of their own stock.

*The description of these gaits will be found in Chapter XIX. 
"It will be readily seen that when the attempt is made to launch a breed and establish a record of genealogy, or pedigree, for the various animals selected for such record, the first pedigrees must be based on unpublished records. Not infrequently some of the foundation stock is recorded simply by name, and nothing is said of ancestors, because nothing is known of them."*

From the above definition, the term "breed" can hardiy be applied to the trotter, because the search has been more for speedy individuals than for a class of horses possessing special qualities. Until recently, pedigrees have been very loosely kept. The Kentucky saddle-horse, although his breeding has been contemporary with that of the trotter, forms now a distinct breed, whose individuals possess the power of transmitting their distinctive traits with reasonable certainty.

The Morgan family of horses is, in this sense, not a breed. It includes the descendants of Justin Morgan, a horse foaled in 1789, three-quarters thoroughbred, and of such remarkable virility that his descendants to this day still bear unmistakably many of the qualities that made their great progenitor famous.

The rules of admission to the Morgan Horse and Register are these:

"1. Any meritorious stallion, mare, or gelding that traces in direct line to Justin Morgan and has at least one-sixty-fourth of his blood; provided the sire and dam were bred in approved speed or roadster lines.

"2. Any meritorious stallion, mare, or gelding having onethirty-second or more of the blood of Justin Morgan; provided the sire and dam were bred in approved speed or roadster iines.

" 3 . The produce of a sire and dam both registered in the Mcrgan Registry."

As a business-horse - a horse of all work-the Morgan horse stands preeminent. No other stallion in the history of Western horses possessed the power of perpetuating good qualities to the the extent possessed by Justin Morgan. The distinguishing

*From Chapter IV., "The Horse," Roberts (The Macmillan Company), a most excellent and practical book, treating of the horse in his every-day aspect. 


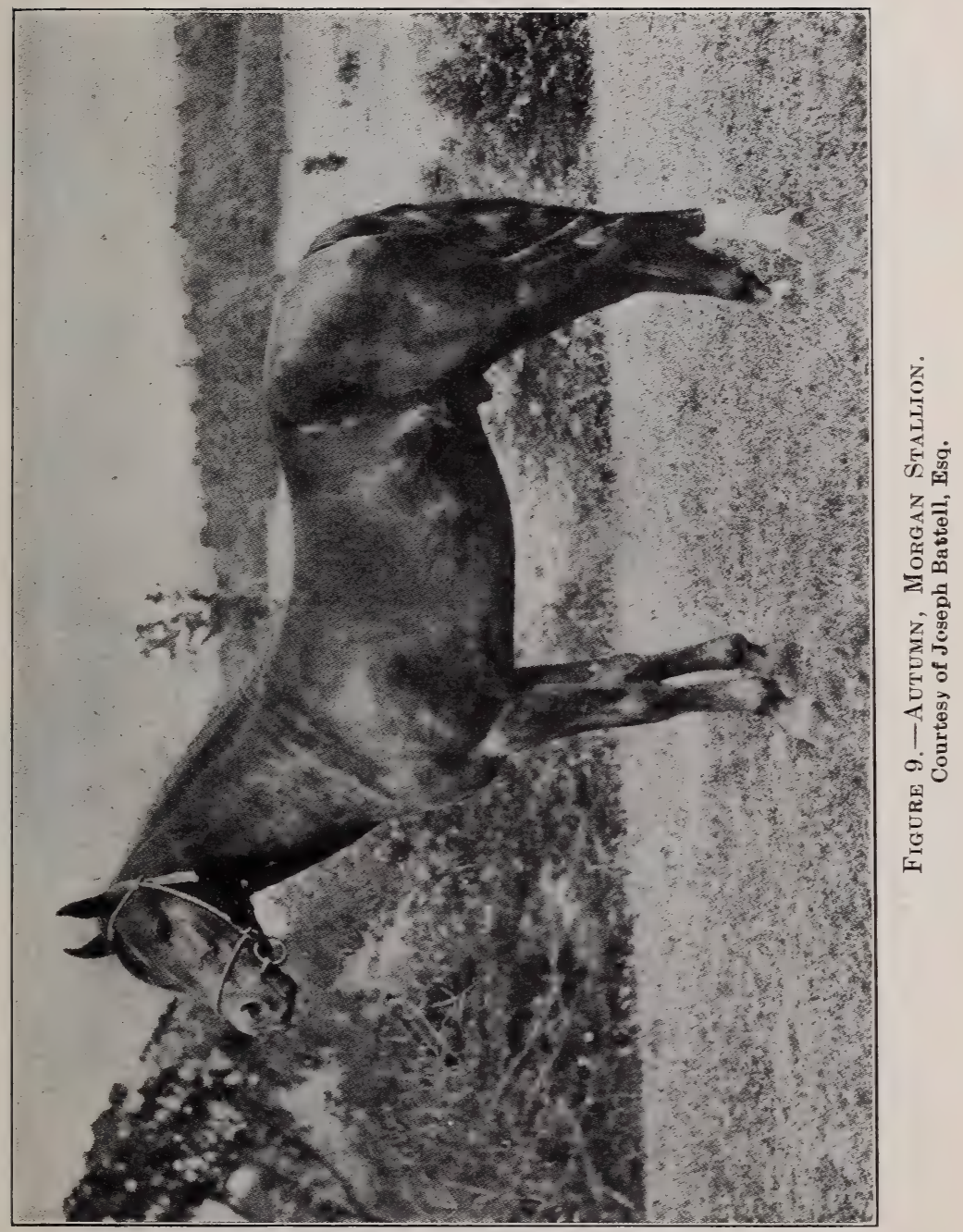


characteristics of his family are: beauty and symmetry of conformation, hardiness, longevity, docility, willingness, and endurance.

The light harness-horse and the lighter sort of work-horses in the United States are, in the main, mongrels. They are so badly bred, so crossed with conflicting strains, that little can be predicted of the quality of the average foal, based on the qualities of its sire and dam.*

The Arab horse is the aristocrat of the horse world. These wonderful animals have been kept of pure blood for "a known period of 3,500 years' ' $\dagger$ in the deserts of Arabia. They have furnished the uplifting, ennobling quality which has been introduced in the blood of commoner horses from a period dating back from 1600 to 2000 B. C.

Their influence is met with in the mustang of the Western plains and in the small Philippine pony, both degenerate Arabs, descending through the Spanish barb. Both are wiry, plucky little animals, showing little of the graceful conformation of their great ancestors, but much of their courage and endurance.

\section{GENERAL DEFINITIONS.}

The perfect male of the horse is called a stallion or an entire. When altered (castrated), he becomes a gelding. The female is a mare.

The young is called, for either sex, a foal. Specifically, the male foal is a colt; the female a filly.

A colt, or filly, becomes of a ge when the corner incisor teeth grow up level with the other incisors of the lower jaw,-about

*This condition has been realized by the better farmers of the country for some years, and, due to this fact and to the efforts of the Bureau of Animal Industry of the Department of Agriculture, the quality of the cheaper grades of horses is being rapidly improved.

$\dagger$ Page 41, "The Arab Horse," Spencer Borden (Doubleday, Page \& Company, New York). 
five. He is aged, under the racing rules, at seven, when he is considered thoroughly mature.

The period of gestation is eleven months. The age of the horse is usually reckoned from the first of January preceding birth. For purposes of record, a thoroughbred foal becomes a yearling on January first after his birth.

To aid in the recognition of horses, they are described by giving their color, sex, age, height, color of mane and tail, points, and by detailing their marked peculiarities. In this description certain technical terms are used:

A snip is a patch of white (skin and hairs) on the nose.

A star is a patch of white hairs in the center of the forehead.

A blaze is a streak of white hairs running down the face, starting from the star.

A horse is bald-faced when the star and snip are connected by a broad blaze.

When the blaze does not run down the axis of the nose, it is termed a race.

White hairs on the legs are almost always limited below by the hoof. They are described by mentioning their upper limits: white heels, white coronets, white pasterns. When the white color extends nearly or quite to the knee or hock, it is termed a white stocking (Figure 3): A white foot is, properly, one where the hoof, as well as the hairs near it, is white.

A horse has black points when the mane, tail, and lower legs are black. If the mane, tail, and lower legs are the same color as the rest of the animal, he is self-colored. A horse is light of the sort when he is paler than the average for the color. It is usually a sign of constitutional debility.

A mane is roached when it is trimmed close on each side, leaving a short, thin line of hair in the center about an inch long, running the length of the crest (Figure 4). It is hogged when the mane is cut closely throughout (Figure 3). 
A tail is banged when it is cut square below the end of the dock (Figure 2). It is thinned when it is shortened by pulling and breaking, but not squared off (Figure 4). It is docked when the dock and hair both are cut off from eight to eleven inches from the root of the tail.

A brand is a mark burned in the skin of a horse, leaving a scar of some definite design to establish ownership.

Clipping is the process of shortening the hair of the coat by means of clippers.

Singeing is the process of burning long hairs in the coat until they are the same length as the rest.

Wire cuts are the scars of wounds made by barbed-wire fences. They are characteristic in appearance, and frequently, by their location, cast suspicion upon the soundness of the animal. Usually the wounds causing them were only skin deep, when the resulting scars are merely blemishes.

A rope burn is a scar or wound made by chafing the skin of the fetlock by a rope. Like a wire cut, it is usually only a blemish.

The height of a horse is determined by measuring, in hands of four inches each, the altitude of the top of the withers. A full-grown horse, fourteen hands two inches high (written: $\left.14: 2^{\prime \prime}\right)$, or less, is a pony.

Generally speaking, a ble mish is any irregularity that mars the beauty or symmetry of a horse, while a defect is one that reduces his usefulness.

The forehand of a horse includes that part in front of the rider. The part in rear is termed the haunches.

Of a pair of horses, the near one is the left, the off one is the right. The near side of a horse is his left side; the off side, his right.

A sound horse is one that is not affected with any disabling disease or injury; an unsound horse is one that is suffering 
from any malady, acute or chronic, however slight, or that has been disabled in any degree by disease or injury.

An acute disease is one attended by more or less violent symptoms and coming speedily to a crisis, while a chronic disease is one that continues a long time, mild as to intensity and slow as to progress. An acute disease results in a speedy recovery, or death, or it may assume a chronic state. A chronic disease is difficult to cure, and yields only to long-continued treatment.

The Law of Warranty.-When a horse is purchased, the seller should furnish a bill of sale, setting forth the description of the horse and guaranteeing certain things, as, for example, that he is sound; that he is sound and kind; that he is serviceable for certain specific work, etc.

This bill of sale is the new owner's guarantee of title to the horse. It also insures him against defects existing prior to the date of sale.

\section{A warranty does not go forward of the date of sale,} unless it explicitly states so.

If a person buys a horse that goes lame immediately or soon after purchase, he can recover on the guarantee only by showing that the horse exhibited the same lameness before the sale. Similarly with a horse warranted kind that runs away or balks after sale. Unless the new owner can establish similar viciousness before the sale, he cannot recover damages from the former owner.

This arises from the fact that all that can justly be expected from the seller is that he state truly in his warrant what the history of the horse has been, not what his subsequent history may be. 


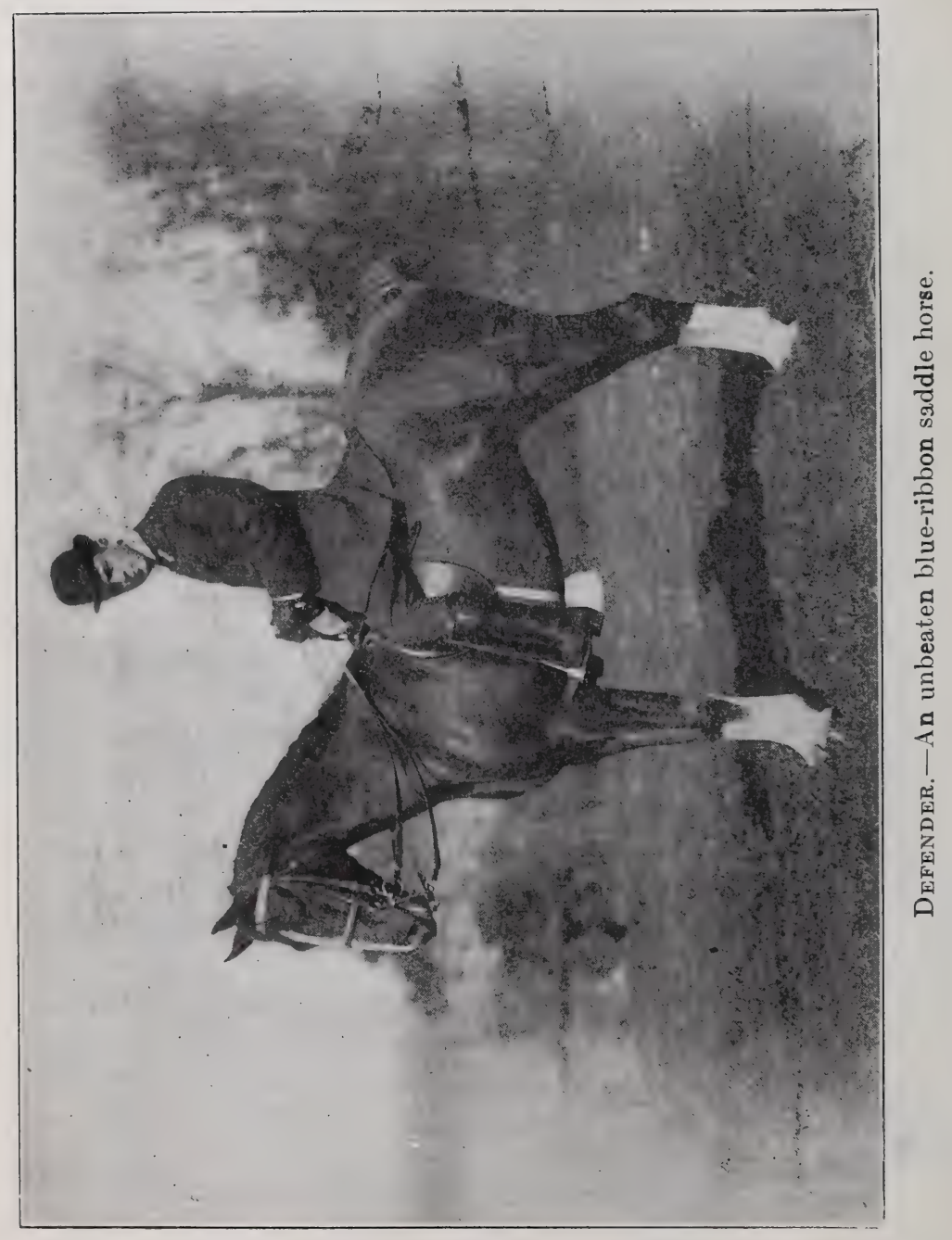




\section{CHAPTER II.}

\section{AGE, AS DETER MINED BY THE TEETH.}

The value of a horse, after he reaches maturity, is proportioned to the remaining period of his usefulness. It is, therefore, of importance to a purchaser to know approximately, and without being compelled to rely on the testimony of others, the age of the horse he is buying.

It is very easy for anyone, however little he may be familiar with horses, to distinguish the young from the very old animal. Signs of wear are apparent in the stiffened action, in blemishes on the members, and, more than all, in the elasticity of the skin. Aristotle says: "If, in pinching up the skin from the lips, it is promptly retracted, the animal is young; if it remains wrinkled for a long time, he is old."

Because the coat hides the skin, those signs of age that the skin betrays in hairless animals cannot be detected in the intervening years between youth and old age. For our guide during this period we must go to the teeth, which appear and grow and change their shape according to laws that are fairly regular.

Up to five years the teeth give very reliable information; from five to nine this information is good; after nine the limits of error increase rapidly, and little reliance can be placed on the teeth as a sole means of judging age.*

*There are horsemen who claim to judge accurately the age of all horses, solely by their teeth. Such a claim, while honestly made by many competent horsemen of experience, is often not made good in practice. The teeth do furnish an excellent suggestion as to the age of the horse-good enough to protect the careful observer from imposition-that is all that should be claimed for them by the amateur horseman. 


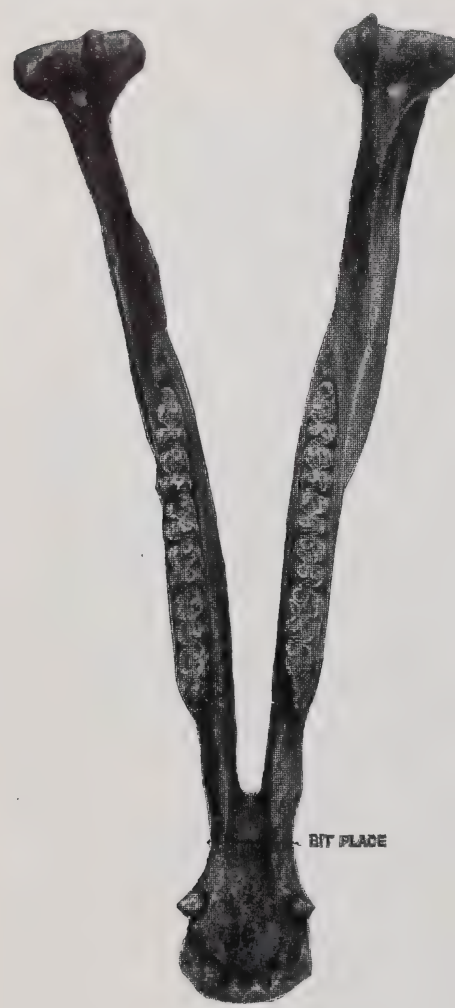

Figure 10. - The Lower JawBone in Plan, Showing Teeth

The back teeth, molars, are six in number on each side of each jaw; those in the lower jaw are"shown in Figure 10.

In addition to these twentyfour molars, another molar sometimes appears in front of the others, more often in the upper jaw than the lower, and rarely in both jaws. These molars are rudimentary and usually temporary, appearing before the colt is a year old and usually disappearing before he is three. They sometimes remain indefinitely. These teeth are usually called wolf's teeth, but are sometimes called blind teeth, from a fancied influence on the horse's sight.

The molars are difficult to examine on account of their location, and their usefulness as evidence as to age ceases at five, when all the temporary ones have been replaced by permanent teeth, whose aspect changes slowly.

The changes in the other teeth are quite regular up to that age. For this reason, inspection of the molars to determine age is rarely resorted to.

The inspection of the incisors, the twelve teeth in the anterior portion of the horse's jaw, is the usual means employed to approximate the age of horses. In inspecting them, the following details are examined:

First: Whether they are temporary or permanent.

The common names for the incisors, naming them each way from the middle of the jaw, are center, intermediate, and corner. 
When the foal is born none of the incisors have appeared. About a week later the two center teeth are through the gums. In a month the intermediates appear, and after eight or nine months more, the corner teeth. These teeth are small, thin, and white, and of little interest as a means of determining age to the ordinary observer. Up to this time the colt's very appearance marks his infancy-he is leggy, small in the body and neck, his mane and tail are woolly and characteristic in appearance.

For the next year and a half, to the casual observer, these teeth change but little; their grinding surfaces wear away, but they retain much the same appearance they had at one year. Because these teeth appear while the colt is still drawing his sustenance from his mother, they are called milk-teeth.

Between two and a half and three years, the center milkteeth have fallen out and permanent ones have taken their place.

When the horse approaches a given age-three, for instance -he is said to be rising three; after he has passed it, he is three off until he is three and a half; after that period, he is rising four.

The age of the colt at three is easily determined when we find the center incisors permanent and the rest temporary.

At four the intermediate temporary teeth are shed and replaced by permanent ones, and at five the temporary teeth are all gone.

Figure 11 shows very plainly the difference in appearance between the temporary (corner) and the permanent (intermediate) teeth.

Simply by opening the colt's lips the observer can tell his age near enough for all ordinary purposes. As a rule, a horse less than five is not mature enough to be put to hard work; his development is not complete, and what would be quite suitable employment for a mature horse would probably prevent the full development of a colt and by so much destroy his future usefulness. 


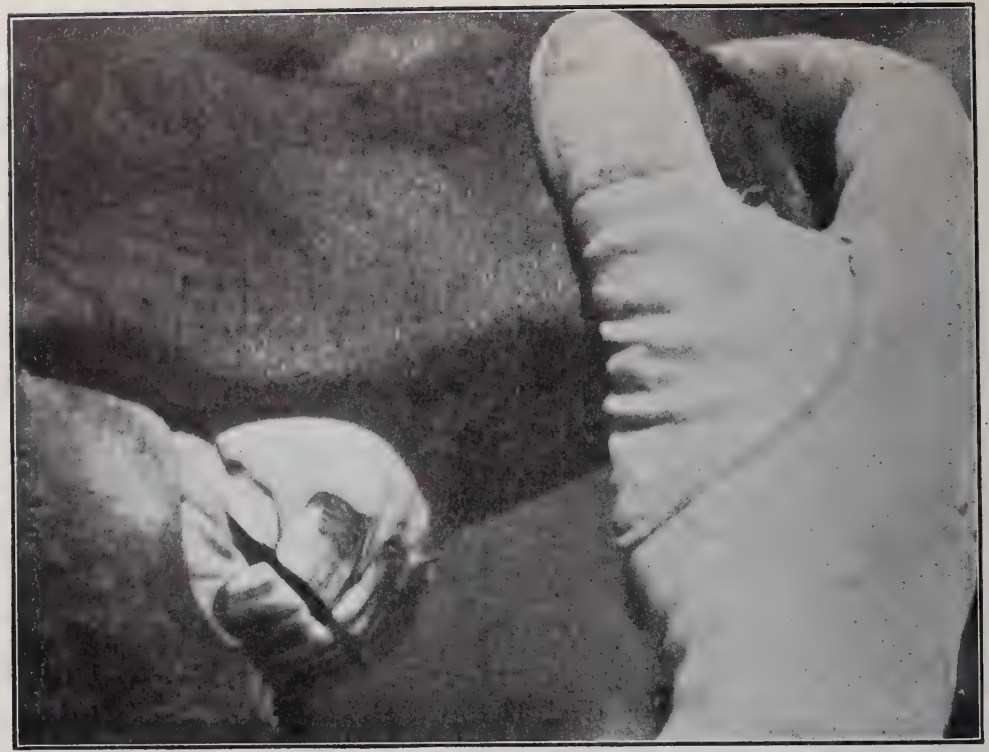

Figure 11. Temporary (Corner) and Permanent (Intermediate and Center) Teeth-Four Years Old.

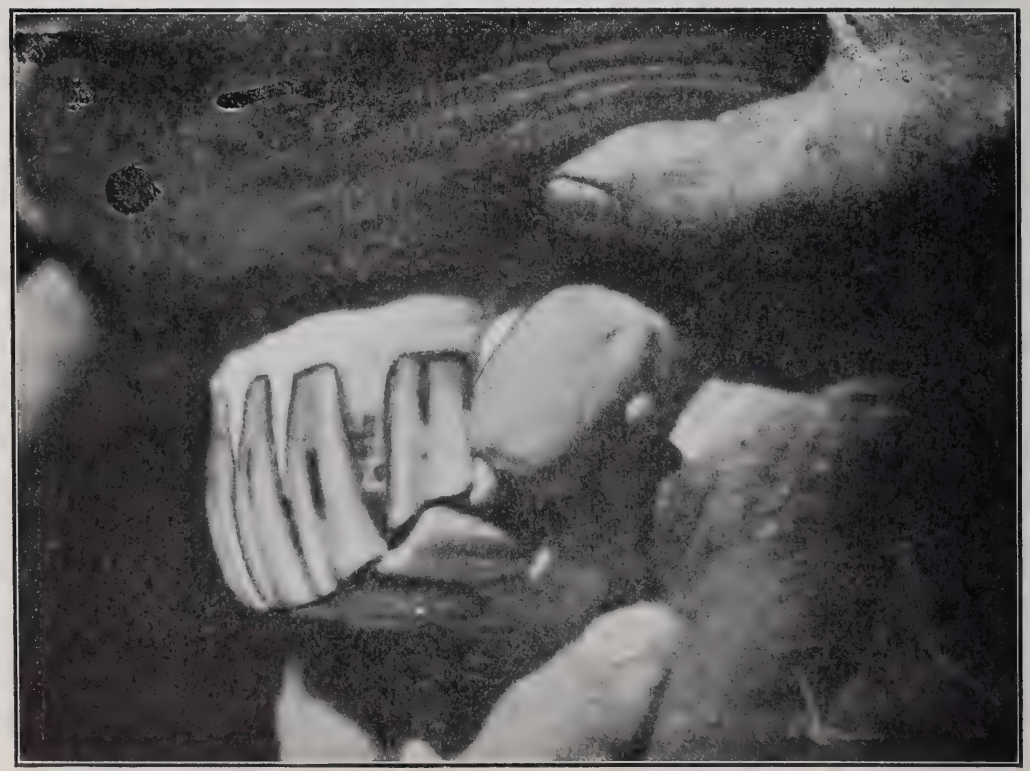

Figure 12.-Showing Angle of Meeting of Upper and Lower Teeth In a Horse Twenty Years Old. 


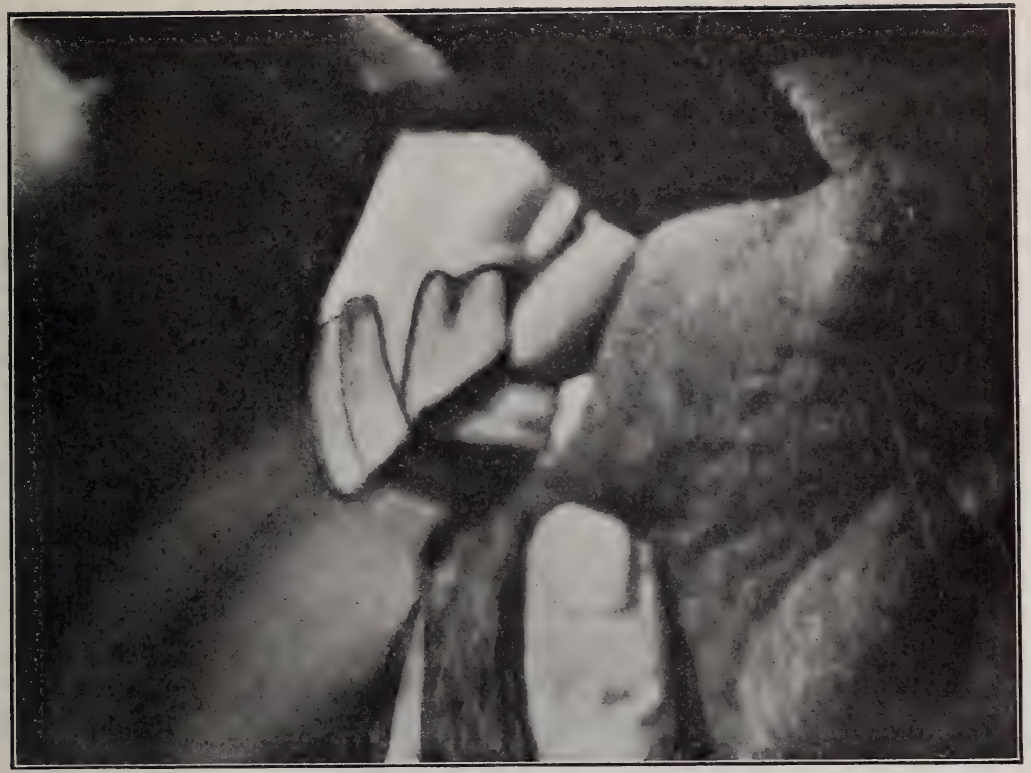

Figure 13.-A Parrot Mouth.

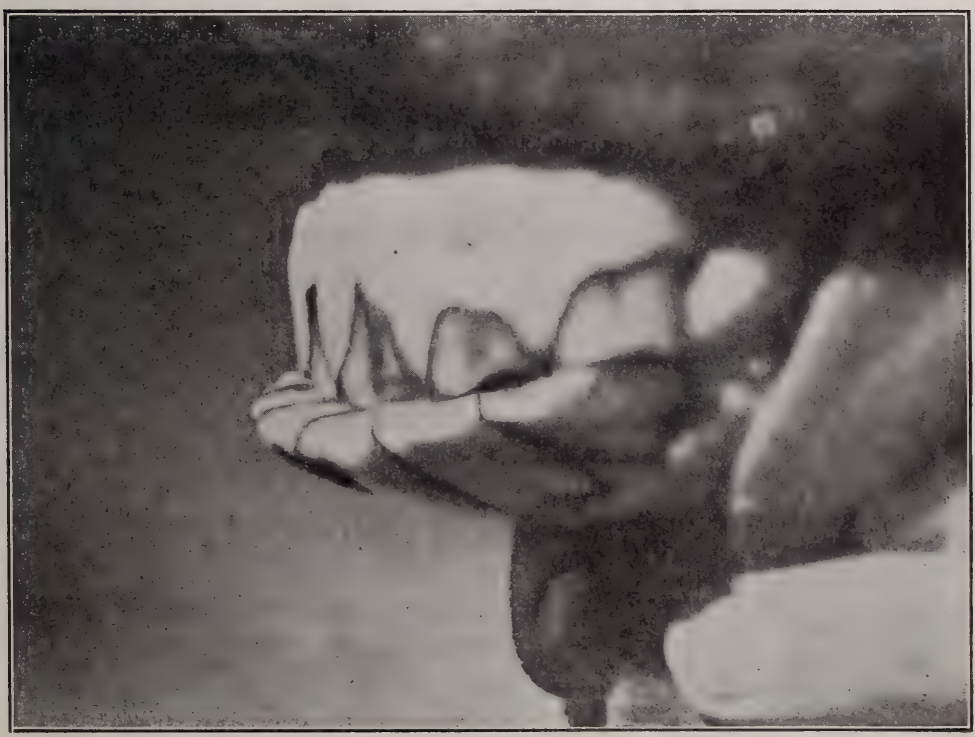

Figure 14.-An Undershot JaW. 
Sometimes the temporary teeth are pulled to make the colt appear older, and occasionally the corner teeth and intermediate, especially in the upper jaw, are shed at nearly the same timeabout four. However, this is not the rule.

Second: The angle at which the teeth of the two jaws meet.

The younger the horse, the more nearly the angle made by the prolongation of the front faces approaches 180 degrees. This angle becomes more and more acute as the horse grows older. Compare the angle made by the outer faces of the upper and lower teeth in Figures 11 and 12.

\section{Third: Whether or not they meet accurately.}

If the teeth do not meet accurately, the tables of the teeth do not wear as uniformly as in the normal case and their appearance is not a good index of the horse's age.

If the upper jaw is longer than the lower one, the upper teeth will, when the mouth closes, project beyond the lower ones. This malformation is termed parrot mouth. The contrary case, much more rare, is termed undershot. The cuts on the opposite page illustrate each case. It is very difficult to approximate the proper age of horses possessing either of these malformations, since the teeth, not meeting, do not wear away according to the general rule.

The horse whose mouth is shown in Figure 14 has the habit of biting at the woodwork of his stall, the picket-rope-anything within his reach. This habit is known as cribbing, and is the cause of the wearing away of the upper teeth. This animal was known to be between eighteen and twenty when this picture was taken.

Fourth: The appearance of their outer faces.

The teeth of a young animal show smoother surfaces (are less stained and chipped on the edges) than the same teeth in older horses. Young teeth are whiter than old ones, and have not such pronounced deposits of tartar on the margins of the gums. Compare Figures 15 and 16. 


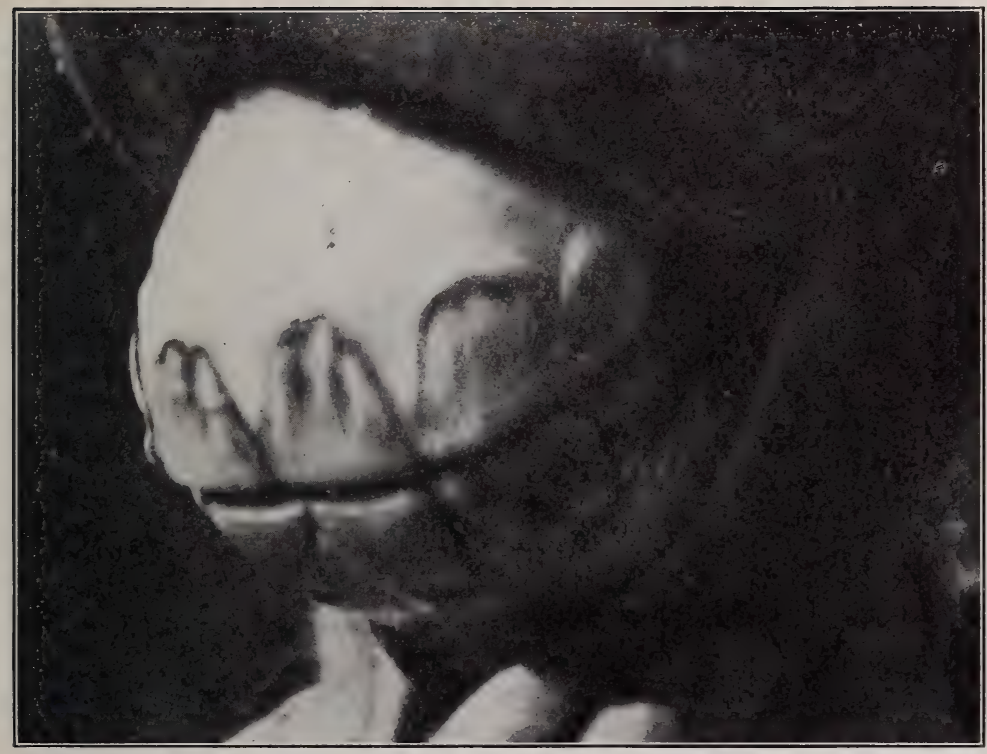

Figure 15.-Front View at Four.

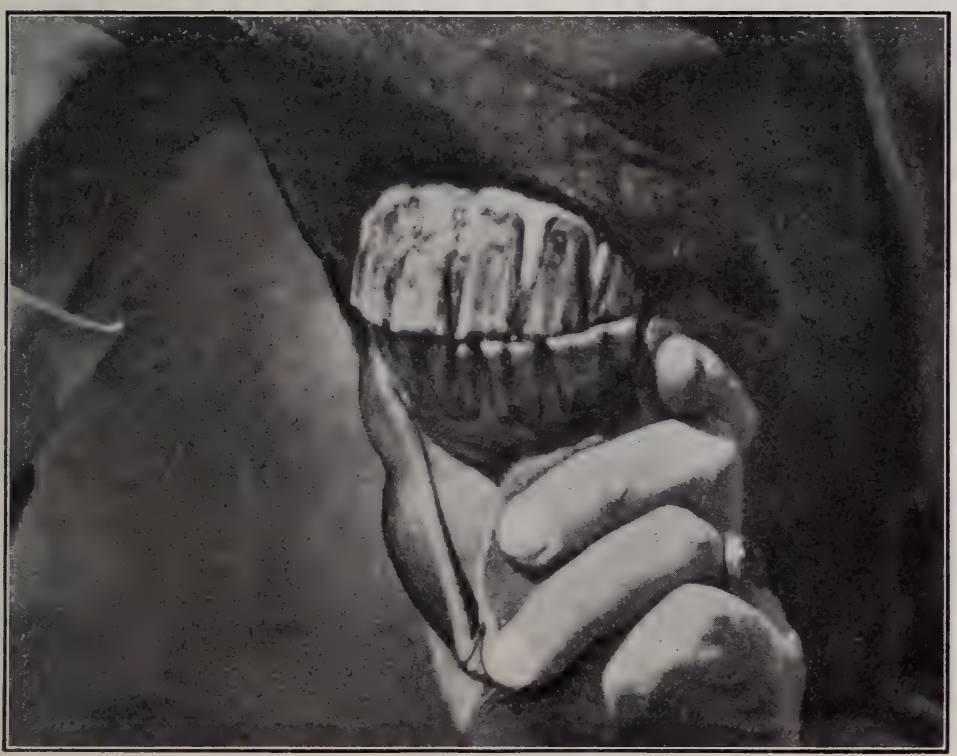

Figure 16. - Front View at Thelve. 


\section{Fifth: The shape of the corner teeth.}

The tables of the teeth are the surfaces that meet when the jaws close. When the permanent corner teeth come up, at five, the profiles of their tables are right lines. The upper tooth does not, usually, meet the lower tooth exactly, but projects slightly to the rear. As the teeth wear off by grinding against each other, the forward part of the upper corner tooth wears away faster than the rear part, and a hook appears. This hook-like appearance is characteristic of horses seven and older, IF THE TWO CORNER TEETH DO NOT MEET THROUGHOUt. If they do, the teeth will wear evenly, and the profile will remain a right line. The hook is almost never present at five, is slight at six, and quite pronounced at seven. Compare Figures 17, 18, and 19.

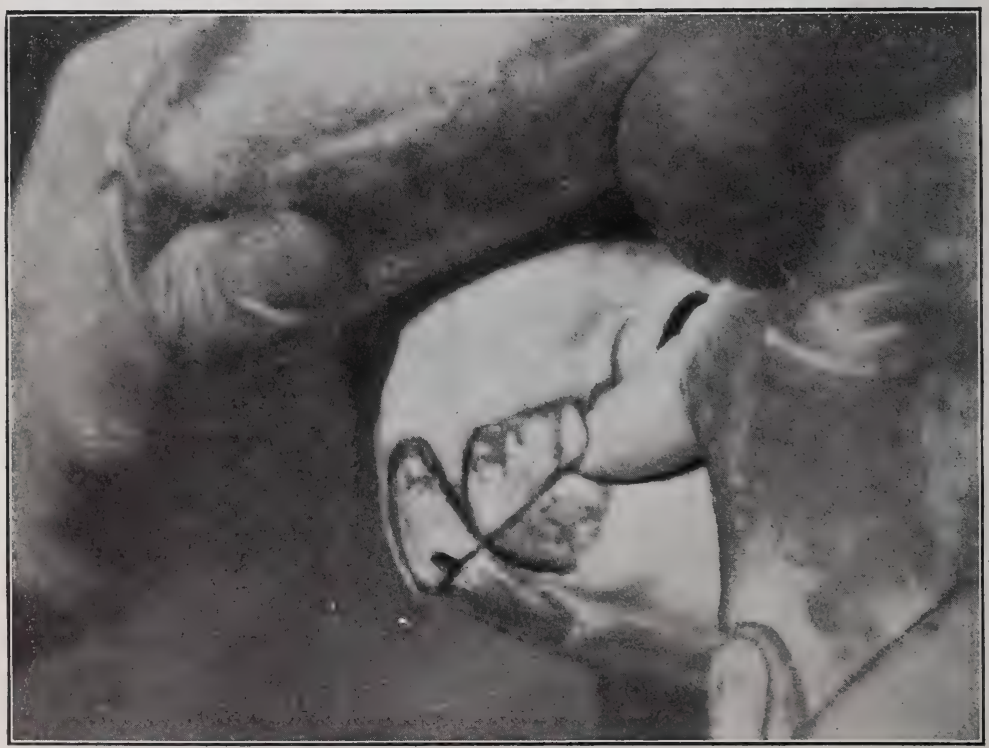

Figure 17.-Side View at Six. 


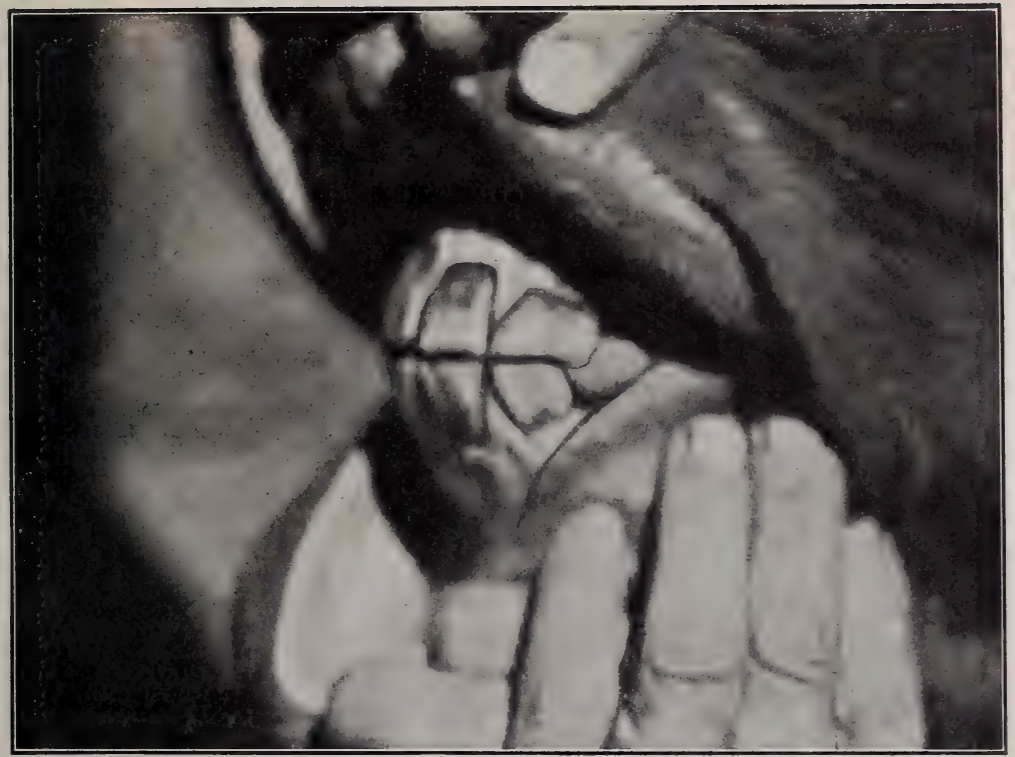

Figure 18.-Side View at Seven.

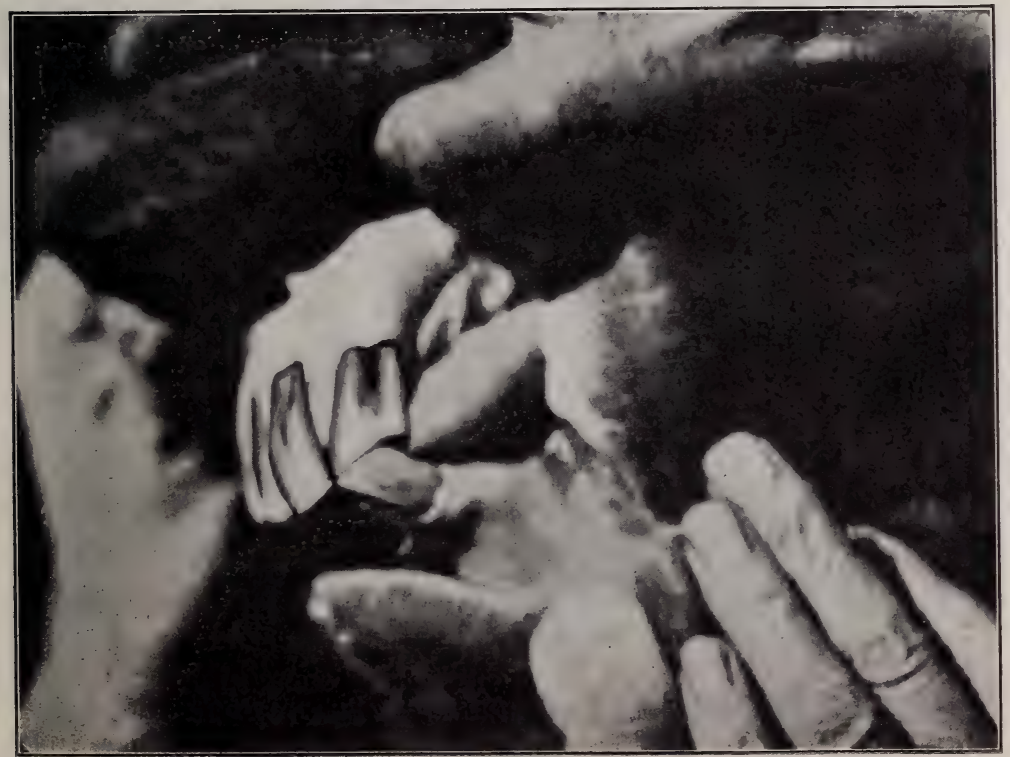

Figure 19.-The Hook at Nine. 


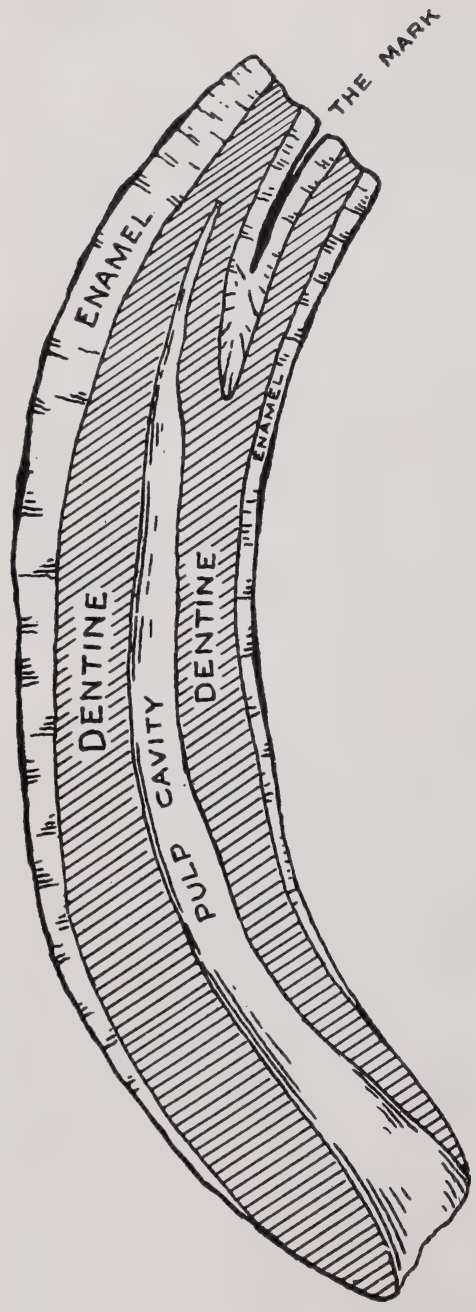

Figure 20.-Longitudinal Sectron of Center Incisor.

Drawn by Capt. C. B. Hagadorn, 23d U.S. Infantry.
Sixth: The direction and length of the teeth.

As seen in the cut, Figure 20, the tooth in its original shape curves more rapidly towards its outer end. The shape of the remaining portion of the tooth is not altered as the tooth wears off and is pushed forward. The height of the molars remains fairly constant, and thus the distance between the jawbones at the outer end also remains constant.

As the exposed ends of the teeth lose their curvature and the straighter portion of the original tooth comes into view with advancing years, they meet farther and farther to the front, and the visible portion of the tooth becomes longer. Contrast Figures 11 and 12. At the same time the teeth become narrower in diameter, and so appear more closely bunched in the older animals. Contrast Figures 18 and 23. The plumpness of the gums is less in old horses than in young ones. Contrast Figures 11 and 12. 
Seventh: The mark, the dental star, and the shape of the tables.

All the details above enumerated are preliminary to the examination of the tables of the teeth and confirmatory of what is to be learned from them.

The structure of the incisors is the same for all: A central cavity, the pulp cavity, containing the nerves, blood-vessels, and secreting tissues, is contained in the axis of the tooth. Surrounding this pulp cavity is dentine, a dense and ivory-like substance, forming the body of the tooth. This dentine in the per-

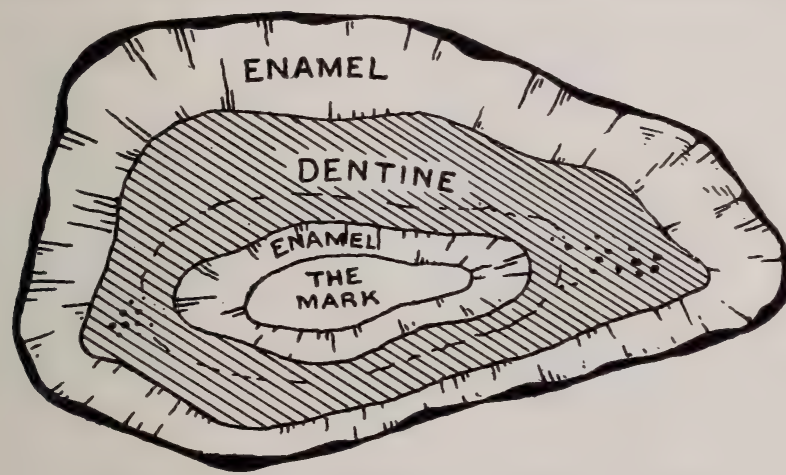

Figure 21.-Cross-Section of Center Incisor.

fect tooth has a deep hollow in its outer end. Over the surface of the tooth and lining the depression in its outer end, is ena mel, white, very hard, and of varying thickness. The depression in the tooth soon becomes discolored from the débris of decomposing food lodging there. The enamel that crowned the tooth at its appearance soon wears off, but the enamel on the outside of the tooth and that lining its central depression still shows in cross-section on the table of the tooth. The blackened spot in the center of the tooth, with its surrounding ring of white enamel, is called the mark, and is present in every permanent incisor for about three years after its appearance. By this time, in the ordinary case, the grinding of the teeth against each other has worn off that part of the tooth con- 
taining the depression, but for another year the discoloration of the body of the tooth, due to the chemical action of the contents of the depression, is still more or less visible.

As the tooth wears down and exposes the pulp cavity, its secreting tissues deposit dentine to fill up the cavity, to protect the nerves and blood-vessels from injury. The dentine so formed is yellower in color than the original dentine of the tooth, and as the tooth gets more and more worn down, assumes somewhat the form of a star, hence its name, dental star. At first this new dentine appears as a yellowish line in front of the enamel of the mark. This is because the pulp cavity is spread out quite thin near the end of the perfect tooth. It narrows and broadens deeper in the tooth until its final shape is circular. The circular shape is not found until the horse is about twelve, although this rule is extremely elastic.

At three or four the observer can be sure enough of the horse's age without looking at the tables, but after that they should be consulted.

At five the horse's mouth presents quite positive evidence of his age. Looking at the outer faces of the teeth, they appear smooth and clean. The edges are sharp; there is no hook in the upper corner teeth; the gums are plump; the horizontal and vertical axes of the teeth are not far from equal. Looking at the tables, the mark is found to be clear in all the teeth; the center and intermediate teeth show tables nearly rectangular in shape, and the axis of the tables at right angles to the jawbone is nearly twice as long as the other one. But it is in the corner tooth that the surest evidence is found. As the other incisors appear, at three and four, the mark is entirely surrounded with enamel, but the corner tooth comes up as a shell, with the inner wall missing, and not until the tooth has been in use for from six to nine months is the outer portion of the wall worn down to the level of the inner portion. This peculiarity of the corner tooth at five, once seen, should never be"mistaken. 
At six the hollow of the mark has been worn off the tables of the center teeth, but the enamel is still there; it is discolored; and sometimes appears not very different from the marks in the other teeth-a little less dark and its margin less pronounced. The mark is plainly present in the intermediates and corners, and the wall of the corner tooth is up all around. The tables of the teeth at six usually lose something of the rectangular shape, becoming more rounded on the longer sides.

Looking at the exterior faces of the teeth, the hook is beginning to appear and the teeth are losing their fresh, clean appearance. There is nothing positive to go by in the six-year-old mouth, except the presence of the mark in the intermediates and corner teeth, and even this is sometimes misleading.

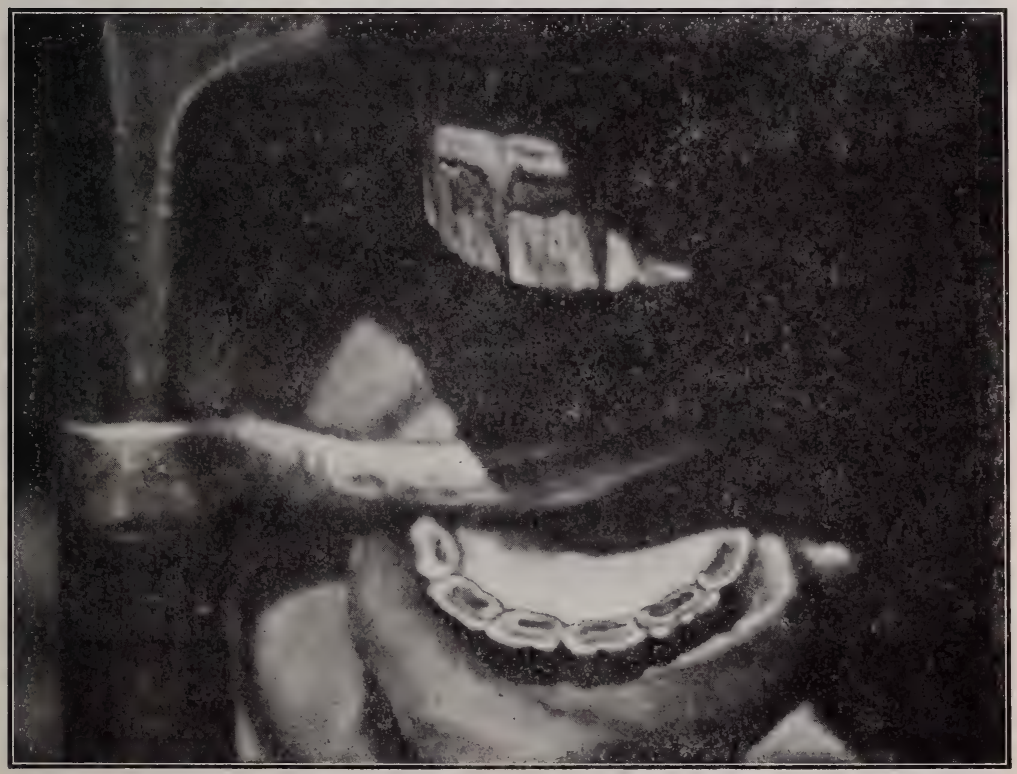

Figure 22.-The Tables at Frve. 


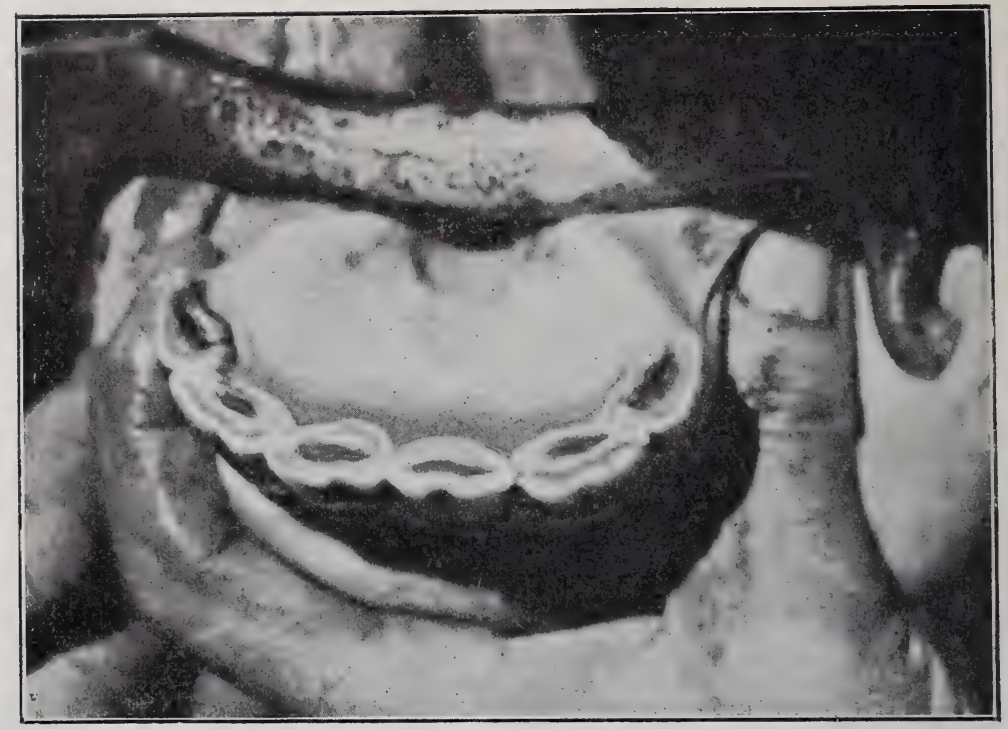

Figure 23.-The Tables at Six.

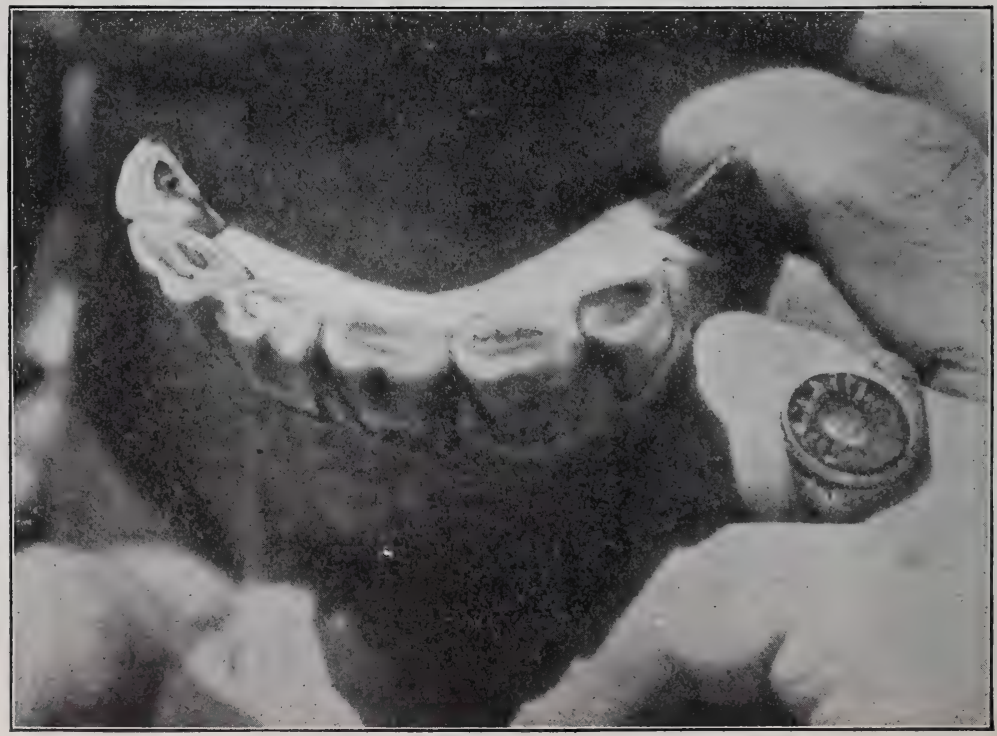

Figure 24.-The Tables 


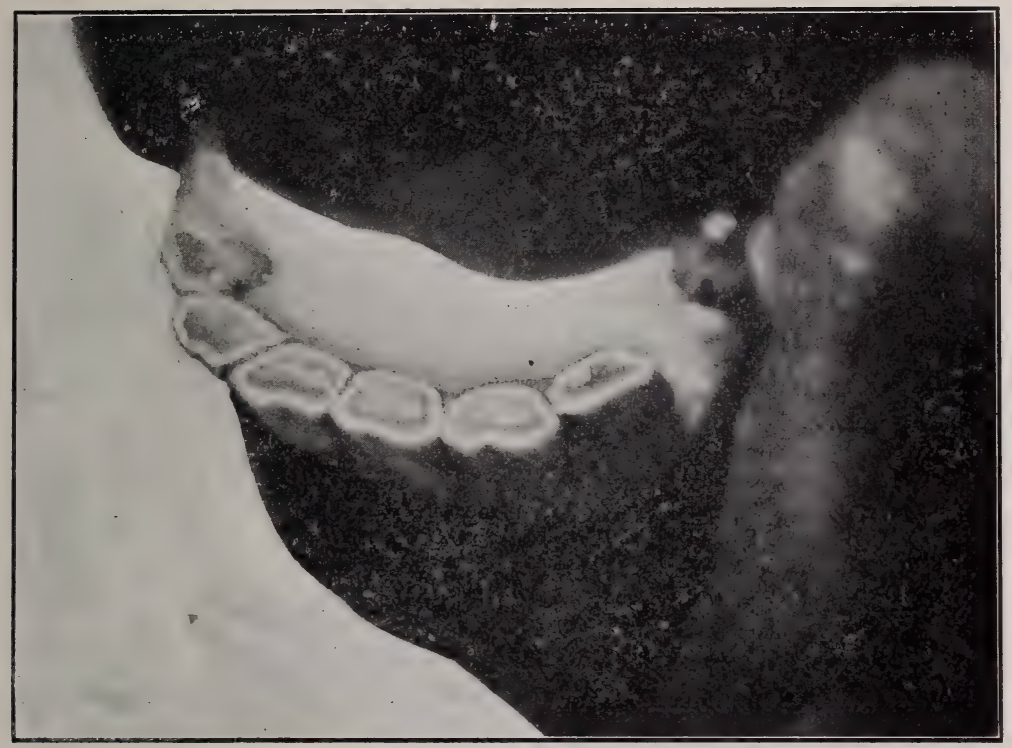

Figure 25.-The Tables at Eight.

At seven the yellowish line of the dentine that has filled up, the pulp cavity shows quite plainly in the center teeth and may show in the intermediates. The mark is gone from the center teeth and faint in the intermediates; it shows quite plainly in the corners. The tables are much more rounded in outline. The exterior aspect of the teeth is quite changed; they are much longer and their angle of meeting is more acute. The hook is now plainly visible, except in those mouths where the posterior corners of the corner teeth meet exactly, and it is the presence of this hook, together with the presence of the mark in the corner teeth, that makes the seven-year-old mouth fairly easy to interpret.

Dishonest dealers frequently rasp off the hook to make the horse appear younger than he is. 


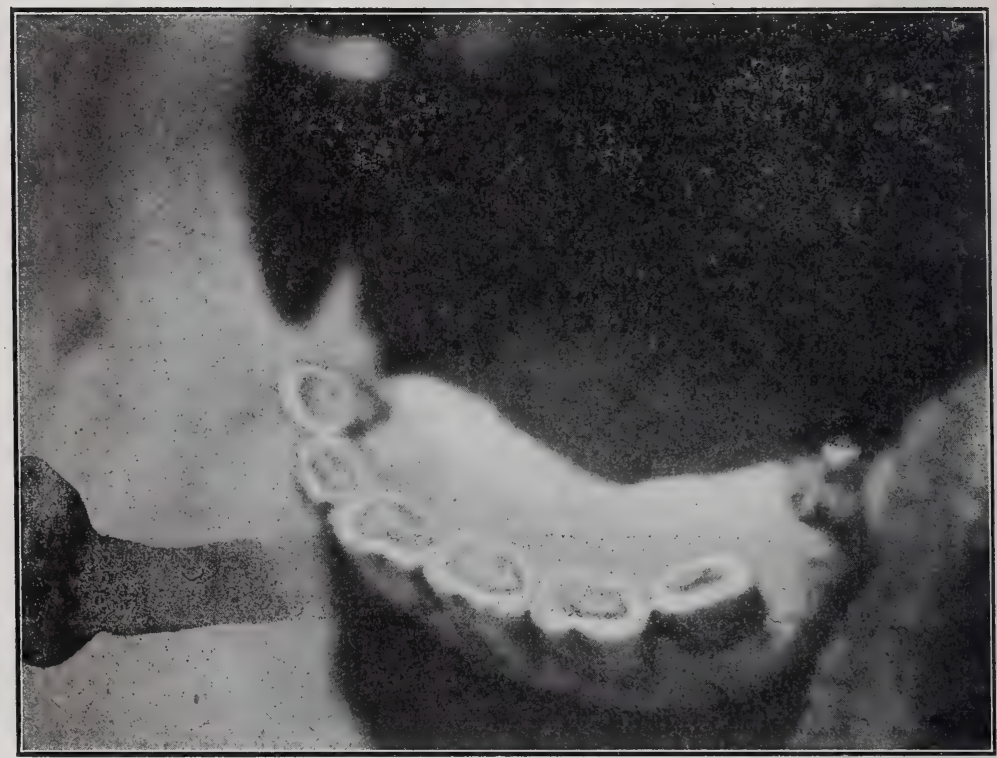

Figure 26.-The Tables at Nine.

The central enamel is still present in all the teeth, although the discolored portion is usually worn off in the center teeth.

At eight the mark is gone from all the teeth, although the corners are still discolored and the central enamel is found in all of them. The line of the dental star is better defined in the center teeth. The tables are more rounded than before and the line joining their centers is a flatter curve than in the younger mouths. A comparison of Figures 22, 23, 24, and 25 will show the gradual flattening of this curve.

Viewed from the side, the angle of meeting of the teeth has grown much more acute than at seven.

The principal test to be used in distinguishing between an eight and a nine-year-old mouth is to see whether the central enamel is gone from the center teeth. If it is still present, the 
horse is probably eight; if it is worn off, he is probably at least nine. Just as the presence of the temporary teeth shows the colt-age, so the absence of the central enamel shows that the horse is more than eight - that he is "past telling" with any degree - of certainty. It is much more difficult, even with this central enamel as a test, to distinguish between the eight- and the nineyear-old horse than it is to tell a four-year-old from a fiveyear-old.

In fact, it must be impressed upon all that there is no inviolate rule for the growth and wear of the teeth. Differences in the density of the dentine, differences in food and method of feeding, or bad stable habits, will cause teeth to vary widely in appearance in horses of the same age.

At nine the tables of the center teeth are quite rounded, the dental star is much more rounded in them than before.

From nine on the indications of the horse's age become increasingly less reliable., Mayhew says: "The greater the number of years, the more difficult it is to arrive at the exact determination of the age. After the twelfth year there is but little probability of judging it correctly; after the sixteenth, all is confusion, for there are no positive signs that will enable us to give a definite opinion upon this point, and it is better now to be cautious, or remain silent."*

The amateur had better go farther than that and refrain from any positive judgment after nine.

When the dental star becomes round and the tables triangular, the horse is probably twelve or more; and when the necks of the teeth become small and widely separated, he is approaching very near to the end of his period of usefulness.

In judging horses for age it is best to proceed leisurely. Open the horse's lips, and view first the faces from the side. Look for temporary teeth; see if the teeth meet evenly; see if the upper corner tooth has a hook; observe the plumpness of the

*"The Horse's Mouth," Edw. Mayhew, 3d edition, p. 104. 


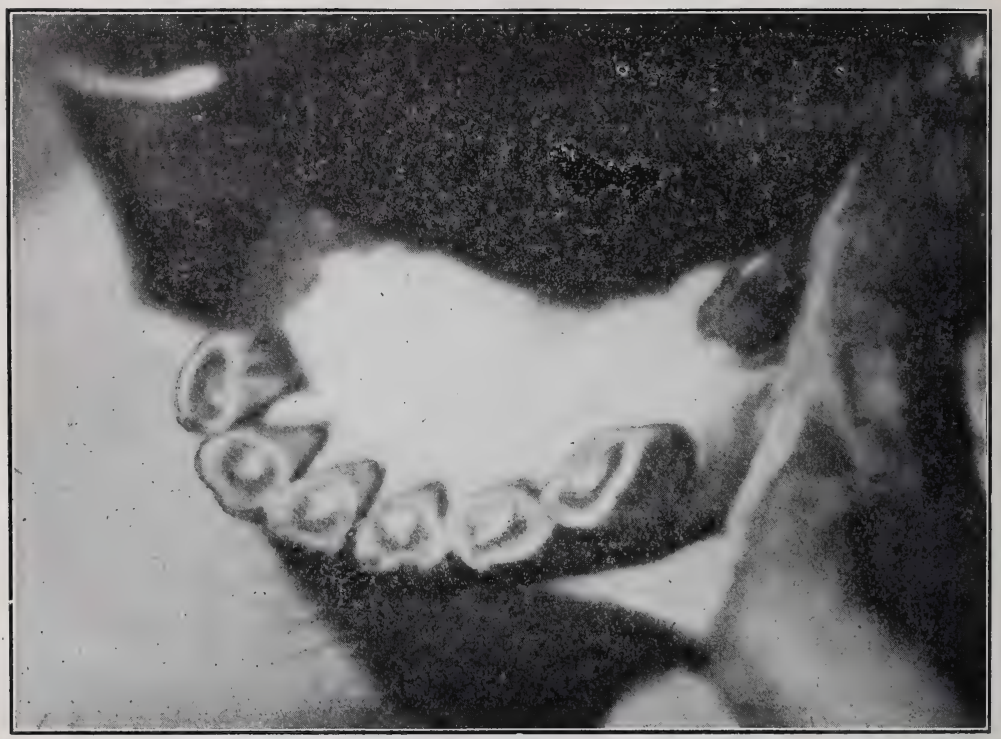

Figure 27.-The Tables at Twenty.

gums; the edges of the teeth, to see if they are chipped; their margins near the gums; for tartar. Look next at the front faces of the teeth, and compare the relative lengths of the axes of the center teeth, remembering that the greater the disparity in these lengths, the older the horse. Next, open the horse's mouth, and look at the tables. The first thing to notice is the table of the corner teeth to see if the wall has grown up on the inside; look for the mark, the shape of the tables, the dental star, the curvature of the line joining the centers of the tables, and the slope of the inner faces of the teeth. If the mark is gone from all the lower teeth, look for it in the upper. The horse that has the mark in all his upper teeth is probably not very old--perhaps between nine and thirteen, probably not more than the latter. Beware of triangular tables; they are never found in the young horse-always in the old. 


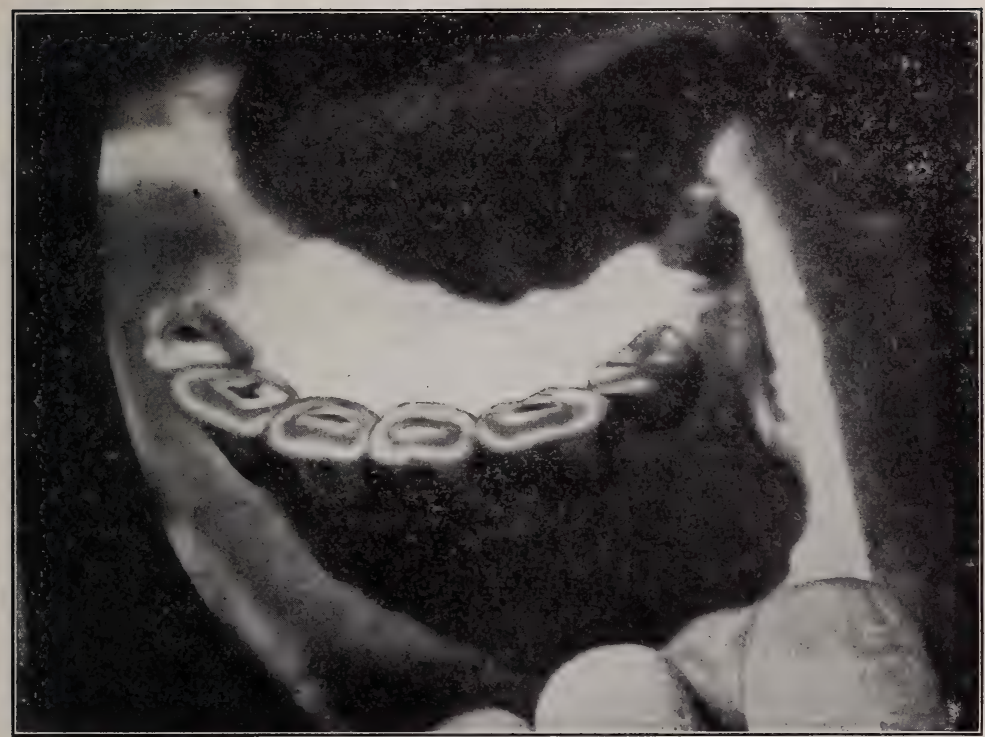

Figure 28.-An Abnormal Mouth-Mark Clearly Visible in All the Teeth at Twelve.

Having applied all these tests, reconcile all discrepancies as nearly as may be and make the estimate modestly, remembering that to be cock-sure in an estimate of a horse's age from the evidence of his teeth alone, is a sign of ignorance.

Figures 16 and 28 show the front view and the view of the tables of a horse known to be twelve at the time the photograph was taken. He was a restless horse, who objected to a scrutiny of his mouth, and the first hasty glance at the tables showed all the marks present and the wall of the corner teeth fully grown up. An observer, satisfied with that evidence alone, might say once, "Six years old"; but a more careful look at the shape. of the tables would render that estimate very doubtful, while a single glance at the stained and chipped exterior, covered with 
tartar, the long vertical axis of the center teeth and their slope, would confirm the error.

A horse's teeth are said to be bishoped when ahole in the imitation of the mark is burned in his teeth. As the false mark cannot be surrounded by the enamel of the genuine one, and as the other tests for confirming the evidence of the mark will necessarily fail, the deception is easy of detection. It is a trick rarely resorted to.

The tushes, or canine teeth, usually appear at about four, are usually perfect at five, and show greater or less signs of wear after that.

They usually are absent in mares. This fact, and the uncertainty of the time of their appearance and their rate of growth, makes them almost useless as an aid to the determination of age. A bright, clean tush, showing little signs of wear, is a good index to a young horse; while a flat-topped, chipped, and yellow tush is a usual accompaniment to age. It is not wise to place much more reliance upon them. 


\section{CHAPTER III.}

\section{INFLA M MATION.*}

In all the higher animals the tissues (bones, muscles, capsules, ligaments, tendons, glands, etc.,-in brief, all parts of the body) are nourished and kept alive by the circulation of the blood. Blood consists of a pale-yellow fluid, carrying in it myriads of white and red semi-solid bodies called corpuscles.

The red corpuscles, under conditions of health, very largely outnumber the white ones. They are without volition and float along, charged with oxygen to support life in the cells composing the tissues.

The white corpuscles have a volition of their own; they act as the scavengers of the tissues. They have the power of absorbing and of digesting other micro-organisms, and thus protect the body from disease germs.

Blood, leaving the heart through the aorta, is carried by the arteries, branching and rebranching, to arterioles, which terminate in capillaries. The arteries and arterioles have impervious walls, but the capillaries, subdividing into a veritable lace-work, so as to reach the neighborhood of every element, have cellular walls, which permit the passage through them of the fluid and solid parts of the blood. In the capillaries the flow of blood is uniform, when in a state of health, towards the vein-

*This subject is introduced at this point because it is an absolute necessity to understand, in a way, what inflammation is, what produces it, and how to reduce it, in order to properly understand what follows.

This chapter is adapted from the discussions of the subject, pp. 487-493, in the chapter on General Diseases in the work of the Bureau of Animal Industry on the "Diseases of the Horse." The cuts are copied from cuts in that work. This is a work that should be in the hands of every horse-owner. 
lets-the termination of the veins that carry the blood back to the heart.

Figure 29 shows, highly magnified, a healthy, living membrane of a frog. The broad band, $a a$, on the left of the cut, is a veinlet; $c$ is a capillary. The lighter-colored disks in the vessels and in the con necting tissues are white corpuscles; the darker ones are red corpuscles.

Ordinarily, the red corpuscles float in the center of the current,

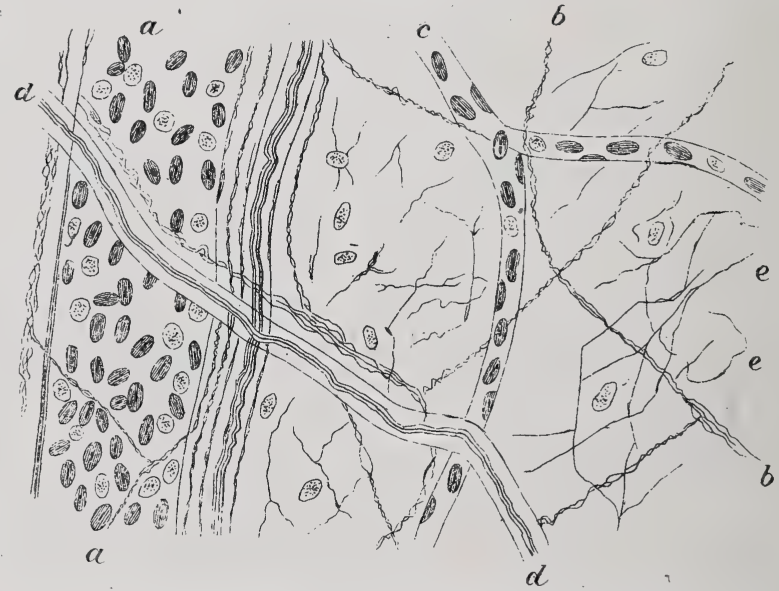

Figure 29.-Highly Magnified Living Membrane of a Frog, Non-inflamed.

while the white ones, due to a certain volition of their own, float along near the walls of the capillaries. The nutrition, received into the blood from the digestive apparatus, as will be shown later on, replaces worn-out tissues. The oxygen of the red corpuscles is consumed in maintaining the heat of the body, and the blood flows on, taking with it the dead cells of worn-out tissues, the red corpuscles, largely deprived of their oxygen, and the white corpuscles, with their burden of absorbed germs, through the veins in a steady stream to the heart. From there it is pumped into the lungs, blue in color and exhausted of vitality, to be vitalized with oxygen and relieved of its waste matter. From the lungs it goes back to the heart again, purified and enriched, to repeat its function. As the result of repeated 
experiments, it has been estimated that it takes, in the horse, thirty-one seconds for the blood to complete this round of circulation.

If the flow of the blood in the capillaries, for any reason, is impeded, the white corpuscles pass through the walls of those

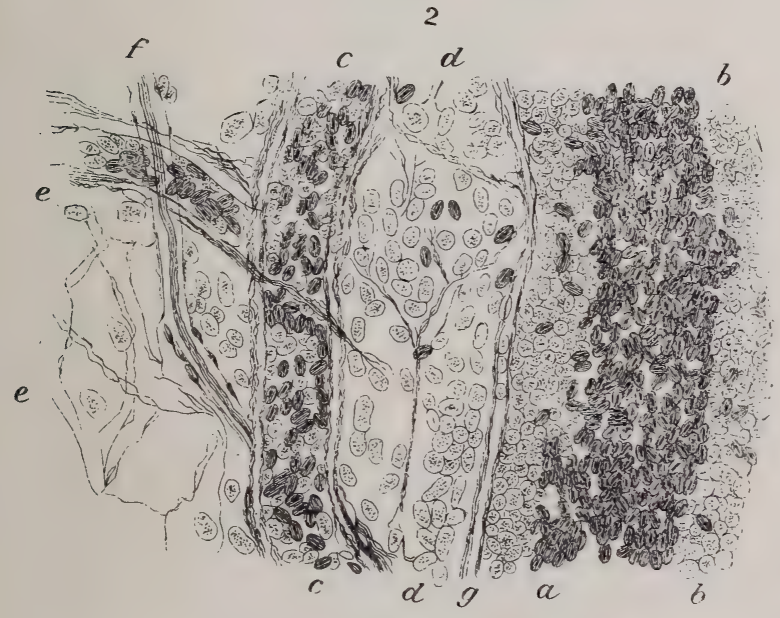

Figure 30.-Highly Magnified Living Membrane of a Frog, Inflamed.

vessels and accumulate in $\mathrm{the}$ neighb o r ing tissues. These corpusclespossess the power of mult i p l ying indefinitely, and with great rap i d it y; the nucleus of one corpuscle di vides into two, and each of these into others, and so on. The cells that largely compose the tissues possess, in a greater or less degree, this same property, and it is the accumulation of these minute organisms that accounts for the swelling that accompanies infla mation.

In Figure 30 is shown, magnified to the same power as in the preceding cut, a similar living membrance, but inflamed. The multiplication of the corpuscles is clearly shown, and also the migration of the white corpuscles.*

*Let it be understood that this discussion is the merest outline of the wonderful processes of nourishment and destruction of living tis- 
Inflammation itself may be described as the perverted nourishment of any part. An injury, the presence of a foreign body, or some abnormal quality of the blood itself chokes the flow of blood through the capillaries and the veins. The heart keeps pumping blood into the affected region, and there is no corresponding drain. This excess of blood is forced through the walls of the capillaries, the tissues become overcharged with it, and the cells and white corpuscles, over-stimulated, begin to multiply. Crowding together, by their own numbers they soon deprive each other of the necessary nourishment, and they die. Other germs, less beneficent than the cells and white corpuscles, if present in the tissues, or if introduced by the cause of the inflammation, take this occasion to multiply, to destroy other cells, and to die themselves in turn. These dead cells, corpuscles, and germs, suspended in the fluid of the blood, form the whitish, malodorous substance known as pus.

Figure 31 shows a section of the uninflamed wing of a bat, much less highly magnified than in the preceding cuts. The enlargement is not enough to show the capillaries connecting the arteries and veins. The same spot in the membrane was then wounded with a needle, inflammation set in, and Figure 32 shows, under the same microscope, the enlargement of the capillaries, due to the increased flow of blood, and the accumulation of the corpuscles.

Often there is an unnatural accumulation of blood in any part, caused either by an increased flow of blood to the part or by an obstruction that prevents the free exit of the blood through the veins from the tissue affected. This is called congestion of the part. In either case there is an increased supply of blood,

sues; that it is very, very inadequate. The term "corpuscle" is wrongly used to describe all the bodies carried in the fluid of the blood and "cell" to indicate the atoms of which the tissues are built. "Germ" is used to vaguely designate those living micro-organisms that laymen should be willing to dismiss with the knowledge that one must be very wise to understand them. 
and, as a result, increased combustion (oxidation), manifested by heat, and augmented nutrition, manifested by swelling.

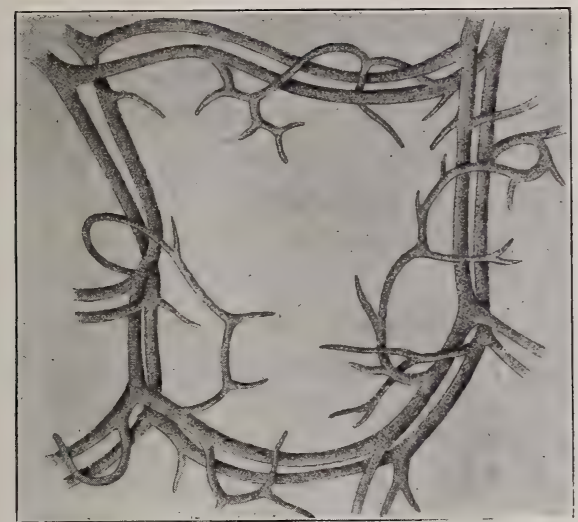

Figure 31.-Highly Magnified Section of the Wing of a Bat, Not Inflamed.

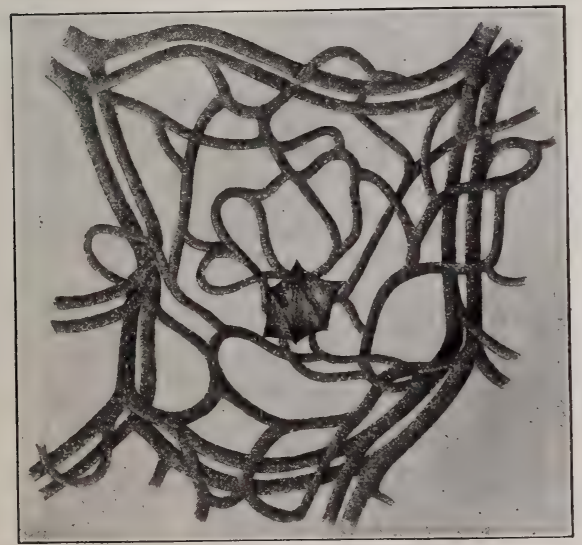

Figure 32.-Highly Magnified Section of the Wing of a Bat, Inflamed. active, abscesses are sometimes set up in organs distant from the original injury; at other times the infection attacks the
Pus may be confined by limiting membranes provided by Nature to prevent the migration of the pus to sound tissues. Such a sore is termed an abscess. If the pus escapes externally from an abscess and the channel of escape is similarly lined by a limiting membrane, the channel is termed a sinus.

Pus forming without such a limiting membrane invades the surrounding tis sues and destroys them. Such a sore, when open is called an ulcer.

Any injury or wound in which pus forms is said to suppurate or to be infected. If the pus is absorbed into the circulation while the injurious germs are still infection attacks the 
corpuscles of the blood itself, destroying them. In either cast blood-poisoning is said to have set in.

Sometimes the affected part dies. This is said to be mortification or gangrene in soft.tissues, and necrosis in bone.

The local signs of infla m mation are redness of varying degree, pain, swelling (except in bone), and heat. The general symptoms are fever and loss of condition. In aggravated cases the vital organs gradually suspend their function, and death from exhaustion results.

The treatment of inflammation is the same in principle whatever be the part inflamed. Inflammation is hypernutrition, attended by excessive blood-supply. Any agent which will reduce the blood-supply and prevent the excessive nutrition of the elements of the part will serve as a remedy. The means employed may be used locally to the parts, or they may be constitutional remedies, which act indirectly.

In the treatment of sick horses, as in the treatment of ailing human beings, the administration of drugs should be sparingly resorted to by amateurs. Proper feeding and watering, cleanliness and sanitation in stables, and careful nursing, will keep veterinary bills down.

Indiscriminate use of drugs is seldom beneficial or economical.

In all cases of inflammation, seek first to re move the exciting cause. This may be some foreign substance, which irritates the animal directly, or it may be some decomposing substance, full of disease germs, in the stable.

Rest is the next requisite. Motion induces an increased flow of blood, and blood supplies the food for inflammation. The patient should be in a darkened stall, free from noise or anything that will excite him.

Cold and hot applications reach the same end by opposite means. Cold applications-ice-bags, cold bandages, fomentations, etc.-contract the blood-vessels and soothe the nerves, 
while warm applications, either wet or dry, increase the circulation by expanding the blood-vessels, and so put an end to the congestion existing in the inflamed part.

In cases of chronic inflammation, the surrounding tissues may have been left so weakened by it that they do not perform their functions properly. Then they need stimulating to allow them to recover strength by the application of liniments containing mild stimulants, or by massage. If this does not bring about satisfactory results, a veterinarian should be consulted. Blood-letting, the use of severe counter-irritants-blistering or firing - or the use of strong tonies or stimulants, should not be attempted by amateurs.

In all cases of inflammation it is of the greatest importance to limit the diet to small quantities of easily digested foods, freshly prepared and frequently offered. Food should not be permitted to remain before the patient long. If refused or only partly eaten, remove it, clean the manger thoroughly, and offer a fresh supply in a couple of hours. No invalid is more capricious about his food than a sick horse.

When the tissues have been destroyed by inflammation, they are replaced by the formation of new tissues, different from the old in appearance and structure. This new tissue is called a scar. 


\section{CHAPTER IV.}

\section{THE HEAD AND NECK.}

The relation of the bones to the soft tissues of the head and neck is shown in Figure 33.

The face is that part of the head seen from directly in front, between the nostrils and the forelock.

The forehead includes that part of the face between the forelock and a line drawn between the inner corners of the eyes.

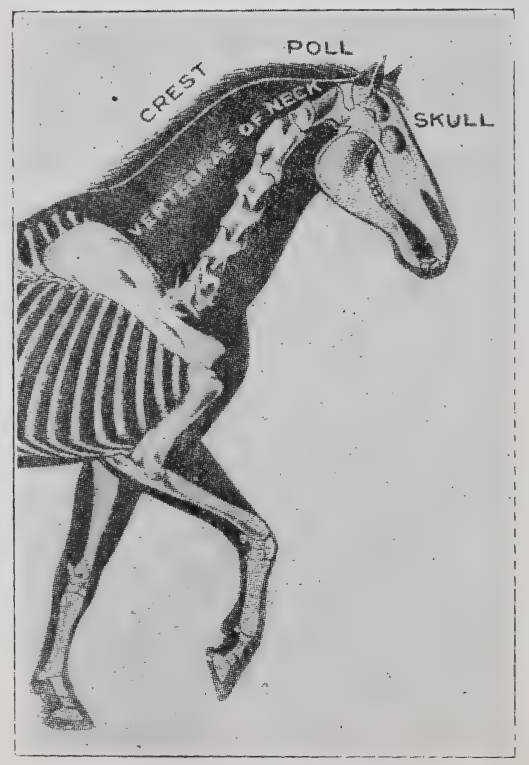

Figure 34.-Skeleton of Forehand. 
The temples are the regions at the sides of the forehead, between the eye and the ear.

The nose is that part of the face below the forehead and above the nostrils.

The cheeks are the two sides of the head, to right and left of the face.

The muzzle includes the nostrils and lips.

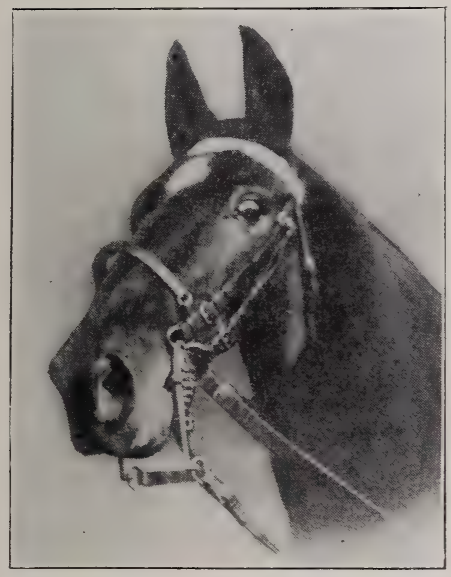

Figure 35.-Head of a WellBred Horse, Front Face.

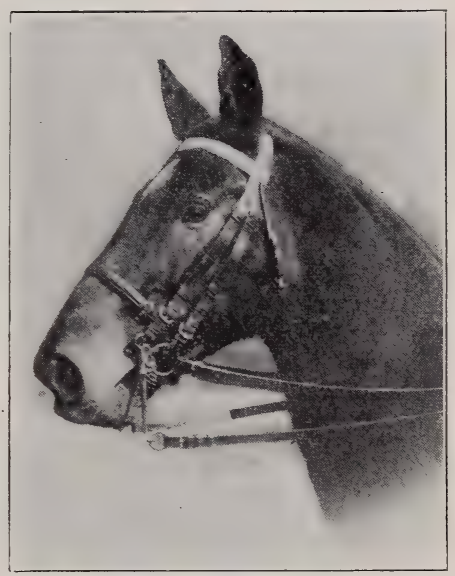

Figure 36.-Head of a WellBred Horse, Profile.

The brain of a horse is very small, about the size of a polo ball. To destroy a horse by shooting, aim at the intersection of two imaginary lines drawn from each eye to the diagonally opposite ear. If the revolver is held at right angles to the plane of the face, a shot thus placed will instantly and painlessly destroy the animal.

In the well-bred horse the head should be of medium size, lean, wide between the eyes, finely chiselled and terminating 
wide at the nostrils. It should be wide from the eye to the angle of the jaw; wide under the jaw, wide at the base of the skull (where the head and neck join). The nose should be straight; the nostrils large, wide, and without many hairs. The fleshy borders of the nostrils should be thin, firm, and sensitive.

The ears should be small, fine, and nervously alert. In changing position from front to rear, they should describe small circles. They should not droop to right and left.

Horses possess very acute sense of hearing, and the ears, large and funnel-shaped, locate the direction of the origin of noises by rotating until the maximum sound is received. "As flight (running away) is the horse's chief natural means' of selfprotection, he has great ability in turning his ears to the rear without altering the forward position of his head. In a pitched battle with carnivorous enemies, wild horses employ their eyes and ears, as a rule, in a backward direction, while using their hind feet as weapons of assault; and even when making a forward rush at an enemy, they almost always 'put back' their ears. The fact of a horse looking backwards is at once made manifest by his showing 'the whites of his eyes.' These actions of eyes and ears are so closely connected in the horse with fear and anger that he often performs them without any direct incentive when influenced by these feelings. Hence, all experienced horsemen regard an unprovoked putting back of the horse's ears and showing of the whites of his eyes as a reliable warning to 'look out.'"

It is to be remarked that the signs of warning above mentioned are usually accompanied by a contracting and flattening of the nostrils.

The ill-bred horse shows a heavy head, narrow brainspace, contracted jaws, coarse throat-latch, and loosely hung, insensitive ears. His muzzle is set thickly with coarse hairs, has small nostrils, and too much flesh in the lips and margins of the 
nostrils. Nothing is clear-cut about his head. His general appearance, when in repose, is sleepy and lymphatic; when in action, sulky and unwilling.

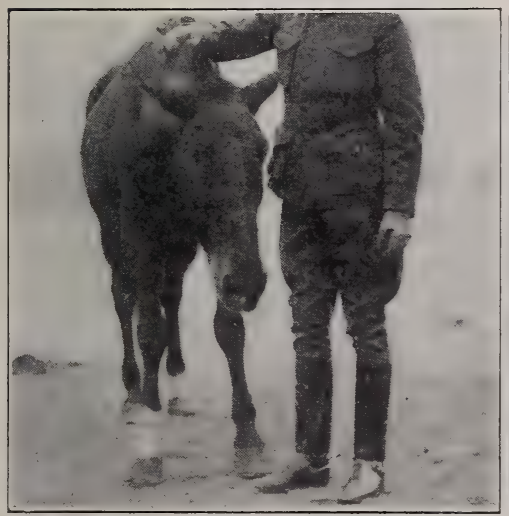

Figure 37.-The Ill-Bred Horse, Full Face.

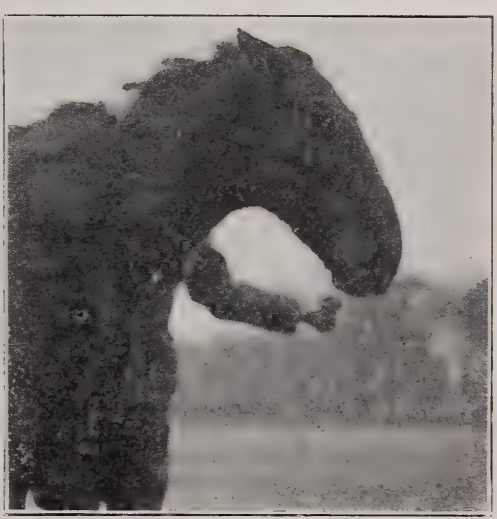

Figure 38.-The Ill-Bred Horse, Profile.

The eyes should be full, clear and bright, and symmetrically placed. They should not be watery; the pupils should be black and of equal size. The lids should be thin and firm. The eye, to inspire full confidence in the horse, should be large, prominent - to secure a large field of vision - and kindly in expression.

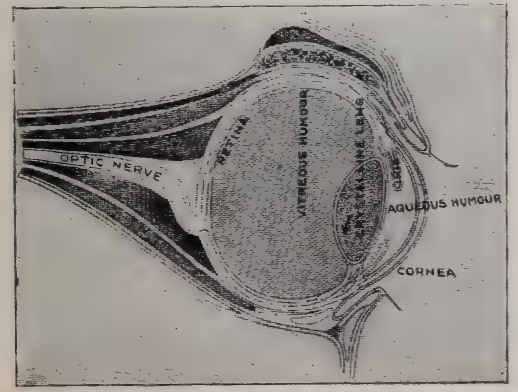

Figure 39.-The Eye, in CrossSECTION.
The eye is a sphere, containing two chambers (Figure 39): one, the anterior, is filled with aqueous humor; the other, many times larger, with vitreous humor. The lining of the posterior chamber of the retina, the development of the optic nerve. Between the two chambers is placed 
the crystalline lens. In front of the anterior chamber is the cornea. The cornea, crystalline lens, and the two humors, are perfectly transparent in the healthy eye. The crystalline lens is screened by the iris, a sensitive membrane that is pierced at its center by the pupil. The iris is capable of expanding and contracting, and so can regulate the supply of light admitted to the retina through the pupil.

Looking closely into the sound eye, a fringe of sooty, spongy aspect will be seen, attached to the edge of the iris, heavier above than below. It is called the corpora nigra, and is a provision of Nature to partially absorb the light entering the eye and to supply the protection given to the human eye by the overhanging eyebrow.

The pupils should dilate and contract equally and freely, The iris should be of uniform color. Frequently there is lack of color in the iris. The visible effects of this condition is the whitish ring surrounding the pupil, known as wall-eye.

An opacity of the cornea is a positive defect that limits the field of vision of the horse. Such a horse is usually a shyer, nervous and undesirable for any sort of fast work.

The wall-eyed horse must not be confused with the horse that "shows the white of his eye," already discussed. In the ordinary case the white does not show, but an excitable, nervous horse, suffering from timidity or fear, will open his eyes unduly wide and so show the whites of them. It is a sign of nervousness or vice, or both, and, while often merely the result of brutal treatment, is always an undesirable quality.

As a protection to the eye, to remove foreign particles that. adhere to its outer surface, Nature provides the haw, a thin membrane that, in a restful state, appears as a thin fold at the inner angle of the eye. When the eye is irritated by dust, hail, chaff, or the like, the ball is slightly withdrawn into the socket and the haw is stretched across the eye, removing rueshanically the irritant, assisted by a profuse flow of tears. 
Blindness is common among horses. If it results from an injury to the external eye or from cataract, it is easy of discovery; if from disease in, or destruction of, the optic nerve, it is not so apparent.

A cataract shows itself as a milky opacity in the interior of the eye. Its seat is in the crystalline lens or its coverings. What is known as the candle test is the surest method of determining whether an opacity in the eye is or is not a cataract. In a partially lighted place a lighted candle is held in front of the eye. If the eye is perfect, three images will be seen-one, the front one, erect, is the reflection from the outer surface of the cornea; the second, also erect, is the reflection from the front surface of the crystalline lens; the third, inverted, is the reflection from the back of the lens. As the candle is raised or lowered, the first and second images go up or down, the third moves in a contrary direction. If a cataract is present, the inverted image is blurred, or wanting altogether; if the trouble is in front of the lens, there will be but one distinct image.

A good preliminary test for blindness is to raise the hand from below to the level of the eye and near it, then to withdraw it, but not so rapidly as to cause appreciable air-currents. If the horse does not wink or dodge, there is grave suspicion cast at once on his vision in that eye.

In order to give lightness to the head, and at the same time to afford room for the attachment of the various muscles of mastication, some of the bones of the horse's face are hollowed out, leaving blind cavities, opening only downward. These cavities are called the facial sinuses, and seem to have no function, except that mentioned.

The neck includes seven of the vertebræ of the spinal column. The muscle that moves the foreleg forward is attached to the head and the first four of the neck vertebræ; the longer this muscle is, the greater will be its contractibility and consequent leverage on the bones of the foreleg and the stronger will be the 
action of the limb. In saddle-horses, nothing is to be gained by increasing the weight of the neck muscles beyond that necessary to give a sure and graceful carriage to the head and a quick and free forward swing to the front leg. The neck should, therefore, be long and slender, without too marked a crest. (Figure 1.) The neck, at its upper end, should be spare and flexible. This condition, together with width between the jaw-bones, is necessary in saddle-horses; without it, they are stiff and unhandy.

The horse shown in Figure 40 is an example of an otherwise good horse, spoiled by too much flesh in the neck. He has the neck of a stallion, and the inference is that he was gelded comparatively late in life. Castration is usually performed when the colt is about one year old. If the operation is done, as is sometimes the case, when the colt is very young, he is apt to be underdeveloped in the forehand when he is matured. If the time of castration is postponed until two, three, or later, the development of the forehand will more and more resemble that of a stallion. The operation is more easily and more safely performed on a young than on a mature animal.

The excess of flesh on the crest of the horse in Figure 40 thirty pounds or so-makes it impossible for him to handle his head and neck easily, and he is hard to turn or stop quickly in consequence. He is not a good drill-horse, although he has very comfortable gaits and is kind and willing.

The horse shown in Figure 41 is a saddle-horse "de luxe." His neck is thick at the base, but it is light at the crest and tapers nicely. He should be able to control it easily.

A ewe-necked horse is one whose crest is concave.

The nasal membranes should be smooth, moist, of uniform color, and of a bright appearance. Any dullness of these membranes, any discharge from the nostril, and any ulceration, or scars of old ulcers, should be viewed with gravest suspicion in examining a strange horse. 


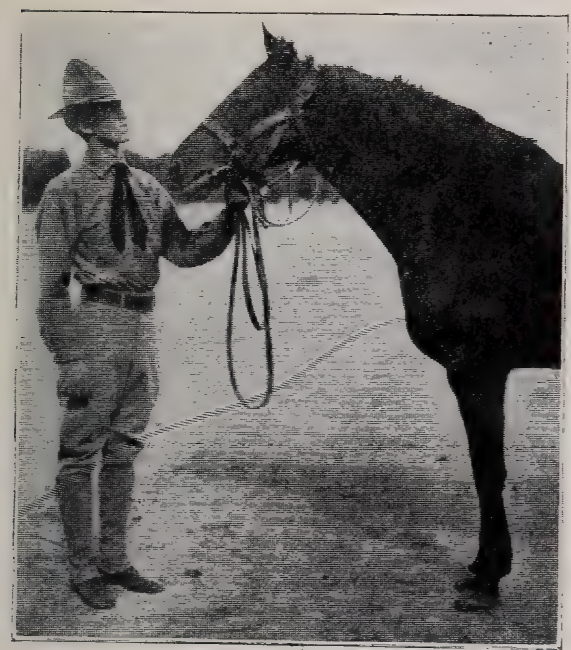

Figure 40.-An Overweighted Neck.

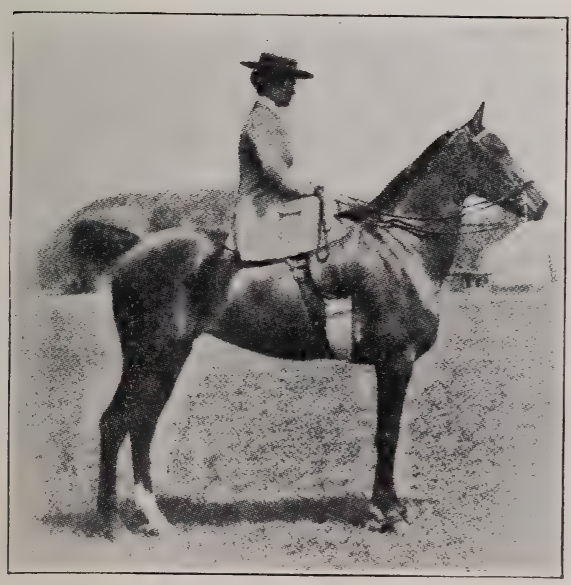

Figure 41.-A Saddle Type. Courtesy of "The Rider and Driver."
Glanders is a highly contagious disease of germ origin, incurable, and, in $\mathrm{th}$ is latitude, usually fatal. It is, of all diseases incidental to the horse, the most malignant and the most to be dreaded. It is highly contagious to human beings also, and necessarily fatal to them. In dealing with a case of glanders, the greatest care should betaken to protect one's self from the germs.

If the glanders germ attacks the internal organs of the horse, the disease is known as glanders; but if it attacks the skin or the vessels of the skin, the disease is called farcy.

Glanders usually . manifests itself by a 
clear, watery discharge from one nostril, lighter in color than in the case of a common cold. "A singular characteristic of glanders is that it generally attacks one nostril only, and that is the left one; only a few cases having occurred where it commenced in the right nostril. Mr. Dupay, a celebrated veterinary surgeon, and director of this school of surge:y at Toulouse, mentions that out of eight hundred cases of glanders, which occurred during his practice, only one was affected in the right nostril."

Farcy manifests itself in small tumors, soft at first, then breaking into an ulcer. "The farcy buttons occur most frequently on the side of the lips, on the sides of the neck, the lower part of the shoulders, the inside of the thighs, or the outside of the legs, but may occur on any part of the horse."

Farcy is always accompanied by the internal form of the disease, although the latter may not be manifested by the nasal discharge.

In order to discriminate between glanders and other diseases of the nasal membranes, the mallein test is frequently resorted to. Mallein is made by exposing a pure culture of the glanders germ to dry heat sufficient to kill the germs. This dead culture is then treated chemically to preserve it and is injected hypodermically under the skin of the neck, usually, of the suspect. His temperature is taken twenty-four hours before the injection and again at the time of the injection. It is then taken every three to six hours for forty-eight hours afterwards. If the place of injection becomes materially inflamed and remains so for from two to five days, with an inflamed spot at least five inches in diameter, and a persistent rise of temperature of two degrees or more is noticed, the suspicion is fairly well confirmed. The animal should then be allowed to remain under observation in isolation for a month. If now the test is applied with similar results, the 
animal should be killed and burned and all his equipment and surroundings burned or thoroughly disinfected. If, however, on the second test he does not respond, a third test should be made at the end of another month, which may safely be regarded as final.

Any horse presenting a discharge at the nostril should be at once isolated, and his stall and all his equipment thoroughly disinfected.

Nasal gleet is a chronic diseased condition of the nasal membranes and of the linings of the facial sinuses. It is the result of neglected colds (bad stable management), or ulcerated teeth, and is a stubborn disease to cure. It is marked by a discharge from the nostrils, one or both, offensive odor, and frequently by no other outward symptom. Nasal gleet and glanders are frequently mistaken, one for the other.

Influenza is a highly infectious disease, usually of brief duration. True influenza usually spreads in waves of contagion over large areas. It is easily spread and difficult of treatment. The patient is stupefied, hangs its head, is not easily roused; the eyes become inflamed and tears flow profusely. It is frequently followed by disabling complications.

Catarrh is inflammation of a mucous membrane. It is called by various names, depending on its location.

Cold in the head is an inflammation of the mucous membrane of the nasal passages and neighboring regions. It is manifested by dullness, fever, a watery discharge from the nose, and sometimes by an inflamed condition of the eyes. The patient should be exercised very little, placed in a loose stall, well ventilated, but free from drafts. Like the human disease of the same name, the watery discharge, as the disease progresses, becomes thicker and of a whitish color. Colds in the head ought not to be neglected, nor should animals so affected be put to severe work until cured. 
Strangles, or diste mper, also an infectious disease, manifests itself by catarrhal symptoms and by enlargements of the salivary glands lying near the angle of the lower jaw (the parotid glands). In the general case these glands suppurate and make an absicess easily recognized. An animal usually has this disease but once, and rarely after becoming of age. The danger from strangles is in the permanent thickening of the air-passages and permanent injury to the breathing apparatus in consequence.

Poll-evil is an obstinate abscess on top of the head. It results from an injury received there, which sets up an inflamamation that develops into an abscess. The muscles of the neck, in the region of the poll, extend downward and backward. Pus can easily burrow in between them and follow the course of these muscles. Since, from its position, such an abscess cannot readily drain its pus unless artificial drainage is provided, the pus will work down into the sound tissues, infecting them deeper and deeper. Any abscess where natural drainage is not possible is termed a fistula. Like other fistulas, poll-evil is the result of neglect.

Blind staggers, or congestion of the brain, is a brain disease, similar to apoplexy. A horse affected with it will fall down and struggle about in a spasmodic fashion, injuring himself in his spasm and threatening injury to any other animal near him. It is a not uncommon disease, and is liable to recur at any time. Relief is obtained by blood-letting. The jugular vein is opened, and, after a sufficient amount of blood is drawn, is closed again, leaving a scar of operation, usually not hard to find and always worth looking for.

The jugular channel is well shown in Figure 8. It is a groove on the lower margin of the neck. By rubbing the thumb briskly several times down the channel with considerable pressure and then pressing hard at the lower end of the channel, the jugular vein will be closed by the pressure. It will fill rapidly from above with blood and will become distended. 
The operation of blood-letting is sufficiently simple and safe to warrant any horse-owner to attempt it in cases of blind staggers or congestion of the lungs in emergencies when professional skill is not available. The flow of blood from a vein is easily controlled. By tying a stout cord around the base of the neck tightly, the jugular veins will be compressed enough to dilate them, when they are easily seen. The fleam-blade of a farrier's knife is used. The point of the fleam is laid near the vein and is driven into it by a sharp blow of a stick on the back of the fleam. If the vein-wall is cut, the blood will flow freely in a constant stream. It should be caught and measured as it flows. From two to four quarts should be drawn-never more than fourdepending on the size and condition of the horse. A large, fat horse will stand the loss of more blood than a smaller horse in thin flesh will.

The vein can be closed by sticking a pin through the walls of the vein at right angles to the cut and then winding horse-hair or strong linen thread around the ends, figure of 8 fashion.

This method of closing wounds is a very useful one to remember. A horse whose skin has been cut by barbed wire or by other means can be saved an ugly blemish, if the edges of the wound are at once pinned together, placing the pins an inch or so apart, and then lacing horse-hair or thread around the ends of the pins.

In the jugular wound the pins should be left in only three or four days. The wound in the skin can be kept open by putting a plug of oakum or absorbent cotton in it until the pins are withdrawn.

Blood-letting should be resorted to, without professional assistance, only in extreme cases-when it is evident that the animal will die unless relieved. 


\section{CHAPTER V.}

\section{BITS-THEIR ACTION, INFLUENCE, AND PROPER USE.*}

A bit is an instrument devised to convey instructions to the horse from his rider in accordance with a set of signals concerning his guidance and control, whose separate meanings he has been taught to know.

The perfectly trained horse that has a perfect temper needs a bit that conveys these instructions without pain. Such horses are, unfortunately, rare, so bits must be devised that not only convey instructions as to gait and direction, but that are capable of inflicting pain when the temper of the horse inclines him to disregard these instructions.

The point of application - the seat - of the bit is on the bars of the horse's jaw, about one-third of the distance from the tushes to the molars (Figure 42).

Figure 43 shows a simple bar bit in its normal position on the horse's jaw. $†$ The horse's tongue lies in the opening between the two rows of teeth, under the bit, and, at rest, fills the space under the bit and partially supports it.

* An effort is made here to describe only the action of ordinary bits in common use, on normal mouths. The subject is a very broad one, and must necessarily be briefly touched on here. Captain M. Horace Hayes' admirable work, "Riding and Hunting," contains an exhaustive discussion of this subject.

The author is indebted to Major Edwin St. J. Greble, 3d Field Artillerv, for much that is contained in this chapter.

tThe same bone furnished the subject for this picture that was used in Figures 42 and 44 . To make Figure 43 and in Figure 44 the bone was set at an angle, so that the bearing of the bit would show as if seen from the front. 
The two ridge-liketportions of the bone of the lower jaw between the molars and the tushes are called the bars, and form the

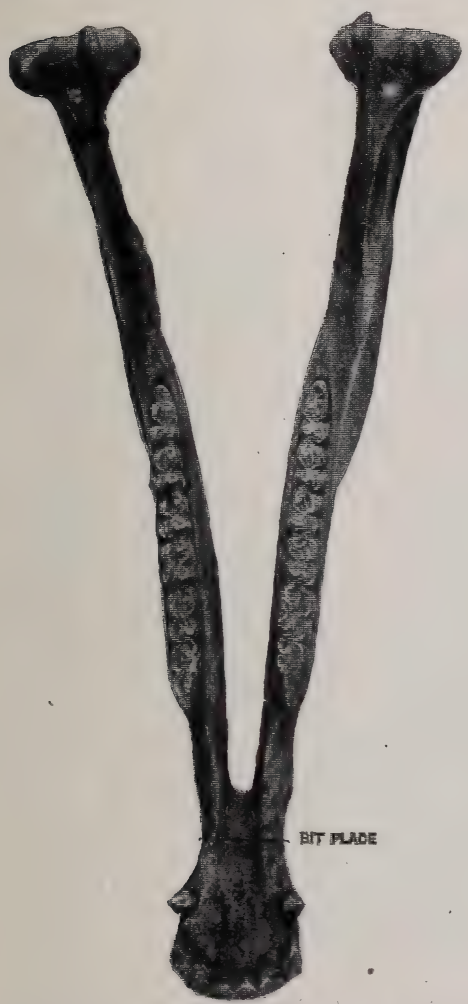

Figure 42.-The Lower Ja w-Bone in Plan, Showing Bit-Place. points of application for the bit.

As regards their action on the horse's jaw, bits are classified as bar, snaffle, and curb bits.

A bar bit is an unbroken bit that acts, without leverage, directly on the horse's jaw, as in Figure 43. The bar bit is supported partly on the bars of the horse's jaw and partly on his tongue. This is tough, leathery, and insensitive. When the pressure of the bar bit on the horse's jaw becomes painful to the bars, he relieves the pain by thrusting his tongue further under the bit, thereby lifting it from the bars and transferring the pressure to his tongue.

To nullify this action of the tongue and still have a bit that is not, with proper use, excessively severe, a hinge is introduced in the center of the bar bit, and the resulting bit is called a snaffle bit.

By pulling on the reins of a snaffle bit, a pincer action is developed by the closing of the angle between the halves of the mouthpiece. This raises the hinge, lifting the mouthpiece off the tongue, and applies pressure to the bars in a way impossible of relief by the tongue. 
The snaffle may be made an instrument of torture by jerking it or by "sawing" on it.

Both b a r a nd snaffle bits should have large, g e n e rous mouthpieces and should be very little longer $\mathrm{t} h$ a $\mathrm{n}$ the width of the mouth, and should be so adjusted that $t h e$ mouth $p$ ie ce touches the corners of the mouth when no pressure is applied to the rein.

The bar bit is more used as a drivingbit, the snaffle for riding. Both bits are manufactured in a $\mathrm{great}$

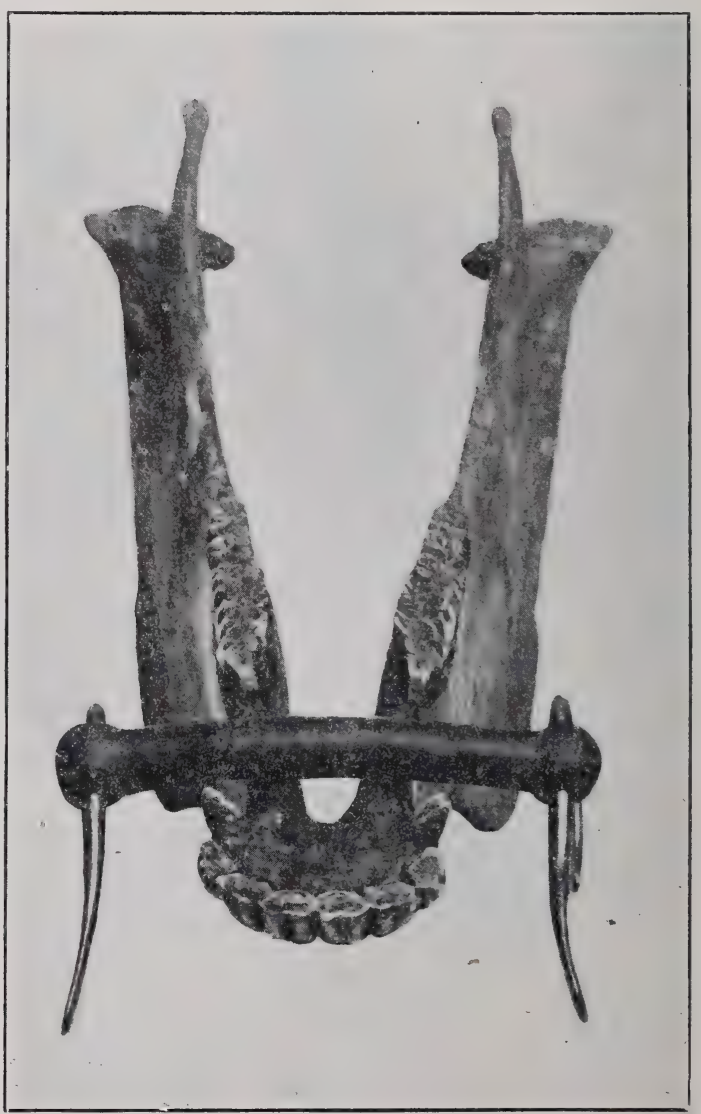

Figure 43.

variety of shapes, each variation designed to defeat some defanse developed by horses in an effort to avoid pain. The bit 
shown in Figures 44, 45, and 46 is a rery useful shape for a snaffle bit.

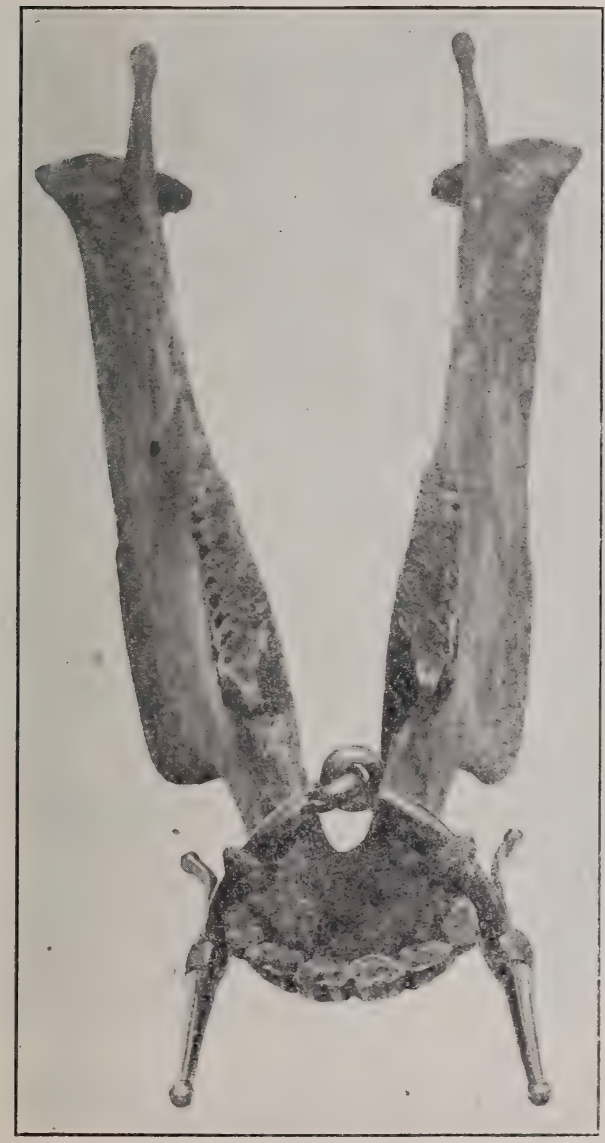

FigURE 44

The bit that has the least painful influence on the horse's mouth is the rubber-covered bar bit. Theoretically, this is the ideal bit.

Mechanically any bit not having lever action a c ts as shown in the accompanying plates.

In Figures 45 and 46 AB represents, graphically, a force, a c ting through a pull on the reins fastened to a bar or snaffle bit, on the horse's jaw at A. Resolving this force into its two components, $\mathrm{AE}$ at right angles to the horse's jaw and $\mathrm{AD}$ parallel to it, AE will then represent the actual useful restraining force and $\mathrm{AD}$ the wasteful force, operating merely to raise the horse's head. 
The force AD acts on the corners of the horse's mouth, or on his molars.

As a matter of fact, this lifting effect has a larger influence on the attitude of a young horse while being broken than in the

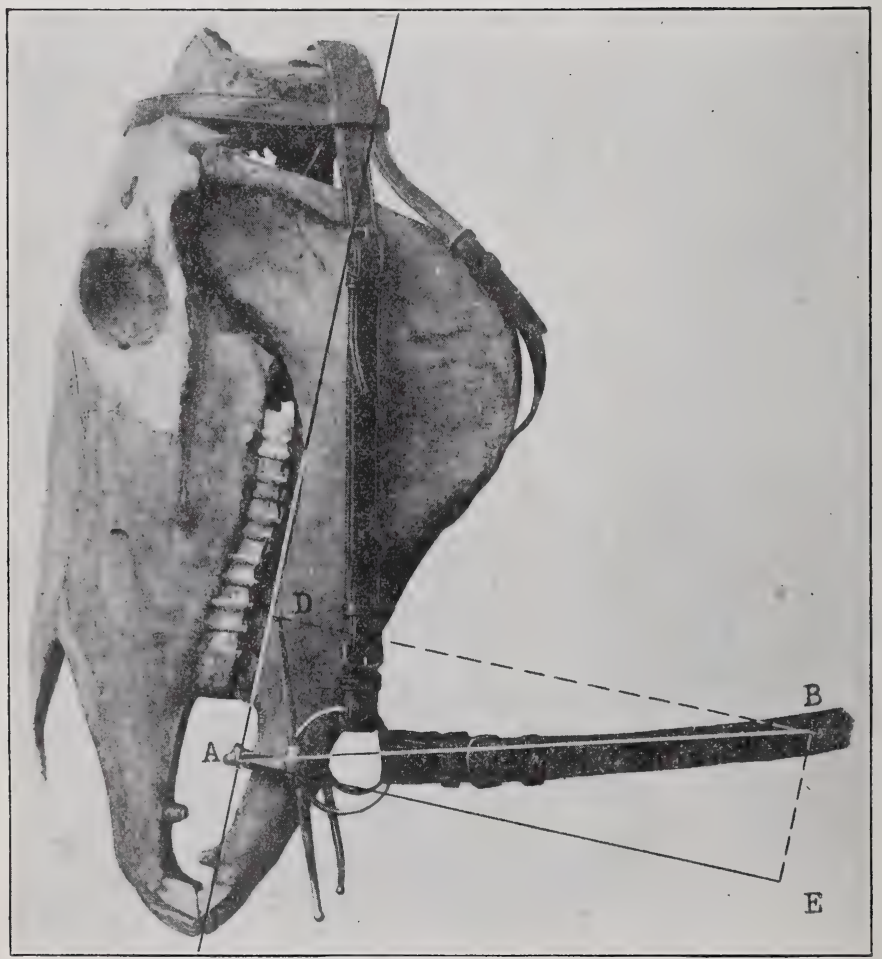

Figure 45.

The relative lifting and restraining influence of a pull exerted with the hands held low and the horse's head nearly vertical.

case of an old horse whose schooling is over. The latter learns to meet difficulties of this sort, if not made vicious or sulky by bad treatment, and renders good service in spite of them in a 
manner that often surprises the thoughtful horseman. The theory that the horse is not a reasoning animal receives severe

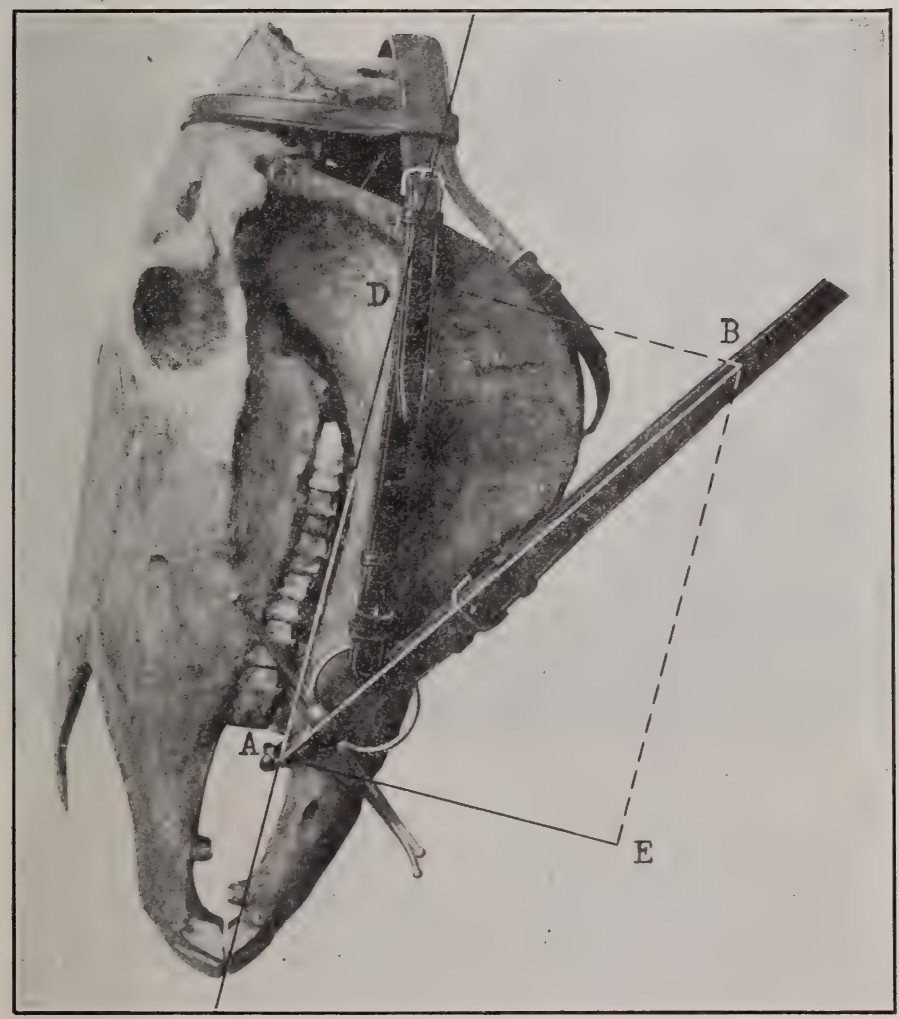

FIGURE 46.

Distribution of the force exerted through the reins when the hand is held too high, or when the horse's nose is thrust to the front.

tests in the cases of honest, faithful animals who do their work well in spite of impatience, conflicting signals, and frequently abuse. 


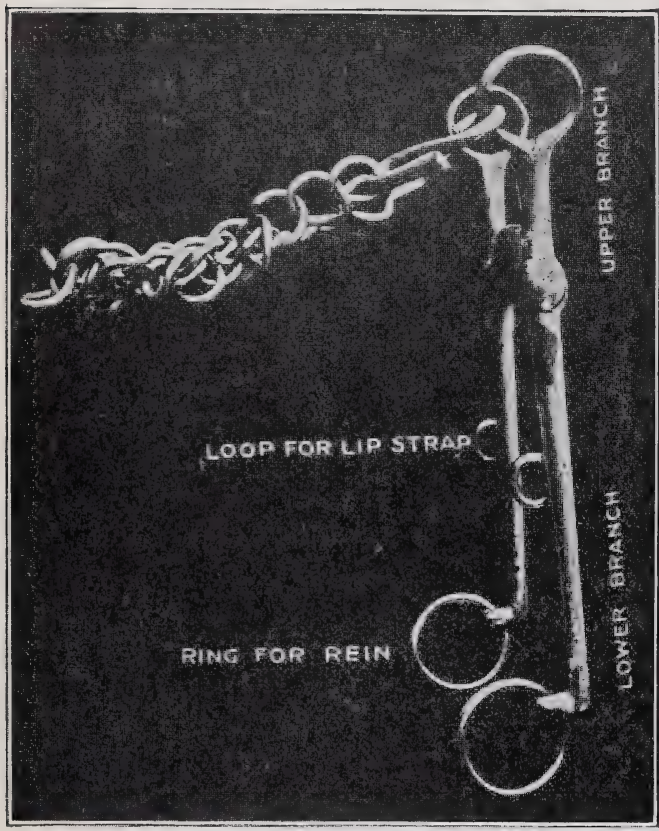

Figure 47.

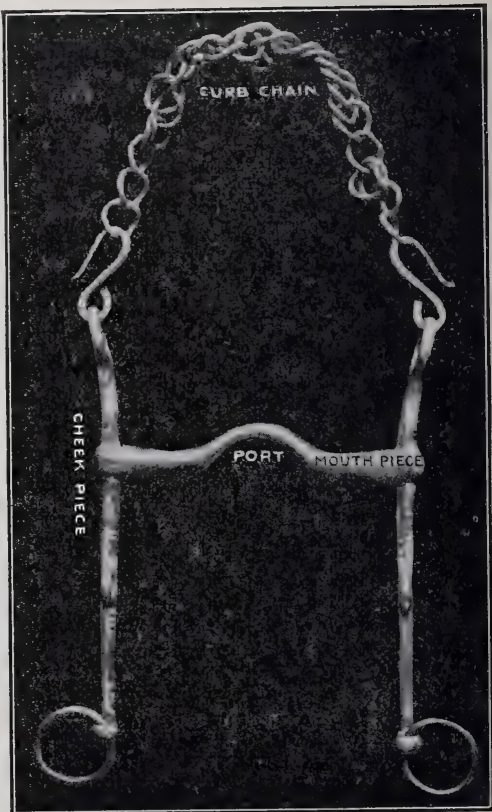

FIGURE 48.

The curb bit (Figures 47 and 48 ) is a bit operating on an entirely different principle from the two other kinds just discussed. In the curb bit the force exerted by the pull on the rein is increased in intensity by the leverage of the bit, and the possibility of inflicting pain is greatly augmented.

The curb bit consists of two cheek-pieces with a mouthpiece connecting them at such a point that the upper branch of the cheek-piece will be about half the length of the lower one. This ratio is by no means fixed, however. The upper branch is usually between one and a half and two inches in length. The mouthpiece should be large in diameter. It has a curved central nortion, 1 called the port. The object of the port is to take 
pressure off the tongue, when the bit is in use, and to localize it on the bars. The port, when the bit is at rest, lies on the tongue. When the bit is used, the port revolves upward and forward, away from the tongue, with the result that the insensitive tongue is freed from its influence. At the upper ends of the cheekpieces are rings for the attachment of the curb-chain. This chain should be so adjusted that, when it is brought into use, it will lie in a smooth depression of the jaw-bone, called the chin-groove.

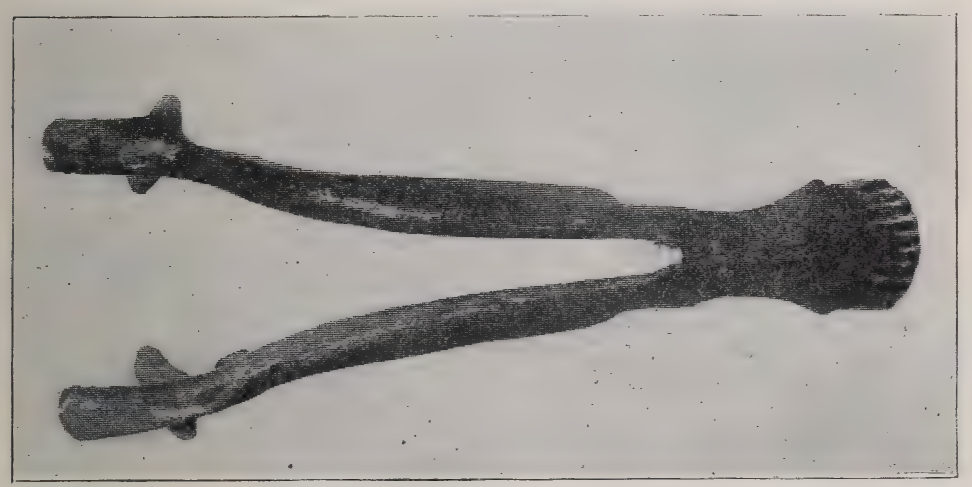

Figure 49.-The Under Side of the Lower Jaw-Bone.

The chin-groove is the rounded portion of the jaw-bone just forward of the angle of the $V$. In health, it is smooth and rounded, and admirably fitted to receive the pressure of the curb-chain without injury to itself. The two branches of the jaw-bone are very thin and sharp on the under side, where they unite to form the chin-groove, and it is, as will be seen, highly important that the curb-chain should fit into the chin-groove, and not lie on these sharp bones.

There should be loops on the posterior edges of the cheekpieces, half way from the rein-rings to the mouthpiece, to attach the lip-strap to. This strap is often necessary to prevent the horse from getting the lower branch of one of the cheek-pieces 
between his teeth or lips, and so defeat the object of applying pressure to the sensitive bars.

The principle of the curb bit is a very simple one. The power is applied by a pull on the reins to the lower ends of the

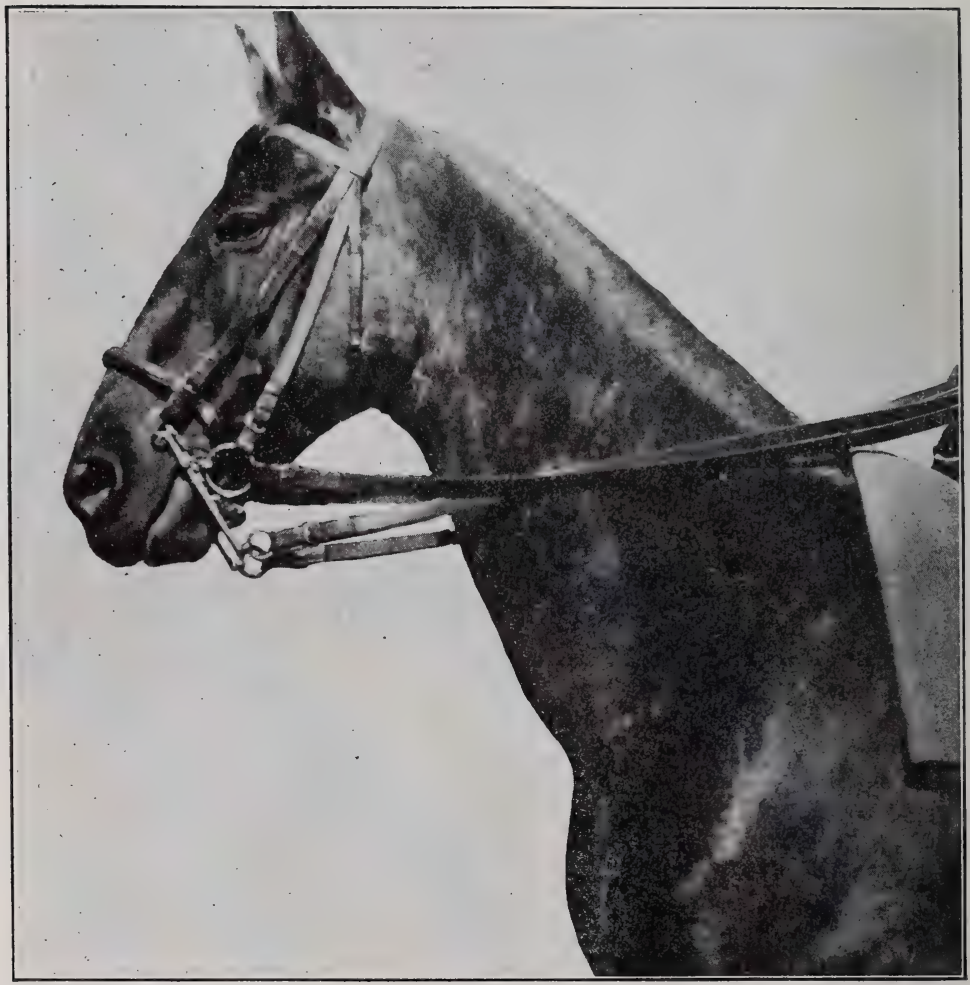

Figure 50.

cheek-pieces. The point of the horse's head to which this power is transmitted depends upon the adjustment of the bit and curbchain. If the curb-chain is too loose, the bit will revolve around the mouthpiece as a fulcrum, and the cheek-pieces of the bridle 
will receive the load and apply it to the poll. This tends to bring the horse's head down. The curb-chain will lie in a plane nearly parallel to the plane of the cheek-pieces of the bit, and but little force will be applied to the bars or to the chin-groove. The bit will slip up in the horse's mouth, and will be held either by the lips or by the molars. Such a bit is said to fall through, as in Figure 50.

The objection to having the curb-chain too loose is that the power of the bit to restrain the horse, because of the pain it inflicts, is lost to the rider.

The power is always applied to the curb bit at the lower end of the lower branch. Whether the bit is a lever of the first or second order will depend on where the horse feels the most pain when power is applied.

If the chain is twisted so that it does not lie smoothly in the chin-groove, if it slips up on the sharp edges of the jaw-bone, or if it pinches the lips, the curb-chain will hurt the horse more than the mouthpiece does, and the lever will be of the second class. This is, of course, undesirable. The horse will try to get away from the curb-chain by throwing his head forward, and a "hardmouthed"' horse is the result.

If the curb-chain fits smoothly in the chin-groove, if it is not so tight as to pinch the lips at all times, or so loose as to let the bit fall through, a pull on the reins will cause the mouthpiece to hurt the bars more than the chain hurts the chin-groove. The fulcrum will then be at the upper end of the cheek-piece,the weight will be applied at the bars by the mouthpiece, and a lever of the second class results. This is the proper adjustment of the curb-chain, and is what should be sought for.

When the bit falls through, the mouthpiece is slid up along the bars to find a fulcrum at the corners of the horse's lips or against the molars. It often happens that the lips, that have wrinkled up by the sliding upward of the bit, are caught between the curb-chain and the mouthpiece. The result is that, in the 


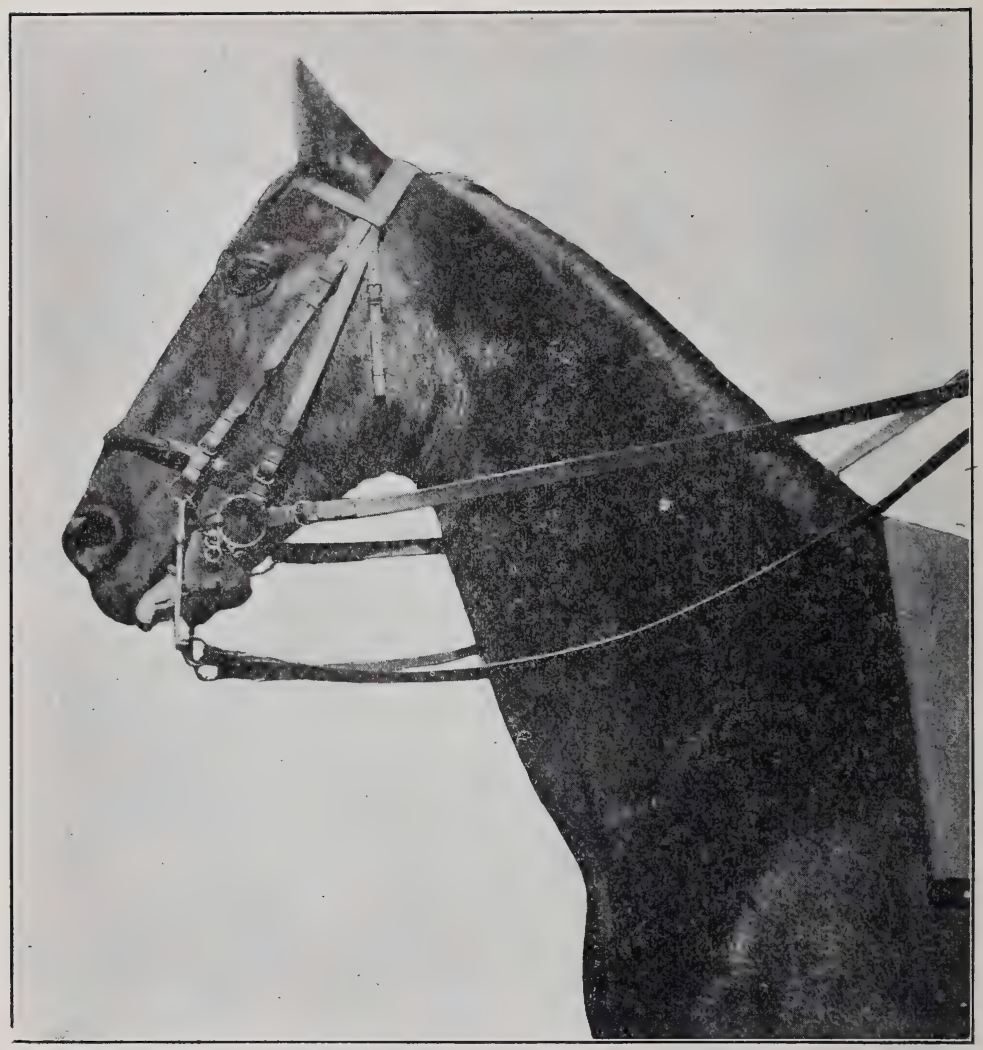

Figure 51.

effort to get away from the pain caused by this pinching, the horse does not notice the painless pull on the poll,tending to drag his head down, but does notice the pain to his lips, and throws his head forward to avoid it. Thus the pinching of the lips makes the bit a lever of the first class.

When the curb-chain is too tight, so that it slips up out of the chin-groove to the sharp edges of the branches of the jawbone, the bit is said to stand stiff, as in Figure 51. 


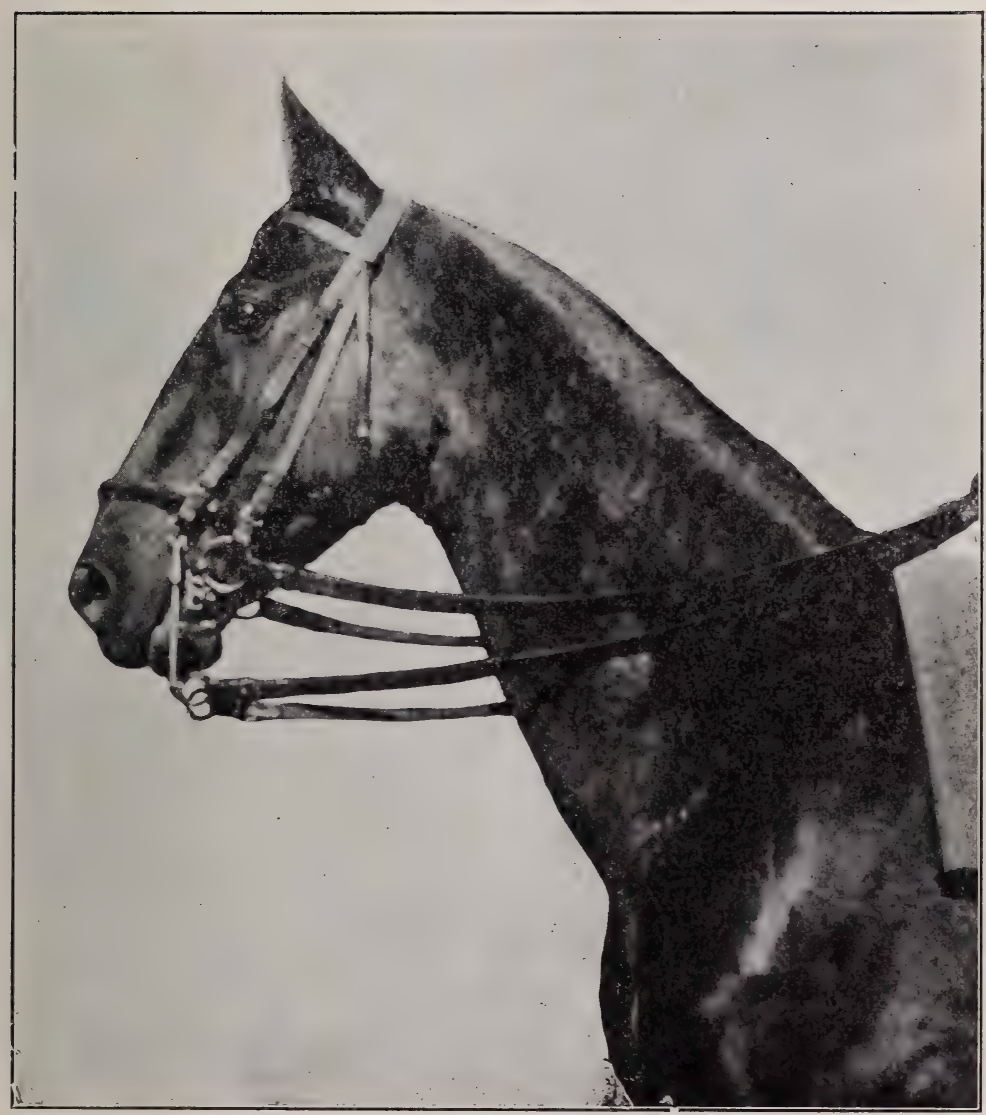

Figure 52.

The horse usually opens his mouth when the bit stands stiff and sticks his nose forward. These actions should at once tell the rider that the bit is out of adjustment, and he should adjust it. The correct adjustment is shown in Figure 52. The chain fits easily into the groove, as the reins are tightened; the lips are not wrinkled or pinched, but the mouthpiece remains in its place, 


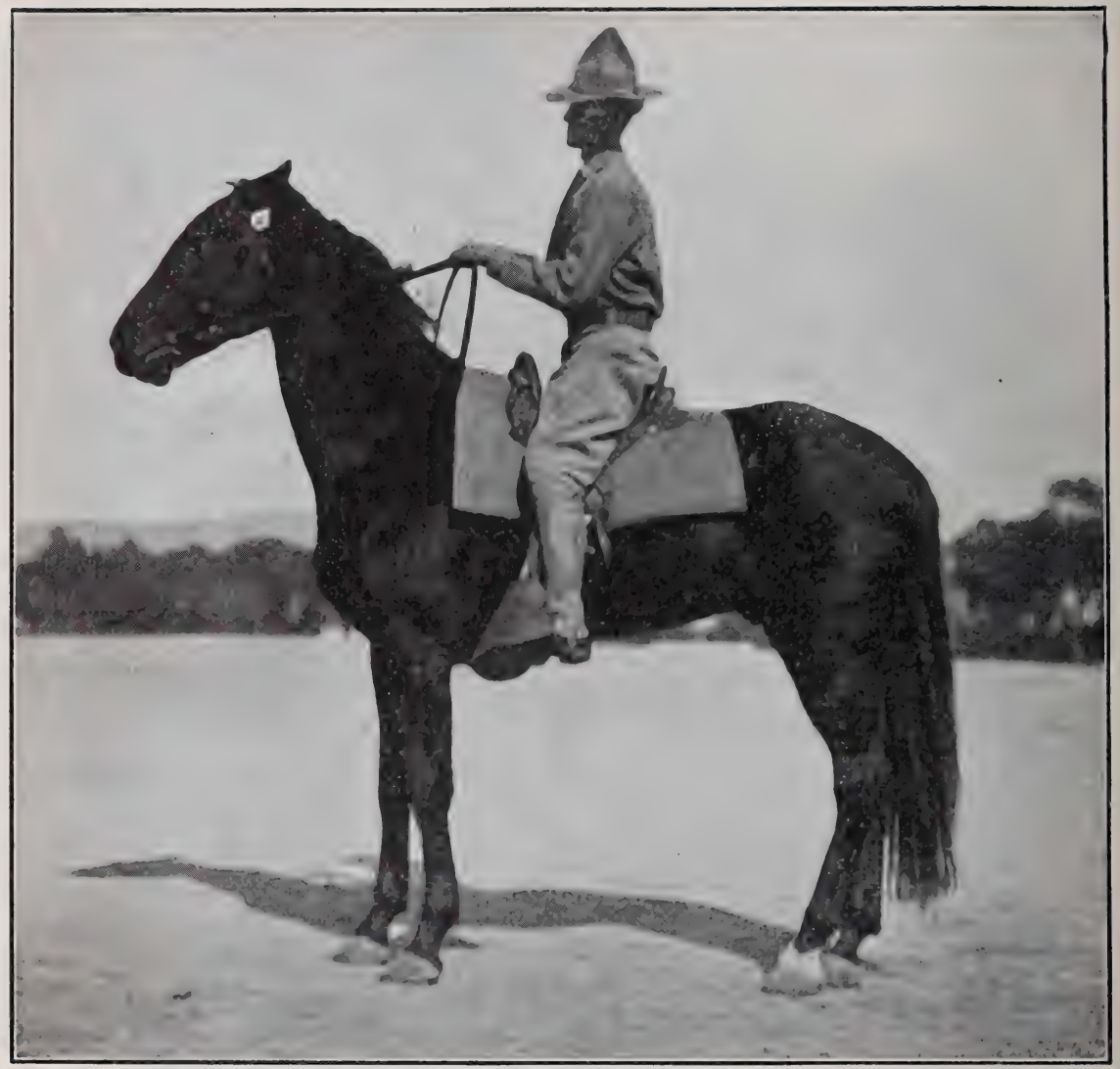

Figure 53.

Hands too high, ungraceful, and ineffective.

an inch below the corners of the lips. The bit does not revolve so far as to waste the greater part of the exertions of the rider in a painless pull on the head.

In fitting a horse with a curb bit, there is no better rule to follow than is used in fitting a man with a shoe-try it on. If it pinches the lips, it is too narrow; if there is play enough to 


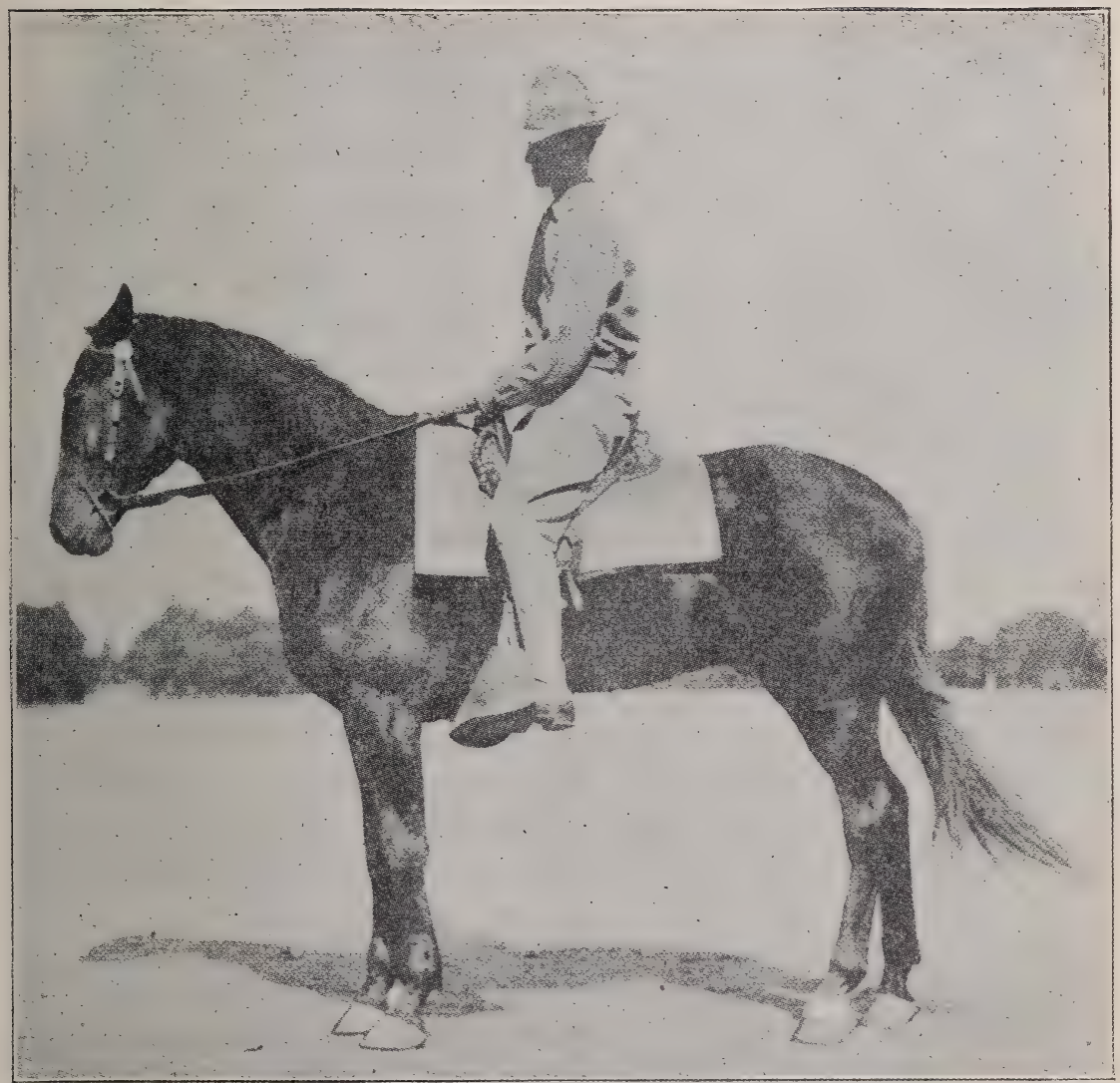

FIGURE 54 .

Proper position of hand using snaffle bit to minimize the lifting effect of the bit.

allow the corners of the port to bear on the bars as the bit slips from side to side, it is too wide. There should be just room between the cheekpieces of the bit for the cheek-straps of the bridle, the curb-chain fastenings, and the horse's muzzle, with say a quarter or three-eighths of an inch added to prevent chafing. 
Before mounting a horse, the rider should always examine the adjustment of the bit with as much care as he puts in his inspection of the saddle. Whether or not the horse will be comfortable - and if he is not comfortable, the rider will not bedepends largely on the fit of his equipments, and, more than any other single thing, on the fit of the bit and curb-chain.

The snaffle bit and the bar bit as well, as we have seen, tend to make the horse raise his head. The hands of the rider, in consequence, when using the snaffle, should be held as low as practicable to counteract this tendency. Figures 53 and 54 illustrate this point.

The low position of the hands does not influence the action of the curb bit, for the depressing action of that bit lies in the bit itself, and the position of the hands, within limits, has no effect upon it. The low position is much the more graceful, however, and, because the hands are nearer to a point of support, adds to the security of the rider.

The ordinary curb bit exerts a downward pressure on the poll, which increases as the curb-chain is loosened, allowing the upper branch to revolve further forward and downward. This is objectionable, but as no bit has ever been devised that removes it without introducing more objectionable features, it is a condidition that must be accepted for the present.

The best arrangement for guiding and controlling horses is the bit and bridoon in common use among good horsemen the world over. The combination is shown in Figures 50, 51, and 52. This enables the rider to use the comfortable snaffle or bar bit for the ordinary business of riding. The curb remains always at hand, out of the way, simple, powerful, ready to control the horse in those rare moments, for the well-trained and wellhandled horse, when the snaffle is insufficient.

A Pelham bit is one that combines, in a way, the functions of bit and bridoon. There are many varieties of Pelham bits, but the main object of them all is to do away with the second 
mouthpiece of the bit and bridoon by attaching the bridoon reins to rings at the end of the mouthpiece of the bit.

There are thousands of variations of the three classes of bits described in this chapter.* In all these variations the one object sought is to manufacture a bit that will control the horse and, at the same time, guide him. A horse is an animal of low intelligence; unless startled or hurt, he is usually willing to do as he is bid. When suddenly alarmed, his small intelligence is entirely absorbed in how to escape from the cause of his alarm. In such a moment his rider must have an instrument that, by the pain it can inflict, will draw his attention away from the thing that threatens to the thing that hurts. As a creature of habit, he has learned to obey certain signals in a set way; if the bit, while inflicting pain, also gives the signal he has learned to obey, he will instinctively obey it. Then the infliction of pain should cease.

In selecting a combination of bit and bridoon, the bit should be powerful, but perfect fitting, and the bridoon as comfortable as possible, in order to let the horse know definitely the difference between guidance and control. The guidance should be mild, the control absolute.

* One firm in New York, dealing in nothing but bits, sends out a catalogue of over four hundred pages describing their goods, and several bits are described on each page. 


\section{BITTING.*}

"I have nothing to say about the snaffle, except that it ought to be rather thick, so as to reduce its severity, and that it should be placed at about an equal distance from the bit and the corners of the mouth.

"The form of a curb bit and the position it is placed in the mouth are points of great importance. It is impossible to decide at first glance what kind of a curb will suit a young horse best and what position it should occupy in his mouth. Baucher says that he would use the same kind of a bit for all kinds of horses, which statement is the consequence of his pet theory that all horses have the same kind of mouth. I will here content myself with saying that even the most inexperienced horseman will state that horses go better in one bit than in another, and that certain animals will go kindly in a snaffle, but will resent the use of a rather severe curb. This is a generally accepted fact, which has been amply proved. We can find the best curb for a horse only by trial. But there are always certain principles to help us in making our experiments, which we may sum up as follows:

"The curb which is used at the beginning of the breaking should have a thick mouthpiece, low port, and short cheekpieces, so that it may be easy to the mouth. Its width should be proportionate to that of the mouth of the horse. If it is too narrow, the lips will be compressed by the cheekpieces; if it is too wide, the horse, either in play or to relieve the bars of the mouth from pressure, will bring it too much over on one side of his mouth, so that a part of the port will rest on one of the bars, and consequently the mouthpiece will exert an uneven pressure, which will almost always cause the horse to carry his head sideways.

*From "Breaking and Riding," by James Fillis, pp. 10-13. 
"In order that the curb may fit properly, it should be wide enough for the cheeks to keep clear of the lips on each side. The mouthpiece should have an even feeling on each side of the mouth and should be midway between the tushes and the corners of the lips, and consequently it will be lower in the mouth than the snaffle, in the case of a double bridle. Later on I shall point out some exceptions to this rule. The lower ends of the cheekpieces, yielding to the pull of the reins, cause the upper ends to revolve forward, and thus to produce pressure on the bars of the mouth. The curb-chain, which prevents the upper ends of the cheeks from revolving forward, increases the pressure on the bars proportionately to its shortness. Hence, the length of the curb-chain should be proportionate to the lightness of the horse's mouth, which we are unable to estimate in the crse of a perfectly green horse. With such an animal, we shculd at first leave the curb-chain very loose, as there will always be tri e to take it up. It would not, on the contrary, be right to say that there is always time to slacken a tight curb-chain, which causes pain that will continue to be felt by the horse after the curbchain has been let out. If, however, we begin with a loose curbchain and gradually shorten it to the desired extent, we shall avoid hurting the bars of the mouth and irritating the horse to resistance, and we gain time. But if, at the beginning of the work, we hurt or even irritate the bars by undue pressure, we shall fail to obtain any of the required indications. By artificially increasing the sensitiveness of the bars, we fail to estimate it correctly, and work on a wrong method from the beginning. The bruising or even the mere irritation of the bars does not disappear as soon as the work is finished and the bridle taken off, but continues for a more or less long period. Consequently, when the next lesson is given, the bars are congested and painful. The rider will then be apt to form an opinion of the effects he produces on the mouth of the horse without taking into consideration that it is in an abnormal condition, and he will 
increase the evil which has been done, and he will become more and more unable to correctly estimate what is the natural condition of the mouth. In a word, he will do the very things he ought not to do. From the foregoing observations we can see that, at the beginning of the breaking, the curb-chain should be loose - in fact, it is better to take it off.

"The knowledge of the mouth of a green horse is an important and delicate matter. In order to gently feel the mouth without spoiling it, we must begin with great lightness of hand, and gradually increase the pressure up to the point of making the horse feel it, which sensitiveness varies in degree according to the animal. If a horse yields to the light pressure of a curb that has no curb-chain, of what use is the curb-chain, and what is the good of seeking for a more powerful means of restraint?

"I have thoroughly broken horses, not only for the manège, but also for outdoor work, without using a curb-chain, which may remain hooked up on one of the curb-hooks, so that it may be instantly used in case of need. As a rule, it should not be employed unless the rider finds that he needs its help. When he uses it, he should never put more tension on it than is actually required; the proper maximum being when the curb-chain is tightened up so that it makes an angle of forty-five degrees with the lower jaw.

"As the tension of the curb-chain should be proportionate to the sensitiveness of the bars, so should the pressure caused by the pull of the reins be proportionate to the resistance. If this resistance is slight, the effort to overcome it should be light, and the point of its application should be high up on the jaw; if the resistance is great, the effort should be energetic and it should be applied low down. Therefore, without greatly altering the middle position which the mouthpiece should occupy between the tushes and the corners of the lips, we may raise or lower the mouthpiece so that the horse may yield his jaw by, respectively, a light feeling of the reins or by a strong pull on 
them. In other words, the softer the mouth is, the higher should be the mouthpiece; and the harder, the lower should it be placed. In no case, however, should it press on or even touch the corners of the lips or the tushes.

"We learn from the foregoing remarks that the proper tension of the curb-chain and the right position of the mouthpiece in the mouth of the young horse can be found only from experience, which should be gained from very slight effects that can be gradually increased in severity as the case may demand." 


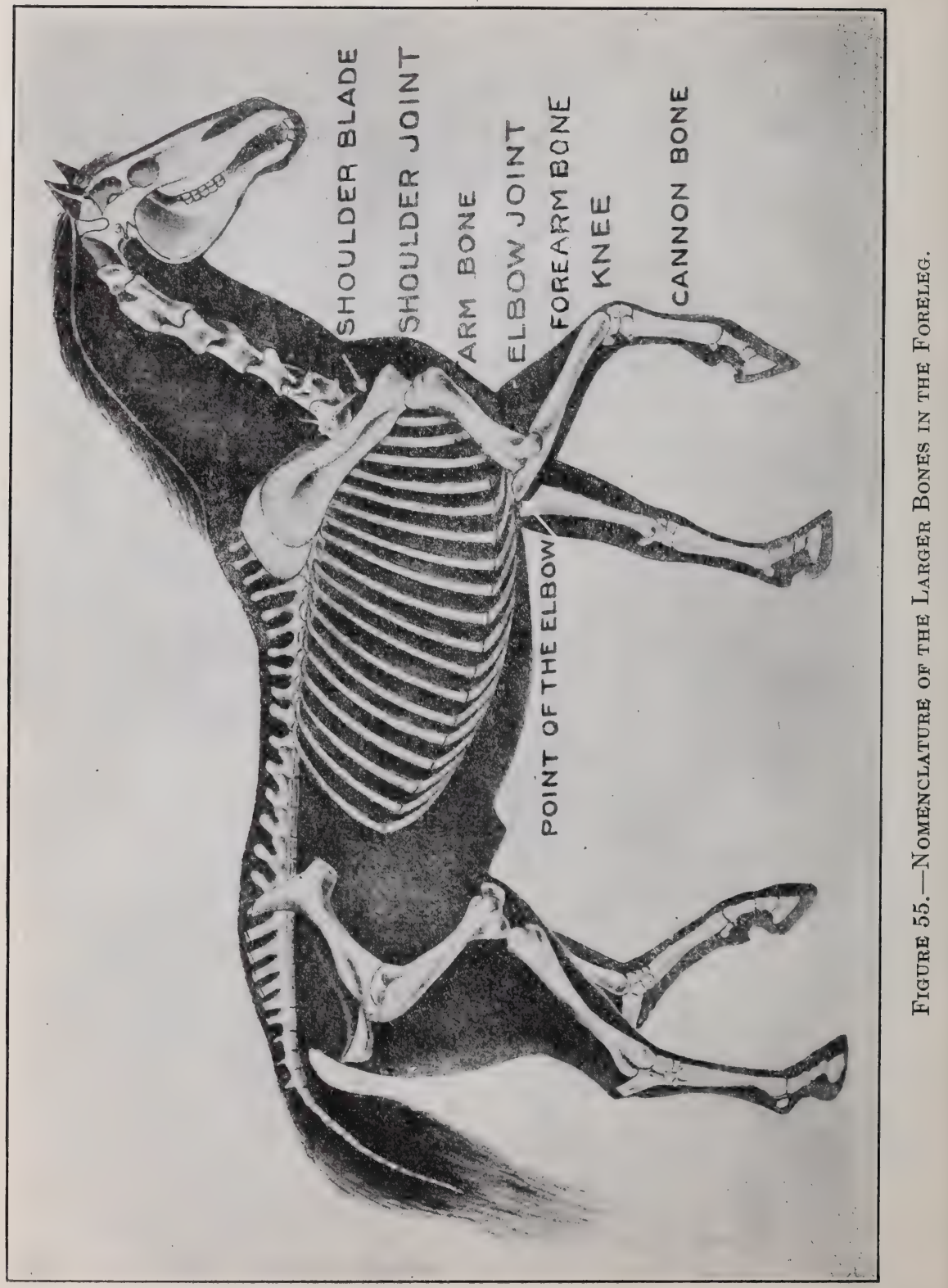




\section{CHAPTER VI.}

\section{THE FRONT LEG.}

Beginning at the top, the bones of the front leg are named as follows: shoulder-blade (scapula), arm-bone (humerus),

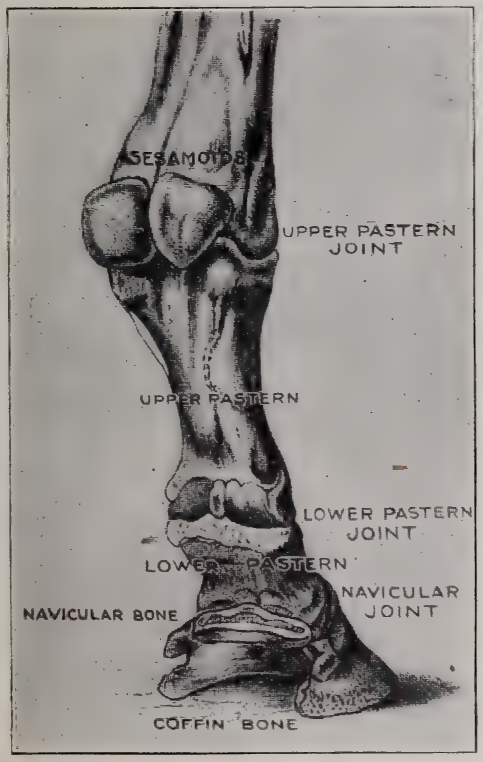
THE BONES OF THE FoOT.
FiguRE 56.-NOMENCLATURE OF

forearm-bone* (radius), the bones of the knee, cannonbone (Figure 55), the splintbones, of which there are two, one each side of the cannon-bone (A, Figure 59), the sesamoids, upper and lower pastern-bones, navicular-bone, and coffin-bone (Figure 56).

The joints are the shoulder-joint, the elbow-joint, the knee, the fetlock-joint, the lower pastern-joint, and the navicular-joint.

The external nomenclature of this region is shown in Figure 57.

The shoulder-blade, which has no bony connection-no articulation-with the trunk, is bound to it by muscles alone. The horse has no collar-bone. Below, it articulates with the

*The ulna, the upper portion of the forearm-bone, reaching from just below the elbow-joint to the point of the elbow, a separate bone in the cot, becomes completely united to the forearm-bone in the adult horse. 
arm-bone at the shoulder-joint. Unlike the other joints in the horse's anatomy, these two bones are not bound together by numerous ligaments, but by one very strong enveloping ligament,

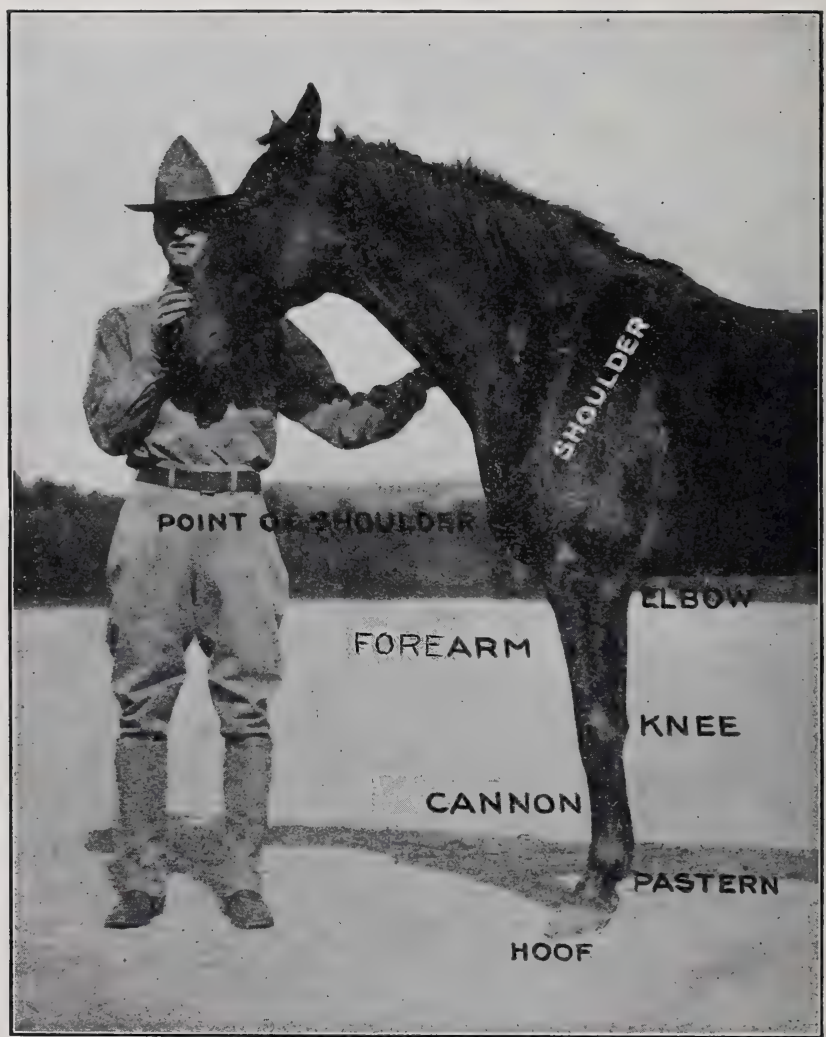

Figure 57.-External Nomenclature of Front Leg.

which permits great freedom of extension and flexion, and some side-play. It is a very strong joint, and is not liable to sprain, except from external causes. In almost every case of obscure 
lameness in front, the trouble lies below the shoulder-joint. The point of the shoulder marks the position of the shoulder-joint. The shoulder-blade should slope well forward, towards the point of the shoulder, in order to insure a comfortable seat for the rider. The arm-bone articulates with the forearm-bone at the elbowjoint. This joint is a little below the upper end of the leg-bone, and the projection of the bone, above the joint, is called the elbow. In order that the horse shall be "handy" in front, or have a free action, the elbow should have considerable lateral motion. The absence of this condition is termed tied down to the chest.

Sprains in the elbow-joint are very rare. All bones are covered with membranes that secrete either bony tissue or fluids needful to keep the bones properly moist. At the elbow and hock, these membranes are not covered by muscles, but directly by the skin. Inflammation, resulting from a blow to these unprotected parts, is not manifested in the usual way, but by an increased seçretion of fluid, accompanied by a thickening of the skin and membranes over the injured part. This fluid is the same that is found in the familiar water-blister. When the elbow is injured, the resulting "blister" is termed a capped elbow (Figure 58). This trouble is found most frequently in horses carelessly or ignorantly shod, and stabled on brick, concrete, or granite block floors, and is due to the shoe, or the floor, striking the elbow when the horse lies down. It is sometimes called a shoe-boil, and, while easily removed, if taken in time,s till its presence argues some weakness in the foreleg that prevents the horse from easing down properly in the act of lying down; he brings his elbow to the ground with more force than a perfectly sound horse of good conformation should do.

Between the leg-bone and the cannon-bone is a group of small bones, six in front, called carpals, and one, larger, in rear, called the trapezium (Figure 59). The joint formed by these bones is called the knee. It is a hinge in the continuity of leg- 
bone and cannon-bone, whose function is to enable the foot to be brought forward without striking the toe on the ground, and, by the elasticity of its cartilages, to reduce the shock of impact of the foot with the ground.

The trapezium is a bone placed at the back of the knee to afford a lever-like attachment for the tendons that bend the knee. The carpal-bones are arranged in two layers, three in a layer. The upper three articulate, with thick cartilages between, with the leg-bone. The lower three carpals rest on the metacarpals, of which there are three. One, the great metacarpal, or cannon - b o n e, continues the bony column towards the foot. The other two, on either side of the cannonbone, are rudimentary, and are called splint bones (Figure $59 \mathrm{~A}$ ).

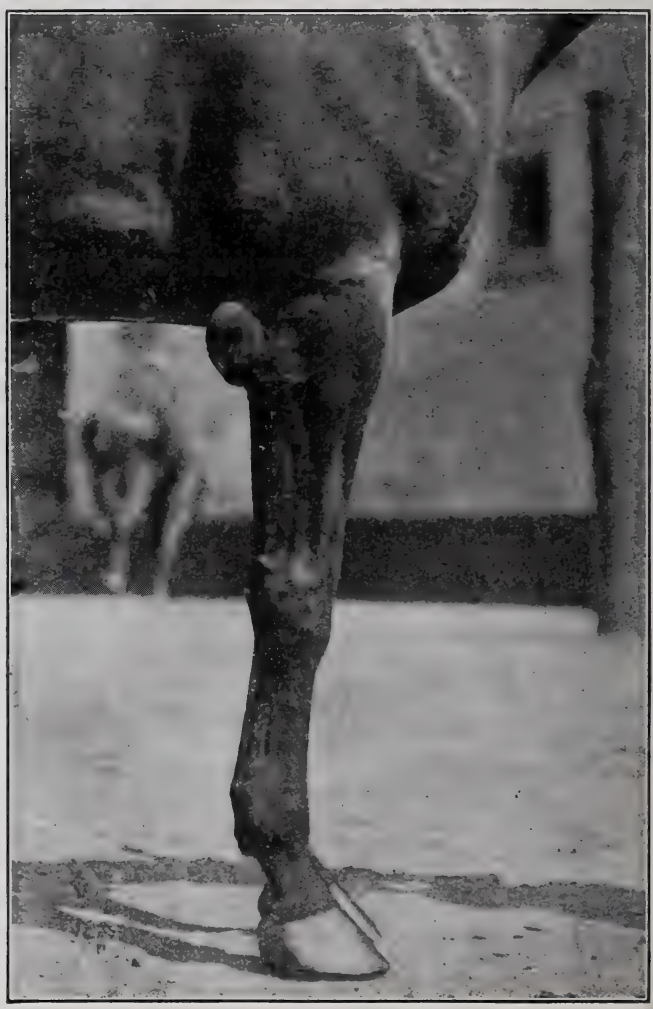

Figure 58.-Capped Elbow. 
When viewed from the front or side, the knee should be broad; wedge-shaped, when viewed from the rear.

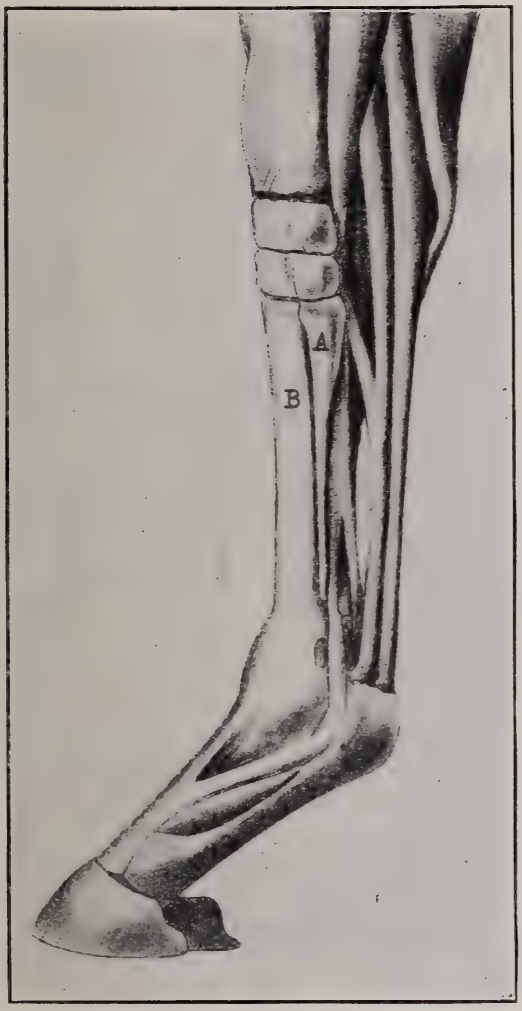

FIGURE 59.

The leg below the knee should not become rapid ly smaller, but should taper gradually towards the upper pastern-joint. When it is decidedly smaller just below the knee, the horse is said to be tied in below the knee.

Horses that are kneetied usually owe that defect to a small trapezium. This makes them deficient in power where it is very necessary.

Any wound or injury to the knee caused by a horse falling on his knees is called a broken knee, whether the skin is merely broken, or the bones shattered (Figure 60). It is as living motive-power that a horse is valuable. Anything that brings

To illustrate the position of the splintbone. A, with reference to the bones of the knee, the cannon-brne, $\mathrm{B}$, and the tendons in question the reliability of the foot. of the columns through which this power is exerted-his legs-or the pilot that governs the direction of its application-his sight-is of the highest importance to investigate. For that reason it is important to know whether or not 
a horse is sure on his front feet. Broken knees are a sign of a failure at some time in his history; hence a most careful scrutiny of the front faces of his knees should be made.

It often happens that a horse falls and bruises his knee in a perfectly innocent way, but such happenings are rare. As a rule, the fall is due to some defect in the horse himself. The would-be purchaser is wise who rejects finally any horse with broken knees.

The back tendons, leading from the trapezium to the pastern, when strained, are causes of lameness. This strain occurs more often in saddle horses that are galloped when tired. It is noticeable by an enlargement of the tendon, or its sheath, below the knee, usually nearer the knee than the

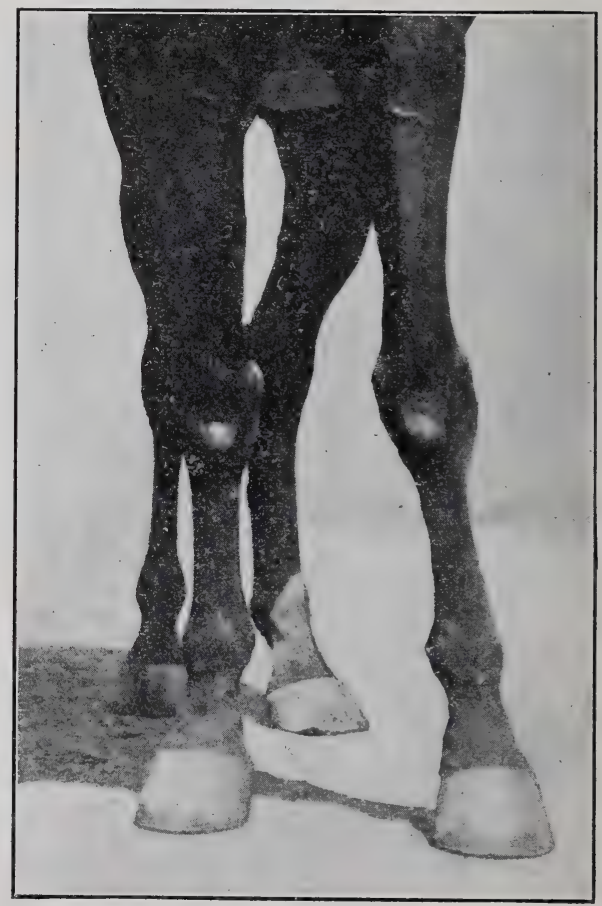

Figure 60.-Broken Knees. pastern, and a tendency to keep the knees bent forward when at rest, to ease the strain on those tendons.

A tendon is a dense, fibrous tissue that connects a muscle with a bone. Its function is to transmit the energy developed by the contraction of the muscle to the bone. 
A ligament is also a dense, fibrous tissue, and serves to bind two bones, usually, together. Tendons are usually of the shape of ropes, and do their work, while ligaments are of a variety of shapes. The ligament that binds the shoulder-blade to the armbone, at the shoulder-joint is like a broad, enveloping bandage. The ligaments joining the head and withers of a horse and supporting the vertebræ of the neck resemble closely the cable and supporting rods of a suspension-bridge. The bones of the knee and the hock are held in place by numerous ligaments of a variety of shapes, while the ligament that supports the contents of the abdomen, hung between the ribs, the hips, and the under side of the pelvis, is shaped like a hammock.

A cartilage is a dense, highly elastic substance that envelops the ends of bones at joints.

There is no room for muscles between the knee, or the hock, and the ground. The space between the skin and the bones is filled with tendons, reaching from the muscles of the shoulder and arm to their attachments on the cannon-bone, pastern, and foot, with ligaments binding the bones together, the sheaths of these tendons and ligaments and the nerves, blood and other vessels supplying the lower leg and foot. All these tissues are compact, lying closely together. They should be cool to the touch, smooth and firm. Any puffiness, any undue heat, any sensitiveness or roughness are sure signs of disease.

Often when a horse is idle and is over-fed, his legs will swell and will become feverish and painful. The animal will move in a stilty, stiff way. This lameness will disappear with proper feeding and exercise, and it should not be confused with the lameness resulting from ligaments or tendons strained from overwork.

In the young horse the three metacarpals are separateb ones. Due to injury, or conformation, or improper shoeing, or overwork, these bones throw out bony deposits that graduallyu nite them. In the aged horse this union is a normal condition, and, 
if the bony tumor marking the union is not so high as to interfere with the action of the carpals, or far enough back to interfere with the action of the tendons and the suspensory ligaments, no harm results. This is the simple splint (Figure 61).

A beaded splint is a series of two or more such enlargements, running down the splint-bone.

If the bony deposit spreads to the back of the cannon-bone and across it to the splint-bone on the other side, it is called a pegged splint. This is its worst form, is incurable, and results in chronic lameness.

If the bony growth encroaches upon the carpals, or interferes with the tendons or ligaments, serious lameness, usually incurable, results.

In Figure 59 the position of the splint-bone, $\mathrm{A}$, with respect to the knee-bones, the tendons in rear, and the cannon-bone, $\mathrm{B}$, is clearly shown. The tendons, when the horse is in motion, are in constant motion up and down. They are immensely strong, inelastic tissues, covered with delicate membranes that supply the lubricants necessary to permit them to slip easily and freely.

Any bony growth on the rear of the splint-bonew ill interfere with this ease of movement, and the roughness of the bony tumors will lacerate and inflame the sheaths of the tendons.

If the bony tumor encroaches on the knee-bones, it is seen easily that much damage will result.

If, however, the union between the bones $\mathrm{A}$ and $\mathrm{B}$ is effected by a growth between the bones and to the front, there is no moving tissue that is interfered with,and lameness will not result.

The extremely large splint shown in Figure 61 has apparently not inconvenienced the horse in the least.

A wound on the upper end of the inside splint at A, Figure 59 , caused by the shoe of the other front foot striking it at high gaits, is called speedy cut. This is a very serious defect. The interference that causes it happens only at high speed; the pain 
resulting is very great, sufficient often to bring the animal to his knees, and to cause deplorable accidents.

The line of the foreleg should be nearly straight, the cannonbone prolonging the radius. If this line bends forward, the horse stands over

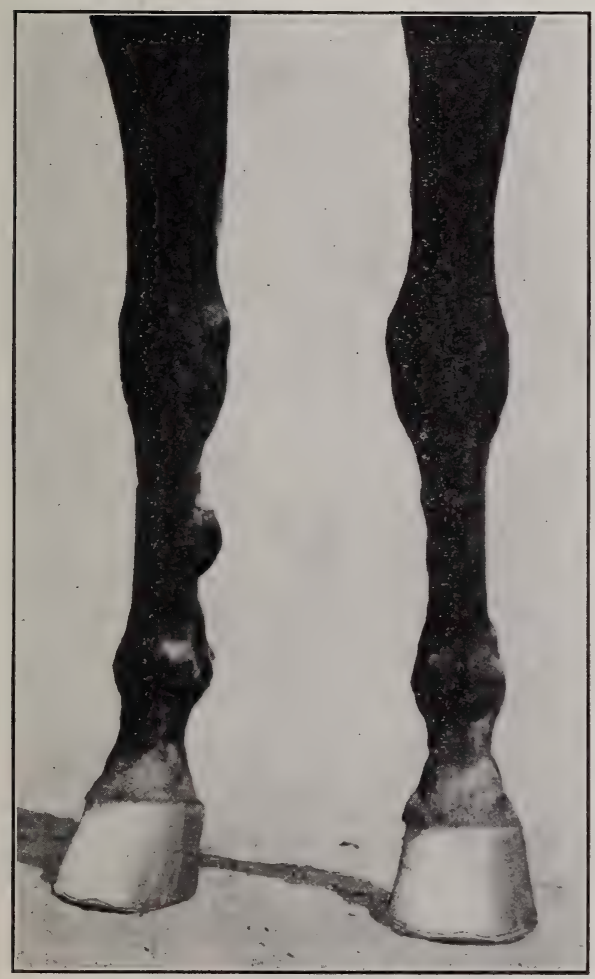

Figure 61.-Simple Splint. at the knees; if it bends back, he is calf-kneed. The former is a sign of muscular deficiency -lack of power. A calf-kneed horse, if put to hard work, is apt to strain the tendons or ligaments.

The fetlock should be smallnot as broad as the knee when viewed from the front, nor any broader when taken in profileit should be flat from side to side.

The skin should be closely drawn without puffiness, and the joint should bo clean cut.

Wind-galls, due to enlargement of the membrane secreting the lubricant for the joint, and containing it, and caused by violent exertion or overwork (Figure 63) are often found at the fetlock and ankle. 


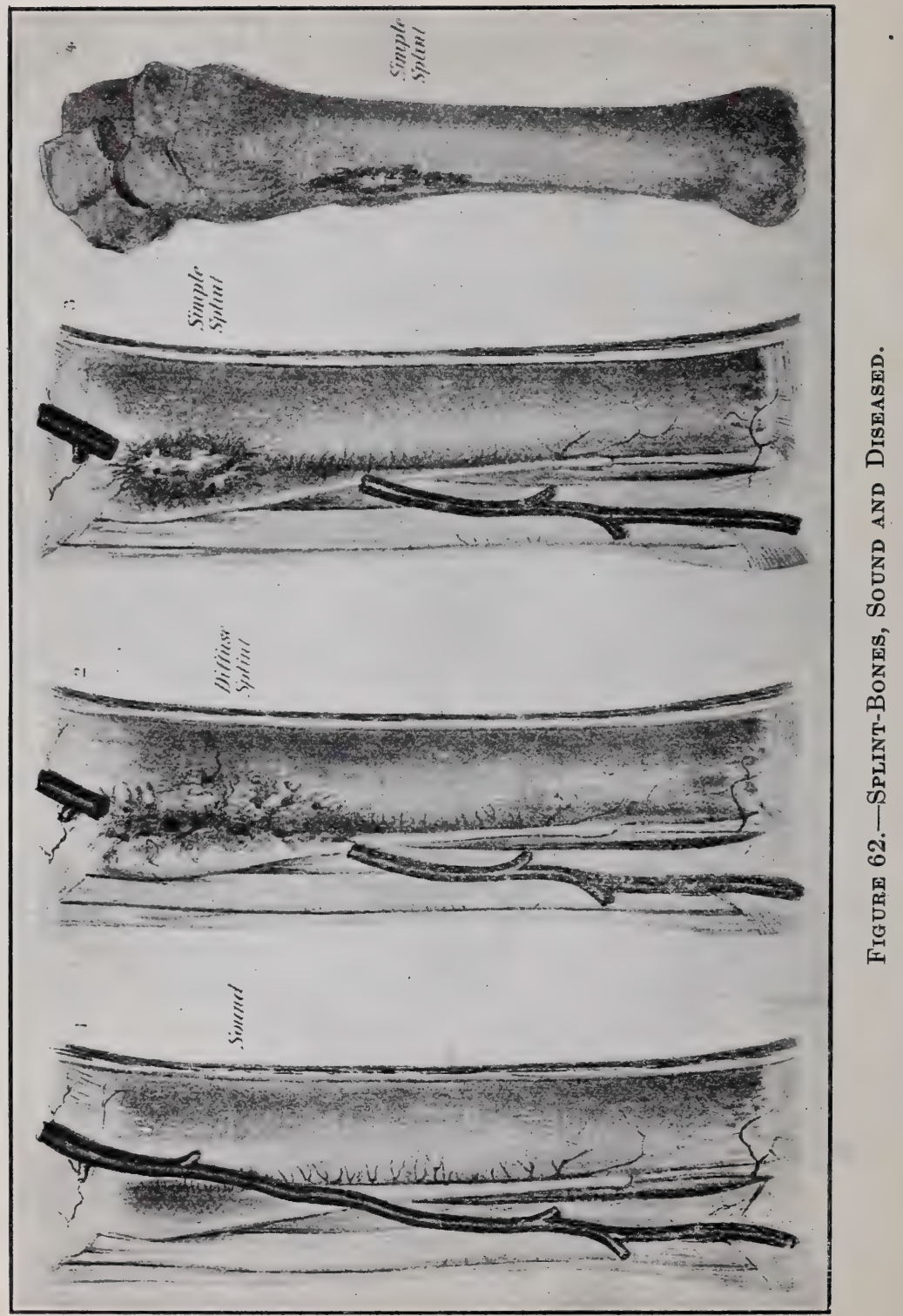


If they are soft to the pressure of the finger, and cool, they are little more than blemishes; if they are soft and hot, indicating inflammation, they are the result of a strain to one of the tendons; if hard and inflamed, they result from some injury to the

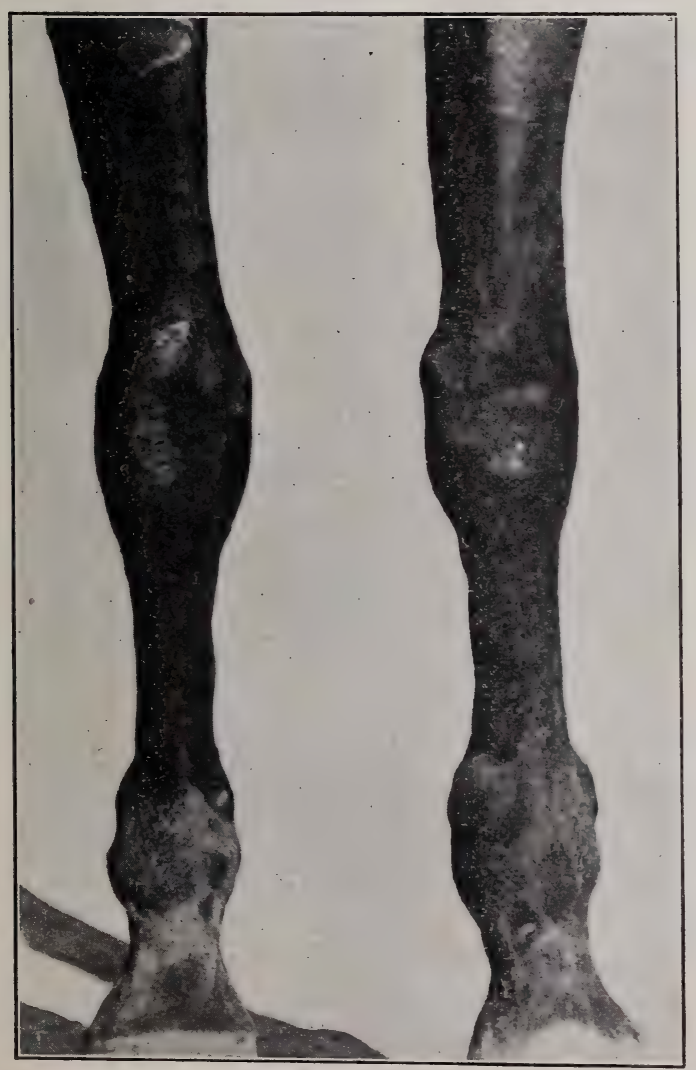

Figure 63.-Wind-Galls. bone or its c o vering. Both of these twolatter conditions are serious and demand attention.

Under the back part of the fetlock is a horny growth, called the ergot. It seems, $1 \mathrm{ike}$ the other horny growth higher up on the inside of the radius, called the c h e s t n u t (Figure 72 ), to be of no functionalvalue. Any bony deposit upon the pastern bones is termed a ringbone. If the deposit is above the joint between the two pastern-bones, it is a high ringbone. This 
is its most common form, and is easily detected. If the ringbone is confined to the side of the joint, it is less serious than if it extends to the back or front of the joint, when an incurable lameness results. Most serious of all is the low ringbone, which involves the joints between the lower pastern-bone and its neighbors. This is difficult for the amateur to detect, as it is generally contained within the hoof.

Sidebones a re bony enlargements in the heels, showing just above the hoof.

The pastern should slope well from the rear to the front, and should be very elastic in action. Too great a slope causes undue tension on the tendons and ligaments. About forty-five degrees of slope is best. More slope than that would indicate weakness in this part. The slope of the pastern is de-

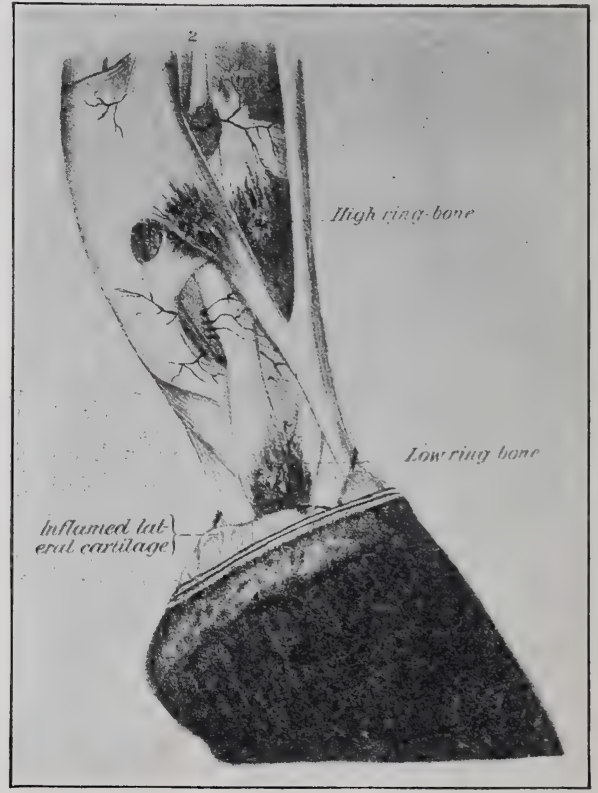

Figure 64 termined by the length of the upper pastern-bone;--the longer the bone, the greater the slope, and the reverse. A short, upright pastern is an almost invariable sign of a rough saddlehorse. 
The principal function of the foreleg is to support weight, to carry the forehand and its load ahead and out of the way of the propelling haunches. It must be so shaped that it can perform this work without injury to itself and carry its load as nearly level as possible.

Elasticity in carrying its load is secured through the cartilages and muscles. The shock of impact is transmitted at each joint, partly to the bone above the joint and partly to the muscles controlling the bone below it, through the tendons connecting them. The smaller the angle between two adjoining bones, the greater will be the portion of the shock transmitted to the muscles. In the foreleg, three joints are between bones inclining more or less to each other-the fetlock-joint, the elbow, and the shoulder-joint. If the upper pastern-bone is long, it will slope well from the cannon to the hoof; if it is short, it will stand straight. Similarly, a short arm-bone will bring the point of the shoulder nearer the elbow and straighten the shoulderblade.

The foreleg of the camel is straight from the foot to the upper end of the shoulder-blade. Consequently, the shock of impact is carried to the shoulder muscles, lessened only by the elasticity of the cartilages between the bones. As a result, the camel is the most uncomfortable saddle-animal known.

The slope of the shoulder should be about forty-five degrees and that of the pastern about the same. The horse shown in the half-tone on the following page may be taken as a model of conformation. His shoulder-blade slopes at the proper angle, and is very long. His forearm is very long, and strongly muscled. His elbow, knee, and pastern are smooth, clean-cut joints. The cannon is short and prolongs the forearm.

A straight shoulder and a straight, short pastern should be avoided. The horse will not only be uncomfortable to ride, but he will "pound" himself at the faster gaits and become lame from the concussion. 
Splints, sprained tendons and ligaments, ringbones, sidebones, wind-galls, and most of the diseases of the feet are due to this concussion:

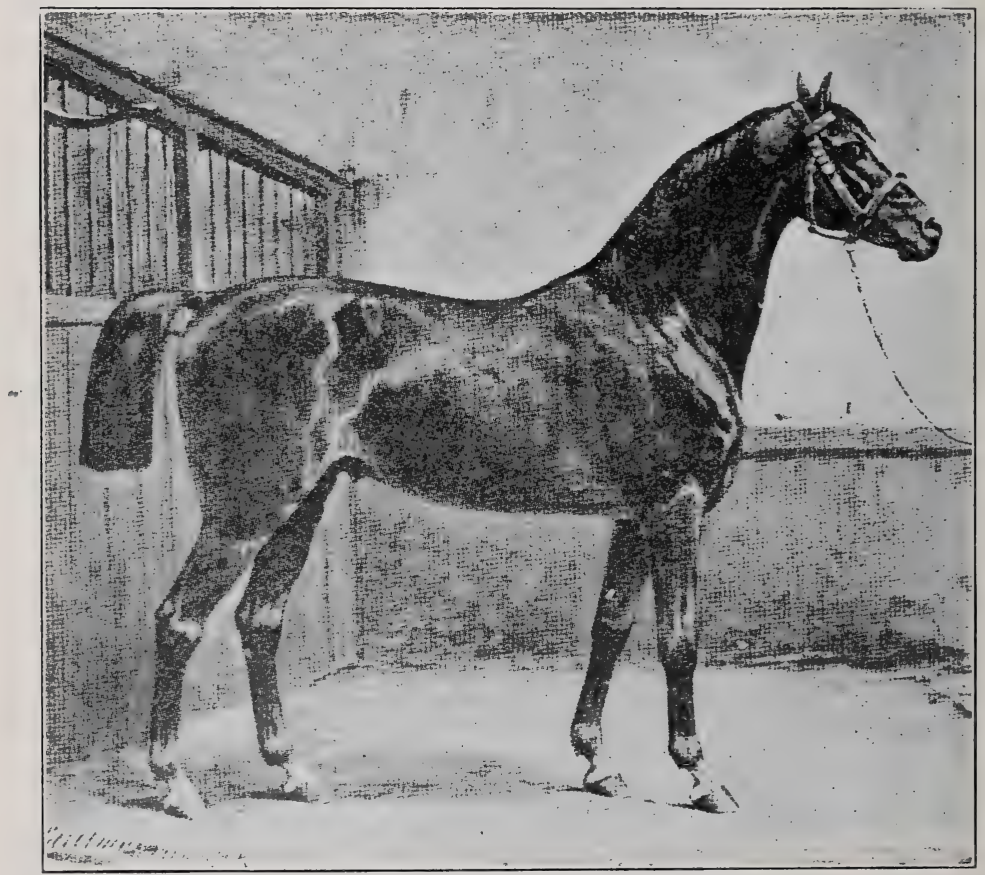

Figure 65.-A Model of Conformation. From the painting by Otto Eerelman. 


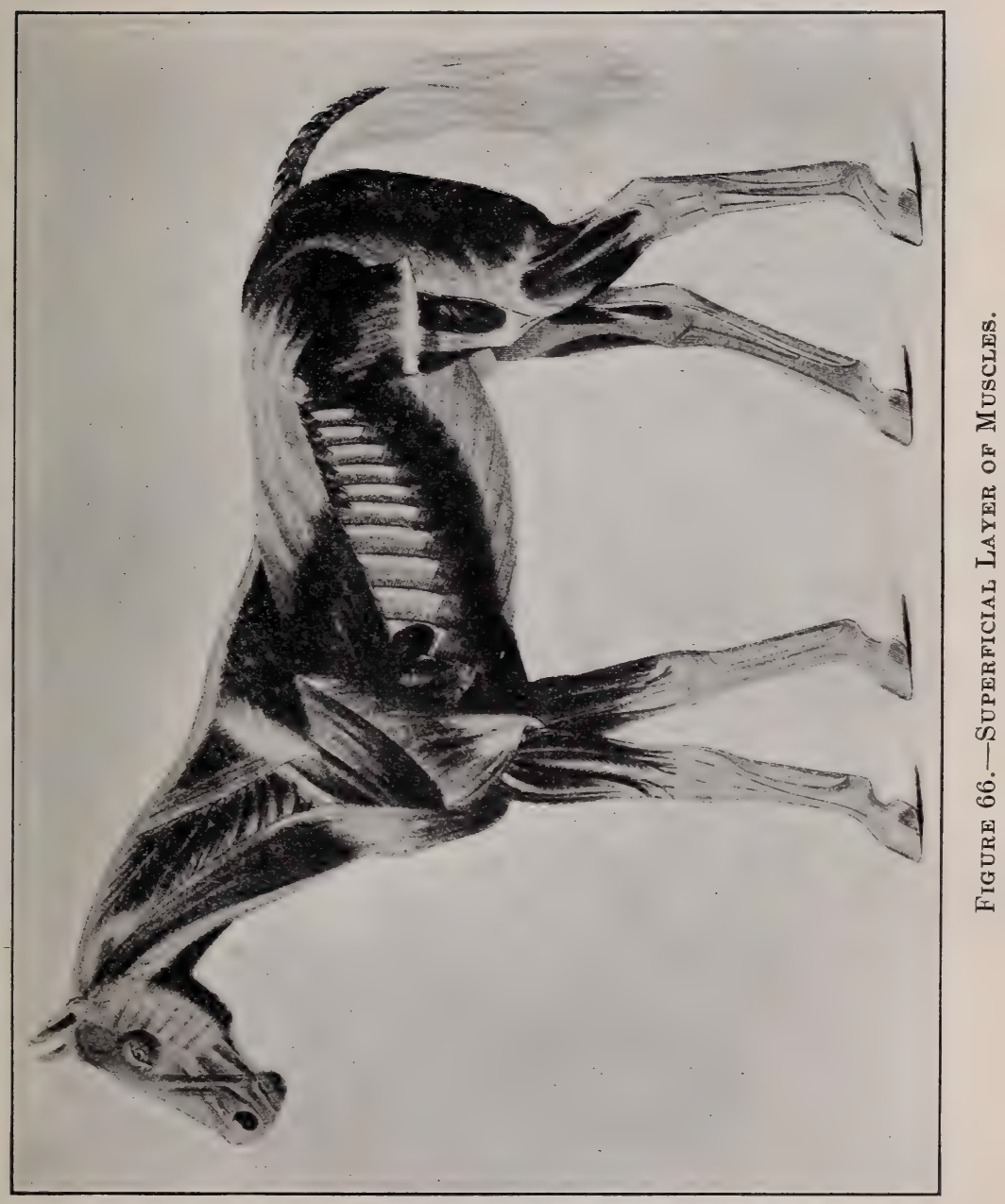




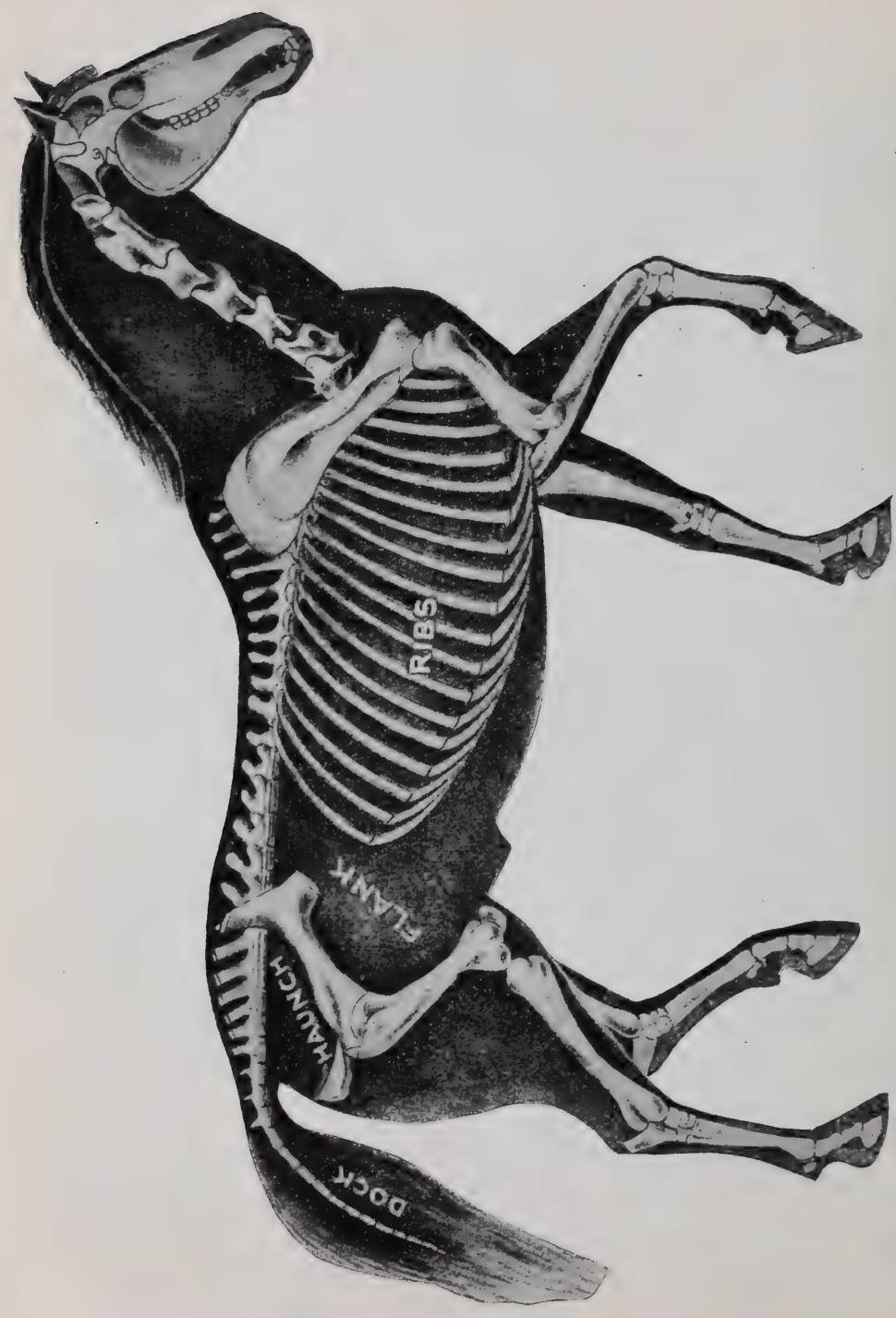

인

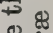

ธี

8

녕

ग

形

สี

ีํำ

$\exists \rightarrow$

.

\%

당

舫

.

$\frac{6}{0}$

헌

윽

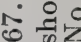

봉

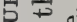

등

工.

응

등

푱

웛

.2

응

넨도

․․․

สㅎㅀ

엥으

율를

(4)

+ 50.0

ㄷ․․․․․

을

ธํํ을

ตี้ 


\section{CHAPTER VII.}

\section{THE BACK.}

The back is mainly of interest because it furnishes the position of the saddle, and it is necessary to know something of its anatomy to be able to place the saddle and its load so they will not injure it.

The bones of the back sre eighteen vertebre of the spinal column, and the ribs. The first eight of these rertebre. with their museular corerings. are called. taken collectively. the withers The upper spines of six or seven. usually, of these bones are much longer. as can be seen in Figure 6\%, than or any of the others, and they furnish points of attachment for the suspensory ligament of the neck and for several important muscles of the back, shoulder, and ribs.

In front of the haumeh-bone are six vertebre. called the lumbar vertebræ; they slope towards the front. All the vertebrie of the back are well padded with muscles on the sides. but are very close to the skin on top, and these upper extremities must he very carefully protected from any pressure.

Looking at Figure 66 . the muscles of the back are seen to be broad and long. These museles have slight mofions: they are several inches thick, and ane admirably adapted to receive the saddle and its load. provided the load is kept off the spinsl column and is evenly distributed.

On each side of the withers, a little lowe: than their erest. lie the upper ends of the shoulder-blades. These bones are tipped with a broad, thick band of cartilage-indicated in Figure 67 - to protect the bone itself from injury. 


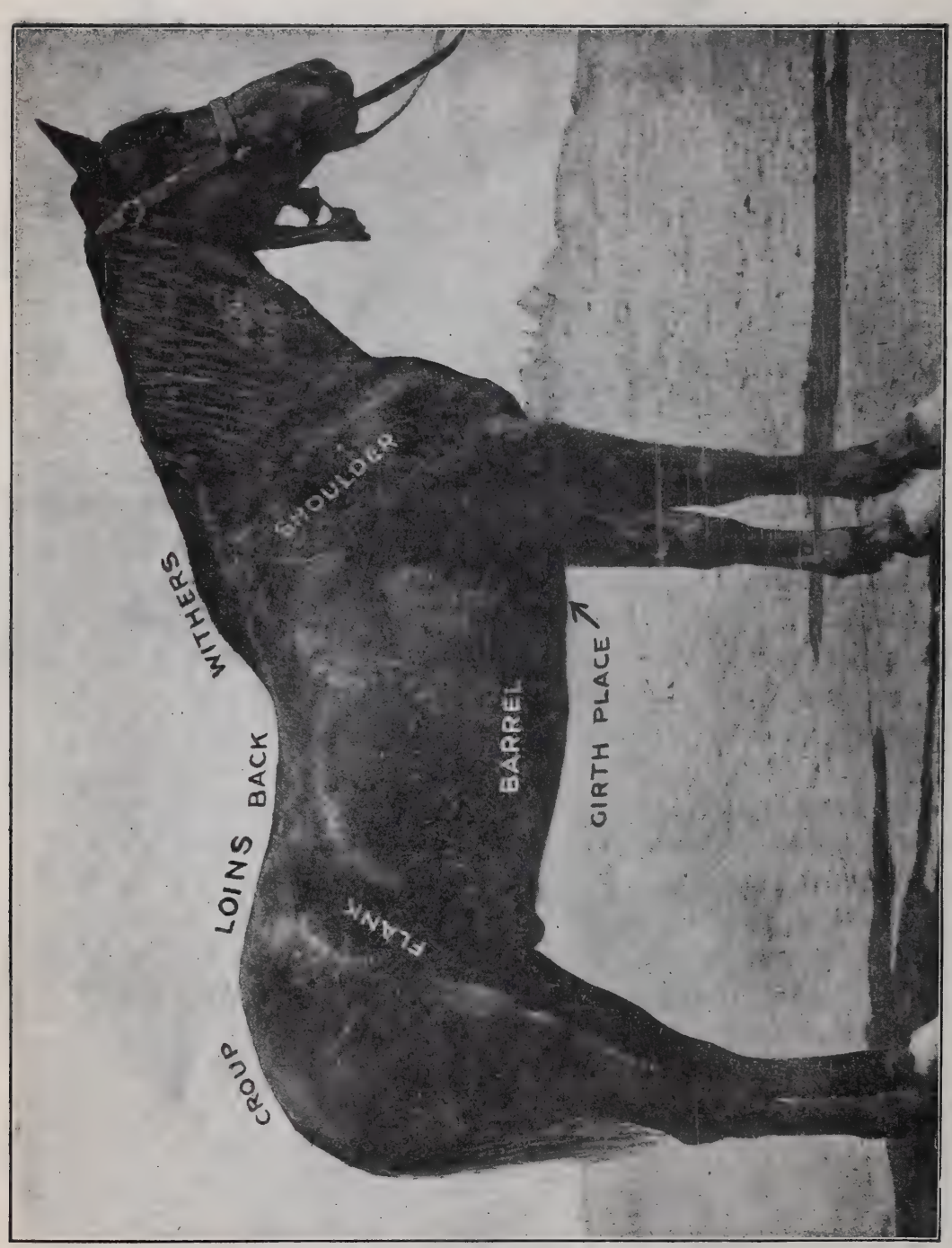

خ்่ 용 텅윤든드 들 류융 4 원 \pm \% 킹은 픙 냉 $+\infty=0$ 므 ․ㄹㅎㅇㅝ i c 过专 ठद्य 00 ㅇ․워 क 을 कै N. $\infty \approx$ \& 0 \& 0

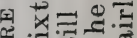
= क

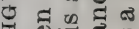
I d... ते का की उٓ ข

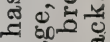
+ ฮิ

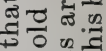
(I) हี 웡 幽 ¿

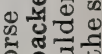
융

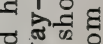
흥 荛。 สี क वृ 늘 . स्ते चै की 어 올르 
The shoulder-blade, as has been said, has no bony union with the spinal column. It is simply bound on the ribs and spinal column by a number of very strong muscles that control its movements. The center of its motion is about one-third its length from the upper end. When the foot is brought forward, the lower end of the shoulder-blade swings forward and upward, around this center of motion, and the upper end swings backward and downward.

The saddle must be so placed as not to interfere with the free play of this bone. It has been found that if the front of the side-bar of the McClellan saddle is placed so that three fingers can be laid between it and the shoulder-blade when the horse is standing, the play of the bone will not be interfered with.

The saddle in ordinary use for pleasure-riding does not need to be built to carry any load but the rider. It has a very small, rigid frame, called the tree, is carefully and thoroughly padded, and needs no blanket or pad under it to protect the horse's back. A leather sweat-pad, called the numnah, should be used under it to protect its padding from becoming ruined by sweat,

These saddles should be padded to fit each particular horse. and should not be used on another horse. If this precaution is taken, the saddle will naturally fall on its proper place and will stay there. As long as the padding is good and the numnah kept clean, there is small danger of injury being done to the horse's back.

The IIcClellan saddle, however, must often be changed from one horse to another. Its tree is larger and its bearing surface considerable to provide points of attachment for the packs that, from time to time, must be fastened to the pommel and cantle. The horse's back is protected by a folded woolen blanket.

This blanket must be folded very carefully; no wrinkles should be allowed, nor any dirt or other foreign substances, in any of its folds. Anything that causes undue pressure on any spot under the saddle will compress the capillaries of that spot and 
prevent it from receiving the supply of blood necessary to keep it built up. If this pressure is sufficient to chafe the skin, the resulting wound is very liable to become infected, as the woolen blanket, impregnated with sweat, is a favorable place for the growth of microbes. If the skin is not broken, when the pressure is removed the spot affected will immediately become inflamed, and a sore will probably result, under the skin, that will, unless taken properly in hand, finally destroy the skin over it, and become an open sore. In either case the horse is said to have, first, a saddle-gall; then, if this is neglected, it becomes a sore back. If this sore back is along the ridge of the back-bone, the pus cannot easily be drained; it may make sinuses along the spines of the vertebræ, and a fistula results.

Another serious result of a neglected sore back comes when the sore practically heals. Active suppuration has then ceased, and the wound heals over imperfectly, leaving a dead, hard piece of skin over the sore, itself covered by a thick scab. An inert abscess is left under the skin, which breaks out when pressure is again applied to it. This is a sitfast, an obstinate, troublesome sore, that needs constant watching.

If there is time to devote to it, the sitfast should be cut out and the wound compelled to heal slowly, filling up from the bottom with sound tissue.

When the saddle is first removed, the horse's back should be carefully looked over. If any chafed places or inflamed spots are noticed they should be washed clean and briskly rubbed for fifteen or twenty minutes to restore a healthy circulation. Fomenting the back with warm water, carefully drying it before leaving it, is also an excellent treatment. The under side of the blanket should be inspected, to locate the cause of the trouble, and the greatest care should be taken, when the horse is next saddled, to keep all pressure from the sore spot. This can be affected by cutting a hole in the blanket over the sore, saddling carefully, and adjusting the blanket at every halt. 
A saddle-horse should have a flat back, moderately high withers, not too thick, and a sloping shoulder. Figure 65 shows an excellent back. The shoulder is especially good. A long, sloping shoulder, reaching out well in front of the rider, gives him a feeling of security that he cannot have if the shoulder ends near his own knee.

The muscles that pull the shoulder-blade forward are attached to the poll and upper four neck vertebræ; the ones that draw it back are attached to the dorsal and lumbar vertebræ and the first eight ribs. This explains why a horse that is down can be kept down by raising his head and bending it back towards his shoulder. The neck muscles that move the shoulderblade forward-and hence the whole leg-are incapable of acting. If a horse cannot move his foreleg forward when he is down, to get a bearing, he cannot rise.

High withers, extending well back, are generally associated with long necks, long and sloping shoulder-blades, and powerful back museles. Low withers are generally found on animals with short necks and straight shoulder-blades. The withers should not be too fleshy and thick.

The two horses shown in Figures 69 and 70 have each very prominent withers. The one in Figure 69 has very thin withers, and his back slopes too much from the croup. The result is that the saddle could not be kept from chafing the top of his withers, which were always sore after a ride. He was, in consequence, not for duty most of the time, and had to be sold as unfit for saddle purposes.

While he was a coarse, ill-looking animal, still he was very strong, active, and comfortable to ride, and, aside from his sore withers, perfectly sound when sold. But for that defect he would have given many years of useful service.

The horse shown in Figure 70 is a useful specimen of what is termed the general-purpose horse; he is equally good to ride or to drive. He has a strong strain of the American saddle-horse 


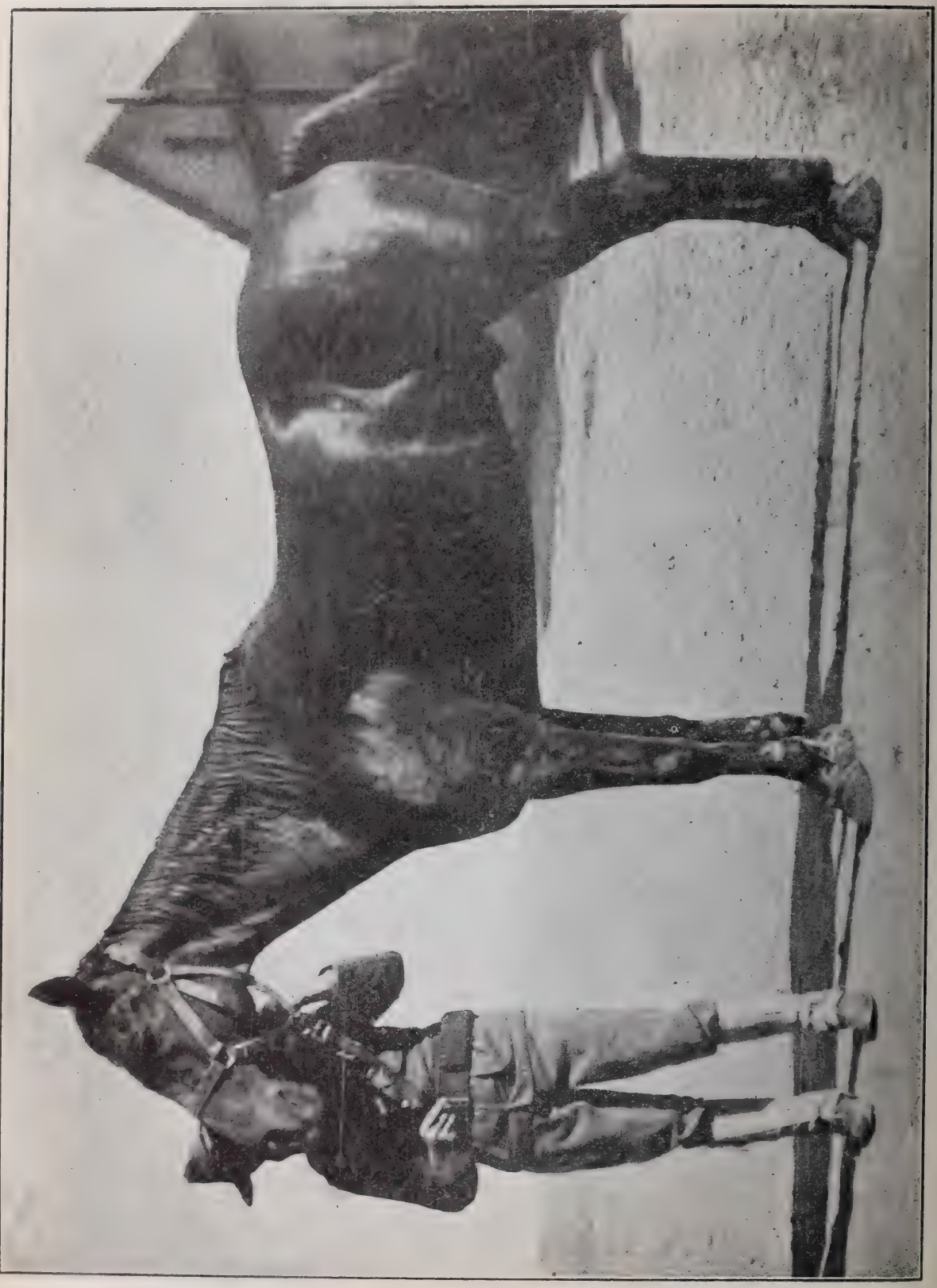

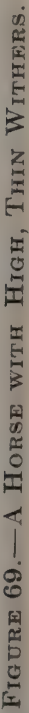




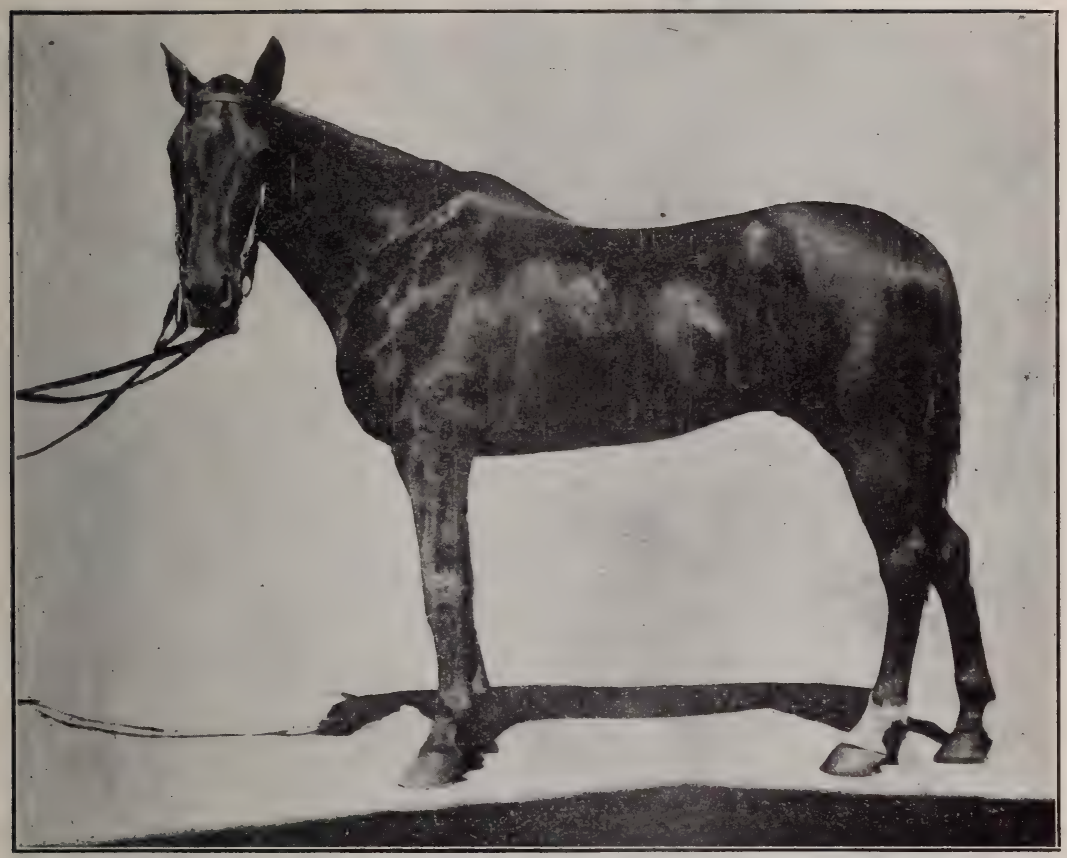

Figure 70.-A Useful Specimen.

with a thoroughbred cross. He is a fine saddler, drives well, single or double, is not dainty with his food, and thrives well in the field. He has been ridden by an officer for ten years, and is as good as ever.

His withers are as high as those of the horse in Figure 69, but not so thin, and his barrel is longer and more cylindrical. The saddle, if placed off the withers on saddling, will stay there with very little watching. He is not shown as a perfect model, but as an example of an extremely useful individual, in spite of what might seem serious defects in conformation. 


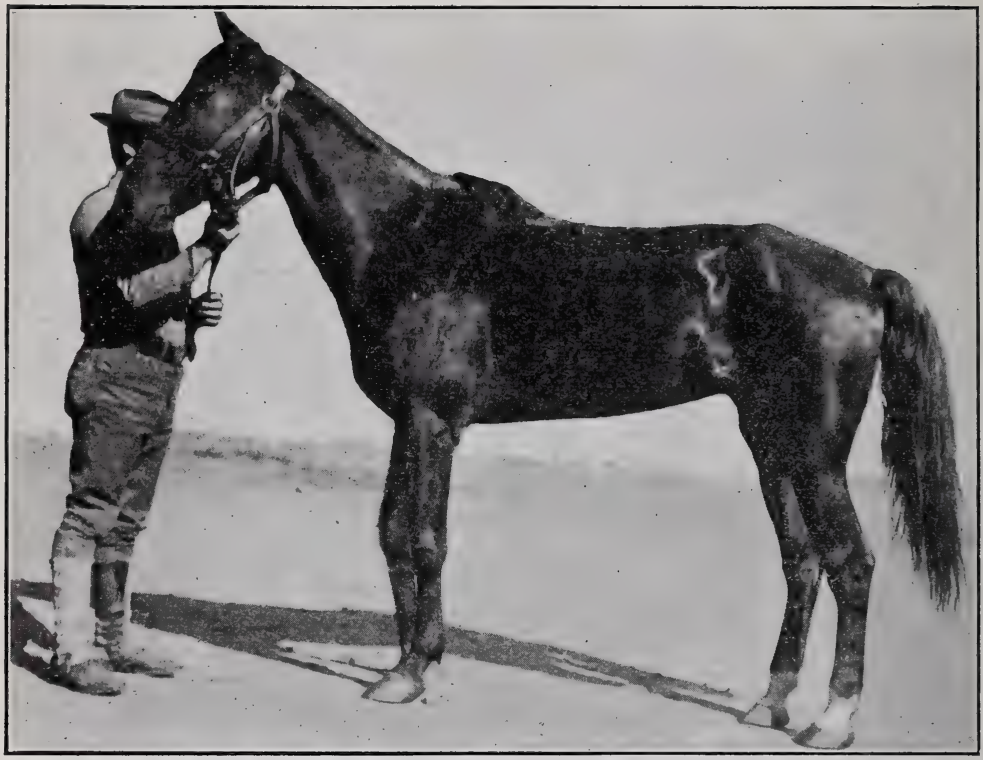

Figure 71. - Nearly Everything Wrong.

The horse shown in Figure 71 has been several years at the Military Academy. His withers are much too thin and prominent, but are kept from ever getting sore, because it is impossible to keep the saddle in its position long enough to chafe them, unless intentionally fastened there with a too tight breast-strap; even then his shoulder is so straight that it has but little play. $\mathrm{He}$ is rough to ride, ungainly, and has no staying power. $\mathrm{He}$ can hardly be said to have a single redeeming trait. 


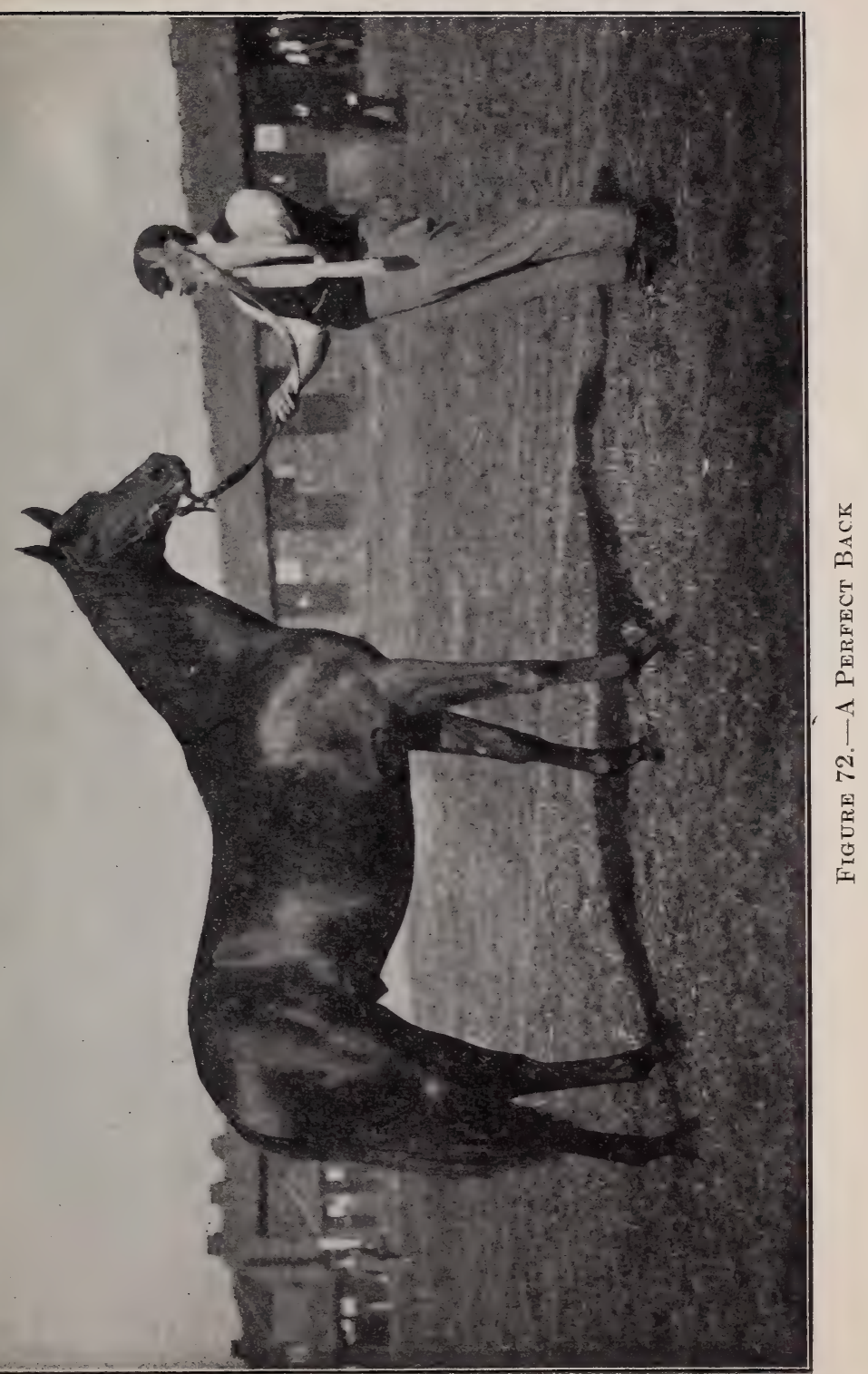




\section{CHAPTER VIII.}

\section{THE TRUNK.}

If the legs and neck were removed from the horse's body, the trunk would remain. It is subdivided into the breast, the chest with its enclosing ribs, the back and loins, the abdomen-the cavity in the rear part of the trunk-and its contents, the hips, and the croup.

The breast is the muscular front portion of the chest, and is bounded by a line connecting the points of both shoulders and by the arm-bone on each side. For saddle purposes, great width of breast is usually at the expense of leaping power and speed, since this width is usually produced by over-development of the shoulder muscles, and not because of increased capacity of the chest.

The lungs and heart are enclosed, by the ribs and diaphragm, in the chest. It is by the expansion of the chest that air is brought into the lungs, and by its contraction that air is expelled. This expansion and contraction is performed by the muscles of the ribs. The greater the expansive power of the chest, the greater quantity of air will be drawn into the lungs, and the purifying and vitalizing of the blood will be more completely performed. The ribs should, therefore, be long, convex, and slope to the rear. A horse whose ribs approach close to the haunch-bone is said to be well ribbed $\mathbf{u p}$.

The cavity of the chest is separated from the abdomen by a muscular partition, called the diaphragm. The entire cavity of the chest is lined by a very smooth, well-lubricated membrane, called the pleura, which envelopes, without attaching itself to, the heart and lungs. The abdomen contains the stomach, the 
intestines, the kidneys, and the various glands whose secretions assist in the processes of digestion.

It is by the expansion and contraction of the chest that the lungs perform their function of purifying and oxidizing the blood. The lungs cannot be too big. The chest, to contain large lungs, should be deep, from top to bottom, long from front to rear, and have great convexity.

The abdomen must also be roomy, but only to a certain extent. If the abdomen is small - "tucked up," as it is calledthere will be little room for food to be stored, the horse will be a dainty eater, requiring frequent feeding, and he will be unfit for hard service. If his abdomen is too large, its excessive weight will prevent the horse from being active or fast, and he will be clumsy and unpleasant to ride. A horse possessing the first fault is said to be herring-gutted, and the last mertinn?d, pot-bellied.

The saddle on the pot-bellied horse is constantly slipping forward to bruise the withers or the shoulders. On the herringgutted horse it keeps sliding back, to the annoyance of the rider.

The contents of the abdomen are held in place by the $\mathbf{a b -}$ dominal tunic, a very powerful ligament, and by other tendons and muscles. This abdominal envelope should continue the lines of the ribs. The profile of the belly should slope gently downward from the sheath to the girth-place.

The loins include the six lumbar vertebræ and their muscular covering. The region of the loins is commonly known as the coupling.

If the ribs slope to the rear well, and the loin muscles are thick and strong, the horse is well coupled. For saddle-horses, the coupling should be short and the muscles strong and thick.

The curve of the profile of the horse's back-from withers to tail-should be, when viewed from the side, smooth and flattened (Figure 70). There should be no "jog" (Figure 71) in front of the haunch-bone in horses in good condition. Most 
horses in low condition show a slight interruption in the curve of the back at this point, due to the wasting away of the muscles filling in the angle between the last vertebra of the loins and the first of those of the croup.

The hips should be well rounded and not too prominent. A horse with too prominent, ragged hips is apt to strike and break them when going through narrow gates or doorways. When the point of the hip is broken, it is easily seen by the lack of symmetry, when viewed from the rear. The usefulness of the animal is not always impaired by such an accident, nor is he always made, even temporarily, lame by it.

The diaphragm is the muscle that controls inspirationthe act of taking air into the lungs. When the air enters the lungs, the diaphragm is pressed against the contents of the abdomen, they in turn press against the abdominal tunic, and it, being fastened to the point of the hip, exerts a pull there at each breath. A broken hip, therefore, cannot rest long enough to heal properly, and the symmetry of the part is always marred.

The region between the hips, the loins, and the posterior ribs is called the flank (Figure 67). This should be well filled out and not too large. In the horse that is well ribbed up, there should be no more than room enough to lay the hand between the ribs and hip. A gauntness appears in the flank after great exertion, or when feeding or watering has been neglected. A horse that is losing condition shows it first in the flank.

The croup should slope downward toward the tail but little and should be convex in profile, viewed either from the side or rear. Horses whose croups slope too much towards the rear are termed goose-rumped (Figure 68). Aside from being unsightly, a goose-rumped horse lacks muscular development where it is very necessary, since certain of the large muscles of the thigh form their attachment there. These muscles originate propulsion, and any lack of development or loss of leverage reacts directly on the strength and length of the animal's stride. The five vertebræ of the croup grow together early in the life of the horse.

The dock is the tail, without its hair.

The hunter shown on the opposite page is a model. He has a perfect back and trunk. 


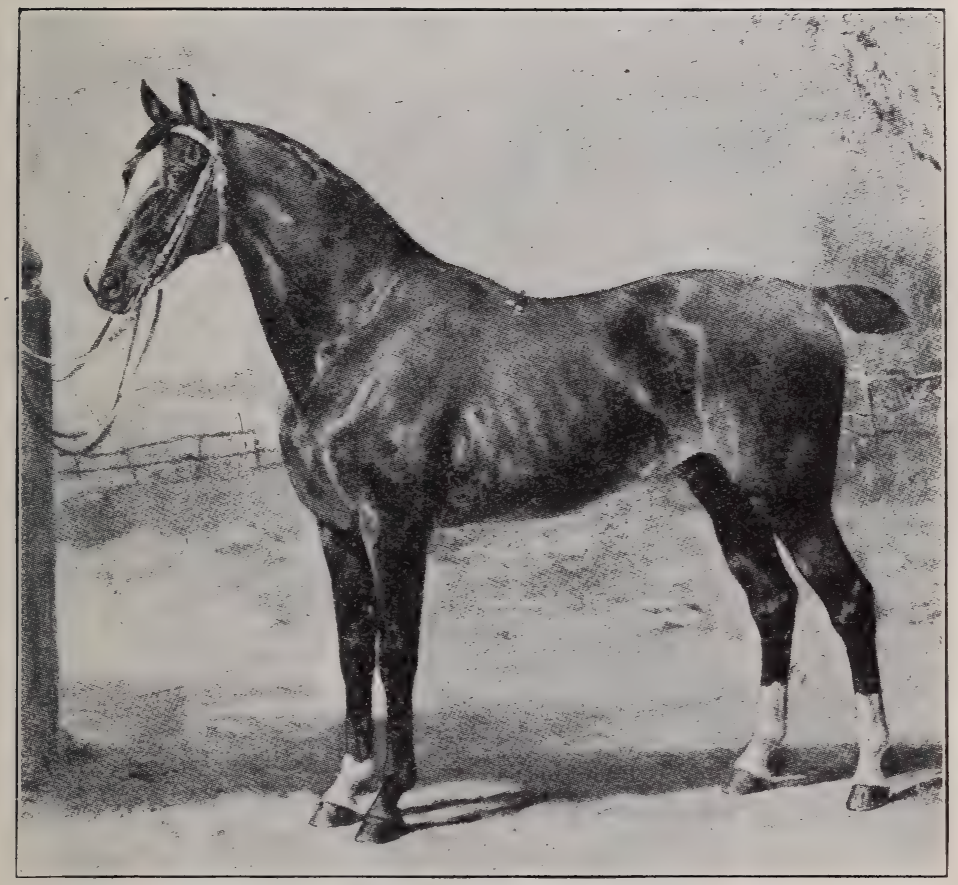

Figure 73.-A Hunter.

From the painting by Otto Eerelman. 


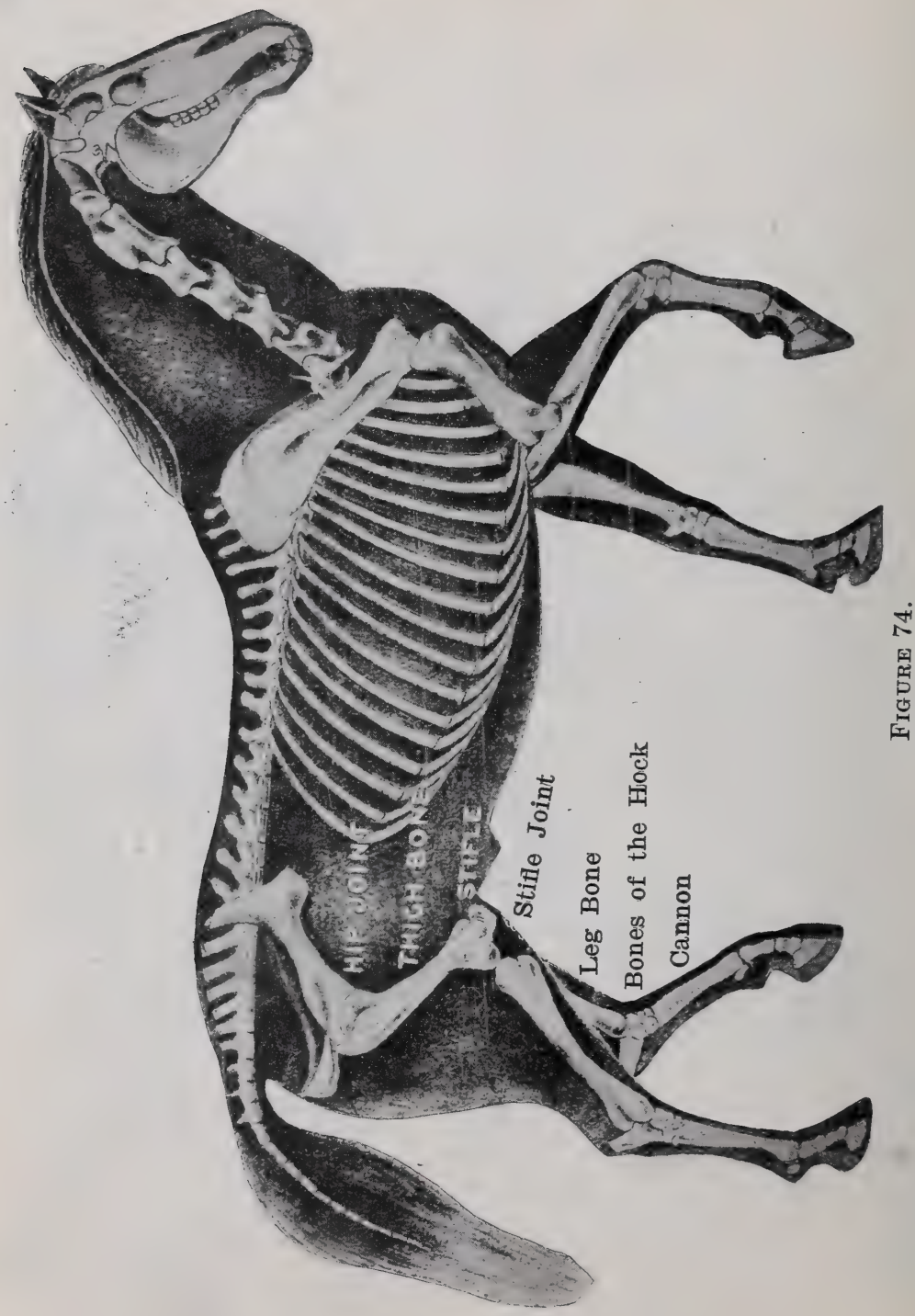




\section{CHAPTER IX.}

\section{THE HIND LEG.}

The column of bones of the hind leg are named in Figure 74 and the external regions in Figures 75 and 76 . The bones from

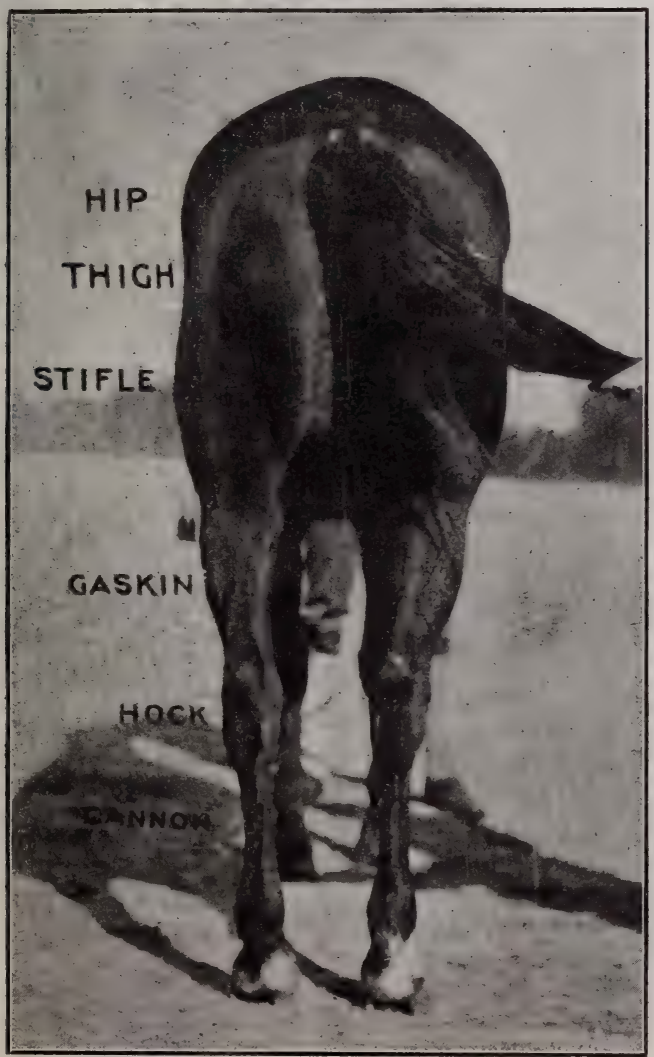

the hock down are named as in the front leg.

The chief function of the hind $1 \mathrm{eg}$ is propulsion; it supports less weight than the front leg (in the proportion of three to five), and is less liable t o suffer from the effects of concussion. The thigh-bone articulates with the pelvis at its lowest point, and slopes forward, downward, and outward to the stifle. It is deeply imbeddFtgure 75.-A Welt-Built Horse, from Behind. ed in muscles of 


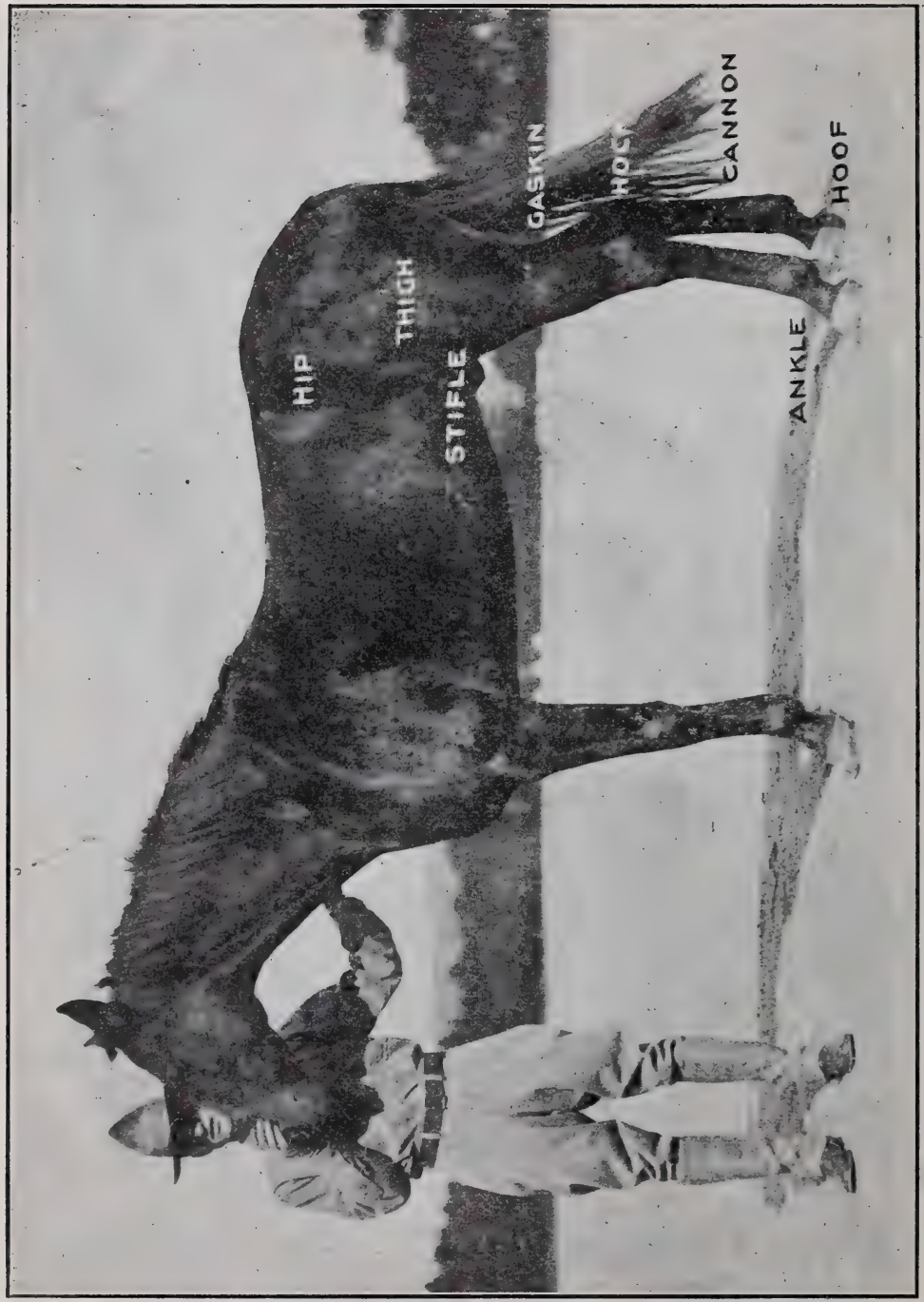

 
great strength and mass, and its position and movements are entirely obscured by them. The thighs should be well filled up, viewed from behind, leaving no open space between the legs. The stifles should be slightly wider apart than the hips, to insure freedom of movement in the stride.

The stifle, or patella, corresponds to the human knee-cap. Its function is to afford additional leverage to certain muscles that advance the leg. It lies in front of the stifle-joint, and is held in place by several ligaments. Dislocations of the patella are rare, but are much more frequent than dislocations of any other joint. A horse suffering from this dislocation is said to be stifled.

The leg-bone, or tibia, lies between the stifle-joint and the hock. The lower part of the muscles of the tibia is termed the gaskin, and it is important for fast work that these muscles be well developed. The muscles of the thigh start the propulsion; it is accelerated by the upper muscles of the tibia and the muscles of the gaskin give the final impulse to the stride. They are smaller and shorter than the upper muscles of the hind leg and their action correspondingly quicker. It is therefore important that their development be considerable.

Aside from the rare dislocations of the patella, and fracture of the points of the hips, there are no common injuries to be looked for in the region of the hind leg, above the hock. This joint, however, is very liable to be disabled by an obscure disease, often difficult to discover, and always, when existing, of a nature that makes the animal permanently unsound. This disease is bone spavin.

The hock is a more complicated joint than the knee. It is composed of six bones, five of which are interposed between the tibia and the cannon-bone, and a sixth placed behind them to act as a lever for certain of the tendons of the leg. In Figure 77 the cannon-bone is the bone at the bottom of each drawing. The tibia, leg-bone, is entirely removed. It articulates with the 


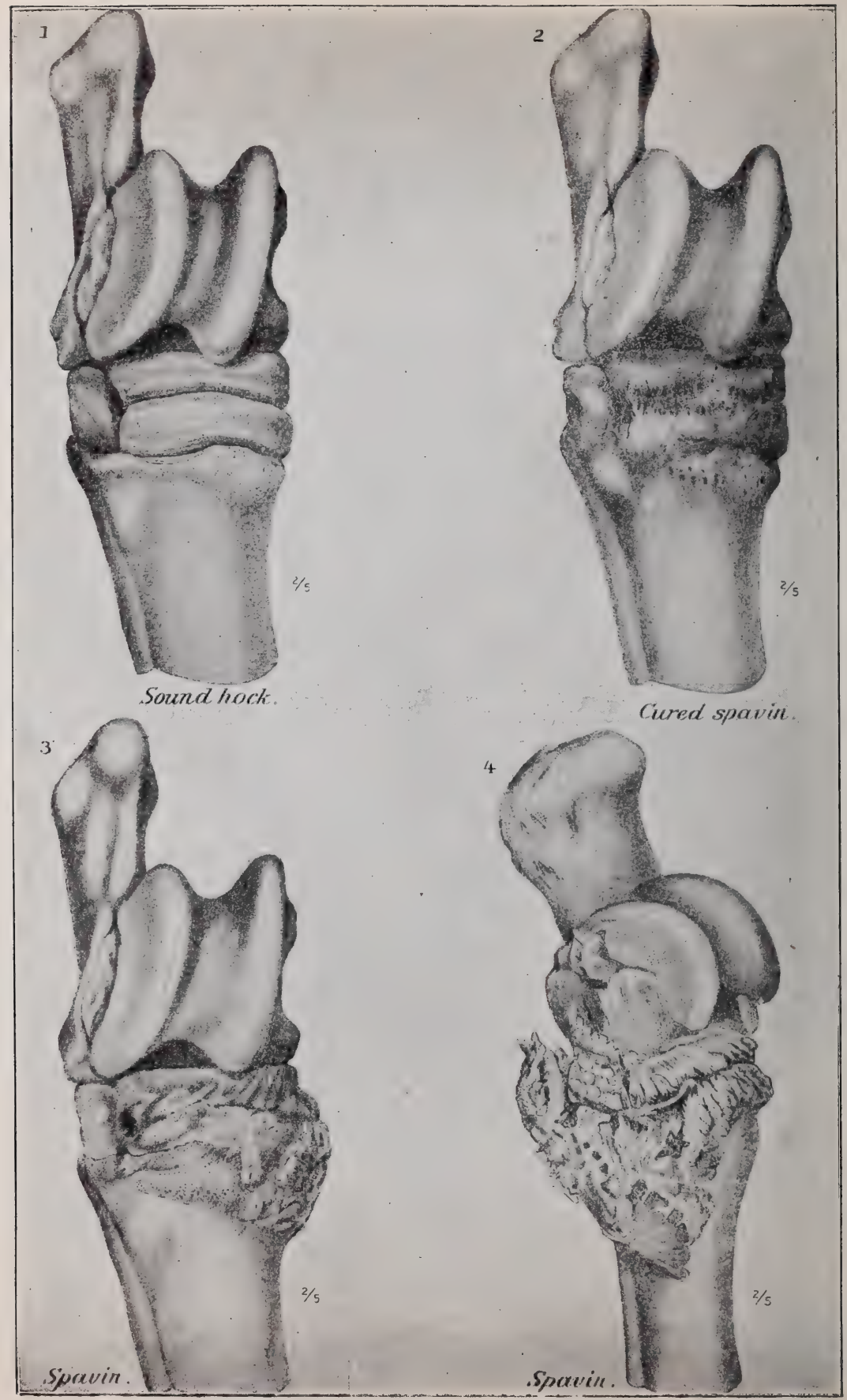

Figure 77.-The Bones of the Hock. 
upper front bone that is so deeply grooved in the cuts. The bone near the numbers $(1,2,3$, and 4$)$, standing back of the others, is the sixth bone referred to, and is the bone that forms the prominence in rear of the hock. The true hock-joint is between the upper bone of the five and the leg-bone; most of the motion of the hock is about this joint, and it is seldom diseased. The other four bones have smaller motions among themselves, but their principal function is to lessen, by the elasticity of their cartilages, the shock of impact.

The properly shaped hock is clean in its outline, with its angularities well defined. The point of the hock should be prominent, and the depressions in front of it should be pronounced; there must be no puffiness about this joint.

The bones are covered with membranes that secrete fluids necessary for their building up and preservation. The cartilages between the bones possess most of the chemical elements of the bones themselves, except the lime and other salts that give the bones their rigidity and strength. When the membranes or cartilages are injured through any cause, inflammation sets in, and the functions of secretion are stimulated. As a consequence, more of the bone salts are secreted than are needed for the maintenance of the bones, and the excess is deposited on the outside, in the form of rough nodules that invade the spaces needed for the proper working of the ligaments and tendons of the joint, or in the tissues of the cartilages, which thereby loose their elasticity and become bone. This deposit may go on until the joint is destroyed by the excess bony deposit cementing the bones together.

In the hock-joint there is a great change in the direction of the energy developed in the propelling muscles, and everything connected with the joints should work smoothly to get the best results. Any strain due to excessive concussion is apt to set up inflammation between the lowest bones of the hock and the head of the cannon-bone. This inflammation, if not stopped 
before the bony deposit begins, results in bone spavin. Its usual seat is shown opposite the upper turn of the letter $\mathrm{S}$ in the word "seat," Figure 78.

The usual treatment of a spavin, after the bony deposit has fairly begun, is to stimulate the deposit by artificial inflammation until the lowest bones are united to the cannon- bone; then to stop the inflammation. Such a spavin is said to be "cured," but it has been cured at the expense of the joint, which has been permanently destroyed. When the spavin occurs between the bones, no visible en-

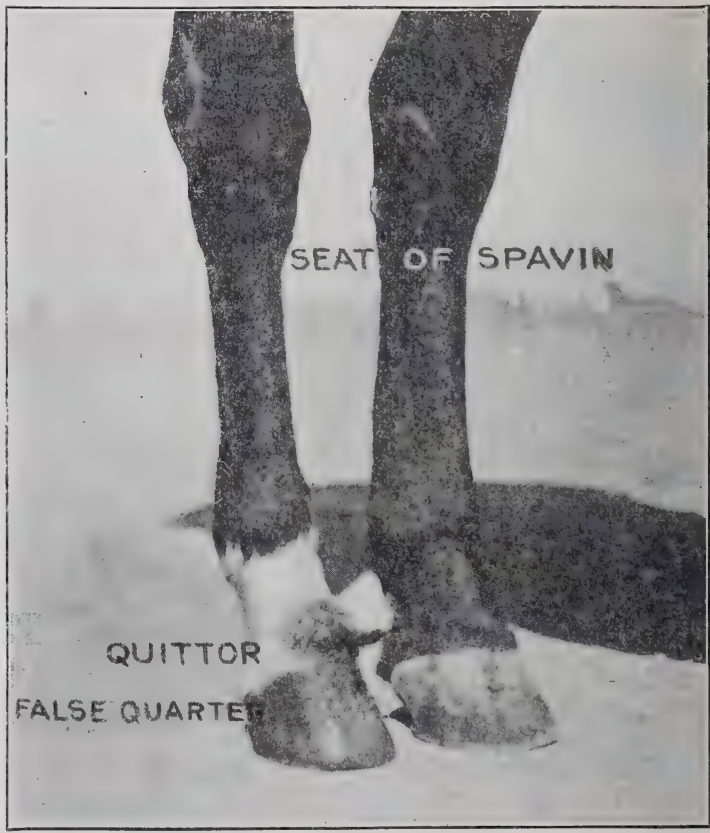

Figure 78.

largement results at first, but distressing lameness, due to ulceration of the cartilage, is caused, that is very difficult to locate. This is an occult spavin.

A spavined horse goes truer after being warmed up. If, after a sharp gallop, in which he travels true, he is allowed to stand for thirty minutes, and then sharply galloped, he will, 


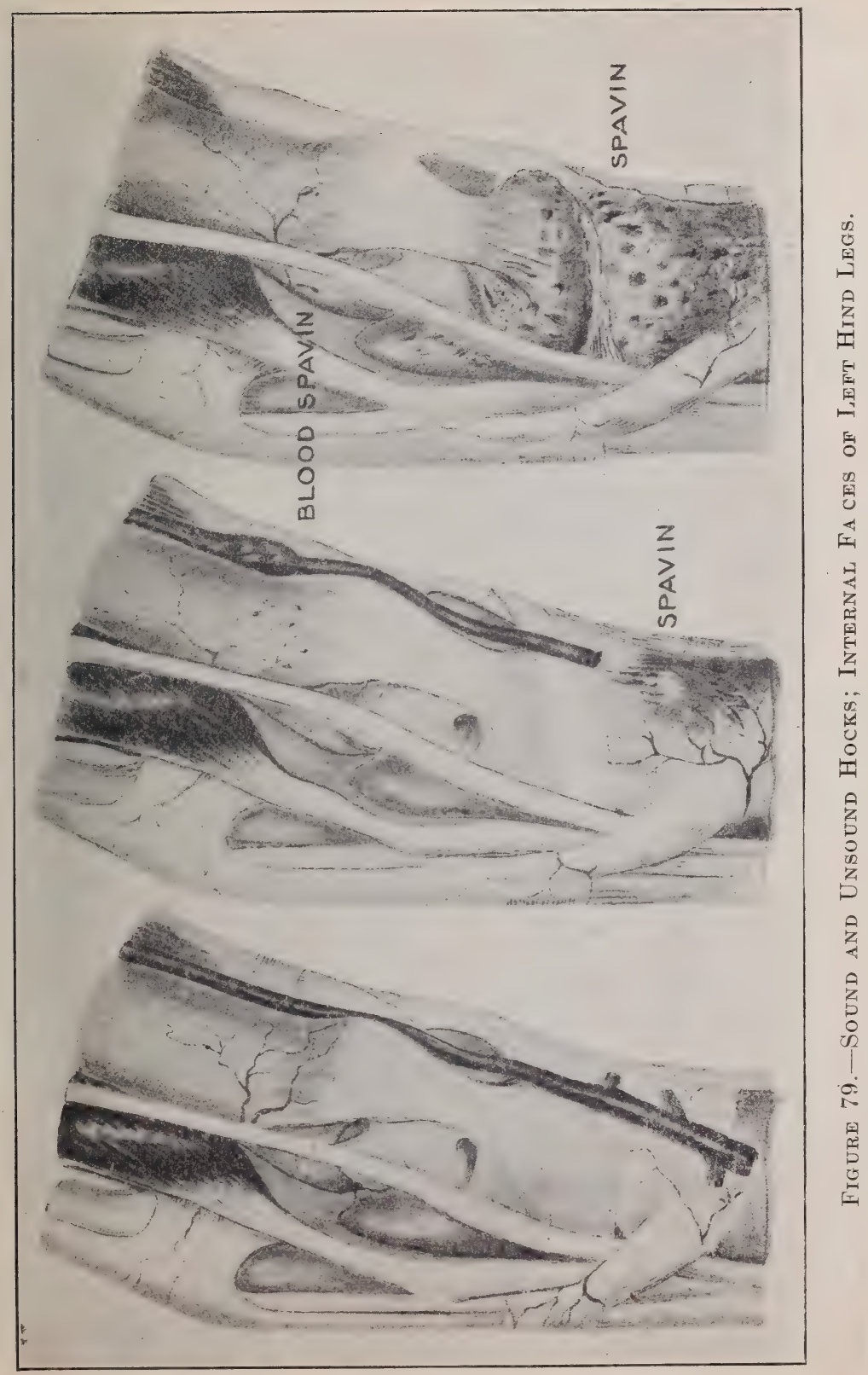


if spavined, go noticeably lame. This is a characteristic of the disease.

If the existence of spavin is suspected, another test is to pick up the foot and bend the hock well, holding the foot up for a minute or so. If the horse travels sound immediately after, he may be assumed to be sound.

Between most of the joints of animals are placed closed membranous sacs, called synovial bursæ, filled with a clear, yellowish fluid, called synovial fluid, or joint oil. Thesesacs are to diminish friction in the joints. Enlargements of these bursæ are called synovial e nlarge me n ts, and are given different names in different parts of the horse's anatomy. About the pasterns, and at the knees, they are called wind-galls; in front of the hock, bog spavin; in rear of, and above it, thorough - pin. None of these enla $\mathrm{r}$ g e m e n t s are, unless very

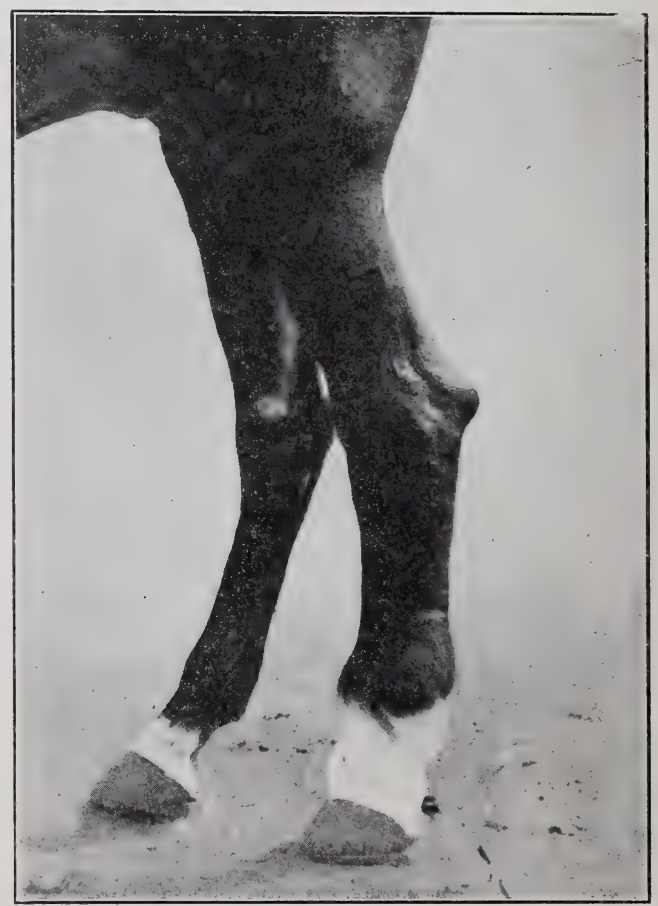

Figure 80.-Capped Hock and Lymphangitis. large or inflamed, causes of lameness. They indicate weakness or defects of conformation. 
Blood-spavin is an enlargement of a large vein running up the leg. It is usually caused by the pressure of a bog-spavin damming the flow of the blood in the vein (Figure 79).

Capped hock, like capped elbow, is, in its first stage, a blister (Figure 80). Its seat is the point of the hock. It is, when first formed, easily removed, causes no lameness, but points to bad stable habits, and is unsightly.

A curb is a protuberance on the back of the hind leg, six inches or so below the point of the hock. It is caused by "a sprain of the tendon, which passes on the posterior of the hock, or of one of its sheaths, or of the strong ligament situated on the posterior border of the upper bone of the hock."*

It is shown by a bulging backwards of the posterior part of the hock, interrupting what should be a straight line between the point of the hock and the fetlock.

The inflammation in a curb, when it first appears, should be subdued by cold applications, and the further treatment of it left to a veterinarian.

Curb is an unsoundness, and a permanent disfigurement. Its commonest cause is making a horse stop suddenly when at a rapid gait, thus throwing an excessive strain on the back ligaments of the hock.

Lymphangitis is a disease of the lymph-ducts (small vessels carrying nourishment to the tissues), near the skin. It is manifested by an unsightly, permanent thickening of the skin. It is not, in its first steps, disabling, but is a serious blemish.

Splints occur sometimes in the hind leg, but less often than in front. The pasterns of the hind leg slope less than those in front. They are more liable to ringbones than the front ones. Sidebones are very rare in the hind foot. 1903.

*Page 349, "Diseases of the Horse," Bureau of Animal ^ndustry, 
Stringhalt is an involuntary jerking up of the hind leg (usually), bending the diseased member more than the sound one. It presents many phases, sometimes showing at the walk only, sometimes at the trot only, sometimes at all gaits. Its cause is unknown. It is very unsightly, is incurable, and usually increases with age.

In conformation the hind leg should be powerful, without being clumsy. The croup should be concave, viewed from side or rear, and the hips not prominent. The tail should be carried away from the buttocks, and should not prolong the curve of the croup. It is noteworthy that a horse possessing courage and mettle always carries his tail well up until utterly exhausted. When his tail drops, while he is in motion, it is a warning to rest him.

Viewed from the rear, there should be a slight concavity between the hips and the stifle, and the stifles should be slightly wider apart than the hips. If the hips are wider than the stifles, and prominent, they are said to be ragged. From the stifle to the hocks, the legs should converge, and the curve of the gaskin should be clean-cut and pronounced (Figure 75). The tibia should be-or should appear to be-very long, and the hocks low, to get great power. The upper bone of the hock-the os calcisshould be pronounced.

For saddle-horses, the hind legs should be "under the croup" - that is, a line dropped from the point of the croup should pass along the cannon, from hock to fetlock, or near it. The legs, from the hock to the ground, should be parallel and straight. If the hocks are nearer together than the fetlocks, the horse is cow-hocked if the hocks are wider apart than the fetlocks, he is said to be open behind. When the cannon slopes to the front from hock to pastern, the horse is sicklehocked. All of these conditions are objectionable. 
The hind legs are less liable to injury than the front ones in saddle-horses not trained to jump, in cavalry-horses, and in polo-ponies, while in hunters and in harness-horses the hocks are the most vulnerable places. 


\section{CHAPTER X.}

\section{THE HORSE'S FOOT.}

The foot of the horse, from a standpoint of comparative anatomy, includes everything below the knee or hock. Practically, horsemen, in speaking of the horse's foot, refer only to the hoof and its contents. The hoof corresponds in its structure to the nail on the toes of other animals.

The foot is one of the most important parts of the horse to study, because it is the seat of so many disabling diseases, practically all of which can be prevented by proper care and use.

The foot is a very complex member. It is built around three bones: the coffin-bone, the navicular bone, and the lower pastern-bone.

The coffin-bone, the lowest bone of all, lies wholly within the hoof. It is wedge-

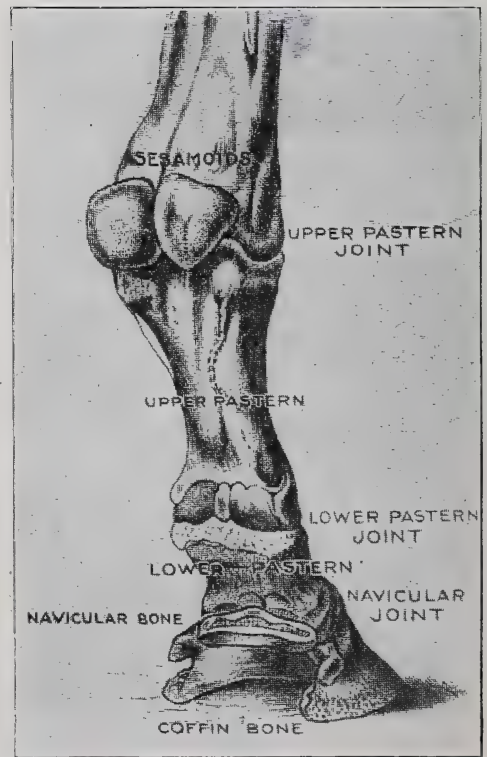

Figure 81.- NoMENCLATURE OF the Bones of the Foot. shaped, concave on its under surface, and cylindrical on the upper sides of its anterior and lateral faces. In rear it branches into two parts, called the wings of the coffin-bone.

Immediately above the coffin-bone, and resting on its highest part, rises the lower pastern- or coronary-bone; and in the 
angle behind the joint, formed by the coffin- and lower pasternbone, fits the navicular-bone. These three bones are bound together by several short, strong ligaments. Two wide and thick pieces of cartilage, continuing the wings of the coffin-bone, called the lateral cartilages of the coffin-bone, fit in behind

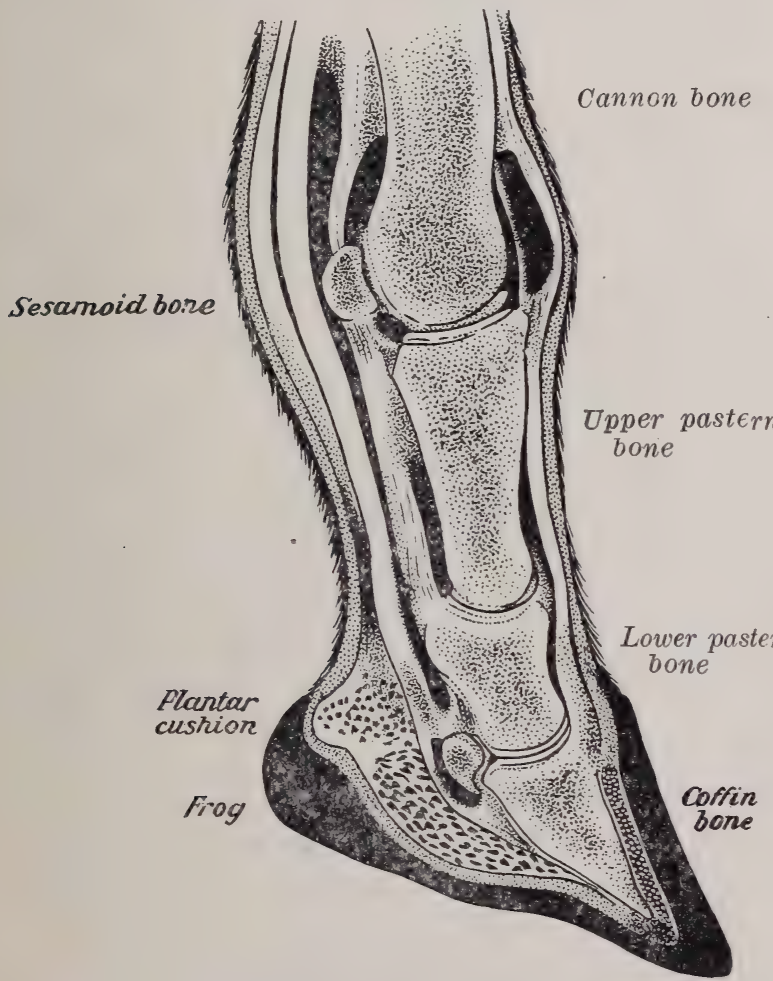

Figure 82.-The Foot in Cross-Section. the three bones, be tween them and the walls of the hoof, and a c t as springs to keep the bones from plung ing too violently into the w e d $g$ e shaped interior of the hoof, when ever the foot strikes the ground.

A large, wide tendon fastens itself to the under side of the coffin-bone, bènds around the roller-shaped navicular-bone, passes behind the coronary-bone, and on up to its muscular development above the knee or hock. This is the principal flexor- 
pulling back - tendon of the leg. Another broad tendon is fastened to the front of the coffin-bone to pull it forward. This is an extensor tendon. Both are well shown in Figure 82.

Under the flexor tendon and the lateral cartilages is placed a soft, highly elastic cushion, called the plantar cushion, that, by its compression between the sole and frog of the hoof on its under side and the tendon and lateral cartilages above it, acts to soften the shock of impact.

Enveloping all the structures above enumerated is the fleshy continuation of the skin, much changed in appearance from that above the hoof. This covering is highly vascular-that is, it is abundantly supplied with nerves and with blood and other vessels that supply the foot. The upper border of this covering is called the coronary band, and along the upper border of this band is another band, called the perioplic ring. Below the coronary band the fleshy covering of the foot is covered with a series of little ridges, called the sensitive la minæ. They fit into corresponding depressions in the inner surface of the wall. These depressions in the wall are called the insensitive la minæ.

On the plantar surface, the fleshy envelope is called the velvety tissue.

The hoof is the nail of the horse. It is composed of three parts - the wall, the sole, and the frog. The wall includes all that portion of the horny box that is visible when the foot is on the ground. The wall is divided into three regions: the toe, in front; the quarters, on the sides; and the heels, in rear. At the heels the wall doubles back, towards the center of the foot, forming the bars. The wall is thickest at the toe and is gradually thinner towards the heels, where it thickens again to form the bars. The outer face of the wall is composed of a great number of filaments, similar to hair in their growth and composition, compacted firmly together with a natural glue, and growing downward from the coronary band. It is covered with a sort of natural varnish that is secreted by the perioplic ring. The 
- function of this varnish is to retain the moisture of the horn, which shrinks on drying and is liable to crack. The interior face of the wall is composed of the insensitive laminæ.

The sole is a horny plate, fitting into the wall, strongly cemented to it and with a V-shaped opening in the back that is lined, for two-thirds the distance from the heels, by the bars above referred to. The ground surface of the sole is arched so

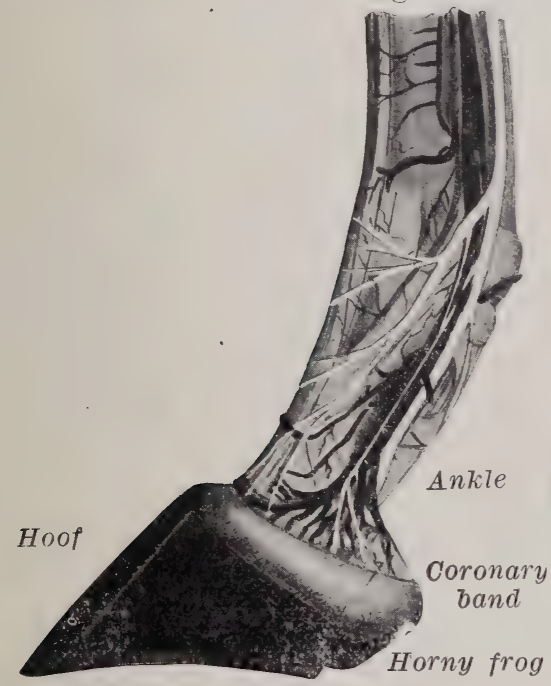

Fig ire 83.- Hoof, Frog, Coronary BAND, AND ANKLE. that, in its natural state, it does not come into contact with the ground.

The frog is a soft, horny wedge, let into the angle $\mathrm{cf}$ the bars and sole, and lying under the plantar cushion.

It is quite dreply clefit at the heels into trio parts that unite towards the angle of the $V$.

W In its natural, healthy state the frog rests on the ground to act as a stay against slipping. For this purpose a healthy frog is much better than any artificial arrangement.

The fore foot is rounder, more spread out, less concare, and a little wider than the hind foot. Its heels are closer together, and the angle of its wall is usually more oblique than the hind foot.

The hoof-wall grows downward from the coronary band. The new growth is always at the top, pushing the old growth downward. This old growth must be removed, either by natural wear, in the unshod horse, or by the blacksmith when the horse is shod. The sole and frog grow in the direction of their own thickness, and surplus growth scales off, unassisted. 
It requires about eight months to grow a new hoof. This growth of wall is faster at the toe than at the heel, and in the unshod horse the wear is greater at the toe, consequently the wall is maintained at the proper height.

The hoof grows faster during a moist, warm season, if the animal is in good health, than it does in dry or cold weather, or when the horse is debilitated. The hoof often shows the effect of the more favorable season by a thickened ring in the horn. Such rings, when of healthy growth, are called grass rings.

When the foot strikes the ground the tendency is to force the coffin-bone down into its wedge-shaped seat. This is prevented by the intimate union between the sensitive and insensitive laminæ (whose folds, if spread to their complete development, would cover more than a square yard), and by the elastic resistance of the frog, the plantar cushion, the flexor tendon, and the lateral cartilages.

The sensitive and insensitive laminæ not only dovetail into each other in the direction of their length, but they are also provided with multiple barbs that also interlock and resist any sliding tendency. All these elastic media unite in receiving the shock of impact and transmit it gradually through the bones and tendons of the legs and to the muscles above for its final decomposition.

The foot itself actually spreads out slightly, and the concavity of the sole is reduced at the moment of impact. For this reason, except when necessary to prevent the undue spreading of the heels while the horse is in motion, shoes should be left open at the heels.

The plantar surface of the foot is shown in Figure 85, after it has been levelled off to receive the shoe. The frog and its cleft are clearly seen. The doubling back of the wall to, form the bars shows plainly at the heels. The line of demarcation batween the sole and wall is shown in the dark line paralleling 
the wall at the toe. The position of this line also shows the thickness of the sole.

A saddle-horse should not have too large a foot. A large foot is characteristic of a slow, lymphatic animal. Its horn is usually less dense than in a smaller foot on a horse of the same size. Such a horse is more liable to diseases of the feet when

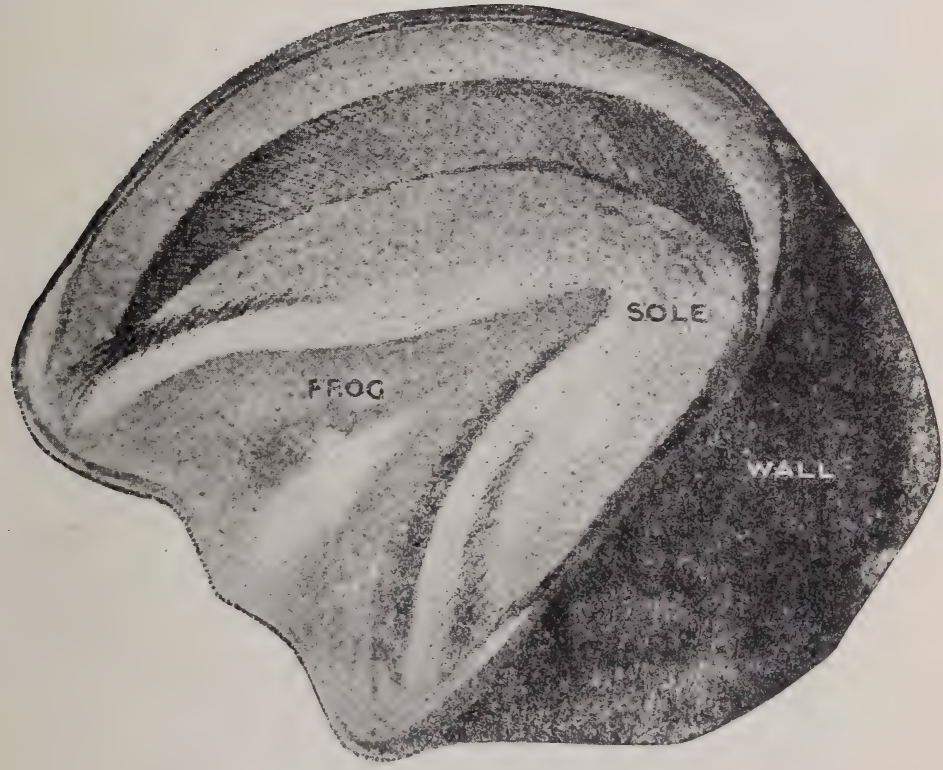

Figure 84.-The Hoof.

the horse is called on to do fast work. Large feet belong properly to draft-horses.

The foot should not be too small, for its smallness will usually be at the expense of thickness of wall.

The feet should be of the same size, allowing for the difference in shape in fore and hind feet, and the angle of the wall at the toe should be about forty-five degrees, getting gradually more nearly vertical as it approaches the heels.

If the angle at the toe is much less than forty-five degrees, the horse is said to be flat-footed. This is usually accompanied by a flat sole and a predisposition to disease. 
A horse that toes-in is said to be pigeon-toed, and outbowed if he toes out. If one foot points to the right or left, while the other one is straight, he is club-footed.

A vertical plane, paralleling the axis of the horse, and cutting the foot at the toe, should split the foot in half, and contain the axis of the leg. In other words, the forearm and cannon should be straight and vertical, and the foot should be set squarely to the front on the same vertical axis. The outer lines of the two forearms usually converge towards the knee, due to muscular development. The column of bones should be straight.

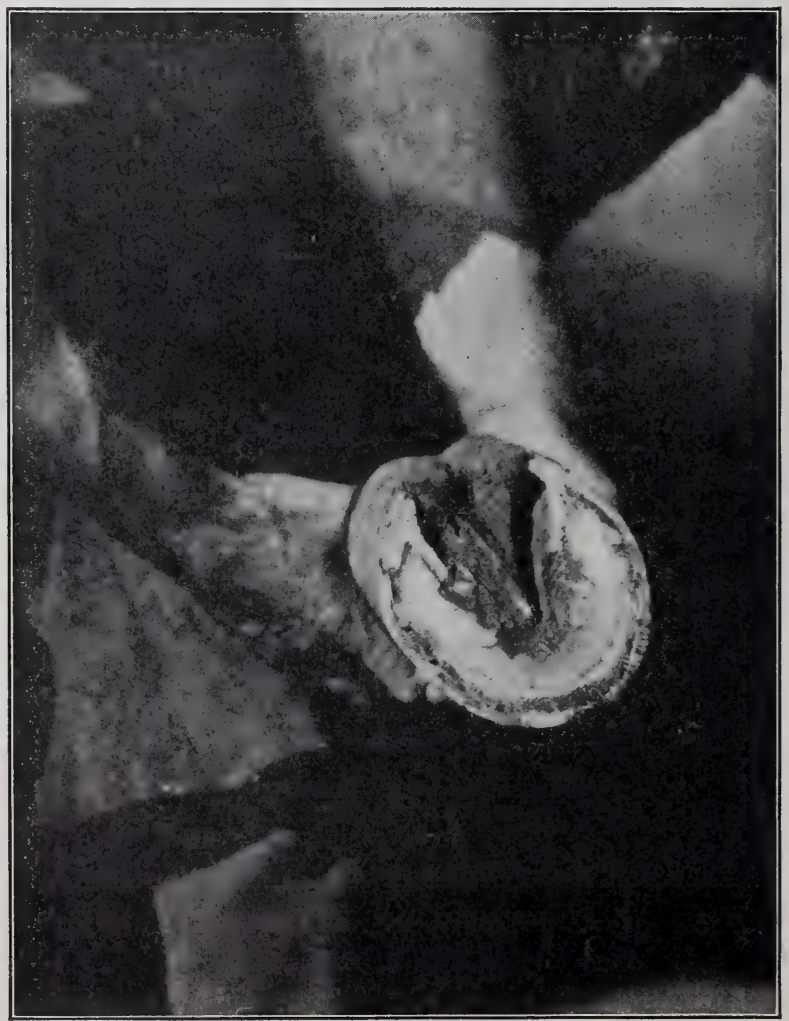

Figure 85.-The Plantar Surface of the Foot. 


\section{CHAPTER XI.}

\section{DISEASES OF THE FOOT.}

As we have seen, there is seldom reason, to suspect disease in the horse in the shoulder or thigh, and only occasionally in the elbow, forearm, stifle, or gaskin. The knee, the hock, and the cannons a re

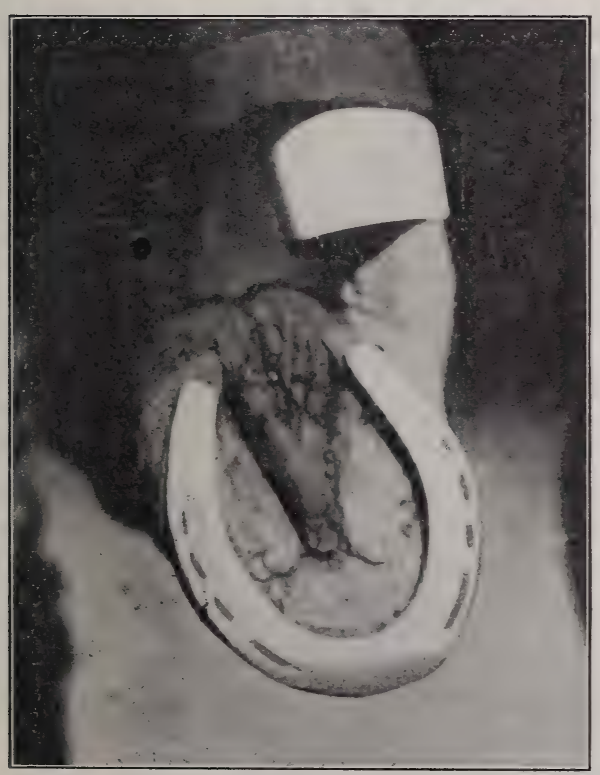
quite often, and the pasterns and feet are especially liable to be the seats of disease. In $\mathrm{th}$ e feet, no part is exempt.

Beginning at the plantar surface, we find a very common disease in inflammation of the frog, called, commonly, thrush.

Thrush is a disease of filth and neglect. The salts of urine have an especially bad influFigure 86. - Thrush and Contracted Heels. ence on horses' feet, and those animals that are allowed to stand in mud-puddles made of the clay of their stalls mixed with urine are very apt to have this disease. It also comes from subjecting the animals to extremes 
of dryness and moisture, from hard work on rough, stony ground, or from being continually working or standing in mud.

The disease first shows itself by a constant moisture and foul odor in the cleft of the frog. If neglected, a thin watery discharge follows, changing into a thick, very offensive discharge; in this stage the frog becomes rapidly destroyed.

The treatment is cleanliness and the removal of the exciting cause. This will usually be sufficient in the first stages. In the late progress of the disease it resists treatment stubbornly, and needs most careful attention. In the absence of a veterinarian, the foot should be thoroughly cleaned, the ragged parts of the frog cut away. The diseased parts should then be dusted with calomel or iodoform, and the cleft packed with oakum. The foot should then be bandaged, to keep out the dirt. If the horse must be used during the day, remove the bandage while the horse is at work, renewing the treatment after the day's work is over. This treatment must continue until the frog is sound.

One of the serious conditions attending this disease is that it is not a cause of lameness until it has reached a very serious stage.

Canker is a disease of the sole and frog that is of germ origin. The canker-germ usually does not attack a sound foot, but is found to be a sequel to thrush or to a punctured wound of the foot. If it originates in a puncture, it is noticed that the wound does not heal, but becomes. more and more aggravated. If it occurs independently of an injury, it is first noticed by its offensive odor, the discharge from the cleft and sides of the frog, and the rotting away of the sole. Surgery is the best treatment.

A corn is a blood-blister in the living tissues of the sole. It is caused by a bruise to that part of the sole between the bars and the wall, where the sole is thinnest. If the horse goes lame in one leg, without apparent cause, his shoe should be pulled, and the seat of corn pared out. If, instead of showing white, the sole shows a discolored spot, with reddish streaks - inflamed 
capillaries-radiating from it, the trouble is from a corn. The treatment is to cut out the sole immediately over the corn, to keep the shoe from bearing on it.

The fore feet are almost exclusively subject to corns. While in motion, the horse strikes the ground first with the heels of his fore feet and with the toes of his hind feet.

If the seat of corn is repeatedly bruised, as is the case when the shoe is left on too long, and the heel bears directly on the seat of corn, it often suppurates, and the inflammation spreads to the velvety tissue and the laminæ. This is an uncommon and extremely serious phase of the disease.

A bruised sole is a similar trouble, resulting from a severe blow to the sole. It is very difficult to locate, and can only be cured by rest, and, when suppuration results, by surgery.

Contracted heels is a common disease among all classes of horses, but especially among saddle-horses. It is a result of diseases that cause the destruction of the frog, or of a wasting away of the frog from disuse, as in the case with horses habituall $\Lambda$ shod with calks. The heels, robbed of the support of the healthy frog, pinch in together (Figure 86). The only remedy is to restore the frog, and usually this is impossible.

Cracked heels, or scratches, is a disease similar to the familiar chapped hands. Its location is in the tender skin over the heels and under the fetlock. It is easily recognized by longitudinal cracks in the skin, showing red under at first. If neglected, the fluids that escape will dry and form thick crusts on each side of the cracks. The cracks often become infected and suppurate. Similar cracks at the bend of the knee and hock, called, respectively, malanders and salanders, sometimes appear, and, in certain badly neglected cases, these regions unite, presenting a most loathsome aspect. Scratches are almost always caused by filth, neglect, or bad treatment, and are curo $d$ by cleanliness and dryness. Extreme cases need expert treatment. 
A good treatment for the first stages of the disease is to bathe the part until it is clean, dry it well, and apply carbolized vaseline locally. This dressing must be frequently changed, as dust adheres to it and, if left on after it becomes caked with dust, it may do more harm than good. The patient must be rested, as the cracks open with each step the horse takes.

Horses that are tied by so long a rope that they can tangle their hind (very rarely the fore) foot in it, will usually struggle to free themselves, and often seriously chafe the tender skin under the fetlock; such a chafe is termed a rope-burn. Because of their position and the difficulty of keeping the part at rest, they are tedious to heal, and, when healed, leave unsightly scars. Ropeburns are merely blemishes when they heal without causing stiffness in the action. On account of their unsightliness, it is best to prevent them by watching horses that are picketed out very carefully until they have learned how to avoid burning themselves. In the stables, care should be taken that a horse is tied short enough that he cannot get his hind foot over the rope.

Brushing, cutting, or interfering are names given to indicate an injury to the fetlock of either a fore or hind foot, done by striking the fetlock with the opposite foot. They are caused by improper shoeing, weariness, or defective action, and are prevented by proper shoeing or by the use of boots or socalled interfering straps.

Forging, or clicking, is the striking of the under side of the shoe or the sole of the front foot by the toe of the hind hoof or shoe on the same side. It is caused usually by defective action. The front foot is slow in recovering from a stride and is struck at the instant it is most bent to the rear. The theory has been advanced that the horse does it willfully, because he likes to hear the click as the shoes come together. It is corrected by special shoeing.

Coronitis is the name for inflammation of the coronary band. This disease is usually the accompaniment of some other disease of the foot. 
Wounds or bruises of the coronet are known by the general name of treads, because they come usually from being stepped on. Treads are dangerous when they affect the extensor tendon, or when they injure the joint between the coffin-bone and the coronary-bone. A tread must be kept,very clean, and infection

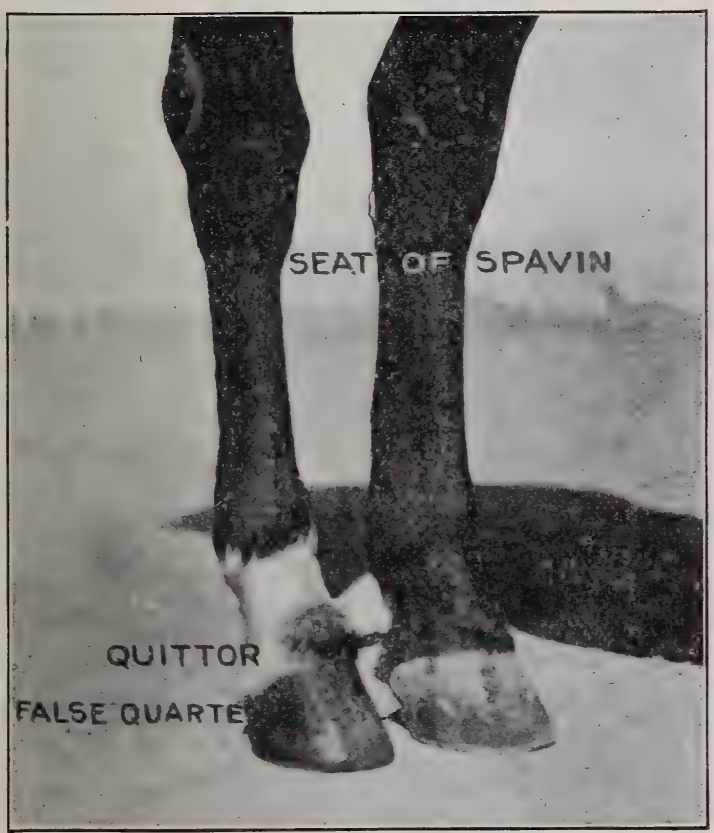

Figure 87.-Quittor and False Quarter. must be very c.a re fu 11 y $\mathrm{g} u$ a $\mathrm{r}$ d e $\mathrm{d}$ against by the use of antiseptic dressings - as iodoform, calomel, or car bolized vaseline.

If the tread is serious enough to destroy part of the coronary b a nd, the part of the hoof that was supplied by the destroyed part fills in, in an irregular way, from the sides and from beneath, and a malformation called false quarter results.

A puncture is a wound to the foot, caused by a nail or other sharp object being driven into the sensitive parts of the foot.

Any infection within the rim of the hoof, resulting in suppuration, forms an abscess that cannot drain downward. As 
the pus accumulates it is forced upward usually until the sinus reaches the rim of the coronary band, where an open sore results. Such a sore; a fistula, is called a quittor. Frequently, in the history of quittors, the sole is finally penetrated by the pus, and natural drainage results. A quittor is almost always the result of neglect, and in its most frequent form is the result of a neglected tread.

Cracks in the hoof running up and down are termed sandcracks when in the toe-usually in the hind feet, and quartercracks when on the inside-usually on the front feet. The outside of the feet is seldom cracked. Cracks are usually caused by defective shoeing or by excessive dryness.

Sidebones are the ossifications resulting from inflamed lateral cartilages. These cartilages help receive and distribute the shock of impact. Inflammation causes bony deposits to replace the cartilaginous tissue. These deposits often grow to be noticeably large.

Navicular disease is the result of an injury to the navicular-bone or to its coverings or attachments that either fractures the bone or sets up destructive inflammation in it.

The navicular-bone is a little roller-shaped bone, lying in the posterior angle between the lower pastern-bone and the coffin-bone. The perforans tendon is fastened to the under side of the coffin-bone. It bends over the navicular-bone, passes behind the pastern, and, bending again over the sesamoids, goes upward to its muscular development above the knee.

This tendon transmits much of the shock of impact. The navicular-bone, pinched in between it and the other bones of the foot, is subjected to tremendous pressure at every stride. Its surface must be smooth and well lubricated in order that the tendon perforans may slip smoothly over it, in response to the action of the muscles controlling it. If the pressure of the tendon is too great for the health of the bone, it breaks, or its envelope becomes inflamed and its structure changes. Its 
surface becomes rough and chafes the sheath of the tendon, and, as the bone is inaccessible to the surgeon, the evil done is irremedial. Navicular disease is incurable and very painful. In order to render the horse unconscious of this pain, and so

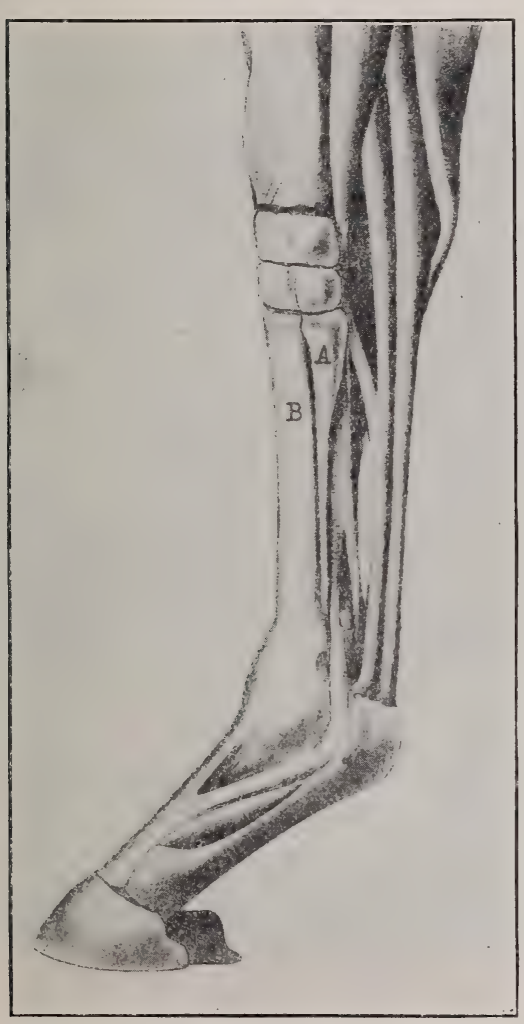

Figure 88. prolong its usefulness until a complete breakdown occurs, a portion of the sensory nerve supplying the foot is removed by an operation called neurotomy.

"In the early stages of navicular disease the symptoms are generally very obscure. When the disease begins in inflammation of the navicular bone, the animal, while at rest, 'points' the affected foot a time before any lameness is seen. While at work, he apparently travels as well as ever, but when placed in the stable, one foot is set out in front of the other, resting on the toe, with fetlock and knee flexed. After a time, if the case is closely watched, the animal takes a few lame steps while at work, but the lameness disappears as suddenly as it came, and the driver doubts if the animal was really lame at all. Later on the patient has a lame spell, which may last during the greater 
part of a day, but the next morning it is gone; he leaves the stable all right, but goes lame again during the day. In time he has a severe attack of lameness, which may last a week or more, when_a_remission takes place, and it may be weeks or months

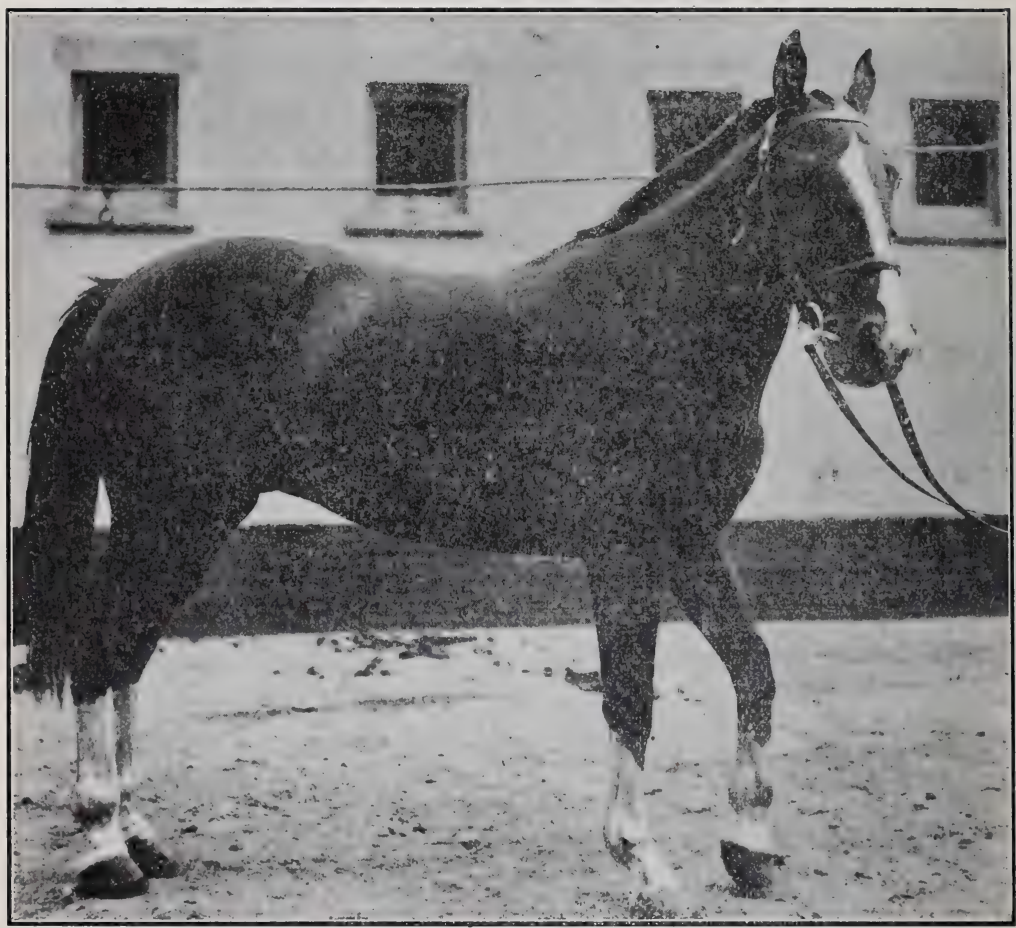

Figure 89.-Pointing a Toe for Navicular Disease:

before another attack supervenes. Finally, he becomes constantly lame, and the more he is used the greater the lameness." ** The polo-pony pointing his toe in Figure 89 went through the phases described above exactly. The first long attack came 1903.

*Page 410, "Diseases of the Horse," Bureau of Animal Industry, 
on during the early spring, and he recovered from it before the polo seasoned open. He played a fast game every fine day during the season. His second attack came on during the next winter and lasted several weeks. The following spring he played well for two months, and then went permanently lame.

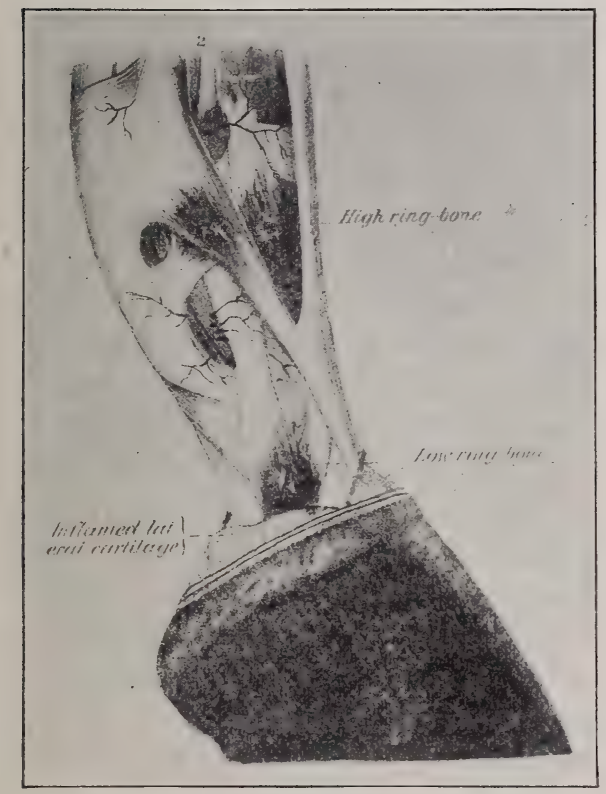

FiguRE 90.

Navicular disease does not attack the hind feet. (There are but two cases on record, according to Möller, an eminent German veterinarian.)

A ring bo ne (Figure 90) is a bony growth on the ankle. It is not a disease in itself, but, like bone spavin, is a result of inflammation in boneproducing tissues. Ringbones a r e caused by blows, sprains, overwork, too fast work on hard roads, jumping, and the like. Horses whose pasterns are too short and upright are more liable to the disease that causes ringbone than those with long, elastic pasterns.

The first symptom is lameness. A puff, hot and harder than the ordinary wind-gall, is noticeable. The ringbones that develop under the extensor tendon or near the navicular joint 
are the most distressing, and are almost sure to produce incurable lameness. Those on the side of the bone, or high up on the upper pastern, are sometimes called false ringbones, and do not always cause lameness. A ringbone is difficult to diagnose in its early stages, but in its full growth can be easily seen and felt. The treatment for ringbone is the same as for spavin. If the ringbone interferes with the action of the extensor tendon or the navicular joint, recovery is impossible. A horse suffering from ringbone in front points his foot by resting it on the heel.

Founder, or la minitis, is inflammation of the sensitive laminæ of the foot. Like all inflammation in soft tissues, it is accompanied by congestion. The excess of blood fluids causes great pressure to be brought on the outer face of the coffin-bone, sufficient in very severe attacks to force that bone through the sole, causing dropped sole. In acute attacks the horse gives every evidence of suffering great pain. He is very lame, the pulse and temperature rise rapidly. He breathes rapidly, with nostrils open and heaving sides. He refuses food, but drinks copiously. The coronets and ankles are hot and dry, and the artery of the fetlock throbs noticeably.

If only one front foot is affected, he relieves that foot of as much weight as possible by advancing it and resting it on its heel. When urged forward, he either carries the lame foot in the air, hopping from the other, or he puts it carefully forward on its heel and quickly advances the other of the pair. He has great difficulty in turning towards the side of the lame foot.

If both front feet are affected, the animal will be very hard to move. He advances by cautiously planting the fore feet and then quickly brings his hind feet well forward. When standing, he rests his head on the manger or hangs it down nearly to the floor.*

*The discussion of founder is condensed from Dr. A. A. Holcombe's article on Diseases of the Fetlock, Ankle, and Foot, "Diseases of the Horse," p. 417, et seq. 
If the hind feet are affected, they are planted well to the front to bring the weight on the heels, and the fore feet are carried back, supporting as much of the weight as possible. It is extremely difficult for a horse foundered behind to move at all. All four feet are seldom affected at the same time.

In mild cases the attacks last but a day or two. More serious cases run their course in one to two weeks. The more often the cases recur, the longer will be the period of recovery.

The causes of founder are many and apparently unrelated. Concussion is a prolific cause; over-exertion when tired, and exhaustion, are equally prolific. Rapid changes of temperaturesudden cooling after becoming very hot, either by watering the horse copiously, or by standing him uncovered in a draft-is a very common cause and the one most easily prevented. Neglect of "cooling out" a hot horse in summer might cause laminitis; in the winter the same neglect would be more apt to cause congestion of the lungs, followed by pneumonia.

Chronic laminitis is the result of continued attacks of laminitis. There is always fever in the feet. Due to the inflammation, more horn is deposited than the hoof needs; it is of poor quality, and the hoof becomes misshapen and scaly. Rings, showing this morbid growth, appear in the hoof. These rings usually correspond to each acute attack. They are roughly parallel to the coronet, as shown in Figure 91. The altered position of the coffin-bone is also shown there. These rings are easily distinguished from the grass rings in a healthy foot, referred to in the last chapter.

Seedy toe is a cavity in the horn, usually in the toe, due to a loss of secreting power in the laminæ. It is usually a result of founder.

The anatomy of a horse is such that the muscles of the foreleg are at rest when he is standing squarely on both front legs. This is not true behind, where he supports his weight alternately on each leg, resting the other on its toe. 
A horse that does not stand squarely on a front foot is said to point it. If he points it on the toe, the trouble will be found in the flexor tendon, or on some tissue that it works against, not in the laminæ. Hence, a horse pointing on his toe is suspected of navicular disense or strained back tendons. A horse having corns would point on the toe. If he rests it on the heel, it is to relieve pain in the laminæ or under the extensor tendon, and he is suspected of founder or ringbone.
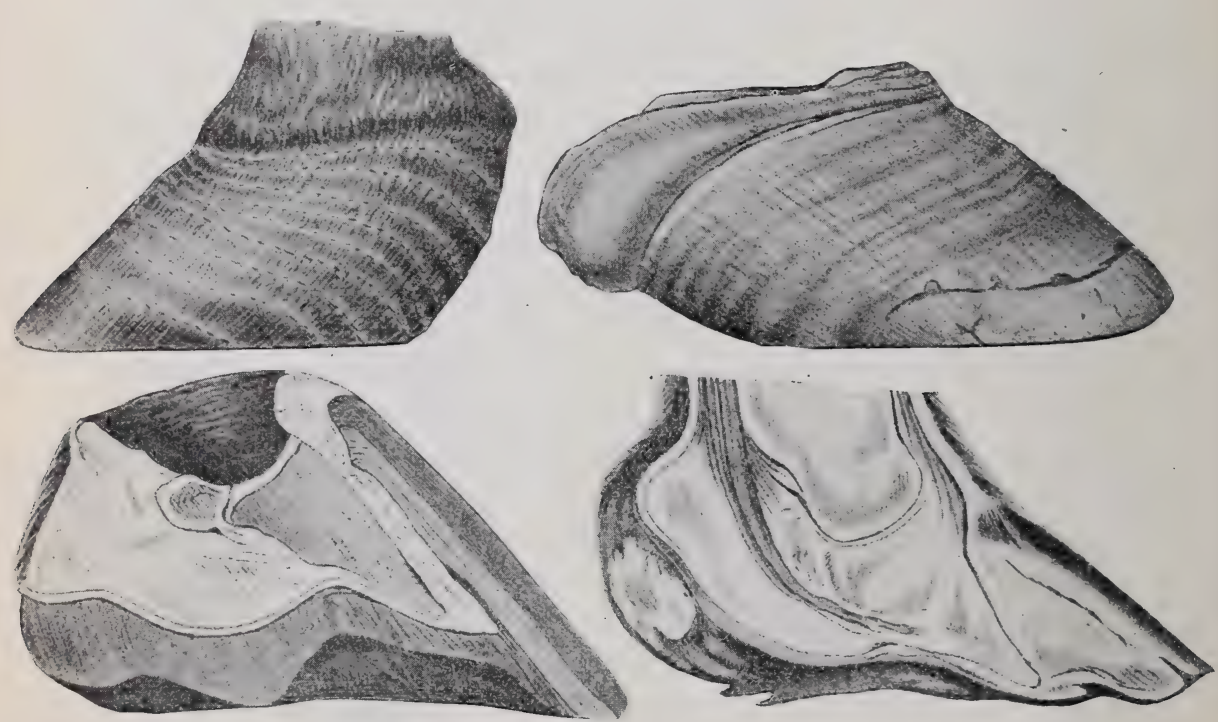

Figure 91.-Foundered Feet 


\section{CHAPTER XII.}

\section{THE PRINCIPLES OF HORSESHOEING FOR HORSES WITH ORDINARY FEET.*}

As has been shown in Chapter $\mathrm{X}$, the horse renews his hoof in about eight months; and that the surplus growth of the horn of the wall must be removed, either by the wear resulting from the

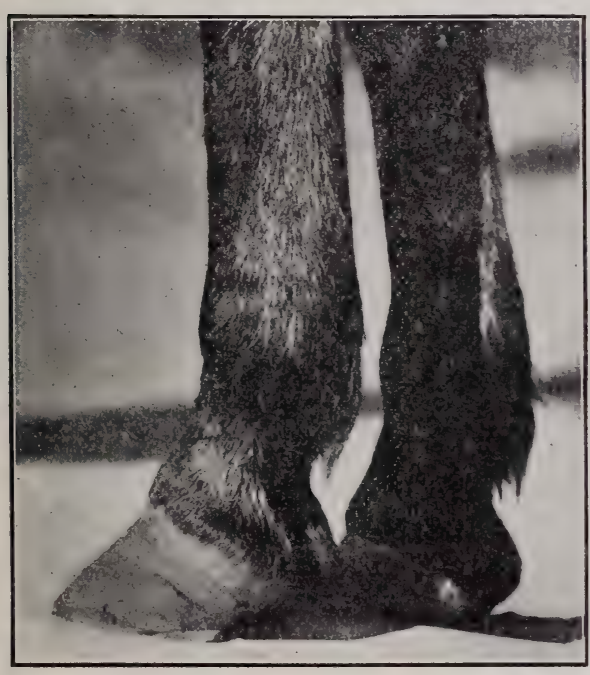

Figure 92.-Appearance of a Shoe, LEFT ON TOO LONG natural movements of the horse, or by artificial means, while the surplus growth of the sole and frog scales off of itself when no longer needed.

The horn of the horse's hoof, while quite enough protection for sensitive tissues beneath while the horse is at pasture, is not sufficient while he is at work, and the artificial protection of the horseshoe is necessary.

The shoe protects the wall from wear, and consequently is carried by the wall, in the latter's growth, away from the sole. The wall

*This chapter is adapted, by permission, from Fitzwygram's "Horses and Stables," 1901 edition, making on:y such changes as are demanded by our Cavalry Drill Regulations. 
grows much faster at the toe than at the heel, dragging the shoe forward slightly, and gradually changing the angle the coffin-bone makes with the pastern-bone. This has the effect of diminishing the work of the extensor tendon at the expense of the flexor tendon. Not only is this equilibrium destroyed by leaving the shoe on too long, but the heel of the shoe

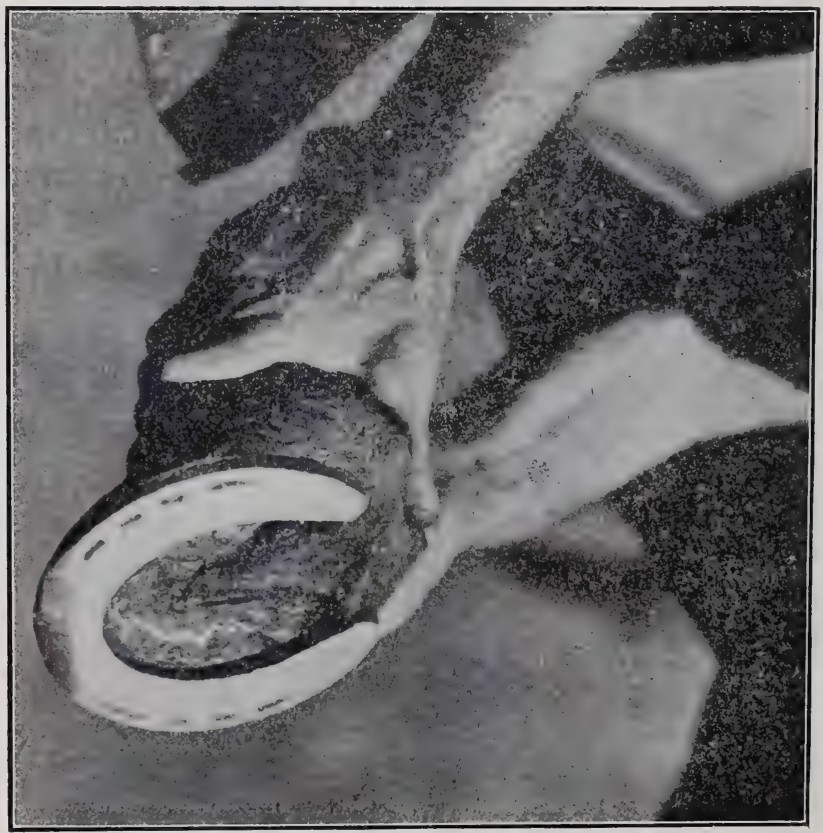

Figure 93. - Shoe on Too Long

gradually bears more and more on the seat of corn, rendering lameness from corns extremely liable.

Experience teaches that four weeks is the safe limit to leave the shoe on without re-seating it. This gives importance to the first rule in the care of the horse's feet:

All shoes to be remoyed at the end of a month's wear. 
Figure 93 shows a shoe that has been on about seven weeks. The frog has shrunken and the shoe is brought forward. The worn appearance of the toe would lead to the belief that the horse is a stumbler.

All shoes have the fault of preventing the natural expansion and contraction of the foot, due to the elastic action of its tissues. To restore this elasticity and to rest the foot, the following rule should always, when possible, be observed:

After shoes are removed, the horse should, if practicable, be left barefoot for twenty-four to forty-eight hours.

Proper use, proper feeding, and proper shoeing understood, no practice will prolong the period of usefulness of a horse, or do as much to prevent lameness, as this one.

Any stableman of intelligence can be shown in an hour how to take off shoes properly. It is an easy matter, the day before a horse is to be shod, for the stableman to take off his shoes and pinch off the surplus wall. Even if he must be shod the next morning, the rest over night will do him much good.

Before removing the old shoe, each clench should be carefully and fully raised (Figure 94).

The careful and complete raising of each clench is necessary to avoid injury to the crust. If the clench is not raised, a part of the crust will be torn away as the nail is drawn, and the wall weakened by so much.

After raising the clenches, the blacksmith next loosens the shoe with the pincers, beginning at the heel. When all the nails but the front one on one side are loosened, he begins at the other heel, working towards the toe again. Having loosened all the nails but the front ones, he seizes the shoe at one of these nails and pries towards the heel. If the blacksmith finds the shoe coming off "hard" he should examine it to see that two or more of the nails have not been driven obliquely, in which case there 
is danger of pulling out a wedge-shaped portion of the crust. In such a case the nails must be pulled separately.

The seat of the newly-set shoe is on the wall at the level of the sole, bearing slightly on the sole. This surface must be prepared most carefully for the shoe by levelling it off so that it is a perfect plane and at right angles to the axis of the foot. In lowering the wall the following rule should be strictly adhered to:

The wall to be lowered to the level of the sole with the pincers, never with a knife.

A line can be followed better and easier with cutting pincers than with a knife. More than that, the proper use of the pincers insures that the wall will be brought down evenly to the sole all around.

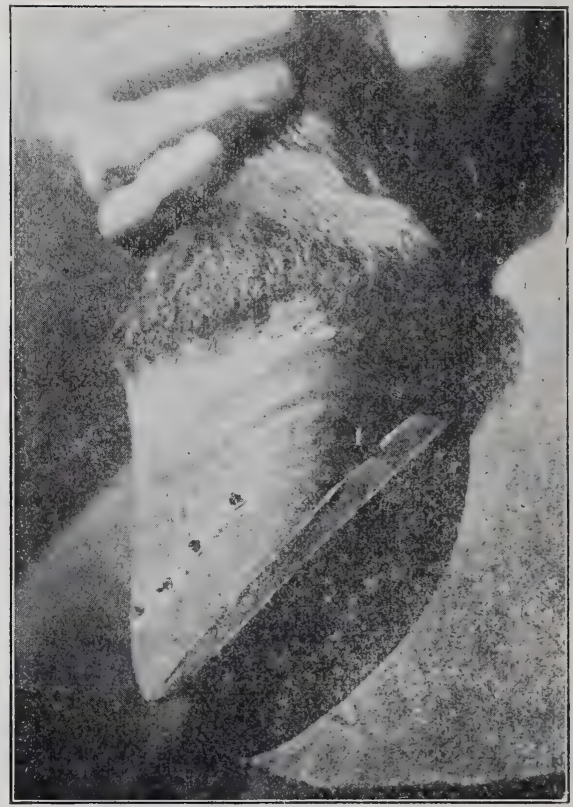

Figure 94.-Clenches Raised.

In the mechanical part of the shoeing it is of the highest degree important that the shoe be put on so that the foot will rest squarely on the ground, and also that the normal height at heel and toe be maintained. The blacksmith, after he has levelled the foot to the sole all around, should put the foot on the floor and verify its bearing before going further. He should also carefully observe any unusual thing in the conformation of the foot. 


\section{Rasp the wall down level with the sole.}

This is to remove the irregularities left by the pincers, and insure for the shoe a bearing surface on both sole and wall. When the surface has been made level, blunt the sharp outer edge of the crust with the rasp.

It has been advocated that the elasticity of the horse's foot is increased by cutting away the bars-" opening out the heels," it is called. This practice is common enough to make necessary the following rule:

\section{The bars are not to be cut away.}

The bars are Nature's support against contraction of the heels and must on no account be cut away. Nor must the sole in the space between the bars and the wall be cut away. This filling-in of the interspace acts as a support to the bars and wall against contraction of the heels. The practice of opening the heels cannot be too severely condemned.

The frog, if healthy, is not to be pared or even trimmed.

The frog, like the sole, requires only to be let alone. It is Nature's pad, or cushion, to lessen concussion in the upper structures when the foot comes to the ground. It can never grow too big. It thrives on concussion. If pared, and thereby deprived of use, it dwindles away.

The frog, when well developed, also acts as a stay against. slipping. A good sound frog is a better stay than calks. If the frog has become injured and is ragged, the ragged parts only should be carefully cut away.

\section{Do not burn out a seat for the shoe with a hot shoe.}

The seat of the shoe may be lightly touched with the hot shoe to mark its inequalities. The marked portions should then be rasped down. To burn out a seat for the shoe dries up the horn of sole and wall, kills living cells that are necessary to the strength of the hoof, and causes the sole to dry out and shrink 
away from the shoe. It is a bad practice that is resorted to only by lazy horseshoers. It should not be tolerated.

Figure 95 shows a foot that has been prepared for its shoe in a very common way, but in a way that violates the last three principles. The sole has been pared out, the wall cut down too much, the frog trimmed, the bars cut away, and, to complete the iniquity, the seat for the new shoe has been burned out.

All of these abuses are easy of detection, except the last, by a very casual inspection of the shod horse.

All shoes should be flat to the sole, not seated in.

Make the shoe to fit the foot, neither longer nor smaller nor wider than the wall, except at the heels, where it may be not to exceed one-eighth of an inch wider than the crust. This

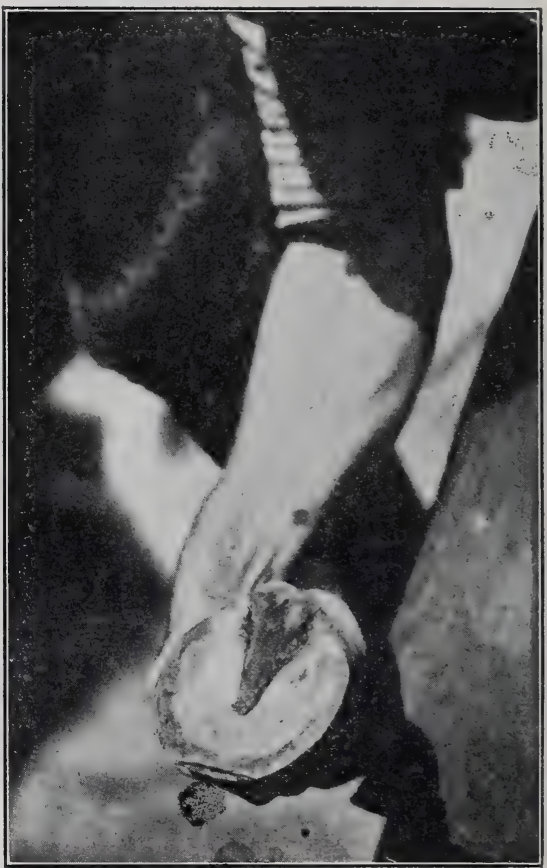

Figure 95.

Sole pared out, bars cut away, seat for shoe burned in with a hot shoe. last provision is to cause the shoe to keep its bearing as the growth of the wall brings it forward.

Five nails are sufficient, three on the outside and two on the inside. 
The front nail on each side should be in the anterior portion of the quarter, and the other nails should equally divide the distance to the heels. This rule is a flexible one.

When a nail has been driven, the point should immediately be twisted off, to prevent possible blemishes to the other feet in case the horse should struggle. After the nails are all driven, the clenches are turned slightly and evened with the rasp, to make them the same length. A slight groove is then made on the under side of the clenches in the horn and the clenches bent into the groove.

Clenches should not be rasped after being turned down.

They should be carefully flattened with the hammer. Any filing, in addition to injuring the enamel, lessens the power of holding.

Except to make this groove for the clenches, the rasp should not be used on the outside wall of the foot. Roughness in the clenches can be smoothed by light taps of the hammer. Rasping the outside of the hoof removes the enamel that is there to keep the foot from losing its moisture by evaporation; in the subsequent drying and shrinking the hoof is often cracked.

The shoe should be neither too large nor too small, but should fit the outside of the hoof perfectly in front of the rearmost nails. In rear of these nails the shoe should gradually broaden, to keep the ends from bearing on the seat of corn as the shoe is brought forward, and to leave room for cleaning the hoof between the frog and wall.

If the shoe is too small-the most common fault-the blacksmith will trim the foot down to fit the shoe, a process called dumping and thereby greatly weaken the wall. The nails, too, are driven too near the sensitive tissues, and there is danger of pricking. Even if the nails do not actually reach the sensitive laminæ, if driven too near it, they will, by their pressure, 
irritate the laminæ and cause lameness. Such a foot is said to be nailbound.

The other extreme- - having the shoe too large - is also liable to be injurious, because of the danger that the shoe may be stepped on, or otherwis e dragged off, or that the horse may stumble.

$\mathrm{B}$ e c o n stantly. on th e watch for $100 \mathrm{se}$ shoes, a nd have them properly removed as soon as discovered.

If the shoe is cast, nails are apt to be left in the hoof or a portion of the hoof may be pulled off with the

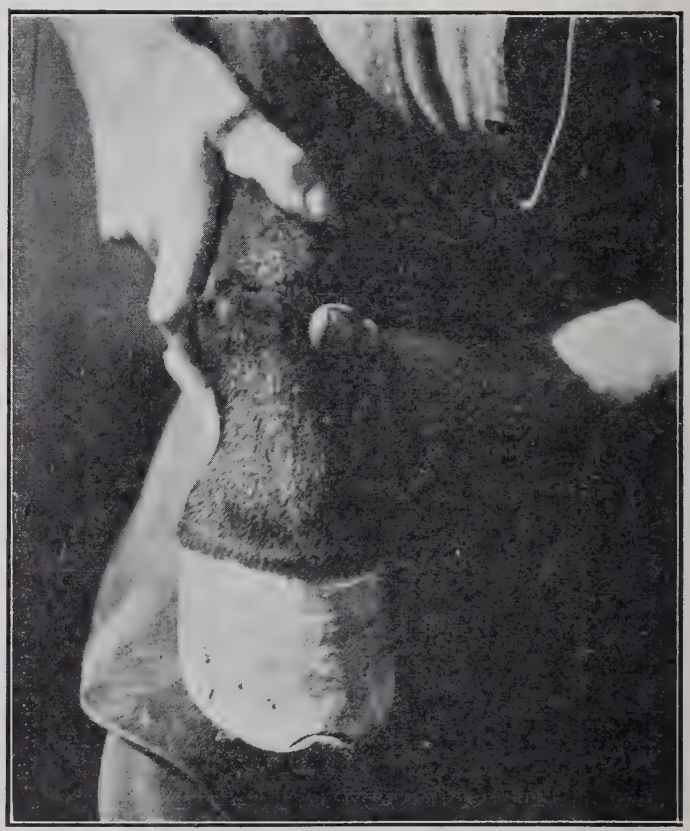

Figure 96.

Shoe too small; wall and clenches rasped away. Note marks of the rasp. shoe. When a shoe is removed, have the other one of its pair, front or rear, removed also, unless the shoe can be soon replaced. The horse travels and walks better when his legs are the same length.

What to look for in a newly-shod horse:

I. No mark of the rasp on the hoof. 
2. That the sole has not been pared out.

3. That the frog, unless it was ragged, has not been trim med.

4. That the bars have not been cut away.

5. That the seat of the shoe has not been burned out.

6. That the nails have been put in as regularly as the state of the crust will admit of.

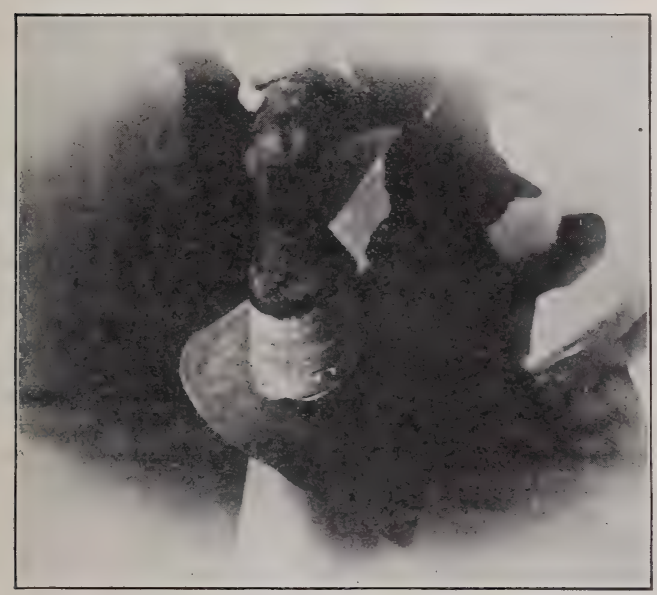

Figure 97.

Shoe too large; nails brought out too low down.

7. That the nails have been brought out one inch above the shoe, in the normal foot. In flat feet they should appear a little less than an inch from the shoe.

8. That the shoes are neither larger nor smaller than the wall, nor longer than the hoof.

9. That the feet are the same length.

10. That the nails fit the nail-holes accurately.

II. That the clenches have not been rasped after being turned down. 
The following extract from the article by John W. Adams, A.B., V.M.D., found on pages 565-569, "Diseases of the Horse," gives an outline of the properties of horseshoes, and the special peculiarities of the chief classes of shoes:

"The shoe is an artificial base of support, by no means ideal, because it interferes, to a greater or less degree, with the physiology of the foot, but indispensable, except for horses at slow work on soft ground. Since a proper surface of support is of the greatest importance in preserring the health of the feet and legs, it is necessary to consider the rarious forms of shoes best adapted to the different forms of hoofs. Certain properties are common to all shoes and may be considered first. They are form, width, thickness, length, surfaces, borders, fullering, nail-holes, and clips.

"Form.-Every shoe should have the form of the hoof for which it is intended, provided the hoof retains its proper shape; but for every hoof that has undergone change of form we must endeavor to give the shoe that form which the foot originally possessed. Front shoes and hind shoes, rights and lefts, should be distinctly different and easily distinguishable.

"Width.-All shoes should be wider at the toe than at the ends of the branches. The arerage width should be about double the thickness of the wall at the toe.

"Thickness.-The thickness should be sufficient to make the shoe last about four weeks and should be uniform, except in special cases.

"Length.-This will depend upon the obliquity of the hoof, viewed in profile. The acute-angled hoof has long over-hanging heels, and a considerable proportion of the weight borne by the leg falls in the posterior half of the hoof. For such a hoof the branches of the shoe should extend back of the buttresses to a distance nearly double the thickness of the shoe. For a hoof of the regular form, the branches should project an amount equal to the thickness of the shoe. In a stumpy hoof, the shoe need not project more than one-eighth of an inch. In all cases the shoe should cover the entire 'bearing surface' of the wall.

"Surfaces.-The surface that is turned toward the hoof is known as the 'upper,' or 'hoof surface,' of the shoe. That part of the hoof surface which is in actual contact with the horn is called the 'bearing 
surface' of the shoe. The 'bearing surface' should be perfectly- horizontal from side to side and mide enough to support the full thickness of the $\pi$ all, the white line. and about an eighth of an inch of the margin of the sole. The 'bearing surface' should also be perfectly flat, except that it may be turned up at the toe. The surface between the 'bearing surface' and the inner edge of the shoe is often beaten down or concaved to prevent pressure too far inward upon the sole. This 'concaring.' or 'seating.' should be deeper or shallower as the horny sole is less or more concare. As a rule, strongly ' cupped' soles require no concaring (hind hoofs, narrow fore hoofs).

"Borders.-The entire outer border should be beveled under the foot. Such a shoe is not so readily loosened, nor is it so apt to lead to interfering.

"Fullering.-This is a groove in the ground surface of the shoe. It should pass through two-thirds of the thickness of the shoe, be clean, and of uniform width. It is of adrantage in that it makes the shoe lighter in proportion to its width; and, by making the ground surface somewhat rough, tends to prerent slipping.

"Nail-Holes.-The shoe must be so punched that the nail-holes will fall directly on the white line. Ther should be confined to the fore half of front shoes, but may occupy the anterior two-thirds of hind shoes. For a medium-reight shoe three nail-holes in each branch are sufficient, but for heavier shoes, especially those provided with long calks, eight holes are about right, though three on the inside and four on the outside may do.

"Clips.-These are half-circular ears drawn up from the outer edge of the shoe, either at the toe or opposite the side wall. The height of a clip should equal the thickness of the shoe. though they should be eren higher on hind shoes and when a leather sole is interposed between sole and hoof. Clips secure the shoe against shifting. A side clip should alwars be drawn up on that branch of the shoe that first meets the ground in locomotion. 


\section{"SPECIAL PECULIARITIES OF THE CHIEF CLASSES OF SHOES:}

"1. A shoe for a regular hoof fits when its outer border follows the wall closely in the region of the nail-holes, and from the last nail to the end of the branch gradually projects beyond the surface of the wall to an eighth of an inch, and extends back of the buttresses an amount equal to the thickness of the shoe. The shoe must be straight, firm, air-tight, its nail-holes directly over the white line, and its branches far enough from the branches of the frog to permit the passage of a foot-pick. Branches of the shoe must be of equal length.

"In fitting a shoe to a hoof of regular form, we follow the form of the hoof; but in base-wide and in base-narrow hoofs, which are of irregular form, we must pay attention not only to the form of the hoof, but also to the direction of the pasterns and the consequent distribution of weight on the hoof, because where the most weight falls the surface of support of the foot must be widened, and where the least weight falls (opposite side of the hoof) the surface of support should be narrowed. In this way the improper distribution of weight within the hoof is evenly distributed over the surface of support.

"2. A shoe for a base-wide hoof should be fitted full on the inner side of the foot and fitted close on the outer side, because the inner side bears the most weight. The nails in the outer branch are placed well back, but in the inner branch are crowded forward toward the toe.

"3. A shoe for a base-narrow hoof should be just the reverse of the preceding. The outer branch should be somewhat longer than the inner.

"4. A shoe for an acute-angled hoof should be long in the branches, because most of the weight falls in the posterior half of the foot. The support in front should be diminished either by turning the shoe up at the toe or by beveling it under the toe.

" 5. A shoe for a stumpy hoof should be short in the branches, and, for pronounced cases, should increase the support of the toe, where the most of the weight falls, by being bevelled downward and forward.

"In many cases, especially in draft-horses, where the hoofs stand very close together, the coronet of the outer quarter is found to stand out beyond the lower border of the quarter. In such cases the outer 
branch of the shoe from the last nail back must be fitted so full that an imaginary perpendicular dropped from the coronet will just meet the outer border of the shoe. The inner branch, on the other hand, must be fitted as 'close' as possible. The principal thought should be to set the new shoe further toward the more strongly-worn side. Such a practice will render unnecessary the widespread and popular fad of giving the outer quarter and heel-calk of hind shoes an extreme outward bend. Care should be taken, however, that in fitting the shoe 'full' at the quarter the bearing surface of the hoof at the quarter be not left unsupported or incompletely covered, to be pinched and squeezed inward against the frog. This will be obviated by making the outer branch of the shoe sufficiently wide and punching it so coarsis that the nails will fall upon the white line" 


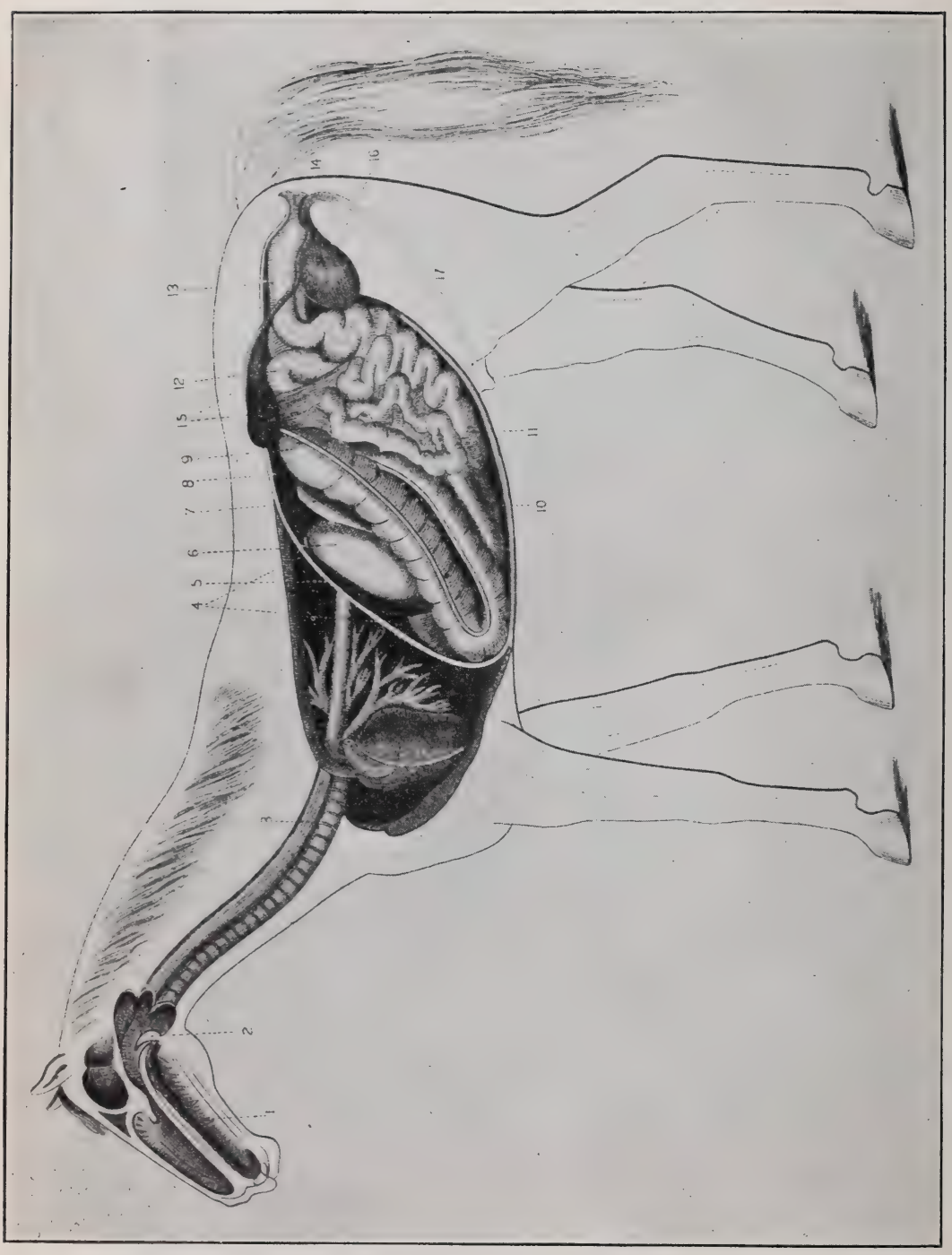

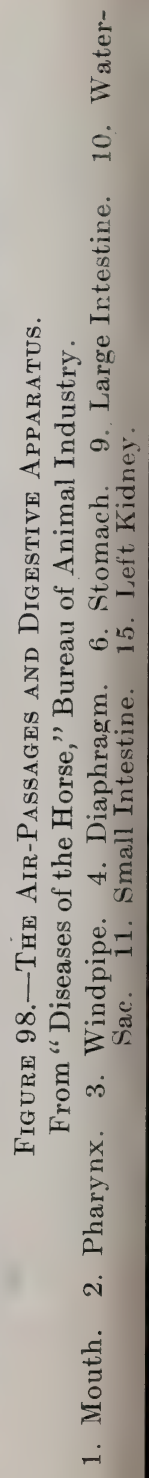




\section{CHAPTER XIII.}

\section{THE HEART, LUNGS, AND AIR-PASSAGES.}

The heart is the organ by which the blood is circulated through the body. It hangs a little to the left of the center of the forward part of the chest, suspended from the vertebræ of the withers, the small end downwards. Its average weight is from seven to eight pounds.

The heart is of interest to the amateur horseman because of the influence disease has on its action. In health, the heart of the ordinary horse pulsates from thirty-five to forty times a minute; the thoroughbred horse, from forty to forty-five. These pulsations of the heart send the blood through the arterial system in a series of waves, each wave corresponding to one pulsation of the heart. These waves constitute what is called the pulse, and it is by counting the pulse and by observation of the relative strength and frequency of the waves of the pulse that the heart-action of the horse is verified.

It must be understood that the number of pulsations above noted is for the animal at rest, or when not undergoing any special exertion. The pulse will become higher during exertion, the amount of the increase depending on the extent of the exertion. The pulse will be higher in horses kept in fine condition, in warm stables, and fed on selected forage, than in animals more roughly stabled and fed. It is higher in young horses than in old ones. Fear or excitement also tend to augment the pulse.

When the animal is at rest, a pulse of from 50 to 55 indicates a feverish condition, the cause of which should be investigated. From 70 to 75 beats a minute indicates a very serious condition, demanding prompt and energetic action. 
The arteries, where the pulse is felt, are the deep-seated blood-vessels; the veins lie nearer to the surface. There are several places where the larger arteries come close enough to the skin to be felt, but the best place to take the pulse is on the under side of the angle of the under jaw, where an artery bends around the bone. The pulse can also be counted by placing the hand against the side.

"The temperature of the horse is determined roughly by placing the fingers in the mouth or between the thighs, or by allowing the horse to exhale against the cheek or back of the hand. In accurate examination, however, these means of determining temperature are not relied upon, but recourse is had to the use of the thermometer. The thermometer used for taking the temperature of a horse is a self-registering clinical thermometer, similar to that used by physicians, but larger, being from five to six inches long. The temperature of the animal is measured in the rectum.

"The normal temperature of the horse varies somewhat under different conditions. It is higher in the young animal than in the old and is higher in hot weather than in cold. The weather and exercise decidedly influence the temperature, physiologically. The normal temperature varies from 99.5 to 101 degrees Fahrenheit. If the temperature rises to 101.5, the horse is said to have a low fever; if the temperature reaches 104, the fever is moderate; and if it reaches 106, it is high. Above this point it is regarded as very high. In some diseases the temperature goes as high as 108 or 110 degrees. In the ordinary infectious diseases it does not often exceed 106. A temperature of 107.5 degrees and above is very dangerous, and must be reduced promptly if the horse is to be saved."*

"The lungs are the essential organs of respiration. They consist of two (right and left) spongy masses, commonly called 1903.

*Page 17, "Diseases of the Horse," Bureau of Animal Industry, 
the lights, situated entirely within the thoracic cavity. On account of the space taken up by the heart, the left lung is the smaller. Externally, they are completely covered by the pleura. The structure of the lung consists of a light, soft, but very strong and remarkably elastic tissue, which can only be torn with difficulty. Each lung is divided into a certain number of lobes, which are subdivided into numberless lobules (little lobes). A little bronchial tube terminates in every one of these lobules. The little tube then divides into minute branches, which open into the air-cells of the lungs. The air-cells are little sacs, having a diameter varying from one-seventieth to one-two-hundredth of an inch; they have but one opening, the communication with the branches of the little bronchial tubes. Small blood-ressels ramify in the walls of the air-cells. The air-cells are the consummation of the intricate structures forming the respiratory apparatus. They are of prime importance, all the rest being complementary. It is here that the exchange of gases takes place. As before stated, the walls of the cells are very thin; so also are the walls of the blood-vessels. Through these walls escapes from the blood the carbonic acid gas that has been absorbed by the blood in its circulation through the different parts of the body; and through these walls is absorbed, by the blood from the air in the air-cells, the oxygen-gas, which is the lifegiving element of the atmosphere."*

The nasal passages, or nostrils, unite abore the back of the mouth, forming the pharynx. The pharynx is a box-like organ, through which the food passes into the gullet, as well as the air into the lungs. The nostrils and mouth open into it in front, nostrils above, and the gullet and windpipe lead from it in rear, the windpipe below. To guard against the introduction of food into the windpipe, a large valve, 2 (Figure 98), closes it, that is hinged below and that lies, when the horse is

*Pages 119 and 120, "Diseases of the Horse," Bureau of Animal Industry, 1903. 
not eating, over the opening into the mouth. Food entering the pharynx from the mouth pushes this valve into place over the windpipe and passes over it into the gullet. For this reason a horse always must breathe through its nose, as air entering the pharynx through the mouth has the same effect as food of stopping the windpipe; hence it is important never to call on an animal for sudden or energetic action when there are particles of food in his pharynx that may be suddenly drawn into his lung, causing him to choke.

Back of this valve lies the larynx, containing the vocal cords; this in turn opens into the windpipe, which separates, in the chest, into two branches leading to the right and left lungs (Figure 98).

In the lungs these branches divide into bronchial tubes (Figure 98), which, by repeated ramifications, terminate in aircells, where the process of purifying the blood takes place. These air-passages are all lined with mucous membrane, which secretes a slimy fluid called mucous, which, when discharged from the nostrils, is called phleg $\mathrm{m}$.

When, for any reason, this membrane becomes acutely inflamed, a disease exists, which is variously named, depending upon its location in the air-passages.

In the nostrils or pharynx it is called cold in the head; in the larynx and windpipe, laryngitis, or sore throat; in the branches of the windpipe and the bronchial tubes, bronchitis. If the substance of the lungs becomes inflamed, the disease is known as pneumonia.

Lining the chest and covering the lungs are two membranes, called the pleuræ. They are fast to the lungs and chest, respectively, but are completely separated from each other. A lubricant is secreted by each that flows between them, making it easy for them to slip on each other as the lungs are enlarged and satracted. If they become inflamed, the disease is pleu- 


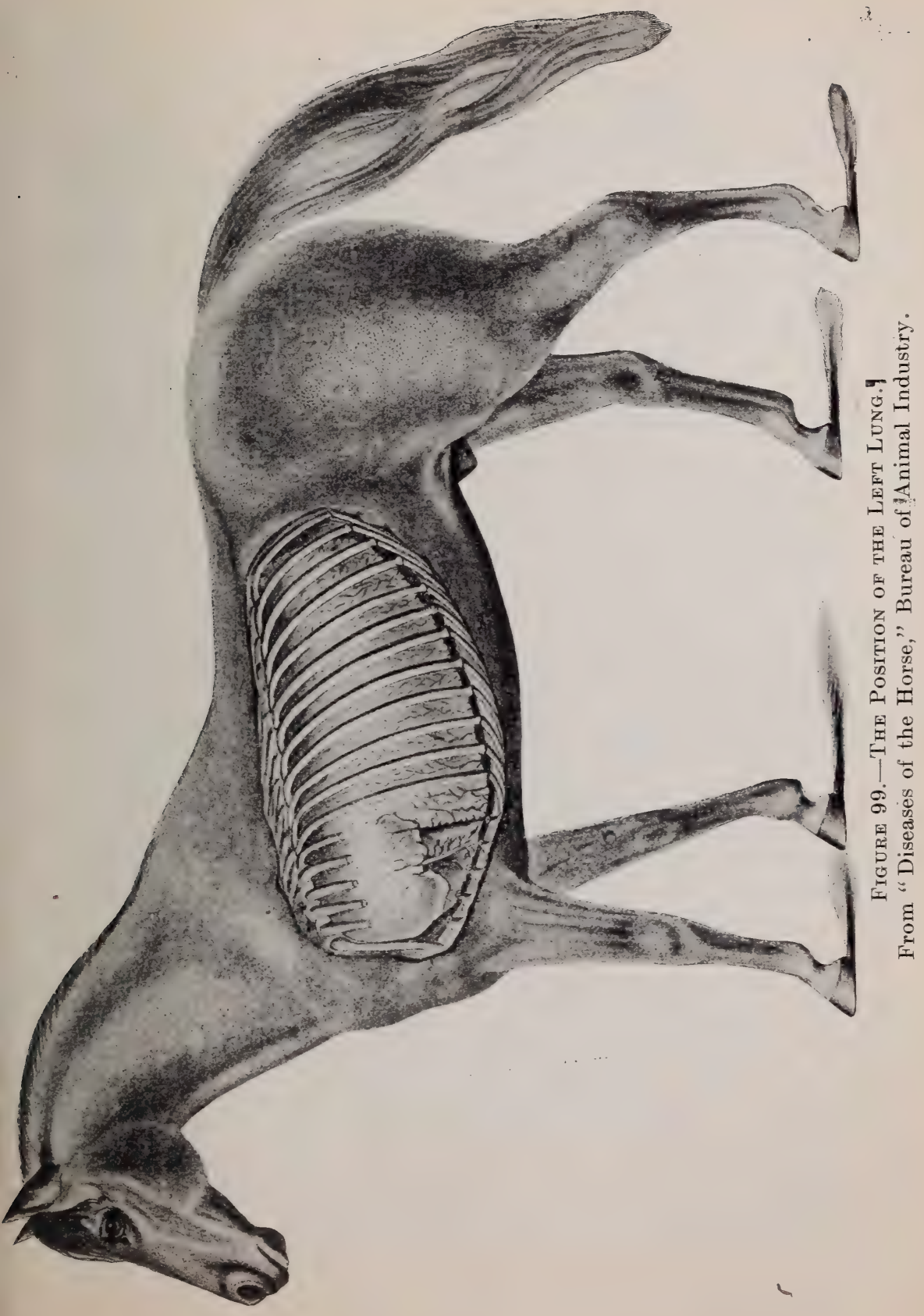


risy. Bronchitis, pleurisy, and pneumonia are allied diseases and rarely exist separately.

Congestion of the lungs is an engorgement of the capillaries of the lungs with blood, caused by over-exertion, or sudden chilling after heating work. The lungs cannot purify the blood fast enough, and, unless the congestion is arrested, the horse dies of suffocation.

When a horse has been driven or ridden very fast for a longer period than should have been the case, the severe strain put upon the diaphragm by the extra exertion will cause violent spasmodic contractions of that muscle. This condition is called thumps, and is similar in origin to the familiar hiccoughs. Usually the flank is shrunken, and the posterior angle of the ribs thrust outwards. The jerky motion caused by the spasm shakes the whole body. The pulse is not accelerated in thumps; it often is weaker than normal. If not relieved, death usually results.

If the disease appears while the animal is on the road, he should be stopped at once; the saddle or harness should be removed, and the body and legs should be briskly rubbed to draw as much of the circulation to the skin as possible. As many persons as are available should be put at this work. When the body has become warm and the spasms relax, the patient should be warmly blanketed and should be put in the nearest box-stall, out of drafts. Two or three days' careful nursing will usually complete the convalescence.

Thu mps attacking a horse on the road is always caused by injudicious use. Thumps may be followed by congestion of the lungs, especially in the winter, or by founder in the summer.

These are all acute diseases. From repeated attacks, the membranes become thickened or their vitality becomes impaired, and certain chronic diseases result. 
Thick wind is the name for the chronically diseased and thickened condition of the smaller bronchial tubes. The amount of blood that can be purified is limited by this disease, and the horse shows distress and labors when worked fast or hard. He seems to struggle for his wind-to gasp for breath. It is not accompanied by noise, and the inhalations and exhalations recur at equal intervals. There is no medical treatment for this disease. If the horse is very carefully fed, is not exercised at all while his stomach is full, and is worked lightly and at slow gaits, he may finally recover partially, and gradually become more and more serviceable.

Broken wind or heaves is caused either by a rupture of the air-cells, or by a partial paralysis of the muscles of the cells that assist in expelling the air. In this disease the ordinary action of the lungs and diaphragm is not enough to clear the lungs, and a second contraction is necessary.

The diaphragm is a dome-shaped muscle, rising from the abdomen into the hollow of the chest. By its muscular action the lungs are squeezed against the ribs and the air thus mechanically pushed out of them. With the withdrawal of the diaphragm the lungs expand and follow it, and so fill themselves with the fresh air that is so necessary to the life of the animal. If the stomach is overloaded with coarse food, the diaphragm will be mechanically and constantly pushed against the lungs, and so limit their powers of expansion. While this condition exists, if the animal is called on for any extra effort, the lungs will not respond to the demands made on them by the circulation, and the cell walls will be ruptured in consequence. When the processes of digestion remove the obstruction to the lungs' proper action, the evil will still remain. The lung-cells that have been ruptured will leak air into the lung tissue itself, and this air is expelled with difficulty. Horses living in a dusty or badly-ventilated stable are predisposed to heaves. The lungs, being constantly irritated, become chronically inflamed, and the 
muscles of the cell walls lose their elasticity or become partially paralyzed.

Broken wind is easily distinguished from other lung disease by the double effort to exhale air, usually accompanied by a hacking cough. The period of exhalation is longer than the period of inhalation. Heaves, except in very mild, recent cases, is incurable, and the horse is greatly disabled by it.

Roaring is a disease that is characterized by a peculiar noise made by the horse at inhalation. The noise called roaring may be made by a sound horse when excited, or when suddenly put to exertion after a period of idleness, or on account of a cramped position of the head or neck. This noise is not accompanied, in the sound horse, by evidences of fatigue and inability to perform work, as is the case in the unsound horse. Chronic roaring is the result of a paralysis of the muscles of the larynx that control the vocal cords. This paralysis prevents them from being opened sufficiently wide to admit air without vibrating. Often a horse may be affected by the disease-paralysis of the vocal cord - without the accompanying sound. This can be detected by making a sudden motion towards the flank with the hand or whip, when the unsound animal will grunt or groan. Roaring is very disabling, and can be cured only by a surgical operation. This operation consists in reremoving the vocal cord that has become uncontrollable.

Whistling is a variation of the sound made by a roarer. A horse with a severe sore throat may make a whistling sound at inhalation. This should not be considered as evidence that he is a roarer until the sore throat is cured, when, if the horse is sound, the whistling will cease.

A sound horse should breathe noiselessly and easily in all emergencies. A horse that makes any noise or has any difficulty in its breathing, no matter how slight, should not be considered sound. 


\section{CHAPTER XIV.}

\section{THE DIGESTIVE APPARATUS.}

The digestive apparatus consists of the mouth, the gullet, the stomach, the large and small intestines, and certain other organs, into whose functions it is not necessary to inquire in so elementary a treatise as this* one. These organs except, of course, the mouth and a portion of the gullet, are contained in the abdominal cavity.

The food is taken by the lips and is worked back to the upper part of the mouth by the lips and tongue. There it is masticated by the molar teeth and mixed with saliva secreted by the salivary glands. This is the first process of digestion. When the mouthful has been well broken up and saturated with saliva, it is passed back through the pharynx and gullet to the stomach. This is a small organ, having a capacity of three to three and a half gallons. Two-thirds of the lining of the stomach is a membrane that secretes gastric juice. The food is slowly mixed in the stomach with this liquid until it partially changes its character, and is passed into the small intestine, to be there mixed with the digestive juices of the liver, spleen, and other intestinal glands, to be transformed by the chemical action of these reagents until it is ready to be absorbed into the system.

A system of vessels, called lacteals, and the veins, absorb the nutritive part of the food thus transformed and carry it to a large vein near the heart, where it is poured into the blood. This fluid, thus enriched, is carried by the circulation to all parts of the body to nourish it and repair waste tissues. The débris of digestion is forced through the large intestine and is voided as dung. 


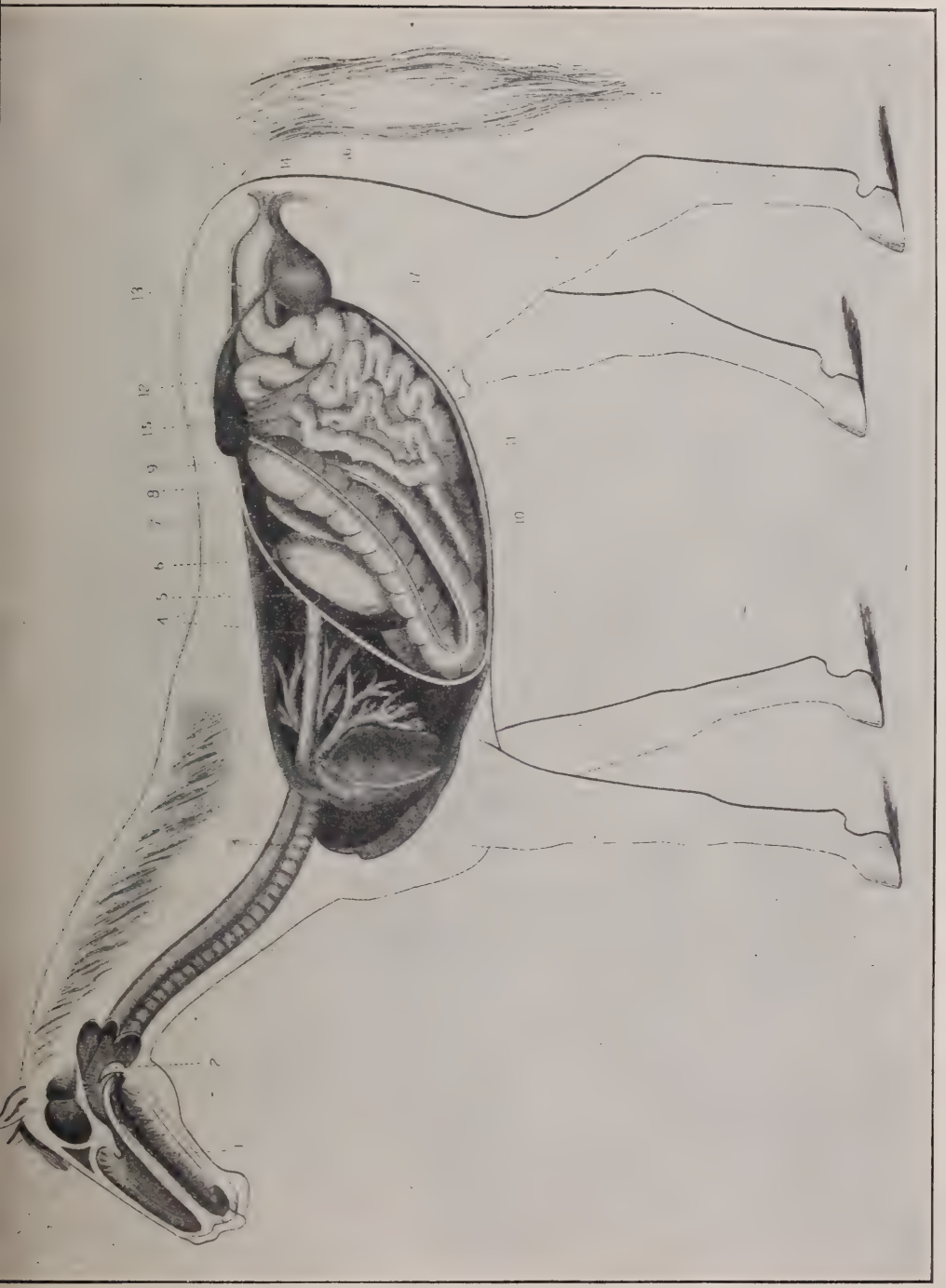

i

P 200

पद तु

दै ठำ

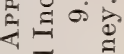

1

E.

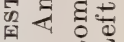

洁部

ค

会政

४

\%)

50

की

ये 四回

A $A=$

进

I

F

1 क ह

记

의

뵹 हू

范

$\stackrel{D}{b}$

质

-i


Water takes a different course. It passes almost directly through the stomach and small intestine to the water-sac or cæcum, where it is stored for use. A portion is drawn off to be mixed with the blood to supply the fluids of the system; the rest, carrying with it certain salts necessary to be removed from the body, is excreted through the kidneys as urine.

The horse is an animal requiring regularity in feeding and watering and a very limited variety of foods to be kept in efficient condition. The horse's stomach is very small; in proportion to his bulk, it is only half the size of the human stomach. It rests upon the large intestine and against the diaphragm, while the small intestines lie further back in the abdomen, more remote from the direct action of the diaphragm. The walls of the stomach are elastic, and permit it to accommodate itself to the bulk of the food that enters it.

The above considerations render it imperative that a horse should not be called on for severe work or rapid exercise immediately after eating a bulky meal. The stomach, distended, interferes with the free action of the diaphragm, and the latter, in its efforts to increase the air capacity of the lungs, squeezes the stomach back against the intestines, and so greatly impedes the processes of digestion.

Very fortunately, digestion is a rapid process in the horse, and the stomach is called on to do but little of the dige tion of the bulkier foods. Water is retained in the stomach or small intestines only when it is absorbed by partially-digested food. This has the effect of diluting the digestive fluids, of delaying the process of digestion, and of mechanically removing from the stomach food that is not ready to be passed to the intestine. In addition, the water cools the stomach and its contents below the temperature at which it best performs its functions. For these reasons horses should not have access to water while eating, or for an hour or two after. 
Hay requires to be thoroughly chewed and mixed with saliva before it càn be swallowed. When it reaches the stomach it is delayed there but a short time, and passes to the small intestine, where the greater part of its digestion is performed. If a horse is fed only hay, the first portion of his meal passes into the intestine very soon, but the stomach retains the succeeding portions for a longer time, and it is several hours before the stomach is empty. In this way the muscles of the stomach get the necessary amount of exercise to keep them in proper condition.

Oats, however, and other concentrated foods are digested almost entirely in the stomach; when they pass into the intestine much of their bulk is rapidly absorbed by the lacteals, and there is little left for the intestine to work on. The result is that the horse is still restless and hungry. If this one-sided ration is continually given him, he will fall off faster than he would do if fed hay alone, and this in spite of the fact that oats contain more elements of nourishment than hay does. Horses given an insufficient amount of hay will eat their bedding, or any rough food they can get, to satisfy the craving for intestinal exercise. Poor hay - that is not musty or dusty - and wheat, rye, or barley straw, although they may contain practically no nourishing qualities, will preserve the strength and health of 2 horse in a remarkable degree. On this account horses on campaign, or in places where good hay is hard to get, ought always to be provided with rough forage of some sort, no matter how poor in nourishing qualities.

The normal processes of digestion must not be interfered with, or sickness or debility will result. A certain amount of the digestion of food is done in the mouth, where the chemical action of the saliva prepares the food for the further action of the stomach. In order that the saliva can reach every part of each mouthful of food, it must be broken up by the teeth. This process is necessarily done in the case of hay, but oats are al- 
ready fine enough to be swallowed and their smooth hulls offer no obstacle to that process. These hulls are insoluble in the juices of the stomach, and, if the oat grain has not been crushed by the teeth, the kernel of the grain passes through the horse unchanged. If it is imperfectly crushed, it will be only partially digested in the stomach, and will pass on to the intestines, to ferment there and to generate gases there that will cause distress and often disease.

Owing to the uniformity in diet and the regular hours of feeding, labor, and rest of most well-kept horses, diseases of the digestive apparatus are comparatively infrequent among that class of horses. They are the most easily preventable of all equine diseases. Unfortunately, many horses are not well kept, and, as a result, "the disease of the horse that is most frequently met with is what is termed colic. This term is applied loosely to almost all diseases of the abdomen that are accompanied by pain. If the horse evinces abdominal pain, he is likely to be put down as suffering with colic, no matter whether the difficulty be a cramp of the bowel, an internal hernia, overloading of the stomach, or a painful disease of the bladder or liver.

"The general symptoms of abdominal pain, and therefore of colic, are restlessness, cessation of whatever the horse is about, lying down, looking around towards the flank, jerky switching of the tail, stretching as if to urinate, frequent changes of position, and groaning. In the more intense forms the horse plunges about, throws himself down, rolls, assumes unnatural positions, as sitting on the haunches, and grunts loudly. Usually the pain is not constant, and during the intermissions the horse may eat and appear normal. During the period of pain, sweat is poured out freely. Sometimes the horse moves constantly in a circle. The respirations are accelerated, and usually there is no fever." 
From the above quotation* it is easily seen that grave errors might be made in attempting to set down a specific treatment for colic. The best treatment, for the non-professional person, is to get the patient free from all harness, in a roomy box-stall with plenty of bedding, so that he will not hurt himself in his spasms of pain - and send for a veterinary surgeon.

Indigestion, or catarrh of the stomach or intestines, is a much more common disease than colic, but it usually does not exhibit such violent symptoms. The mucous membrane is the general lining membrane of the digestive and respiratory apparatus. Inflammation of this membrane impairs the digestive ability of the organs inflamed, and the animal suffers a loss of vitality in direct proportion to the extent of the disease. The symptoms of the disease are an irregular and depraved appetite and a loss of condition. The animal may show colicky symptoms in extreme cases. The bowels are irregular, and the dung contains much of the horse's food that is unchanged by its passage through the animal's body. The horse's skin seems very tightly stretched, and the abdomen is "tucked up."

Indigestion is due to numerous causes; anything that irritates the mucous membrane may cause it. Feeding improper food, bad teeth, causing imperfect mastication, working a horse immediately after eating - all are prolific causes of indigestion. $\dagger$

Lampas, the undue swelling of the membrane covering the forward part of the roof of the horse's mouth, is more an indication of disease than a disease. Treatment of the swelling itself does little good. The cause is usually with the horse's diet or digestion. The old practice was to burn the swellings with a red-hot iron; such a treatment simply aggravates the 1903.

*Page 50, "Diseases of the Horse," Bureau of Animal Industry,

$†$ This disease is, except in cases where its origin is hereditary, one that should be prevented. It will be discussed more at length under the head of "Preventable Diseases." 
disease and adds to the pain. It should never be allowed. Some veterinarians still advocate cutting the roof of the mouth, believing that a little local blood-letting will relieve it. As the cause of the disease is elsewhere, a better practice is to try to find it and correct it. This is more the work of the professional than of the amateur. The existence of lampas does not necessarily indicate a serious condition. A day or two of rest and a few bran-mashes will usually effect a cure.

It is hardly ever advisable for the amateur to attempt to treat diseases of the vital or digestive organs. He will more often injure than help the animal. Rest, good food, and sanitary surroundings are far better than drugs in the hands of men not thoroughly posted on their properties and effects. 


\section{CHAPTER XV.}

\section{STABLE MANAGEMENT.}

The term "stable management" includes the art of proper stabling, sanitary care, feeding, watering, grooming, and nursing of horses.

Stabling and Sanitary Care.-The first requisite for a stable is to provide shelter from inclement weather. In far too many stables this seems to be the only object in view. Of almost equal importance to the item of shelter, for the robust health of the occupants, are ventilation, dryness, and cleanliness.

Economy of air-space is always sought for in stables. The horses are kept in stalls that usually are only large enough for the animal to stand or lie in. All available space in the stable is used for passageways and for storage of forage and equipment of all sorts; no space is wasted. That horse is lucky in a large stable who has as much air-space as the man who grooms him has in his quarters, although six or seven times his weight.*

It is, therefore, of the greatest importance that ample facilities for ventilation exist.

A horse needs shelter to best preserve his strength, but he does not need his shelter heated artificially.

In order to keep horses' coats short and glossy in the winter, owners generally blanket them. Many, in addition, heat their stables. The latter is, in most parts of the United States, unnecessary; but, as it is much more comfortable for the stable-

*Three thousand cubic feet of ventilated air-space per horse is recommended as necessary to preserve his vigor unimpaired, according to General Fitzwygram. He adds that, since horses are not so susceptible to draughts and cold as men are, by ample ventilating arrangements this demand for air-space may be considerably decreased. 
men to work in a warm stable, they persuade their employers that the horses need it, thereby sacrificing the health of their charges to their own comfort.

Horses that are blanketed in warm stables must, when they are taken out, be kept moving or warmly clothed. Otherwise there is, in the winter, grave danger of pneumonia, lung fever, or other similar diseases, and, in the summer, of founder.

Proper grooming of horses kept blanketed in cold stables will keep their coats in order. They will be more willing to work and less liable to suffer from the effects of standing outside in the cold, when the business or pleasure of their owners demands it. Veterinary bills will be kept down, and the only persons to find fault with the arrangement will be the men who have to tend them.

Insist, therefore, on an ample supply of fresh air in the stable. Insist also that the fresh air entering the stables does not produce direct draughts on the horses. The currents of entering air should be diffused by suitable mechanical arrangements.

In damp, cold climates, valuable horses that justify the expenditure are benefited by having open fire-places in their stables to keep them dry and to assist in ventilation. Steam or hot water heating arrangements should not be used to heat the stalls.

\section{Dryness should be insisted on in stables.}

This can only be secured in most climates by building the stables in well-drained situations, open to the air and sunlight.

\section{Cleanliness can be secured only by constant super- vision.}

Cleanliness and dryness go hand in hand. A horse drinks about eight gallons of water a day. This water is used: first, to maintain the fluidity of the blood and other liquids, the moisture of the tissues, and to replace that lost by perspiration; second, to moisten the food and prepare it for digestion; third, 
acting as a solvent for certain noxious salts, developed in the nourishment and maintenance of the body, to excrete the solution as urine.

Much of the daily allowance of water is left on the stable floor by the horse. If he is well bedded, the bedding absorbs it. If the floor of his stall is of clay, unless the most perfect care is taken of it, he will mix clay and urine and manure together into foul mud, an excellent culture for disease germs and a still for the manufacture of ammonia. If the floor is of wood,a very poor floor, by the way,- the urine soaks into it, and, unless perfectly drained, renders it very unsanitary. If of brick or stone, the drainage can be easily maintained if the floor is well made and the gutters kept open.

In any case, to insure both cleanliness and dryness, all the bedding must be taken out of the stall in the morning and the stall cleaned. Such of the bedding as has become urine-soaked must be thrown away with the manure and the rest exposed to the sun and air and thoroughly dried before it is put back. The stable should be opened and well aired, the mangers cleaned, and the dust swept up and carried out.

All persons having animals in their charge should frequently inspect their stables early in the morning, to test the quality of the air in the $m$ and to see that their orders respecting ventilation have been carried out. They should inspect them daily at the hour designated to have the bedding aired, to see that everything is scrupulously cleaned, and again when the stables are prepared for the night, to see that the bedding is clean, dry, and well laid and that the gutters are not stopped up.

Feeding and Watering.- The time of feeding must be regulated according to the uses to which the horses are put. The sequence of feeding should be the same for all horses. As we have seen, water passes almost directly through the stomach and small intestines to the cæcum, or water-sac; the hay com- 
ponent of the food is largely digested in the intestine, the grain component, especially oats, is almost entirely digested in the stomach. Starting with these facts, the order of feeding and watering is easily formulated.

A horse does not usually care for water early in the day. He wants his oats then, and should have them. Oats are concentrated food, full of nourishment and energy. They are easily digested when thoroughly chewed and mixed with saliva. The average horse should be given for his morning meal at least six quarts of oats. They should be plump, of sweet, fresh odor, and free from dust, dirt, or other seeds. After feeding oats, at least two hours should elapse before giving water. After this time ha should be allowed water at every opportunity until again fed. If he is worked hard all day, it is best to give him a second feed of oats at the noon rest-hour, remembering not to water him for two hours after. When he comes in at night, he should find his hay ration in his manger and no oats. An hour afterwards he should be given his grain, and left for the night. If the stables are inspected at various hours of the night, some horses will be found lying down, some dozing in a standing position, some feeding. They like to take their time with their food. Their stomachs are small. They are slow feeders. Food assimilates better if taken slowly. They are light sleepers, easily roused, and they enjoy a nibble of food when awakened.

Often when the stablemen come in, in the morning, in many of the mangers a portion of the food offered the night before will be found uneaten, even when no more than the usual amount had been placed at their disposal. In such cases carefully clean the mangers and feed-boxes before offering more food. The horse is off condition and needs coaxing a little. The food he has been nosing over all night has become stale and unattractive to him. He will do much better if clean, sweet food is given him, and he may be induced to eat quite a little if humored in this way. 
Bran should be fed either dry or steamed. A cold bran-mash is about as indigestible a mess as a horse can be fed. It is soft and watery and easily swallowed. The molars are accustomed to hard, dry food. When food is softened it is ready to swallow, from the horse's point of view, and down it goes. A cold bran-mash is usually full of dry, unmoistened particles; bran does not readily absorb cold water. It is distinctly a food that needs either cooking or the action of saliva to prepare it for digestion. If it is put in the stomach cold and unacted on by saliva, it will ferment and produce indigestion.

If fed dry, it is a food slowly taken into the stomach. It must be chewed to get it moist enough to be swallowed, and the only fluids available are secretions of the salivary glands. When bran, thus moistened, reaches the stomach, it is warm, digestion has begun, and that process continues naturally.

If fed wet, it should be steamed. A large watertight and easily cleaned receptacle should be prepared expressly for this purpose. The bran, mixed with salt in the proportion of one ounce of salt to three pounds of bran, should be put in it, and boiling water, in the proportion of two and one-half pints to three pounds of bran, poured over it. It should then be tightly covered with woolen blankets, and allowed to steam for fifteen or twenty minutes. It should be fed hot, and the receptacle it was cooked in at once cleaned and sunned. After it has been eaten, the mangers should be cleaned thoroughly. Bran-mash sours quickly, and, aside from being a good culture for disease germs, the odor of sour bran is distasteful and makes other food mixed with it not appetizing.

For horses in good health, bran, preferably dry, should be fed one day in seven, and in the evening. Cooked mashes are food for sick or ailing horses.

Horses should have salt, in rock form, in their feedboxes at all times. In addition, fine table salt, a heaping; table- 
spoonful to each horse, should be fed twice a week, either mixed with bran or oats, or placed where they can lick it at their leisure.

The water furnished horses should be pure and fresh, without taste or smell. In the summer, water should stand in the trough long enough for the chill to be taken off. Water in large quantities should never be given horses when they are heated, unless their exercise is to be continued.*

Conditioning Thin Horses. $†-$ "When a horse which is living under apparently favorable conditions becomes emaciated,-neither from overwork nor from extreme age,-an effort should be made to discover the cause of the thinness. Begin by sending for the person responsible for the condition of the horse and for the farrier, and with their assistance solve the following points:

1. Has the horse lampas?

2. Is the tongue sore?

3. Has he wolf's teeth?

4. Are the molars sharp and irregular?

5. Does he quid $\ddagger$ his food?

6. Are the teeth unsound or out of order, or (in the case of a young horse) are the milk teeth remaining in too long, and thereby interfering with the coming of the permanent teeth?

*Charles B. Michener, V.S. (on p. 35, "Diseases of the Horse," Bureau of Animal Industry, 1903), says: "There is a popular fallacy that if a horse is warm, he should not be allowed to drink; many claiming that the first swallow of water 'founders' the animal or produces colic. This is erroneous. No matter how warm a horse may be, it is always entirely safe to allow him from six to ten swallows of water. The danger is not in the first swallow of water, but is due to the excessive quantity that the animal will take, when warm, if not restrained." This opinion from such authority is valuable for horsemen to have, but it is unsafe to permit the average stableman to act on it. Unless you are sure that your man is careful enough and faithful enough to stop the horse at six to ten swallows, it is wiser to adhere to the rule that the hot horse should have no water until cooled.

†From Captain M. F. Rimington's (British Army) little handbook, "Hints on Stable Management," pp. 30, 31.

† A horse quids his food when he has difficulty in swallowing it. 
7. Does he bolt his oats?

8. Does the adjacent horse steal his oats, or bully him?

9. Is he a spare* horse?

10. Does he suffer from parasitic worms?

11. Is his urine normal?

12. Is his liver out of order? (This is indicated by the yellow and bloodless appearance of the gums.)

13. Is he watered regularly?

"If it is still impossible to account for the horse being out of condition, you should next endeavor to find out if he really gets his oats or only a small proportion of them; in a word, if the oats are being systematically stolen. Assured that the oats are not tampered with, it becomes necessary to make further inquiries as to the habits of the horse, as to whether he is restless, or in the habit of fretting or over-exciting himself, either in the stable or when at work. In some cases it is impossible to discover the cause or causes at work. In obscure cases, a complete change of diet, and, as far as possible, of surroundings, often has a wonderful influence. For example, a couple of months' run at grass in the spring or summer is most beneficial to thin, hidebound horses. Failing this, it will often be found useful to fill the manger at each stable hour with chaff; this will give the horse something to pick at, and keep him from fretting. Some men get horses into condition more easily than others, and it will often be found that a thin horse, put into good hands, will improve rapidly."

Grooming is another important item in the care of the horse. Much of the excretion is done through the skin. While at work a horse perspires freely, and the very nature of his work keeps him constantly, while at work, in a dusty atmosphere.

*A spare animal is one that, for constitutiona reasons, does not take on flesh 
The dust and sweat and precipitated salts of perspiration combine to form a cake at the hair-roots that clogs the pores. Drying, it has an unpleasant astringent feeling that annoys the animal. This crust of filth and dirt catches and fosters disease germs and parasites that feed upon the animal and that are never found on well-groomed horses.

Besides cleaning the coat, grooming stimulates the circulation and acts as a tonic to the horse. It rests a tired animal, relieves congestion following a hearty meal by diverting part of the excessive blood-supply from the digestive region. Twenty minutes' brisk grooming in the morning and twenty-five in the evening is the right amount to keep the animal's coat clean and skin healthy. More time than that will be appreciated in the satiny coat of the horse. A horse can hardly be groomed too much. The average horse likes to be fussed with and handled. He enjoys having his legs rubbed and his coat brushed. The currycomb is not so much enjoyed. It should be used merely to loosen caked mud or manure on the exterior of the coat, and, except with the greatest care, never below the knees or hocks. Use only the fingers and brush on the mane and tail. Throw cards and mane-combs out of the stable.

In grooming with the horse-brush, the groom should stand well away from the horse, legs well apart, and, with the brush in the hand next the horse's head (and the currycomb in the other), brush the coat with the lay of the hairs, throwing as much of the weight of the body into the brush as possible. After three or four strokes with the brush, clean it on the comb. Clean the comb every few minutes by tapping it on the ground in rear of the horse.

The sheath should be frequently washed with Castile soap and water, and never oiled. Oil simply collects and holds dust and makes washing more often necessary. The glands of the skin secrete all the oil needed to keep it in condition. 
Keep the long hairs of the muzzle cut short. They have no useful function in the domestic horse and are unsightly.

Keep the fetlock short the year around. In winter it should be an inch and a half long and neatly trimmed. In summer it should be clipped.

This principle in the care and treatment of horses cannot be too closely adhered to: Give your horse plenty of good food and pure water, house him in a dry, clean, and well-ventilated stable, and he will keep surprisingly well. Have him well shod. Work him hard, through long hours, and he will still keep well under the above conditions. When he does get sick or injured, go for a good veterinarian, follow his advice to the letter, and so save your money and your horse.

The following rules laid down in the Cavalry Drill Regulations are so good that they are reproduced here. Every person having to do with horses should observe the m strictly:

Never threaten, strike, or abuse a horse.

Before going into a stall, speak to a horse gently and then go in quietly.

Never take a rapid gait until a horse has been warmed up by gentle exercise.

Never put up a horse brought in a heated condition to the stable or picket-line, but throw a blanket over him and rub his legs and walk him until cool. When he is wet, put him under shelter and wisp him until dry.

Never feed grain to a horse nor allow him to stand uncovered when overheated. Hay will not hurt a horse, no matter how warm he may be.

Never water a horse when heated, unless the exercise or march is to be immediately resumed.

Never throw water over any part of a horse when heated. 
Never allow a horse's back to be cooled suddenly by washing or even by removing the blanket unnecessarily. To cool the back gradually, the blanket may be removed and replaced with the dry side next the horse.

There is no emergency that will justify striking the horse on the head. 


\section{iCHAPTER XVI.}

\section{ENDURANCE OF HORSES.-VICES.-PUNISH MENT.}

The endurance of a horse is the measure of his ability to resist fatigue and is dependent directly upon his powers of digestion and assimilation and the co-ordination of his nervous and muscular systems.

Nuscular power is derived from the contraction of the muscles. The muscles of locomotion are composed of numerous fibers, built up in groups, and attached by a tendon at each end to a bone. One of these bones serves as a fulcrum, the other as a lever. The muscle lies between them. Each of the fibers of the muscle, animated separately by a nerve, contracts, and tho whole muscle is shortened. The bones, when a flexor muscle is contracted, are brought nearer together; they are separated more when acted on by extensors. The muscular action is the same in all muscles - the fibers contract in the direction of their length.

As a muscle contracts its chemical nature changes. It consumes oxygen and certain other elements brought to it by the blood, which come to an active muscle in increased quantities, and it gives off carbonic acid and numerous other waste products

- that the blood washes off through the veins.

The entire operation, the impulse given by the nerve, the contraction of the muscle, and subsequent chemical change in the constituent elements of the blood "feeding" the muscle, the pull on the tendon, and the resultant energy transmitted to the bone, must work in perfect harmony with the corresponding actions of all the muscles involved, and is consummated in an almost inappreciable period of time.

The muscles of locomotion are all voluntary muscles; all are controlled by the volition of the animal. The muscles that 
control the organs of respiration, digestion, and circulation are, almost entirely, involuntary, but their actions are under control of nerve impulses, coming, as a rule, from nerve-centers other than the brain. No muscle contracts unless a nerve animates it, and there must be a nerve impulse for every contraction.

"Prolonged exercise is always accompanied by an expenditure of food, of blood, and of nerve-tissue, by an increased circulation, by an acceleration of respiration, and, finally, by a greater activity" $*$ of the organs of excretion. Admitting this, it is plain that the tired horse owes his condition indirectly to one of two causes: either to nervous exhaustion, or to an excessive clogging of the muscles with waste tissues. In either case, rest and food are the only restoratives.

The ordinary gasoline motor illustrates the situation exactly. A drop of gasoline is exploded by an electric spark in a cylinder. The resultant gases, by their expansion, move a piston that is geared to the wheels, producing locomotion. As long as the supply of gasoline is kept up, the electric batteries remain "alive," and the spent gases can escape and not clog the cylinders, the efficiency of the machine is unimpaired. But let any one of these conditions lapse and the machine stops. So with the horse. As long as the digestive apparatus enriches the blood, the lungs oxidize it, the veins carry away the waste tissues, the skin, lungs, kidneys, and other organs of excretion remove the débris from the system, and the vigor of the nervous system (the horse's electric battery) is unimpaired, so long will the horse do his work. The failure of any one of these functions and the limit of his endurance is reached. He may stumble along a little longer, but it is with apparent labor and to little purpose. He needs rest.

From the exterior of the horse a great deal can be predicted of his powers of endurance. The competent horseman can tell exactly to what sort of work he is best suited-whether he is a *"The Exterior of the Horse," Goubaux and Barriere, p. 415. 
draft-horse, a driver, a saddler, or a general utility horse-but no one can tell which of two horses, externally of equal promise, will be able to do the most work.*

This is especially true of horses bred for speed. If two colts, of similar breeding, are given advantage of the most scientific care and training, are brought up by the same trainer, on the same diet, and with exactly similar treatment, it is usually impossible to tell, until the actual test on the track is made; which will prove the speedier.

The horse doing slow work contracts his muscles slowly; the expenditure of tissue is very moderate, and especially moderate is the expenditure of nerve-tissue. He is tired after a long day's work, but it is the weariness that comes from the exhaustion of the food-supply, not from nervous exhaustion. The circulation, in the ordinarily healthy animal, is quite sufficient to keep the blood pure and the muscles cleared of débris. In fact, much of the food-supply is stored between the muscles and in the abdominal region in the form of fat. This fat is easily drawn on to restore waste tissues in emergencies when extra work is to be done, or when the food-supply is diminished. It also adds to the mass of the horse, and so increases his value for draft purposes. The nerves of such an animal are never over-taxed. $\mathrm{He}$ is kind, gentle, free from vice, and obedient.

The race-horse, the trotting-horse, the hunter, the polopony - "the horse of luxury" generally - has work of an entirely different sort to do. Speed is what he is bred for; speed and endurance. The race-horse is bred in economic idleness. $\mathrm{He}$ is trained to make his machinery perfect and under perfect control. The preparation for a race, after his schooling is done,

* Of a team of large sorrel horses of no particular breed, owned by a contractor doing work at the Military Academy, one horse has used up three team-mates, and is still sound and in prime condition. Nothing in his external appearance would indicate any extraordinary qualities. He does his full share of the work, yet what he thrives under wears out other horses, apparently just as good, in a short time. 
is a matter of weeks, and his work is done in two or three minutes. Yet, with all the preparation possible, after this short period of work, he is more exhausted than is the draft-horse after ten hours' steady pulling. To restore him to his full strength, he must be cooled slowly, fed and watered with judgment, exercised regularly.

The nervous strain in this sort of work is tremendous. The muscular contractions are frequent, violent, and sudden. The supply of blood and the change in the muscular tissues are greatly increased and the débris correspondingly increased. The lungs are called on to purify the blood in greater quantities. The nostrils are dilated and the windpipe straightened to increase the volume of air entering the lungs. The inspiration of all this added work must come from the nervous system, from the brain and other nerve-centers. These organs must be finely developed to do this extra work properly. The result is that the race-horse, as a rule - and in less degree the same is true of the other horses of luxury -is an excitable animal, nervous, high strung, often vicious. He has little of the docility and tractability of the farm-horse.

The polo-pony is called on to play two periods of fifteen minutes each two or three times a week during the polo season; yet in these few minutes of play he earns his oats as honestly as the cab-horse does in his ten hours a day.

The horse should never be pushed to the limit of his endurance. It is not necessary to do this to determine when he has worked enough. The horse's breathing furnishes an excellent witness to his condition. While he is working easily, he breathes without effort. When he begins to tire, his breathing becomes more and more labored, and his heaving flanks will show the effort he is making to keep up. If the horse is not rested then and allowed to recuperate, other unmistakable signs of exhaustion will follow. 
"As to nerve-conductibility, its feebleness or its disappearance is seen in unequivocal signs on the locomotory apparatus; the muscular contractions are weaker and slower; the efforts diminish in intensity and rapidity; the intervals between the steps are no longer equal and in co-ordination; the members meet and strike each other; the gait, at first uncertain, becomes tottering; the head hangs low; the subject becomes more and more insensible to the surroundings; soon he falls in a heap and dies at his task. But, before reaching this point, his steps are less free, heavy, and uncertain; he forges. All these signs should be sufficient, and their appearance demands an immediate cessation of the experiment."**

\section{VICES AND DANGEROUS HABITS OF THE HORSE. $†$}

"The horse is an animal of a noble and generous disposition, and naturally possessed of few vices, although he is occasionally met with having a bad and even furious temper, and, as may be expected, manifests great variety of natural habit. His vices, however, are too often attributable to the effects of improper training and to tricks which he is taught by the treatment and folly of his groom or keeper.

"The first breaking-in of the horse should only be intrusted to persons of mild disposition, as it is by kind and patient treatment alone that we can hope to succeed in rendering this valuable animal truly useful and docile. No doubt but in nine cases out of ten, where horses exhibit furious or stubborn tempers, that these have been produced from the cruelty and ignorance of their first trainers.

"Restiveness.--The most unpleasant and dangerous of all vices possessed by the horse is that of restiveness. Sometimes

* "The Exterior of the Horse." Gouboux and Barriere, p. 420.

†From "The Complete Modern Farrier." Thomas Brown, M.P.S., thirty-first edition, 1900, Chapter XV., pp. 340-360. 
this proceeds from a naturally bad temper and at other times from faultiness in education. This term includes plunging, rearing, kicking, bolting, and general impatience while mounting. A horse with any of the above faults can never be depended upon, for, although we may use means to counteract a particular vice, whether by compulsion or gentle measures, he may exhibit that vice when we are off our guard and are least expecting it. Force may bring him to obedience, and he may succumb to him who has had the determination to subjugate him, but, when mounted by another, he is extremely liable to break out again. A horse that kicks in harness may be driven with safety by a cautious or experienced driver or coachman, but still there is no certainty of his not exhibiting the same trick years afterwards; indeed, most horses which have been kickers return to it again.

"However high the temper which the horse may exhibit, we would recommend that he should be broken from his vices by kind and soothing means and these exercised with patience for a considerable length of time, and force should only be resorted to when all other means have failed.

"There is little chance of reclaiming a bad-tempered horse by harsh treatment; indeed, it will always be found to have an opposite tendency. An ill-tempered groom should never be allowed to enter a stable, however fit he may be for his business in every other respect; for a surly, bullying fellow is sure to frighten horses so much that when he enters a stable they will jump from side to side at his approach. Many a scar has been inflicted by such a man by using his pitchfork instead of soothing the animal for his fault, and if asked how the horse came by the blemish, he invents a falsehood to account for it.

"Rearing.--Rearing is one of the worse vices in a horse, and is practiced with the intent to throw the rider off. Sometimes it is the result of playfulness, but even then it is a dangerous and unpleasant fault. The use of a deep curb and sharp bit will, in some instances, cause even a quiet horse to rear, and when 
this is the case, immediate recourse must be had to the snaffle bridle.

"As in kicking, however, this is seldom or never cured. Horse-breakers have attempted it by absurd and dangerous means -namely, that of pulling the horse backward on a piece of soft ground. This has ruined many horses. If rearing proceeds from determinedly vicious habits, it is a hopeless case, as the animal seldom abandons it. Sometimes horses rear from playfulness, which is, however, very different from that which proceeds from passion.

"Kicking.-The vice of kicking is too often caused by horses being teased, tickled, and pinched by grooms from wanton mischief or thoughtless folly. The habit becomes habitual with the animals, and what was at first only done in play is exercised in anger, and often too when one leasts expects it. In short, it is a dangerous and incurable vice.

"Horses with an irritable or fidgety disposition kick the stall or bail, and especially during the night. This is a great annoyance to other horses in the stable and breaks their rest. Besides, the animal is liable to injure himself seriously, and bring on swelled hocks or other malady. Mares are more given to this than horses; and in either it is difficult to eradicate if once confirmed.

"The vice is seldom eradicated. Never trust a kicker.

"Biting.-This trick often proceeds from play, and is taught by the folly of grooms or stable-boys teasing the animals. But what they have acquired as a sport becomes a fixed habit; and when thwarted in any manner they will sometimes bite with great severity. Like other vices, this is difficult of cure. and it is but seldom they can be really broken of it. Teasing a horse should be strictly forbidden. Biting, like other vices, should never be taught the animal, as it is easier to avoid it than to effect a cure. Gentle treatment is the best suited for all 
our domestic animals and the surest way to command their affections.

"Seizing the Cheek of the Bit.--Some horses are so cunning as to get the cheek of the bit into their mouth, which gives them a great command over their rider or driver. There is no cure for this; and the only thing that can be done is to fasten a piece of round leather, or use some other mechanical contrivance, so that the animal cannot possibly get the cheek of the bit into his mouth. Neither soothing nor beating will remedy this trick, as the horse who has once been guilty of it is sure to seize the first opportunity to repeat it when anything vexes him. Many very serious accidents have happened to persons from horses running away with the cheek-bit between their teeth.

"Running Away.-The only thing that can be done in this case is to use a strong curb with a sharp bit, and at the same time always keeping a firm bridle-hand.

"Shying. - Of all the vices incidental to the horse, shying is one of the worst, and more accidents have happened from it than any other of the vices or defects of the horse. Shying proceeds from various causes, but one of the principal is defective vision; timidity stands next; and it often proceeds from a disposition to be playful. This vice is far less common among high-bred horses than with those which are half-bred, although we have met with it in some of our first racers.

"When we have a horse given to shying, our first attention should be directed to the cause - that is, whether it proceeds from friskiness, timidity, or defective vision.

"When shying proceeds from playfulness, it is difficult to judge what mode of cure is best to be adopted, because if corrected for it, he will associate with any object that diverts his attention the infliction of punishment, which will tempt him to run away under the dread of a flogging; and if caressed for the fault, it is liable to induce him to repeat it. But, of two evils, gentle correction must be adopted, and rather to pass by the 
object than to take him up to it. He should also be spoken to sharply.

"If shying proceeds from fear of new objects, the true way to correct him of this is not to force him up to them, but to pat him and to soothe him, but avoid beating him; and take care to pass the objects of his fear again and again, always going nearer to them every time you pass. This will familiarize him to them. Seeing that these are harmless, he will soon learn to pass by unnoticed any novel object which he may meet with upon a road.

"When an animal is given to shying from defective sight, the only method to effect a cure is to take him up to it, and, in the act of doing so, he must be coaxed to approach it, and on no account must he be beaten; and, although it sometimes happens that the horse will manifest great reluctance to do s, $l_{0}::^{\prime}$ ould be persevered with and not allowed to proceed until he has been closely the object of his fear. After he has been a few times thus treated, he will soon learn to pass with indifference any object which he may meet.

"Restiveness, and Resisting Being Mounted.-Some horses which possess a lively or impatient temper manifest a desire to start off before the rider can get seated in the saddle. Indeed, some will attempt to set off whenever the foot is put in the stirrup. This is a troublesome and dangerous fault, even with the most expert horsemen, and especially so to those whoare inexperienced or infirm. Horses sometimes become so cunning that they know a good from a bad horseman, and finding they are either to be or actually mounted by a timid or indifferent rider, will endeavor to throw him off, or bolt away before he is properly seated.

"When a horse has this propensity, he should be mounted quickly and without fear, and not allowed to proceed on his journey until he is perfectly quiet. Instances are not tew where horses that are generally pleasant and easy to mount become 
restive when too high fed and having too little work. The remedy for this is obvious.

"Vicious While Cleaning.--Very great differences exist in the temper exhibited by horses under the operation of cleaning. Some that are steady and quiet on the road and in the field cannot be cleaned without great hazard to their grooms as well as the danger of laming themselves. This often proceeds from a very sensitive skin and at other times from their grooms having inflicted severe chastisement on some former occasion when cleaning. Besides, ill-disposed grooms, by teasing the animals, or currying them with a broken-toothed comb or uneven-surfaced brush, teach them this bad habit, and have even a delight in seeing the animals show their teeth; and this is continued until it becomes a fixed vice. If a change of grooms takes place, what was done partly in play is then manifested in anger, and serious injuries have been inflicted upon the unsuspecting stranger. It therefore behooves grooms to be cautious how they handle a strange horse.

"There is much variety in the sensibility of the skin of horses, some being so tender that moderate rubbing gives them uneasiness, while others are so much the reverse that the whip hardly excites it. It will not be difficult to overcome this vicious habit. When the groom discovers it, the best plan is to use a gentle hand while cleaning, and lean lightly on those parts which seem most sensitive; and avoid punishing the horses for exhibiting restiveness, and he will soon lose all recollection of the former ill-treatment which he had received from his groom, and become quiet and steady.

"Crib-Biting.--Crib-biting is one of the worst habits which a horse can acquire, and is seldom or ever cured. The horse seizes the manger with his teeth while he stretches his neck forward, and after some spasmodic action of the throat, a slight grunting sound is uttered, which appears to be accompanied by a drawing in of air. The cause of this trick is not yet well under- 
stood; and whether it proceeds from a bad habit, or a defect in the false palate and back part of the mouth, still remains undiscovered, and therefore we shall not indulge in any speculative opinions as to its origin.

"One serious effect of this trick is the wearing down of the teeth; and instances have occurred where they have been broken. It has likewise been found that crib-biters are more liable to colic than those without this vice.

"It has been found that crib-biting is acquired by horses being in the stable with one which has the trick. Among the expedients which have been resorted to for the cure of cribbiting, the edge of the manger has been lined with iron, also with sheepskin besmeared with aloes, tar, and other disagreeable substances, but all with no effect. The only thing in this case is to resort to a preventative, and that will be found in the use of a strap buckled tightly around the neck, which has the effect of compressing the windpipe and rendering it impossible to resort to it; but no sooner is the strap removed than the horse recommences his old habit, so that it must be constantly worn to be of use. But the continued use of it is apt to produce irritation in the trachea, and this will terminate in the affection termed roaring. A five or six months' run in a field has been tried without proving a remedy. Crib-biters are generally in low condition.

"A muzzle barred across the bottom will prevent cribbiting. This must be made only of sufficient width to allow full action to the lips, so that the animal may pull his hay from the rack and eat his corn, but so close as not to admit of him grasping the edge of the manger. Crib-biting is legally considered an unsoundness.

"Wind-Sucking.-This is so intimately connected with crib-biting that it may properly be considered a modification of it, as it is accompanied by a want of condition and the same bending of the neck, with the head drawn inward, is manifested, 
and the horse alternately opens and closes his lips, and a sound is produced similar to sucking air. The remedies attempted have been tying up the head of the horse, except when feeding, and the application of a muzzle with sharp spikes bending towards the neck, which will prick him when drawing in his head.

"Not Lying down.-Horses are sometimes prone to standing constantly, and some only lie down once in a fortnight, or even a longer period. When this is the ease, they are generally liable to swellings in the limbs, and seldom able to go through much work. Such horses should, if possible, be put in a stable by themselves and left at liberty, and a well-made bed will sometimes tempt them to lie down. No means can be adopted to force the animal to take rest by lying down. When it is not possible to place him in a stable alone, an empty box should be constructed, so that he may be left for the night unhaltered in it.

"Pawing.-This is a disagreeable and very bad habit, and proceeds from an irritable temper. Bruised feet and sprained legs too often proceed from it. The shoes are quickly worn down in front, and the litter considerably wasted.

"Weaving.-Animals of an impatient, irritable temper, that dislike confinement in a stable. will sometimes keep moving their head, neck, and body to and fro, like the motion of a weaver's shuttle. These have been called 'weavers.' Such horses seldom or never carry much flesh, from their fretful temper and incessant movement. The only preventative is to tie the head close up, except when feeding."

\section{REWARD AND PUNISHMENT.}

In training and handling a horse, full advantage should be taken of his lack of intelligence and his acute memory. To make a horse understand in his training that he is wanted to back, for instance, the rider must, in the first place, adopt a set of signals that mechanically suggest the idea of backing. The horse is 
standing quietly. The rider's legs are closed, lower legs slightly in rear, to induce the horse to draw his legs under him. The knees are not closed, unless he wavers to the right or left. The hand is lowered and the rein drawn in. He arches his neck, bringing the mass of his head and neck nearer to his body. At the same time the rider leans back. The shifting of the mass of the horse and rider to the rear throws the center of gravity to the rear. The horse has "drawn his legs under him" at the suggestion of his rider's heels, his balance is insecure in consequence, and he steps back. He has done what the rider wishes and, at the instant of yielding, the rider should encourage him with hand and voice. The second time the request is made of the horse by the same signals he steps back more readily, and should instantly be rewarded. Finally, after repeated trials, the horse learns that, when both of the rider's legs are brought back with equal pressure, and he is reined straight back, he is expected to back, because he remembers that when he did respond in that manner to those signals he was rewarded.

Horses do not recognize persons; they do remember rewards and punishment. The author has often noticed, in the riding-hall at West Point, where the same horse does duty for two cadets on alternate days, that certain horses, as the platoon is marched into the hall, appear to be looking for someone. The cadet to whom the horse is assigned approaches him, and the horse makes every sign of recognition, and is rewarded with an apple or a bit of sugar. It seems almost unquestionable that he has recognized an old friend. The next day the other cadet to whom he is assigned approaches him; the horse gives the same signs of looking for someone, then of recognition, and then of disappointment. The second eadet is not his friend of the apple or sugar; it was not the friend, after all, that he was seeking, but the dainty that the friend was bringing.

It is well for horse-users that horses are indifferent to the identity of the persons handling them, otherwise they might ob- 
ject to a change of riders. The greater the intelligence of a horse, the more care must be shown in his training and use. A dull horse becomes sluggish under abuse; an intelligent one becomes vicious.

The tone of voice used by a rider has great influence on a horse, if not used at inappropriate times. It is of no use to be constantly talking to a horse, but a word spoken in a sharp, high tone will startle him, while one in a softer, lower tone will soothe and steady him. Like all other aids in horsemanship, the voice should be used consistently and at the critical moment.

The whole education of the horse is based on the principles of reward and punishment. No animal is more sensitive to approbation than a normal horse. Observe a young horse, that has not been spoiled in training, when he is learning a new lesson. The attitude of his head and ears, the expression of his eye, show that he is watching the aids closely. After successfully executing a command of his rider, if the latter pats his neck and speaks kindly to him- "makes much of him" - he shows his appreciation of the attention by his expression. The rider should be careful to give the neck a good, generous slap-not enough to hurt, but sufficient to attract his attention, and positive enough to show no timorousness. Horses quickly learn whether or not their riders are timid, and are very quick to take advantage of the occasion and follow their own inclination. It often seems as if an old troop-horse enjoys the fears of the recruit. This is also shown in the horses used for the instruction of the cadets of the third class at the Military Academy. Usually only the quietest, steadiest horses are chosen for this work. Some of them plod stoically around the hall, impervious to anything the cadet can do. Others take liberties with their riders, in an apparent spirit of play, that they would never think of showing if the rider were a first-class man. For this reason the pat on the neck should be positive, reassuring the horse that the 
rider knows what he is about and appreciates the work of his horse. It should be accompanied by the voice.

There is only one instant when punishment should be administered to a horse - that is the instant the fault was committed, and punishment should never be given in anger. The horse does not reason; he feels and he remembers. The horse cannot understand why he is punished. What he knows is that certain acts of his are met with reward, certain others with punishment, and, if properly handled,.he will do the things he was doing when he was rewarded and avoid the things he was doing when he was punished. For this reason, when a horse rears, he should be struck with the whip while he is in the air, not after he comes down. If he kicks, he should be struck while actually kicking. If struck after the kick is finished, he will be very apt to kick again. The cause and the effect must come together.

James Fillis, probably the greatest high-school rider of all time, says:* "The great art in breaking is to reward and punish in an appropriate manner; in order to do which we must seize the exact moment of obedience or resistance. Here we must bear in mind the fundamental principle of breaking-namely, that reward should follow obedience as quickly as punishment follows disobedience."

* "Breaking and Riding," by James Fillis (Charles Scribner's Sons, 1902), p. 112, foot-note. 


\section{CHAPTER XVII.}

\section{THE CARE OF SICK HORSES.}

The prescriptions and methods of treatment contained in this chapter are given by Farrier Edmund Lee, U. S. M. A. Detachment of Cavalry, who, for more than twenty years, has had the care of the sick horses in the stable of that detachment. Probably nowhere in the service are horses put to severer tests than here. The stable where he has done his work was overcrowded, damp, dark, and badly ventilated. The horses' work is of the most trying character-part of the year it is violently severe, at other times there is nothing at all for half of them to do. In a word, the horses were badly stabled and irregularly worked. As a result, there was much sickness, especially of the lungs and digestive apparatus. The veterinarian visited the stable every third day and prescribed treatment for the horses on sick-list at the time of his visit. All emergency cases and all the nursing fell on Farrier Lee. In the midst of all these difficulties he has faithfully nursed and "doctored" the sick and the cripples and has prolonged their usefulness as no veterinarian could have done without an equally faithful nurse.

These prescriptions are simple, and, as far as drugs can be, safe. They have the merit of having been tested by many years of successful use.

In these prescriptions a teaspoon is one fluid-dram; a tablespoon, half a fluid-ounce. Medicines should always be weighed or measured as accurately as circumstances will permit.

The troubles most commonly met with in a cavalry stable are sprains, open sores, cuts, thrush, scratches, sore backs, colic, and colds. Polo-ponies are laid up more often with sprains, sore backs, bruises, and ringbones than by any other cause. 
For sprains, a lotion made of four tablespoons of lead acetate and four tablespoons of tincture of opium, mixed with one quart of water is very soothing. This is a stronger lotion than the usual white lotion, which has but two tablespoons of each drug. Opium is a sedative and acts to relieve pain; lead acetate is astringent and tends to contract the capillaries and to cool the part by limiting the supply of blood to it.

This lotion is applied by soaking absorbent cotton with it and fastening it to the part with a loose bandage. The bandage is kept wet by pouring the lotion on several times daily. This lotion is better for sprained tendons and ligaments than for sprained muscles. For the latter, and for sore throats as well, a very efficient stimulating liniment is made of a pint of linseed or olive oil, four tablespoons each of water of ammonia, turpentine, and opium. This is to be thoroughly mixed and applied by hand-rubbing; never internally.

The oil is slow to evaporate, penetrating, and carries the other drugs with it into the affected tissues. The water of ammonia and turpentine stimulate a more active circulation, and the opium allays the pain.

For cuts and open sores, use an ointment composed of a heaping tablespoon of oxide of zinc, rubbed up with one-fourth of a teaspoon of glycerine, four tablespoons of vaseline, and thirty drops of carbolic acid. The zinc oxide can also be dusted dry on the wound. The wound should be first well washed and dried.

Oxide of zinc is an antiseptic - that is, it destroys the germs of disease, putrefaction, or fermentation. It is obnoxious to flies. Carbolic acid is also an antiseptic; the glycerine and vaseline are added to blend the two into a smooth ointment. A cut or an open sore that is not infected needs only to be kept quiet and clean to heal. The principal object of this ointment is to keep disease germs from the cut and to keep it from drying by 
too rapid evaporation. The latter is accomplished by the vaseline, which evaporates very slowly.

In the treatment of open sores or cuts, every effort should be made to prevent infection and the consequent suppuration. It may be safely asserted that suppuration in an open wound or sore is always the result of neglect. Abscesses and internal ulcers become infected by germs brought to them, usually by the blood itself. A severe bruise, for instance, may develop into an infected sore without any noticeable external sign of its presence, but a cut can always be seen, and, if the antiseptics and suitable bandages are at hand, it should not be allowed to fester. An excellent antiseptic wash is made of one part of carbolic aeid to twenty parts of water. This will smart when applied. The addition of one part of glycerine will allay the smarting to a certain extent, without destroying the germdestroying properties of the carbolic acid.

Thrush is a direct result, usually, of bad stable management, but as it does not cause lameness or become prominently noticeable until it is in quite an advanced stage, it is frequently found in old, poorly-drained stables with bad floors, in spite of careful attention to the horse's feet.

A horse affected with thrush should be taken to the blacksmith's shop, where all the ragged and diseased portions of the frog should be cut away. The frog should then be cleaned thoroughly and sprayed with equal parts of carbolic acid and watera very radical treatment, but one that Farrier Lee swears by. The frog is then dusted with powdered bluestone and packed with pine tar and oakum. A leather sole is then laid on and held in place by the shoe. This treatment will be of no avail unless the unsanitary cause of the disease is removed; it will stay its progress, but it will not cure it.

Another very good treatment for thrush is to apply a powder composed of equal parts of sulphate of zinc, bluestone, and sulphate of iron. The zinc sulphate is an astringent and it also 
destroys the diseased tissues; the bluestone has much the same caustic effect and it is also a tonic. This powder is dusted on the frog, which is then packed with oakum, held in place with a bandage, a leather boot, or a leather sole put on under the shoe.

For sore backs, use the familiar "white lotion"-four tablespoons each of sulphate of zinc and carbolic acid in one quart of water. The carbolic acid is of more value if the skin is chafed than when it is unbroken. Its virtue lies principally in its germ-destroying power. This lotion is rubbed by hand on the saddle-gall, if the skin is not broken, and applied to an open sore with a sponge.

If the sore back degenerates into a sitfast, the indurated, scabby portion should be cut out by a veterinarian, and the wound of operation then treated like an ordinary wound.

Care should be taken that sore backs and sitfasts are not chafed; no treatment will cure them as long as the conditions causing them continue to exist.

Colic is often caused in horses that are exhausted by permitting them to drink too freely of cold water. This is a spasmodic colic, very painful, and a sedative and stimulant is needed. Two tablespoons of cannabis Indica (Indian hemp), five drops of morphine, thirty drops of tincture of capsicum, mixed with a pint of water and given at one dose, will usually give relief; if not, repeat the dose in about an hour.

The cannabis Indica soothes the nerves and so lessens the spasms of the muscles, whose actions are governed by the nerves. Morphine is a sedative, and the capsicum is a stimulant to restore the circulation in the walls of the stomach.

Colic caused by indigestion-flatulent colic-is treated with four tablespoons of aromatic spirits of ammonia, two tablespoons of sweet spirits of nitre, mixed in a pint of water and given in one dose. Repeat in an hour, if necessary.

Aromatic spirits of ammonia is useful to expel gas from the stomach and intestines; it is also a safe stimulant. Nitre is also 
a stimulant that acts on the kidneys; it neutralizes irritating acids. Its frequent use is very debilitating and injurious to the kidneys.

For obstruction colic, four tablespoons of oil of turpentine in a pint of raw linseed oil, given at one dose, will usually expel the obstruction.

It should not be very difficult to distinguish between the three kinds of colic mentioned above. The stablemen will know if the horse has drunk too much cold water. The presence of fresh dung in the stall will argue against obstruction colic, and if the distress is not caused by cold water, the assumption in this case would be that the horse was suffering from colic resulting from indigestion.

For coughs, a useful mixture is made of two tablespoons of oil of tar, two tablespoons of glycerine, and two tablespoons of chloroform, mixed in one pint of raw linseed oil. Two tablespoons given two or three times a day is the dose.

For coughs and colds, nursing will do more than drugs. The patient should be kept warm - with blankets in the winterdry and away from draughts. He should have hay in small quantities and frequently changed, for the discharge from his nose will soil it if left before him long. He should have hot steamed bran-mashes and have constant access to water. The disease will then run its course, in the usual case, in a few days. Exercise should be avoided. His nostrils and lips should be frequently washed.

Scratches, whose seat is in the back of the pastern, is a disease that is brought about by the same conditions that produce chapped hands in human beings. The part affected should be carefully washed and dried and kept greased with an ointment made of one part of oxide of zinc to ten parts of cosmoline, vaseline, or lanolin. This dressing should be changed frequently, by thoroughly cleansing the part and re-applying the ointment. The horse can be used, in mild cases, during the treatment. Severer cases demand rest as a part of the treatment, because bending the pastern keeps the cracks open. 


\section{CHAPTER XVIII.}

\section{PREVENTABLE DISEASES.}

Preventable diseases are those that result from improper care or use. A large proportion of the diseases that a horse is liable to comes under this head.

They may be grouped in two general classes: diseases due to bad shoeing, and diseases due to bad stable management. Under the first head come, more especially, diseases in the feet and legs, manifested by lameness.

$\mathrm{Bad}$ shoeing is the commonest cause of all varieties of diseases of this region. If, in fitting the shoe, the wall is not rasped down evenly all around, if the shoe is too small for the foot, and the crust is rasped off to cover up the defect, if the bars are cut away, if the shoe is too high behind so that the frog cannot strike the ground, the result will be felt in the horse's action.

The following diseases are usually caused by improper shoeing, or may be prevented by proper shoeing: speedy cut, splints, strained tendons, broken knees, ringbones, sidebones, treads, brushing, corns, and cracks.

When a horse is laid up for any reason, his shoes should be removed at once. This permits a freer growth of the horn, it gives the frog a chance to get a bearing, and it is a rest to the foot. The plantar surface of the foot should be rasped smooth and the edges rounded off whenever the shoe is taken off, to prevent the wall from splitting.

There is no better way to build up a horse or to keep one in health than to allow him an occasional run at grass. A horse that is a bit run down in flesh will be much benefited by having his shoes taken off and allowed to run for a few days in a pasture. The natural exercise, the green food, 
and the freedom will combine to produce most beneficial results. Every horse should be turned out in an enclosure of some sort every day, if only for an hour or two, whenever possible. Horses brought in hot from work and turned loose will cool out slowly with no damage to themselves. They will take enough exercise to keep from getting chilled.

Pasturing is especially good for diseases of the tendons, ligaments, and bones, and of the breathing apparatus. A horse with a docked tail should not be turned out to grass or in a paddock during fly-time; he must be given his exercise in another way. He will be so tormented by the flies that no benefit will result from his freedom.

The condition of a horse - that is, its state of being generally -is the result of stable management. In a good stable, where clean stalls are the rule, where.good forage is fed, where the water is pure, where the horses are thoroughly groomed, and which is kept dry and fully ventilated, where the doors are wide and high, and all the stable fittings are arranged so that there are no projections to injure the horses, there will be need of the veterinary surgeon but rarely.

A horse is said to be in good condition when he is in vigorous health and strength, and in hard condition when, by proper care and exercise, he is in shape to make his supreme effort, as should be the case before a race.

Exercise is just as necessary to the well-being of a horse as to man. Every horse that is kept in a stable should be exercised at least two hours a day to keep him well. Lack of exercise will weaken a horse as much as overwork. The amount of work expected of a horse should depend upon his condition, and this depends as much upon the exercise he has been getting as upon his diet or sanitary surroundings. A horse that has been turned out to pasture will take enough exercise to keep well, but will not keep in working condition. So a horse that has been convalescing on grass, after a month or two, may seem 
to be in fine condition, but, if put to work, will be found to sweat freely after slight exertion and to tire easily. His condition should be hardened by gradual work or exercise.

Neglect of sanitary care of the feet, by allowing the horse to stand in manure, or in urine-soaked mud, will bring on thrush, scratches, and other diseases of the soft tissues of the feet.

Neglect of grooming is responsible for loss of condition, thus making the horse liable to disease. Much of the excretion of waste tissues is done through the pores. If this way of excretion is closed because of the clogging of the pores, the waste tissues will accumulate near the surface, impeding the flow of blood in the capillaries, the hair will appear lusterless and dead, through being badly nourished, the dead cells of the skin will fill the coat. The horse will appear listless and irritable. His vitality will be low and he will be ready to receive and foster the germs of disease. If he is thoroughly groomed, the circulation will be stimulated instead of retarded, excretion will go on properly, and the coat will show its healthy condition and that of the skin beneath by its smooth luster. Grooming does not benefit the coat by smoothing it, but by cleaning the skin. The smoothing of the coat is the merest incidental.

Bad forage is responsible for diseases of respiration and digestion. Dusty hay is hay that has not been properly cured and that breaks up into minute dust-like particles. These particles are sharp and irritating to the mucous membrane of the lungs, and render it liable to disease. Musty or sour hay, grain, or bran produce indigestion and, ultimately, colic.

Reference has been made to the order of watering and feeding. First water, then hay, then grain,-no water for at least two hours after grain. A horse that has been all day at work comes in at night ravenously hungry. If he finds his oats in the manger, he will rush at them, bolting them without chewing them. With their hard husk, which is mostly cellulose, unbroken, they pass through the stomach undigested, to lie in the 
intestines ready to ferment and cause intestinal disorders. If he is fed his hay first, he will, of necessity, eat it slowly. When, an hour or so later, his grain is given him, the edge of his hunger is broken, and he will be hours at his oats; they will be perfectly digested and will do him a maximum of good.

Dampness and lack of ventilation in stables predisposes the horses to diseases of respiration and to rheumatism. These conditions, also, by lowering the vitality of horses, make them fit subjects for other diseases, especially those of germ origin.

Every stable should be provided with ample openings for the admission of air and for the escape of foul air. The fresh-air openings should be low down and so arranged that no current of air blows directly on the horses. The escape of the foul air should be arranged for at the highest part of the stable, and should be so made that rain or snow cannot enter the stable.

Carelessness in the arrangement of stables is accountable for many injuries from which horses should be immune. Low, narrow doors account for poll-evil and broken hips. Boards splintered by kicks or gnawed through leave rough ends to scratch and blemish horses. Swing-bars whose chains are patched with baled-hay wire, and prominent hooks, nails, or latches where horses might strike themselves, may inflict wounds that are trifling enough in themselves, but when located about the knees or hocks reduce materially the value of a horse, on account of the suspicions aroused by their scars.

Bad saddling and badly-fitting bridles put horses out of business by causing saddle-galls and sore mouths, that just a little care would effectively prevent.

Contagious diseases are frequently allowed to spread, more through ignorance and carelessness than for any other reason. A horse with any discharge from his nose, however slight, should be isolated at once. He should not be turned loose with other horses, or watered where they are watered, or 
have his equipment mixed with theirs. His stall should be disinfected, and his equipment sterilized after his recovery.

Skin diseases, such as mange, ringworm, scratches, grease, and those scurfy diseases at the bend of the hock and knee, known as sallenders and mallenders, and the presence of vermin in a horse's coat, are the surest indices of bad stable management.

As a general rule, a horse of good conformation that is properly fed and watered, thoroughly groomed and stabled in a sanitary manner, will keep well. Hard work, unless pushed to an unreasonable degree, will fatigue a horse, will at times greatly exhaust him, but, unless his condition has been lowered by some preventable cause, no permanent injury will result.

The horse is made for fast or hard work. He is admirably fashioned for it, but the natural laws of his existence must be obeyed or he will break down before his time, not from overwork, but from neglect. 


\section{CHAPTER XIX.}

\section{IRREGULARITIES OF ACTION.}

Irregularities of action result from disease or defects of conformation. A well-put-up horse that is sound follows the usual law of movement.

The natural gaits-modes of progression-of the horse are the walk, trot, and gallop. Some horses have a fourth gait, the a mble-pacing-but it is usually an acquired gait. These gaits a horse assumes, when free to follow his own inclination, without any training or preparation.

The walk is a square gait, where each foot is planted in succession. The body is supported all the time.

The trot is a diagonal gait; the feet are planted in pairs: right fore and left hind, left fore and right hind. In changing support from one diagonal to another there is a slight period of suspension, when the body is wholly unsupported. Aside from this brief instant, the body is supported alternately by one diagonal pair or the other, and never by more than two feet.

In the gallop the feet are planted in succession. One fore foot is constantly leading - that is, planted in front of the other, and the leading fore foot bears the weight of the body for a longer time than any other. The body is advanced by a series of leaps and is much of the time in suspension.

In all of these gaits the feet should move in parallel planes, should be planted squarely, and should not strike each other.

In the walk there should be no halt in the stride. The beats caused by the planting of the feet should be regular and followed by the same intervals. 
In the trot each diagonal pair of legs should sustain the weight of the body for the same length of time.

In the gallop the horse should lead with equal freedom with each fore foot; his feet should be well bunched during the leap, and well extended in receiving the weight of the body and in throwing it forward. The canter differs from the gallop very little; it is the slow gallop. The leap is shorter, the leading foot

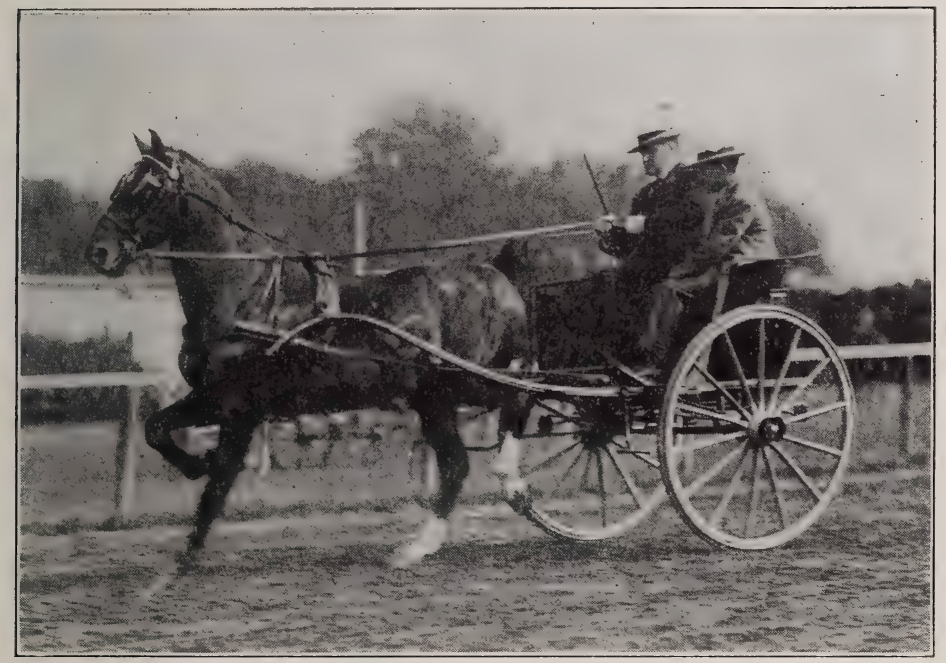

FigURE 102.-."Iowa."

Pure-bred trotting-horse in action.

Courtesy of J. Campbell Thompson, Esq

is not advanced so far. The body is in suspension for a shorter time. The merging of the canter into the gallop is imperceptible. When a horse changes from the walk to the trot and from the trot to the canter, the rider is conscious of the instant the change is made, but as the gait increases to the gallop and the racing gallop, or run, he is conscious merely of an increased speed, not of a change in the arrangement of footfalls. 
There are two artificial modifications of the pace: the rack, where the hind foot foots it ahead of its leading fore foot; and the single foot, where each foot foots it independently of the others. The single foot is a very easy gait indeed for the rider.

The trot has also two artificial modifications: the fox trot, when the fore foot foots it ahead of its diagonal hind foot; and the running walk, where the hind foot foots it ahead of its diagonal fore foot.

The Kentucky saddle-horse has all of these gaits and the walk, trot, amble, and gallop as well. The Kentucky breeder resents having the gaits above described styled artificial, because he has bred his strain of horses to possess them naturally. They are so termed because a horse must either be bred or trained to possess them.*

Lameness may be defined as an alteration of action adopted by an animal in an effort to avoid pain. Most sound horses comply with the rules for the natural gaits given above. Their heads are carried uniformly, without nodding. If a horse is seen to dwell longer on one leg or pair of legs than another, if he nods his head at each step, if he shortens his gallop, or is stiff in his action, it is because there is pain in one of his legs and he is trying to keep his weight off it or to keep from straightening it. He is lame.

The trot is the best gait in which to locate lameness. The walk is too slow; three legs are always on the ground in that gait, and, unless very lame indeed, it will be difficult to locate it at a walk. The gallop is too complex and too rapid a gait for this purpose. The trot, on the contrary, is simple and easily analyzed. It is not too rapid for careful observation. One hind foot and the diagonally opposite fore foot bear the whole weight of the body at any instant.

*See Captain Haves, "Points of the Horse," and Gouboux and Barriere, "Exterior of the Horse," for complete discussions of the subject of gaits. 
In trying a horse for la meness, he is trotted on hard, smooth ground. If, in trotting, the weight is held on one diagonal pair longer than on the other, it is because bearing the weight on the latter pair is painful, and the horse transfers it as quickly as possible to the sound pair. The lameness is thus located in one of the two legs.

The front legs, in addition to bearing their share of the weight of the body, must support, unaided, the weight of the head. When a horse raises his head, he shortens the lever-arm, the neck, and thus throws the center of gravity of his body further back. This relieves the forelegs of part of their load and puts it on the hind legs. By lowering the head the leverarm is lengthened, the center of gravity comes forward, and the front legs relieve the hind ones of part of their burden. So, having located the lameness in one pair of legs, if, when that pair is supporting the body, the head is down, the lameness is behind; if the head is up, the lameness is in front.

If he is lame in both hind or both front legs, he will travel in a stilty, stiff manner, and will, when lame in front, keep his head higher, and when lame behind, lower, than is his natural poise when at rest.

A horse usually turns on his front feet. If he is quickly turned and is noticed to dwell more on one foot than on another, it is an indication of unsoundness in the favored foot. This test will sometimes assist in locating obscure cases of lameness in front.

If, after noticing these irregularities of action on hard ground, the horse is trotted on soft ground, and he travels true, the suspicion that he is unsound, and lame in consequence, is confirmed. If, on the contrary, he has the same peculiarity of gait, the irregularity is probably due to his conformation or to some habit.

Unsoundness in front may sometimes not be detected in the horse's action, when his attitude while at rest will give a 
sure indication of it. A horse that is sound always stands with his front feet equally advanced. By a provision of Nature, the weight-bearing muscles of his front legs are so arranged that when he stands square in front they are at rest. This is not so behind. There he is constantly shifting his burden; one leg supports it while the other rests.

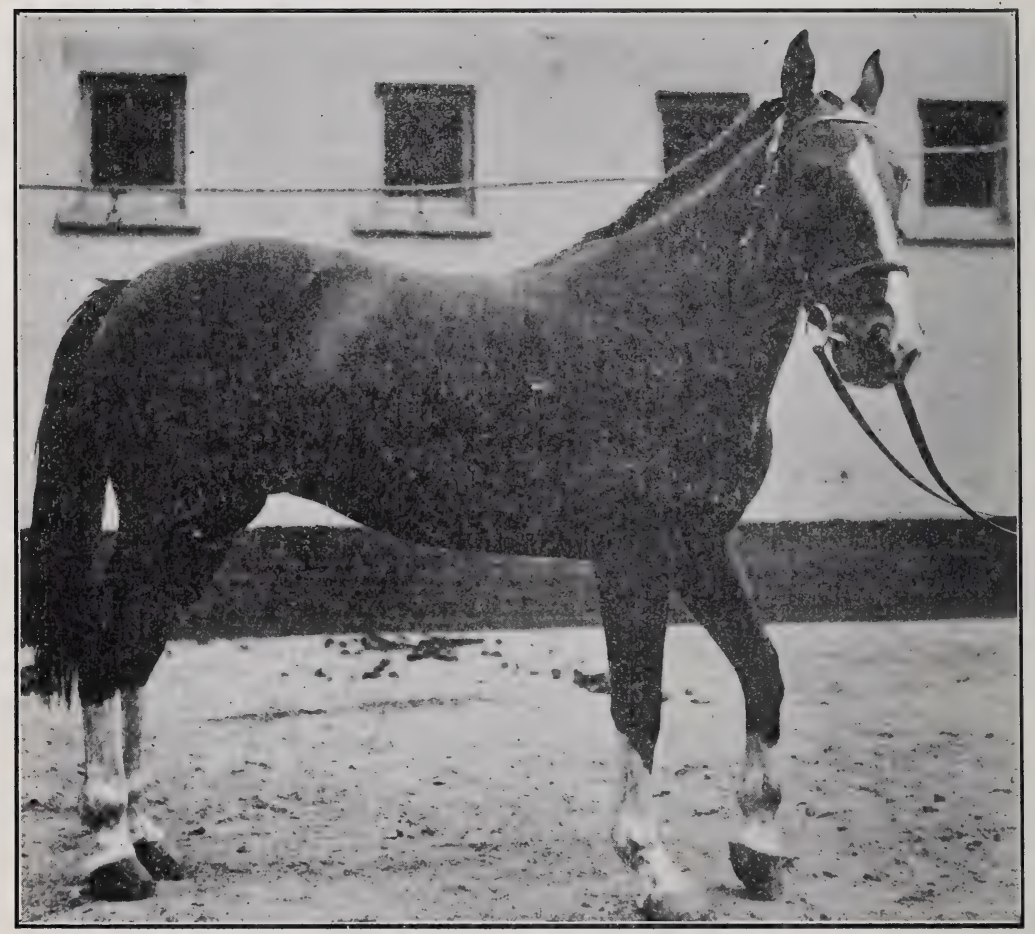

Figure 103.-Pointing a Tok.

If a horse is observed while standing to advance one front foot, or draw it back, resting it on toe or heel, pointing it, as it is called, he is unsound. If he rests the foot on the toe, it is to relieve pain at the heel, to straighten out the flexing ligaments, and the inference is that he has navicular disease (Figure 103). 
If he rests the foot on the heel, it is to relieve pressure at the toe, or the laminæ, and the inference is that he is foundered, or, more rarely, that the extensor tendons are pressing on a bony tumor, and he has ringbone.

Frequently a horse stands level in the stall and goes lame in front on hard ground. This is never the case in diseases of the soft tissues, but is caused by incipient bone disease.

If a horse is lame behind and the location of the disease is not apparent, the services of a skilled veterinarian should be called in. It is difficult enough to properly diagnose lameness in front; he is skilled indeed who can do so behind.

The general rule, that obscure la meness behind is in the hock, and in front in the foot, or in the ligaments and tendons, is a safe one for the a mateur to follow.

Many horses, through lack of symmetry, have peculiar faults of action not properly called lameness, though resembling it. They can be usually corrected by proper shoeing or by the use of boots or straps. 


\section{CHAPTER XX.}

\section{JUDGING HORSES AND THE EXAMINATION FOR SOUNDNESS.}

In the pages that precede an effort has been made to indicate the general conformation of well-built horses, and those diseases and defects to which they are most liable. The application of the theory of what suitable conformation and soundness are will come when the student is called on to purchase a horse for himself.

The general public is suspicious of horse-dealers, more because of its ignorance of the physical and civil laws that relate to the soundness of horses than for any other reason. For that reason a brief investigation into the subject will spare the purchaser much annoyance and mortification.

The law of warranty has been briefly stated in the opening chapter, page 19. Reference to that will convince the reader that the examination of the horse he is going to buy and his trial had best be very thorough and complete, as it will prove a very difficult matter to establish the existence of any unsoundness or defect prior to the date of purchase, in a legal manner, to the satisfaction of a court.

A purchaser must not expect to find many perfect horses; there are few such, and, excepting young horses, the very fact of their being without blemishes argues that they possess some undesirable quality that has limited their use, and that will probably always limit it. He can, however, learn to recognize those glaring defects that make horses especially undesirable to own, and to discriminate between them and lesser defects that can be overcome, or that will not interfere with the use to which the horse is to be put. 


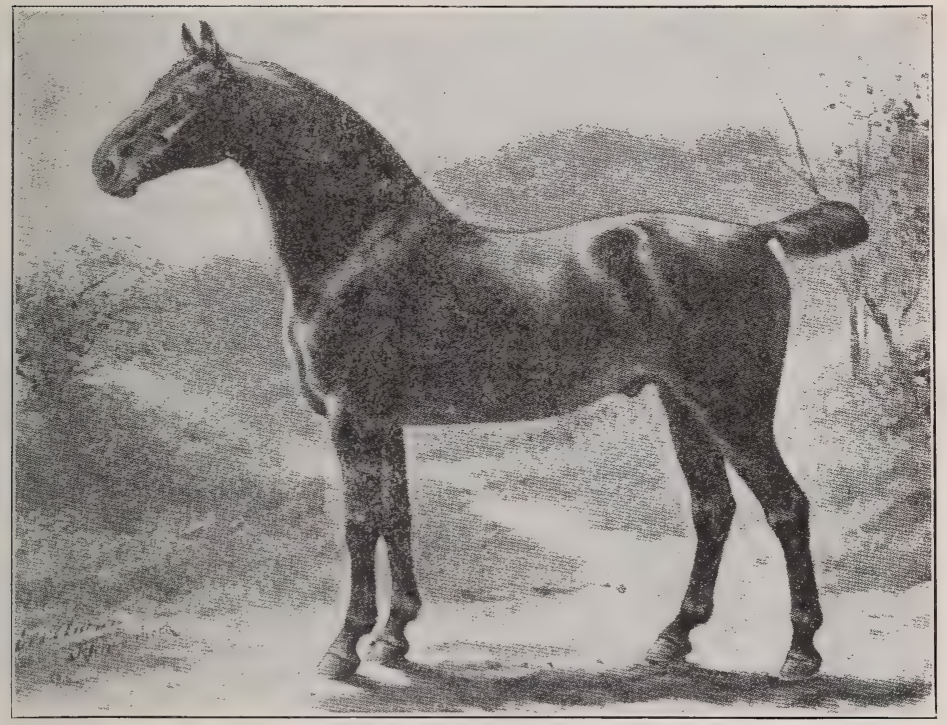

A Study in Conformation.

Courtesy of Otto Eerelman.

It is a surprising fact that most purchasers want to buy a fat horse. This is a failing that, to be successful, dealers must meet by fattening their horses into what is called selling condition. Horses in this fat, smooth condition cannot be put to hard work at once; they are more subject to inflammatory diseases than when properly hardened to their work, and, more than all, the fat covirs up defects of conformation that would be apparent in working condition.

It is always best to see the horse you are thinking of buying in his own stall, when he has not been prepared for your visit. You can then inspect him for such stable vices as cribbing, weaving, or kicking.

Cribbing is an injurious habit of seizing with the teeth the manger, halter-strap, or woodwork of the stall, or any similar 


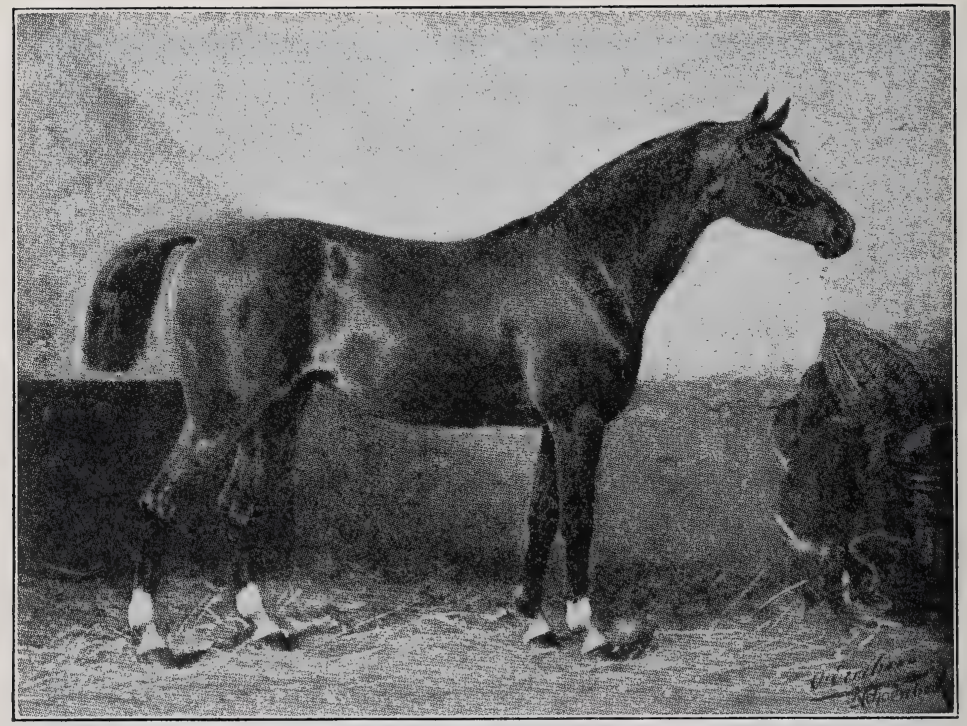

A Study in Conformation.

Courtesy of Otto Eerelman.

thing within his reach, and, at the same time, drawing in his breath with a peculiar noise, known as wind-sucking. It is usually a sign of digestive derangement. A crib-biter can always be detected by an examination of his incisors. The anterior portion of the tables is worn down much more than the posterior. This is one of the few vices horses have that is taught others by example.

Weaving is a stable vice manifested by swinging from side to side in the stall. It is rarely more serious than an indication of a nervous, restless nature. It is a frequent accompaniment of crib-biting.

Kicking is such a serious vice, and so difficult to eradicate, that no horse should be knowingly purchased that possesses it. It is often shown by the appearance of the woodwork of the 
stalls near the heel-posts. A horse given to kicking in the stable usually shows scarred heels and capped hocks.

It should also be noticed whether he points a toe in the stall. The meaning of this symptom has been sufficiently explained.

The inspection in the stall finished, have the horse brought into the light; if his general appearance is satisfactory, and he seems suitable for the purpose to which it is proposed to put him, his age should be verified, and his sight tested in a general way.

Assuring yourself in these three regards, apparent general suitability, age, and vision, the more critical examination is begun. A note-book and a pencil should be at hand to take down such departures from normal conditions as you may notice.

First notice color, sex, and peculiar markings, so as to be able to identify the horse later on. Then proceed to a more critical examination of the eyes.

The best light is that coming directly from above, from a skylight or a high window in an otherwise darkened room. If such a place is not available, bring him to the stable door, closing all apertures behind him. After placing him directly facing the source of light, stand behind his shoulder and look through each eye, from side to side, with great care, noting everything, no matter how slight, that interferes with their perfect transparency. A horse that has any disease, or any mark of disease, in the eye, no matter how slight, is not a sound horse. After the examination of the anterior portion of each eye, from behind, stand in front of him and compare closely both eyes, to see if there is perfect clearness in each, that the pupils are of equal size, and that they dilate and contract equally. If any suspicions are aroused, no matter how slight, of the presence of cataract, the candle-test should be applied.

Go next to the near front leg. Next to the eyes the front legs are of the greatest importance for saddle-horses. Pass 
the hand along the withers and the shoulder for saddle-galls, sitfasts, and collar-galls, and over the elbow for shoe boils.

The knees should be most carefully inspected for broken knees. While no serious injury may have resulted to the horse's knees by his falling on them, while the joint may be perfectly unimpaired, still the fact that the horse has fallen on his knees

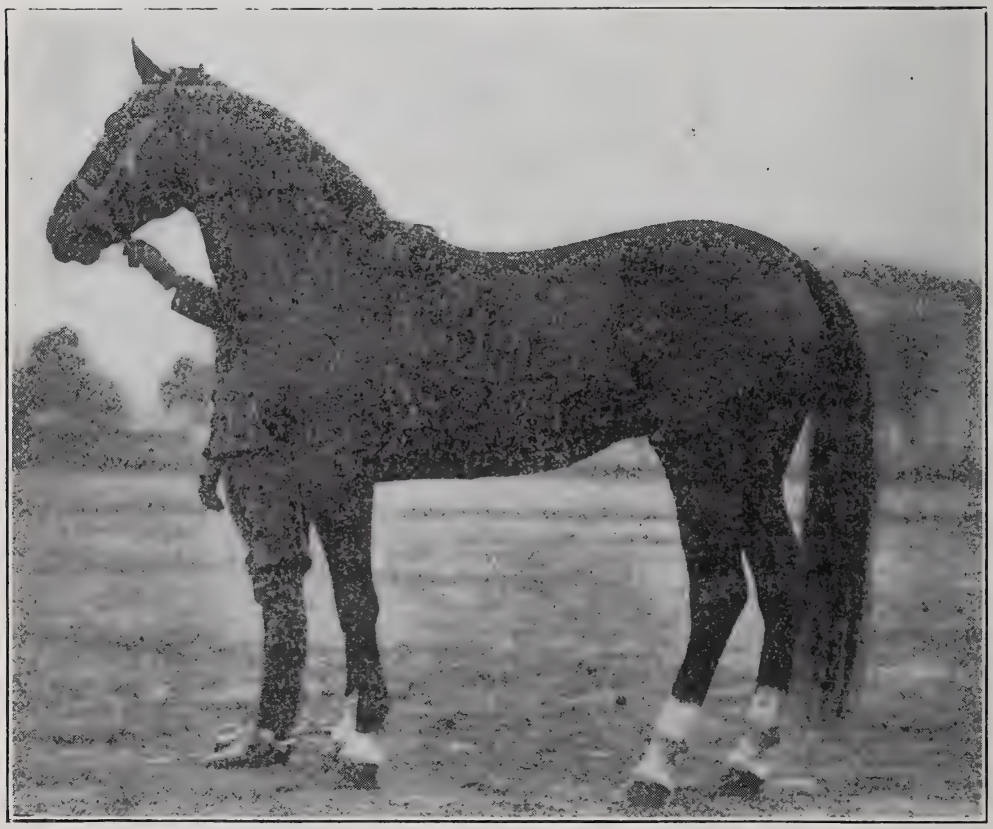

Figure 104.-A Study in Conformation.

at some time in his history should cause the careful purchaser to end his examination with the discovery of scars of broken knees. The nerves of the feet are possessed of marvelous sensitiveness, considering their horny covering, and an animal whose shoulder is sloping enough to plant his foot well out in front of him will not fall, unless he is tired out from extraordinary ex- 
ertions, or unless he is seriously unsound in one or both of his front legs. Whatever the cause of the broken knees, reject the horse.

If the knees are sound, look at the head of the cannon-bone, on the inside, for scars of speedy cut. This, as we have seen, is a defect of action caused by bad conformation. It is a fault difficult to eradicate. The blow is so painful as to frequently bring the horse to his knees. It is liable to recur at any time, and, as the blow is given only when the horse is going at top speed, the accident resulting from his fall is sure to be a serious one. For this reason, unless the horse is wanted for slow work only, reject him when he shows a scar of speedy cut.

Splints are found between the knee and fetlock, on or near the splint-bones. They are recognized as small bony knots, easily felt. If they lie forward on the cannon-bone and not near the knee, they usually are harmless. If they are on the back of the cannon-bone, they may interfere with the action of the tendons. To test this, apply pressure to the tendons. If the horse shows pain by flinching, and the tendons show inflammation, reject him. A pegged splint is almost sure to cause permanent lameness.

Passing the hand down the back tendons, compress them steadily. Any tenderness or signs of inflammation is cause of rejection.

Carefully inspect the fetlock, pastern, and ankle for windgalls, ringbones, sidebones, and grease, and the coronet for treads and quittor.

Inspect the pastern and ankle for scars of firing or neurotomy. Be very suspicious of any scars in this region. A horse that has been nerved has but a brief period of usefulness ahead of him.

Pick up the foot and examine the sole for contracted heels, thrush, canker, and corns. See that the sole is concave, and 


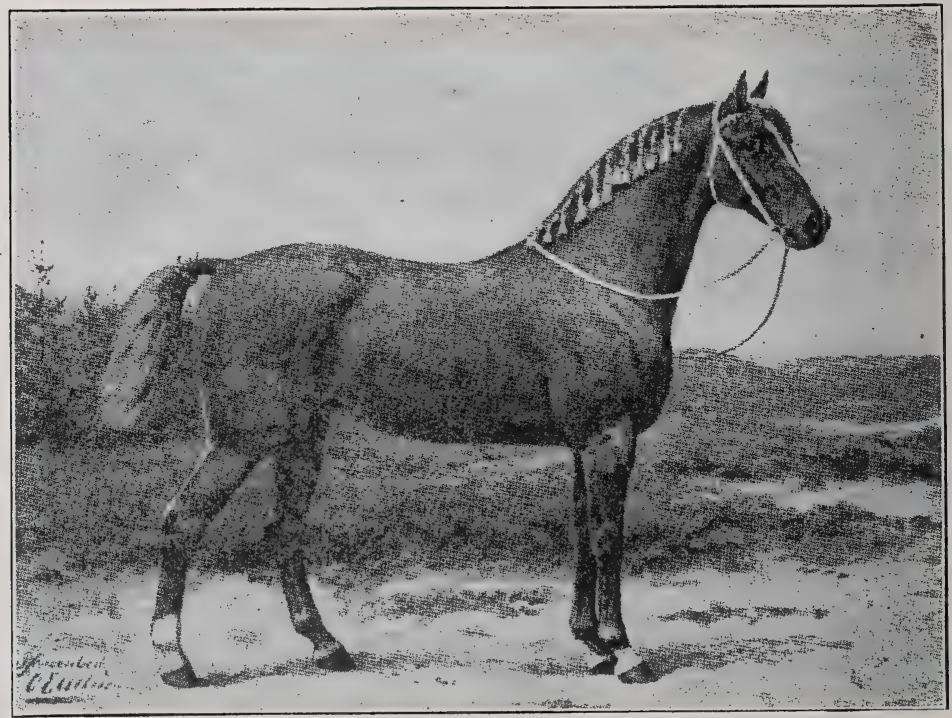

A Study in Conformation. Courtesy of Otto Eerelman.

that there is no irregularity in the shoe. Feel the coronet, walls, and heels for fever, or any other indications of laminitis.

Tap the front of the foot with a knife or a coin for seedy toe, and look carefully for false quarter. Inspect closely the surface of the walls for signs of rasping out founder rings. If this has been done, unless the foot has been most carefully stained, the hoof will show varying colorings. Be especially careful in your scrutiny of a hoof that has been stained or polished.

Inspect his nostrils for discharges of any character. A horse that has a nasal discharge is unsound, and the inspection should be put off for a few days to determine whether the discharge is or is not chronic. The nasal membranes should be moist, pale in color when the horse is quiet, and bright red after sharp exercise. They should be free from scars. 


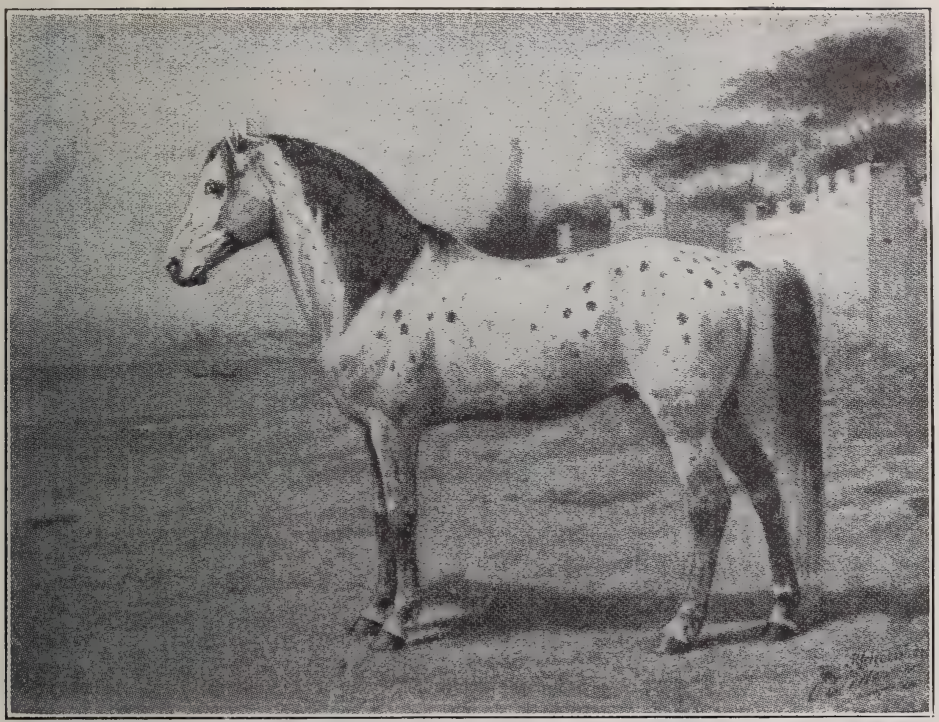

A Study in Conformation. Courtesy of Otto Eerelman.

The ears should be free from not expect a horse to permit his ears to be pulled about willingly, but he should allow them to be handled enough to be bridled easily and to have them trimmed and cleaned.

The poll should be inspected for fistula.

A good horse that has been well broken and kindly handled will not dodge or show the whites of his eyes when handled about the head. Such actions are the surest witnesses to abuse during his bringing up.

Pass then to the off side, examining the jugular vein on each side for signs of blood-letting (to relieve congestion of the brainblind staggers). Examine the withers and back from that side. Go over the right front leg with the same care and in the same manner that you used in the examination of the left one. 
Examine the back, especially the lumbar region, for evidences of kidney trouble. Examine the hip, croup, and stifle. Then pass to the hock.

Raise the horse's tail, pull it to the off side with the left hand, stoop down slightly, and look at the inner side of the off hock

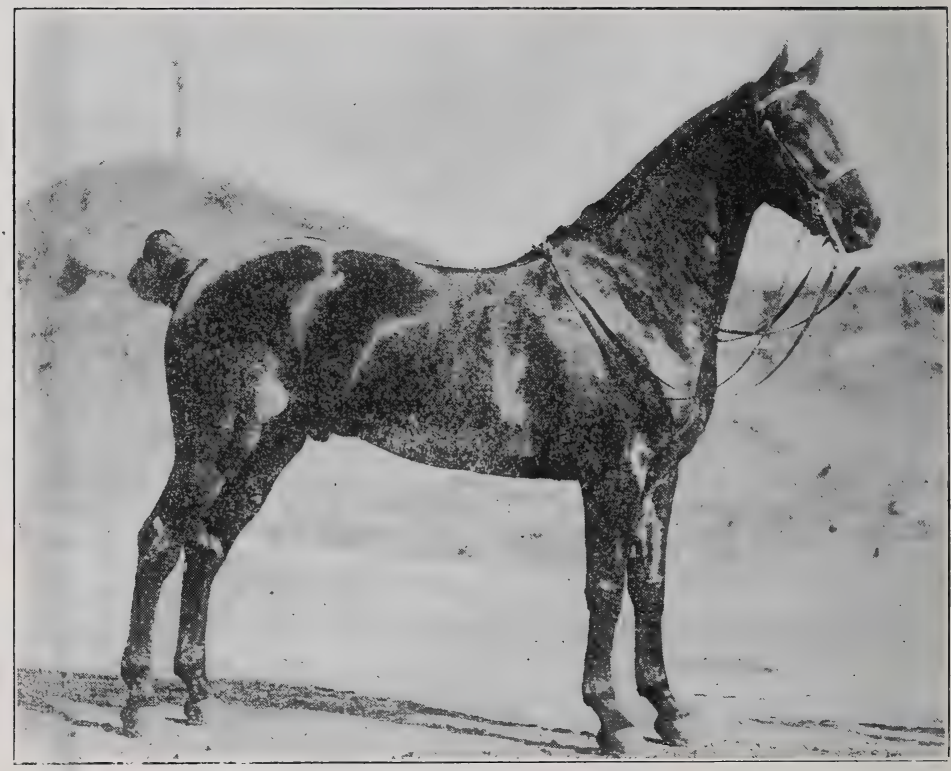

Figure 105.-A Study in Conformation.

from in front of the leg. If there is a protuberance on the lower edge of the hock-joint, inspect it with care for marks of blistering or firing. Feel it; if it is hard, it is probably a spavin, and the horse should not be bought. Look for bog-spavin, and thoroughpin, capped hocks, and curb.

Blistering is the process of producing artificial inflammation, by the application of a powerful liniment, to relieve congestion or to hasten bone-deposit. 


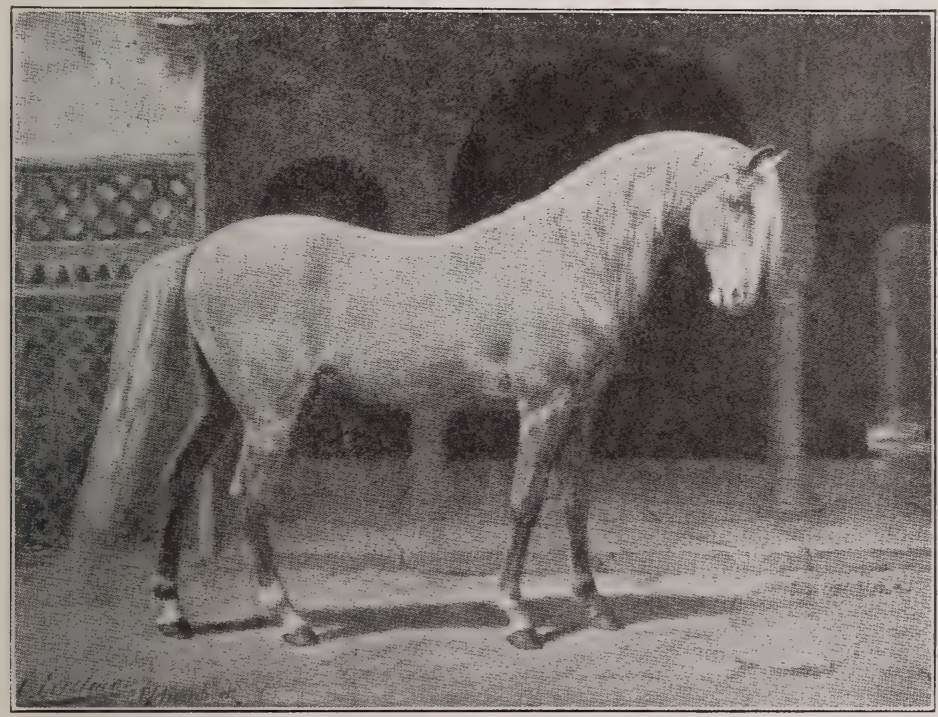

A Study in Conformation.

Courtesy of Otto Eerelman.

Firing produces the same result, in a more radical way, by actually burning the part with a hot iron.

Blistering, if severe, leaves an irregular scar, partly denuded of hair. Rows of dots or thin parallel lines are the marks of firing.

If there is any suspicion of spavin, a simple test is to pick up the leg, bend it well, and hold it up for a minute or two; then drop it, and start the horse off at a trot. If sound, he will not limp.

The cannon-bone should be examined for splints, rare as they are behind, and the tendons examined for evidence of inflamed or sprained tendons. The same critical examination should bə made of the feet as was made in front, and of the left hind leg as was made of the right. 


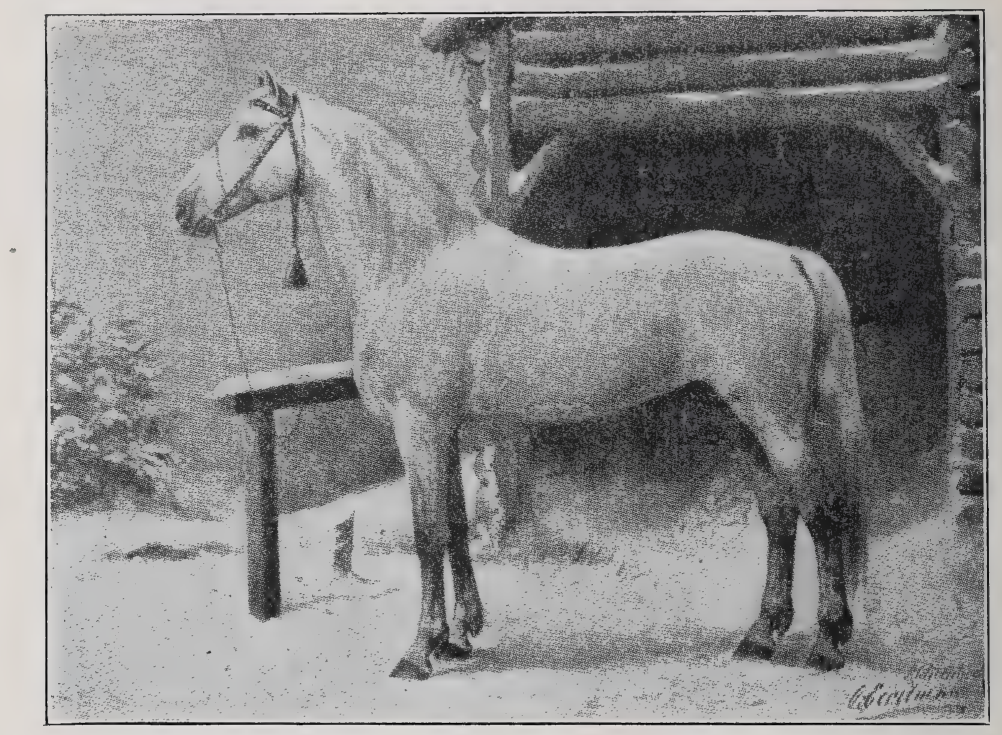

A Study in Conformation.

Courtesy of Otto Eerelman.

Examine the tail; see that the quarters are well filled up behind, and that all is in order under the dock.

Examine the sheath; look under the belly to see that there are no warts or protuberances there, and that the belly is free from scars. Look on all the legs for wire cuts.

The horse's action should next be tested. Have him led at a slow gait away from you, noticing the action of the hocks, pasterns, and feet. Look closely for any dwelling on either hind leg, indicating lameness in the other. Watch his head, to see if he nods excessively.

When he turns, note carefully the ease of action in the front legs, and, as he approaches, note the way he handles his front feet, and the carriage of his head. He should be trotted past the inspector two or three hundred feet, again turned and brought to a standstill near him. 
Avoid horses with hackney knee-action. They are almost sure to go wrong in front while young, and, while stylish, are expensive and not apt to be long serviceable.

Notice his breathing, the expansion of his nostrils, the heave of his sides.

Have him mounted next, and galloped sharply for a quarter of a mile or so, and again inspect his breathing. If he labors noiselessly for breath (thick wind), if the period of exhalation is longer than the period of inhalation (heaves), if he makes a noise at both inhalation and exhalation (whistling), or during inhalation only (roaring), reject him.

Feel his pulse; the most convenient place is at the jaw. A large artery runs around the lower border of the jaw-bone and up on the outside immediately in front of the heavy muscles of the cheek. It can be easiest felt where it curves s.round the jaw-bone, by pressing it gently against the bone. To take the pulse, press the balls of the first and second fingers against the artery. The count should be from 33 to 40 beats a minute; nearer the first number before exercise, and the latter just after. The pulse slows down in old age. It should be strong and regular. The heart can be easily heard by placing the ear at the base of the throat or on the ribs behind the shoulder.

An inspector who buys horses under contract should demand that they come up to the specifications of the contract. Contractors are presumed to have read the specifications before they make their bids. The latter should be based on the value of the horses asked for, and nothing short of that should be expected. When horses of the grade advertised for are worth $\$ 175$, a contractor who agrees to furnish them for $\$ 150$ should not be permitted to put in inferior stock because of his false bid. Not only does the inspector bring himself into disrepute for accepting inferior animals, but honest bidders who are ready to deliver horses up to standard, at a proper price, are cut out of their right to do so. 
The whole theory of advertising for purchase by contract is based on the idea that bidders can learn what is wanted exactly, and can then figure at what price they can afford to make the deliveries. If this theory is perverted by permitting contractors who have made dishonest or haphazard bids to evade their contracts by furnishing as good horses as the price they offer would warrant, it would be better to abandon it altogether.

Well-bred horses that may be predicted as capable of giving good service have about the following conformation:

Head small, clear-cut, and well set on a long, slender neck.

Shoulders sloping well forward, muscular, and long.

Front leg well muscled above the knee, cannon shorter than leg-bone, and both upright and straight, ankle sloping forward, long and elastic; fetlock, ankle, and pastern, smooth, firm, and small.

Feet small, sound, and with well-developed frogs.

Barrel deep, long, and well-ribbed up, about equal in size at girth and middle, and sloping gradually from the middle towards the sheath.

Withers reasonably prominent and well muscled.

Back flat, well muscled, and free from saddle-marks.

Coupling short and strong.

Croup slightly convex, viewed from side and rear. There should be considerable length from loin to tail, and not much curvature.

Tail well set on, and, when the animal is in motion, carried away from the body. The hair should be fine and silky.

Thighs prominent and muscular and well filled up, when viewed from behind. Measured from hip to hock, the thigh should be long.

Hocks clean-cut, not puffy, wide from the side, large and well bent. The point of the hock should not be noticeably prominent. Both hocks, viewed from behind, should be parallel and straight under the horse's body.

The cannon-bone should be flat and broad. Pasterns and feet as in front legs. 
3 (1) 

LIBRARY OF CONGRESS

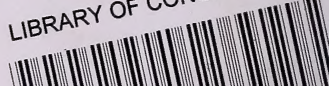

(III 0002860 